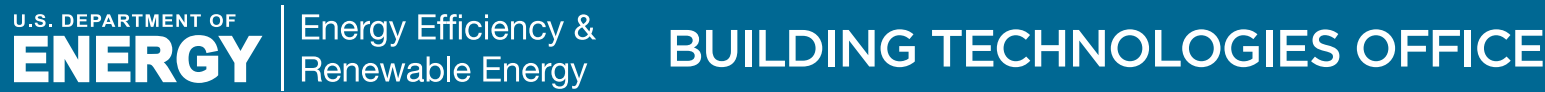

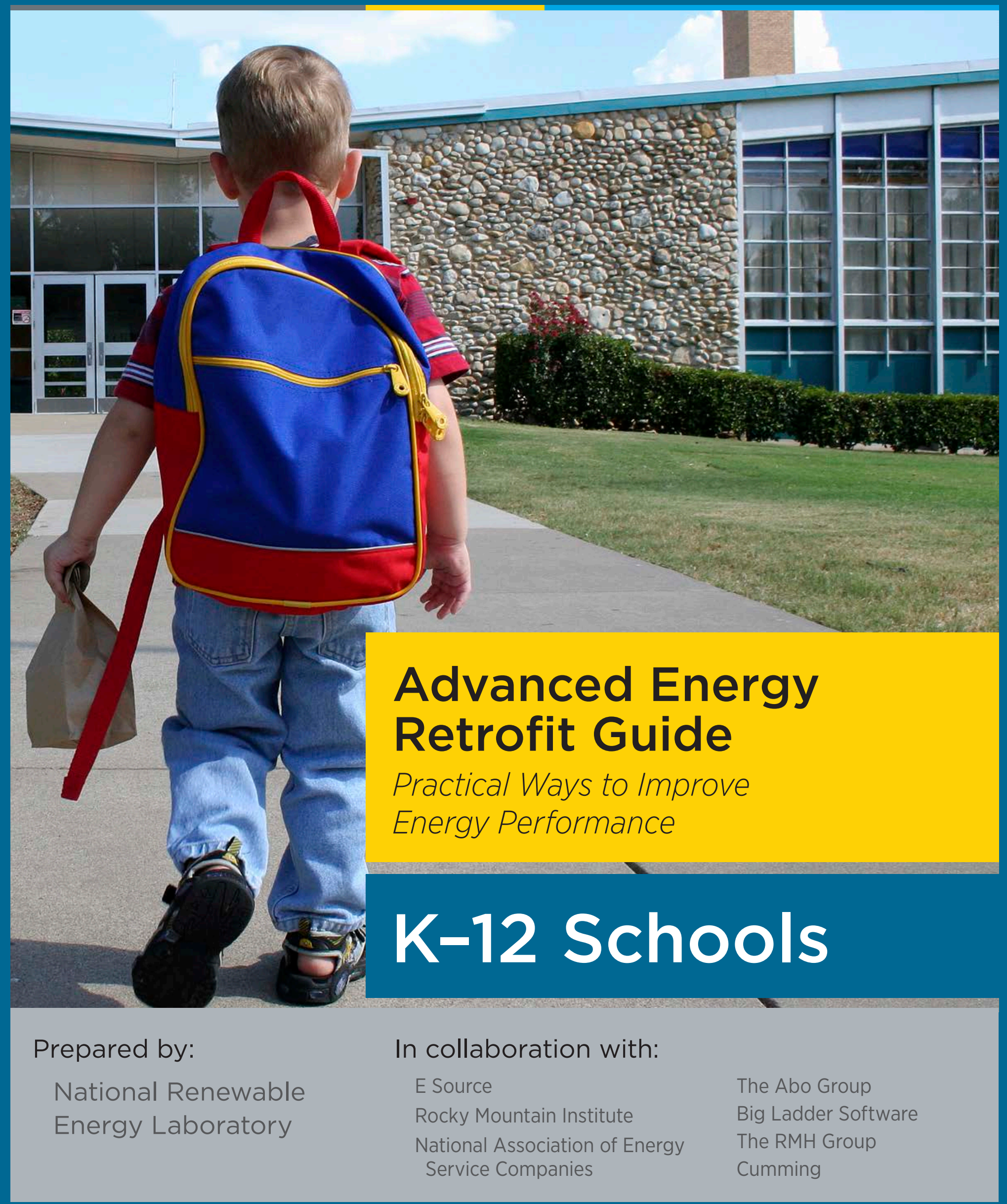





\section{Project Team}

- Robert Hendron, Diwanshu Shekhar, Shanti Pless National Renewable Energy Laboratory

- Ira Krepchin, Lee Hamilton, Anna Stephens E Source

- Michael Bendewald, Elaine Gallagher Adams, Ellen Franconi, Coreina Chan, Roy Torbert, Kendra Tupper Rocky Mountain Institute

- Donald Gilligan, Dave Birr, Nina Lockhart, Patti Donahue National Association of Energy Service Companies

- John Priebe The Abo Group

- Peter Ellis Big Ladder Software

- Phil Kocher, Bob Stahl, Bill Berger The RMH Group

- Stefan Coca Cumming 


\section{Contents}

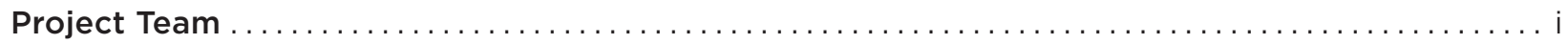

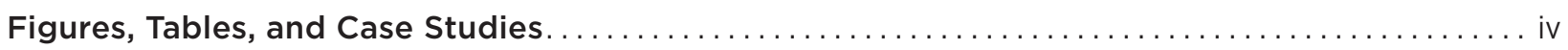

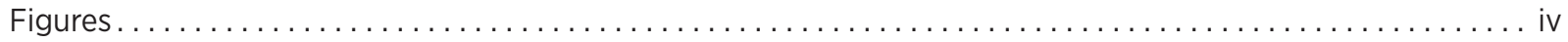

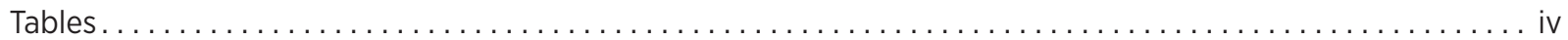

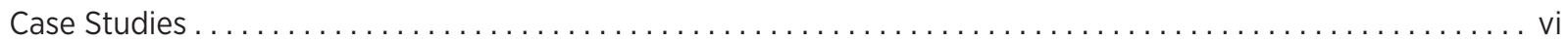

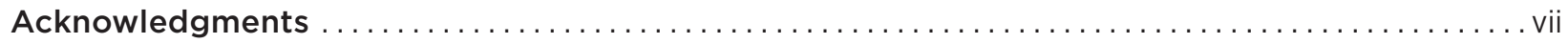

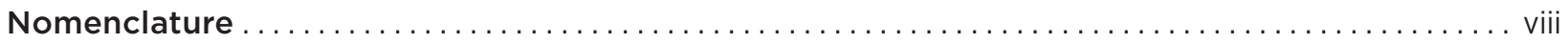

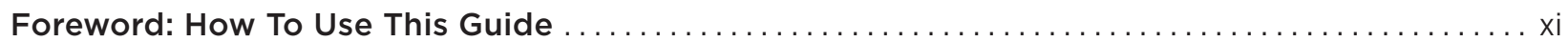

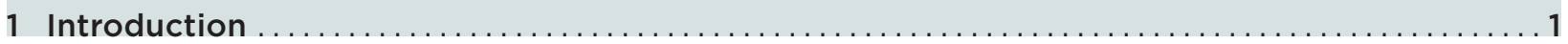

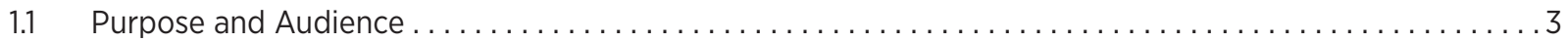

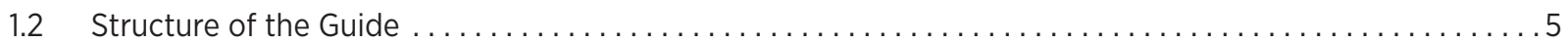

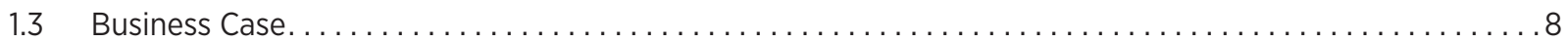

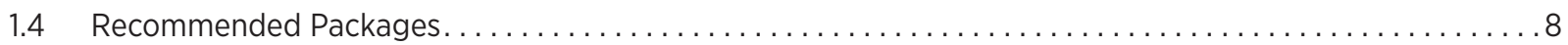

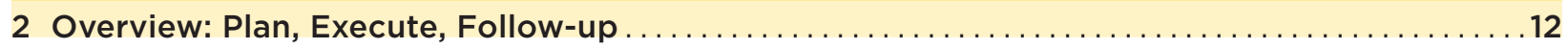

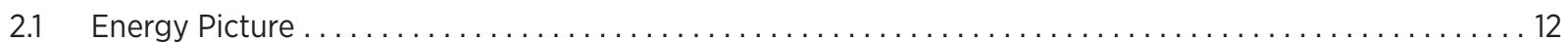

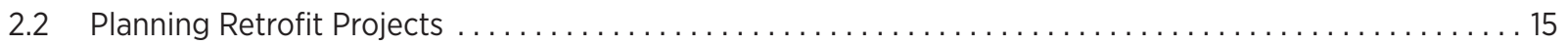

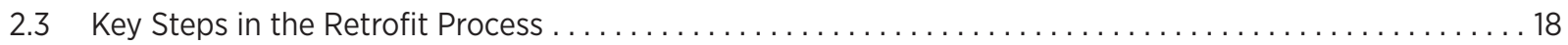

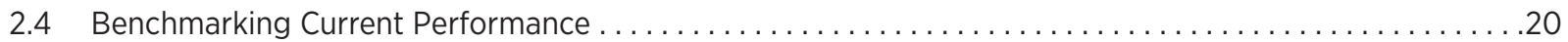

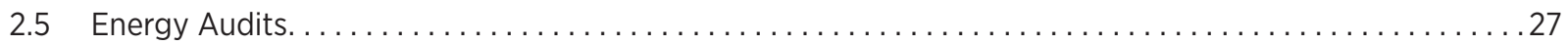

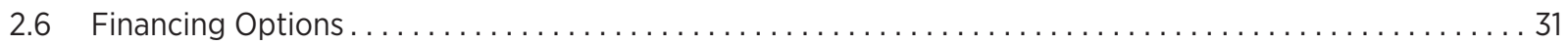

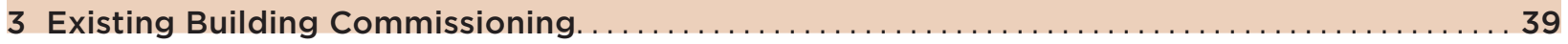

3.1 Existing Building Commissioning Energy Efficiency Measure Summary Table ................ 40

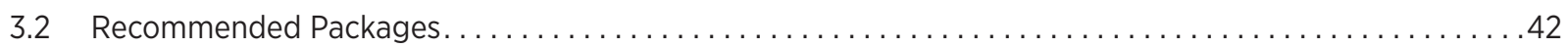

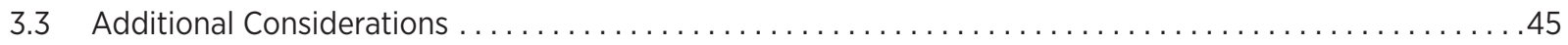

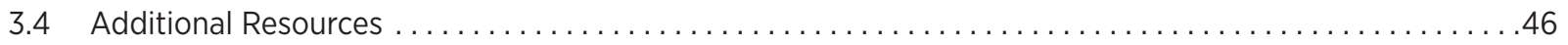

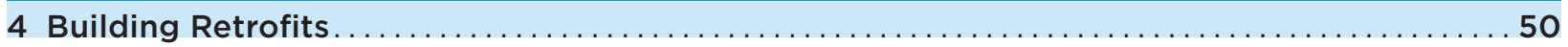

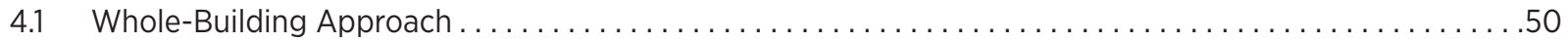

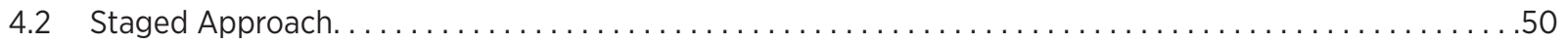

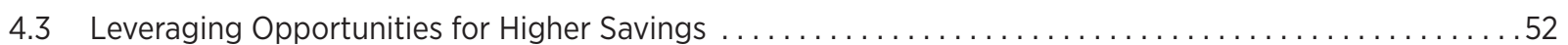

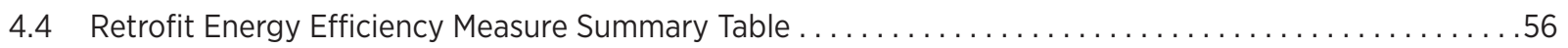

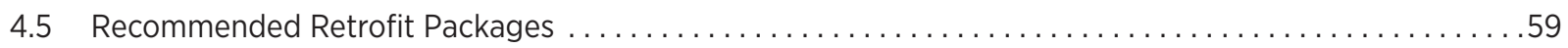

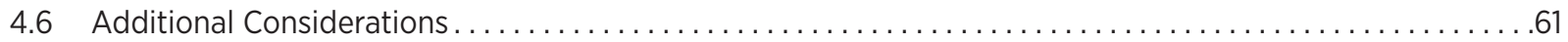

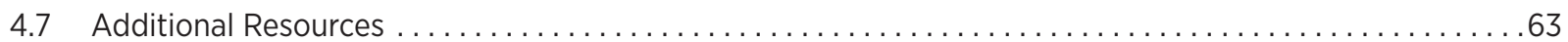




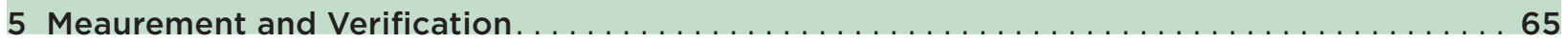

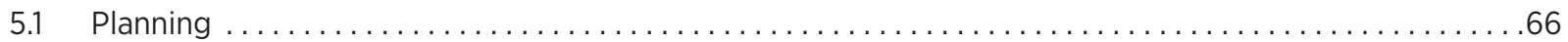

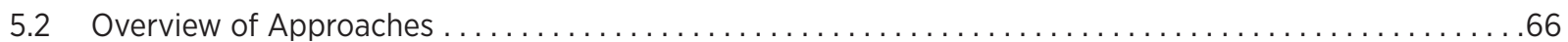

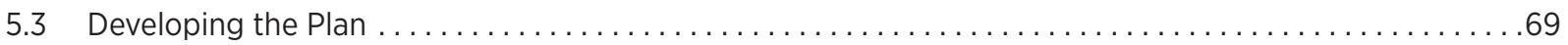

5.4 Recommendations for Specific Energy Efficiency Measures $\ldots \ldots \ldots \ldots \ldots \ldots \ldots \ldots \ldots \ldots \ldots \ldots \ldots$

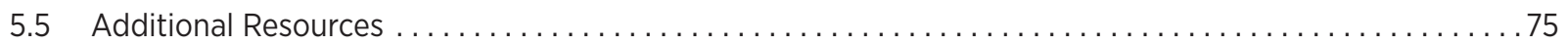

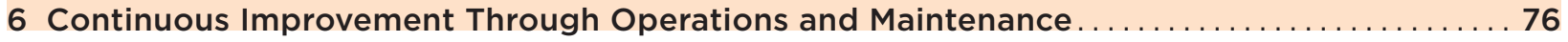

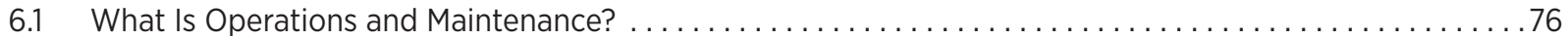

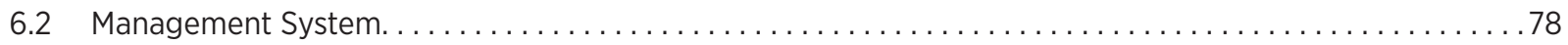

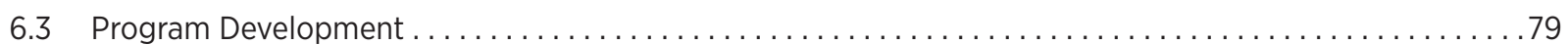

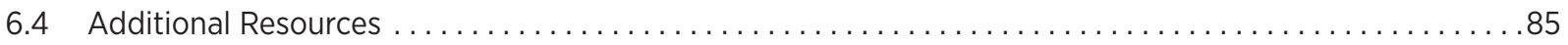

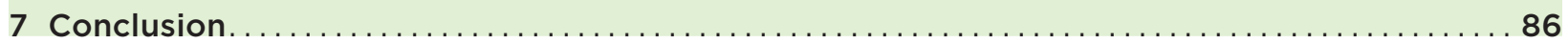

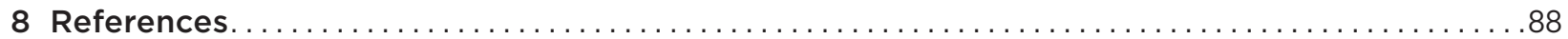

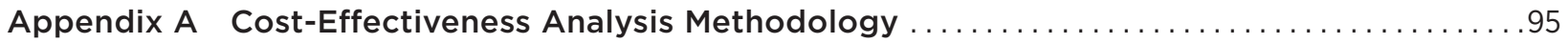

Appendix B Detailed Approach for Selecting Recommended Packages . . . . . . . . . . . . . . 104

Appendix C Detailed Analysis of Individual Retrofit Energy Efficiency Measures

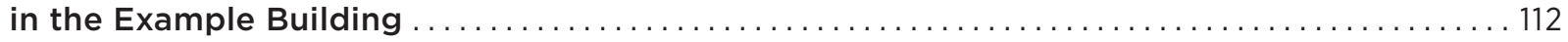

Appendix D Prioritization of All Energy Efficiency Measures Considered . . . . . . . . . . . . 140

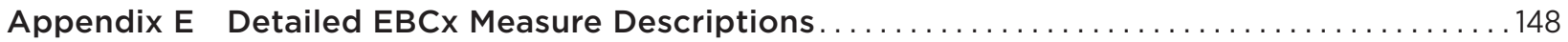

Appendix F Detailed Existing Building Commissioning Energy Efficiency

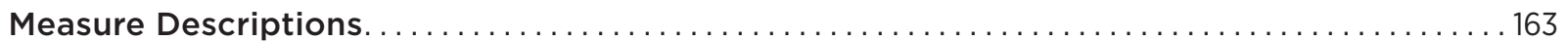

Appendix G Integrated Design Principles for Retrofit Projects $\ldots \ldots \ldots \ldots \ldots \ldots \ldots \ldots \ldots \ldots \ldots$ 


\section{Figures, Tables, and Case Studies}

\section{Figures:}

Figure 1-1

Figure 1-2

Figure 1-3

Figure 1-4

Figure 1-5

Figure 1-6

Figure 1-7

Figure 2-1

Figure 2-2

Figure 2-3

Figure 2-4

Figure 3-1

Figure 4-1

Figure 4-2

Figure 5-1

Figure 5-2

Figure 6-1

Figure 7-1

Figure 7-2

Figure A-1

Figure $\mathrm{B}-1$

Figure B-2

Figure B-3

Figure B-4

Figure B-5

Figure E-1

Figure E-2

Figure E-3

Figure $\mathrm{F}-1$

Figure $\mathrm{F}-2$

Figure $\mathrm{F}-3$

Figure F-4

Figure $\mathrm{F}-5$

Figure F-6

Figure $\mathrm{F}-7$

Figure $\mathrm{G}-1$

Figure $\mathrm{G}-2$

Figure G-3

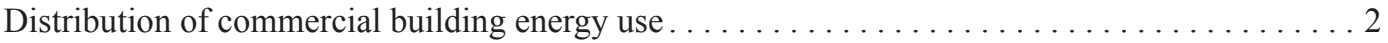

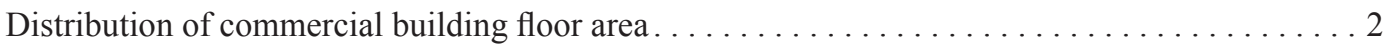

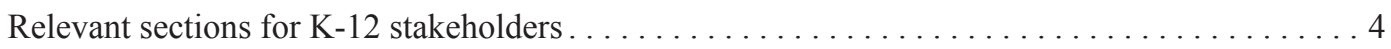

Structure of the guide relative to a typical retrofit decision-making process $\ldots \ldots \ldots \ldots \ldots \ldots 5$

Example EEMs for the two categories of retrofit addressed in this guide $\ldots \ldots \ldots \ldots \ldots \ldots 7$

General process for selecting EEMs included in recommended packages $\ldots \ldots \ldots \ldots \ldots \ldots 9$

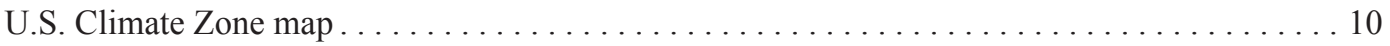

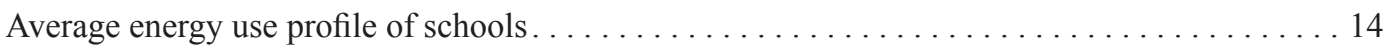

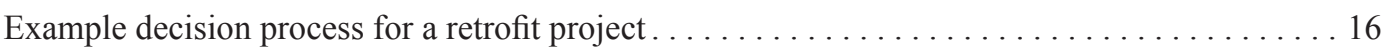

Cost and quality of the three levels of energy audits beyond preliminary analysis $\ldots \ldots \ldots \ldots 27$

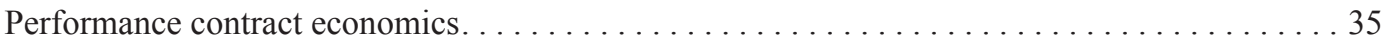

Phases of an effective EBCx project . . . . . . . . . . . . . . . . . . . . 39

Recommended project phases for a staged approach to energy efficiency upgrades . . . . . . 51

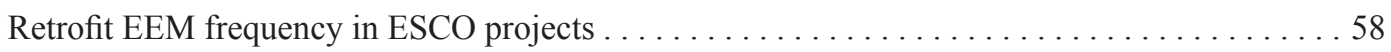

M\&V timeline . . . . . . . . . . . . . . . . . . . . . . . . . 66

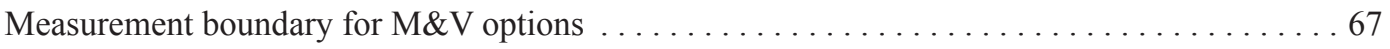

Breakdown of common commissioning problems by system type $\ldots \ldots \ldots \ldots \ldots \ldots \ldots . \ldots 1$

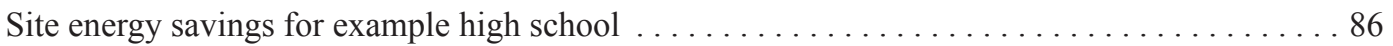

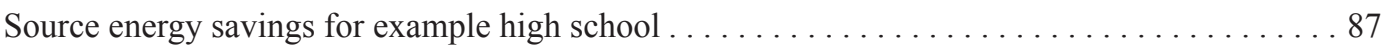

Implied DF as function of required simple payback period . . . . . . . . . . . . . . 96

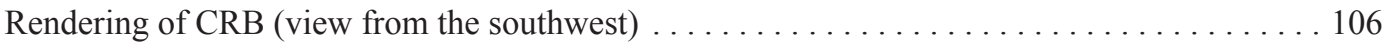

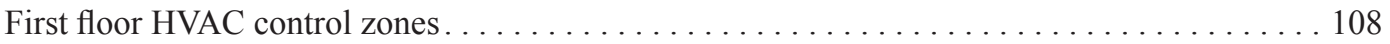

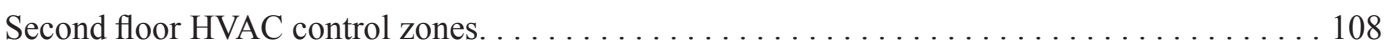

CRB CAV system serving a series of classrooms . . . . . . . . . . . . . . . . . . 109

CRB packaged single-zone system . . . . . . . . . . . . . . . . . . . . . . . 109

Windows exchange energy with the environment through a combination of

convection, conduction, radiation, and air infiltration. . . . . . . . . . . . . . . 151

Economizers include a number of components that must be properly maintained......... 155

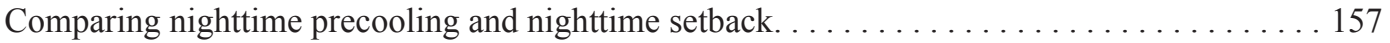

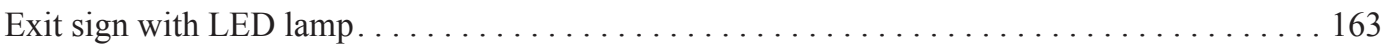

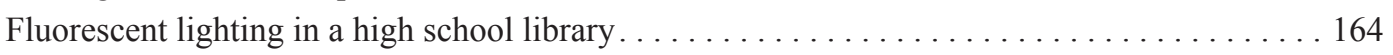

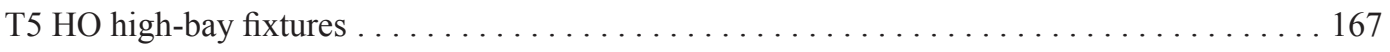

Cooking equipment and holding cabinets can offer excellent

energy savings opportunities . . . . . . . . . . . . . . . . . . . . . . . . . . . . 169

Installation of a reflective roof membrane on a building in Atlanta . . . . . . . . . . . . . 171

Typical rooftop condenser.......................................... 173

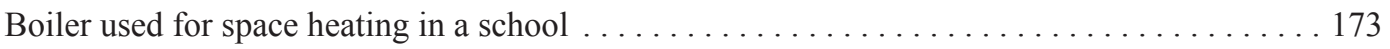

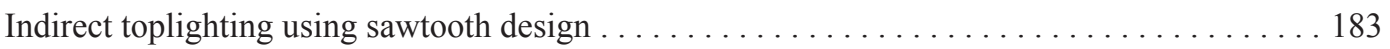

Daylighting enhancement using a light shelf with louvers for top section of the window . . . . 184

Example packages of lighting EEMs for component-level and integrated retrofits . . . . . . 186

\section{Tables:}

Table 1-1 
Table 2-2

Table 2-3

Table 2-4

Table 2-5

Table 2-6

Table 2-7

Table 2-8

Table 3-1

Table 3-2

Table 3-3

Table 3-4

Table 3-5

Table 4-1

Table 4-2

Table 4-3

Table 4-4

Table 4-5

Table 4-6

Table 5-1

Table 5-2

Table 5-3

Table 5-4

Table 5-5

Table A-1

Table A-2

Table B-1

Table B-2

Table B-3

Table B-4

Table B-5

Table B-6

Table C-1

Table C-2

Table C-3

Table $\mathrm{C}-4$

Table C-5

Table C-6

Table C-7

Table C-8

Table C-9

Table C-10

Table C-11

Table C-12

Table C-13

Table C-14

Table C-15

Table C-16

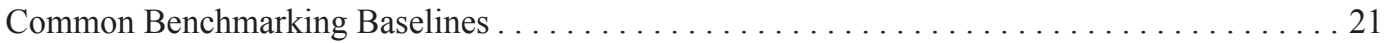

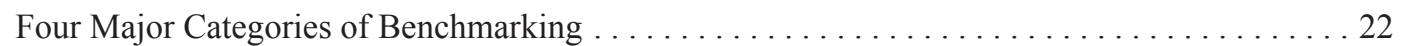

Common EUI Metrics . . . . . . . . . . . . . . . . . . . . . . . . . . . . . . 24

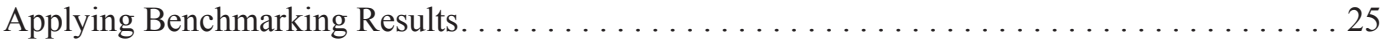

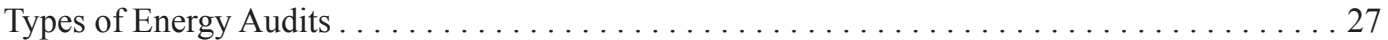

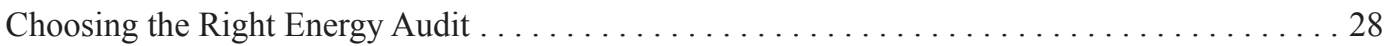

Comparison of NPV for Two Projects. . . . . . . . . . . . . . . . . . . . . . . . 33

EBCx Measure Summary Table .................................. 41

EBCx Recommended Packages-Results of Common Metrics . . . . . . . . . . . . . . 42

EBCx Measures in Recommended Packages . . . . . . . . . . . . . . . . . . . . . 43

EBCx Recommended Package Energy Savings Results ...................... 44

EBCx Recommended Package Financial Analysis Results. . . . . . . . . . . . . . . . . . . 44

Special Opportunities for Achieving Higher Energy Savings . . . . . . . . . . . . . . 52

Retrofit EEM Summary Table .................................. 56

Recommended Retrofit Packages-Results of Common Metrics................... 59

EEMs Included in the Recommended Retrofit Packages ....................... 59

Recommended Retrofit Package Energy Savings Results. . . . . . . . . . . . . . . . . 60

Retrofit Recommended Package Financial Analysis Results . . . . . . . . . . . . . . . 61

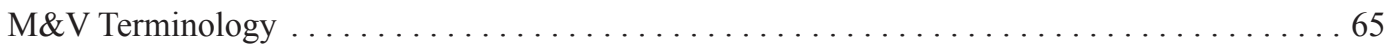

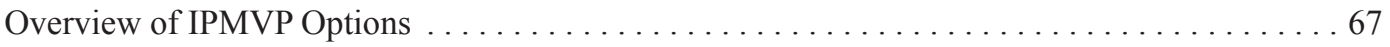

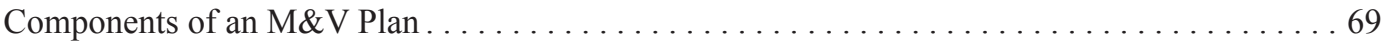

M\&V Measures for Common EBCx (Tier 1) and Retrofit (Tier 2) Improvements . . . . . . . . 71

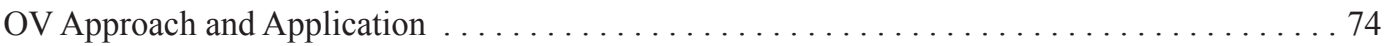

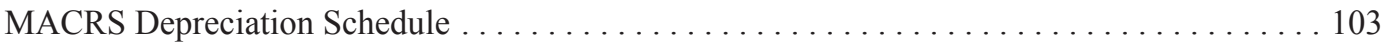

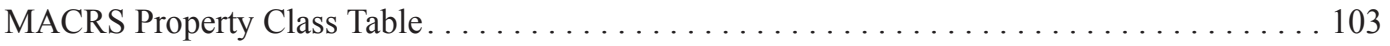

Key Climatic Characteristics of the Five Cities Used in the Development of

Recommended EEM Packages ........................................ 105

Approximate Energy Prices for the Five Cities Used in the Analysis of

Recommended EEM Packages ..................................... 106

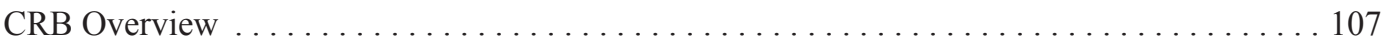

CRB Space Types and Floor Area Distribution. . . . . . . . . . . . . . . . . . 107

Performance Specifications for Multizone CAV Systems . . . . . . . . . . . . . . . . . . . . 109

Performance Specifications for Packaged Single-Zone Systems . . . . . . . . . . . . . . . . . 109

Summary of Cost-Effectiveness Analysis for Individual Measures . . . . . . . . . . . . . . . 113

Key Results of Energy Savings Analysis for LED Exit Signs $\ldots \ldots \ldots \ldots \ldots \ldots \ldots \ldots \ldots$

Key Results of Cost-Effectiveness Analysis for LED Exit Signs . . . . . . . . . . . . . . . 118

Key Results of Energy Savings Analysis for T8 Lamps and Ballasts. . . . . . . . . . . . . . . . 119

Key Results of Cost-Effectiveness Analysis for T8 Lamps and Ballasts . . . . . . . . . . . . 119

Key Results of Energy Savings Analysis for the CFL Retrofit . . . . . . . . . . . . . . 120

Key Results of Cost-Effectiveness Analysis for CFL Retrofit . . . . . . . . . . . . . . 120

Key Results of Energy Savings Analysis for Motion Sensors. . . . . . . . . . . . . . . . 121

Key Results of Cost-Effectiveness Analysis for Motion Sensors . . . . . . . . . . . . . . . . . 121

Key Results of Energy Savings Analysis for Photosensors. . . . . . . . . . . . . . . 122

Key Results of Cost-Effectiveness Analysis for Photosensors . . . . . . . . . . . . . . 122

Key Results of Energy Savings Analysis for T5 Gym Lighting . . . . . . . . . . . 123

Key Results of Cost-Effectiveness Analysis for T5 Gym Lighting. . . . . . . . . . . . . . 123

Key Results Of Energy Savings Analysis for Tubular Skylights . . . . . . . . . . . . . . . . 124

Key Results of Cost-Effectiveness Analysis for Tubular Skylights . . . . . . . . . . . . . . 124

Key Results of Energy Savings Analysis for Exterior Lighting Retrofit. . . . . . . . . . . . . . 125 
Table C-17

Table C 18

Table C-19

Table C-20

Table C-21

Table C-22

Table C-23

Table C-24

Table C-25

Table C-26

Table C-27

Table C-28

Table C-29

Table C-30

Table C-31

Table C-32

Table C-33

Table C-34

Table C-35

Table C-36

Table C-37

Table C-38

Table C-39

Table C-40

Table C-41

Table C-42

Table C-43

Table C-44

Table C-45

Table D-1

Table D-2

Table E-1

Table E-2

Table E-3

Table F-1

Table F-2

Table G-1

Table G-2
Key Results of Cost-Effectiveness Analysis for Exterior Lighting Retrofit . . . . . . . . . . . . 125

Key Results of Energy Savings Analysis for Cafeteria Appliance Replacement . . . . . . . . 126

Key Results of Cost-Effectiveness Analysis for Cafeteria Appliance Replacement. . . . . . . . 126

Key Results of Energy Savings Analysis for Kitchen Exhaust Hood Retrofit . . . . . . . . . 127

Key Results of Cost-Effectiveness Analysis for Kitchen Exhaust Hood Retrofit . . . . . . . . . . 127

Key Results of Energy Savings Analysis for Reflective Roof. . . . . . . . . . . . . . 128

Key Results of Cost-Effectiveness Analysis for Reflective Roof . . . . . . . . . . . . . . 128

Key Results of Energy Savings Analysis for Wall Insulation Retrofit . . . . . . . . . . . . . . 129

Key Results of Cost-Effectiveness Analysis for Wall Insulation Retrofit . . . . . . . . . . . . 129

Key Results of Energy Savings Analysis for Window Replacement . . . . . . . . . . . . . 130

Key Results of Cost-Effectiveness Analysis for Window Replacement . . . . . . . . . . . 130

Key Results of Energy Savings Analysis for Roof Insulation Retrofit . . . . . . . . . . . . 131

Key Results of Cost-Effectiveness Analysis for Roof Insulation Retrofit. . . . . . . . . . . . . 131

Key Results of Energy Savings Analysis for Vestibule . . . . . . . . . . . . . . . 132

Key Results of Cost-Effectiveness Analysis for Vestibule . . . . . . . . . . . . . . 132

Key Results of Energy Savings Analysis for Low-Flow Showerheads. . . . . . . . . . . 133

Key Results of Cost-Effectiveness Analysis for Low-Flow Showerheads . . . . . . . . . . . . 133

Key Results of Energy Savings Analysis for Condenser Precooling . . . . . . . . . . . . . . . 134

Key Results of Cost-Effectiveness Analysis for Condenser Precooling . . . . . . . . . . . . . 134

Key Results of Energy Savings Analysis for Small Staged Condensing Boiler . . . . . . . . . 135

Key Results of Cost-Effectiveness Analysis for Small Staged Condensing Boiler . . . . . . . . . 135

Key Results of Energy Savings Analysis for Variable-Speed Pumps . . . . . . . . . . . . . . 136

Key Results of Cost-Effectiveness Analysis for Variable-Speed Pumps. . . . . . . . . . . . . . . 136

Key Results of Energy Savings Analysis for Premium Efficiency Motors . . . . . . . . . . . 137

Key Results of Cost-Effectiveness Analysis for Premium Efficiency Motors . . . . . . . . . . 137

Key Results of Energy Savings Analysis for DCV . . . . . . . . . . . . . . . . . 138

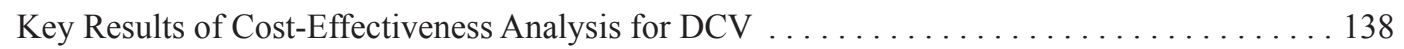

Key Results of Energy Savings Analysis for ERV . . . . . . . . . . . . . . . . . 139

Key Results of Cost-Effectiveness Analysis for ERV . . . . . . . . . . . . . . . . . 139

Prioritization of EBCx Measures. . . . . . . . . . . . . . . . . . . . . . 140

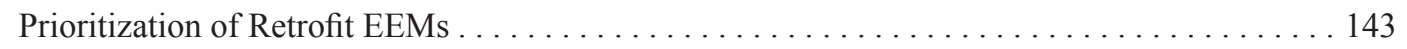

Covering Your Losses: Estimated Costs for Heating Outdoor Pools . . . . . . . . . . . . . 150

Recommended Temperature Setbacks and Setups for U.S. Climate Zones . . . . . . . . . 157

Additional EBCx Measures That Should Be Considered . . . . . . . . . . . . . . . 162

Potential Savings for Controlling Lighting Using Motion Sensors $\ldots \ldots \ldots \ldots \ldots \ldots \ldots$

Additional EEMs That Should Be Considered . . . . . . . . . . . . . . . . . . . . 179

Visual Needs for Space Types in K-12 Schools . . . . . . . . . . . . . . . . . . . . 182

Impacts of Recommended Lamp and Fixture Upgrades to Existing Ceilings . . . . . . . . 187

\section{Case Studies:}

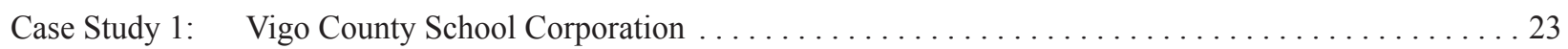

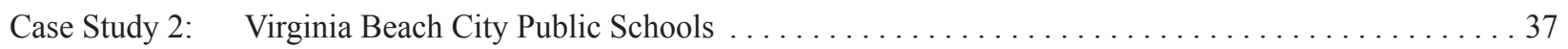

Case Study 3: Century Middle School Retrocommissioning ......................... 47

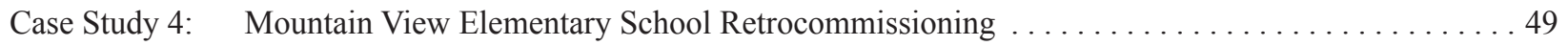

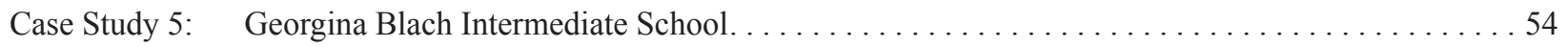

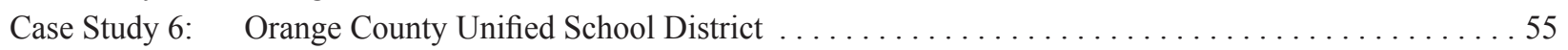

Case Study 7: The Pingry School—The Carol and Park B. Smith Middle School . . . . . . . . . . . 62

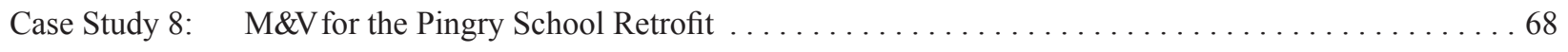

Case Study 9: $\quad$ East Valley Middle School Retrocommissioning $\ldots \ldots \ldots \ldots \ldots \ldots \ldots \ldots \ldots \ldots \ldots \ldots \ldots$ 


\section{Acknowledgments}

The authors express their appreciation to Arah Schuur, Jeremiah Williams, Monica Neukomm, Kathleen Hogan, and Joe Hagerman of the U.S. Department of Energy Office of Energy Efficiency and Renewable Energy for providing the resources and leadership necessary to develop this Advanced Energy Retrofit Guide (AERG).

We also express our great appreciation to Guopeng Liu, Bing Liu, Andrew Nichols, and the rest of the AERG project team at Pacific Northwest National Laboratory (PNNL) for their collaborative efforts to produce this series of guides. Much of the material presented in this guide was written jointly by the NREL and PNNL project teams to provide the reader with the best information available.

Finally, we recognize a few of the many individuals who contributed valuable information, ideas, and guidance throughout the planning, development, and peer review phases of this project:

- Dean Armstrong National Renewable Energy Laboratory

- Nick Bengtson PECI

- Robert Bisson Manitoba Public Schools Finance Board

- Eric Bonnema National Renewable Energy Laboratory

- Rachel Buckley E Source

- Cara Carmichael Rocky Mountain Institute

- Alberta Carpenter National Renewable Energy Laboratory

- Jason Click Media Fusion

- Eliot Crowe PECI

- Mark Effinger PECI

- Mark Frankel New Buildings Institute

- Al Hicks National Renewable Energy Laboratory

- Cathy Higgins New Buildings Institute

- Paul Hutton Hutton Architecture Studio

- John Jennings Northwest Energy Efficiency Alliance

- Peter Larsen Lawrence Berkeley National Laboratory

- Matthew Leach National Renewable Energy Laboratory
- Bing Liu Pacific Northwest National Laboratory

- Guopeng Liu Pacific Northwest National Laboratory

- Bill Livingood National Renewable Energy Laboratory

- William Miller Lawrence Berkeley National Laboratory

- James H. Morris III Virginia Beach City Public Schools

- John Murphy Trane

- Victor Olgyay Rocky Mountain Institute

- Andrew Parker National Renewable Energy Laboratory

- Stuart Reeve Poudre School District

- Thomas Schneider North Penn School District

- Marjorie Schott National Renewable Energy Laboratory

- Justin Stein National Renewable Energy Laboratory

- Mark Swisher The Office of Mark Swisher

- Paul Torcellini National Renewable Energy Laboratory

- Lia Webster PECI

- Stefanie Woodward National Renewable Energy Laboratory 


\section{Nomenclature}

\begin{tabular}{|c|c|}
\hline ADR & asset depreciation range \\
\hline AEDG & Advanced Energy Design guide \\
\hline AERG & Advanced Energy Retrofit Guide \\
\hline $\mathrm{AHU}$ & air handling unit \\
\hline ASHRAE & $\begin{array}{l}\text { American Society of Heating, Refrigerating and Air-Conditioning } \\
\text { Engineers }\end{array}$ \\
\hline BAS & building automation system \\
\hline BOMA & Building Owners and Managers Association \\
\hline Btu & British thermal unit \\
\hline $\mathrm{C}_{0}$ & initial investment and related cash flows in Year $\mathrm{O}$ \\
\hline CAV & constant air volume \\
\hline CBECS & Commercial Buildings Energy Consumption Survey \\
\hline $\mathrm{C}_{\text {depr,eem,t }}$ & $\begin{array}{l}\text { tax deduction for depreciation of energy efficiency measure/package } \\
\text { in Year } t\end{array}$ \\
\hline$C_{\text {depr,ref,t }}$ & tax deduction for depreciation of existing equipment in Year $t$ \\
\hline$C_{\text {disp }}$ & disposal cost of existing equipment \\
\hline CEC & California Energy Commission \\
\hline $\mathrm{C}_{\text {energy,elec,t }}$ & annual electricity cost savings in Year t \\
\hline $\mathrm{C}_{\text {energy,gas,t }}$ & annual natural gas cost savings in Year $t$ \\
\hline CFL & compact fluorescent lamp \\
\hline cfm & cubic feet per minute \\
\hline$C_{\text {incent }}$ & NPV of financial incentives \\
\hline$C_{\text {inst }}$ & installation cost of measure/package \\
\hline $\mathrm{C}_{\mathrm{mv}}$ & additional M\&V costs \\
\hline CHPS & Collaborative for High Performance Schools \\
\hline $\mathrm{CO}_{2}$ & carbon dioxide \\
\hline $\mathrm{C}_{\mathrm{om}}$ & additional O\&M costs \\
\hline COP & coefficient of performance \\
\hline $\mathrm{C}_{\text {plan }}$ & cost of project planning \\
\hline $\mathrm{C}_{\text {pur }}$ & purchase cost of equipment \\
\hline CRB & DOE Commercial Reference Building \\
\hline $\mathrm{C}_{\text {rem,eem }}$ & remaining value of measure \\
\hline $\mathrm{C}_{\text {rem,ref }}$ & remaining value of reference equipment \\
\hline $\mathrm{C}_{\text {repl,eem }}$ & replacement cost for energy efficiency measure/package \\
\hline
\end{tabular}




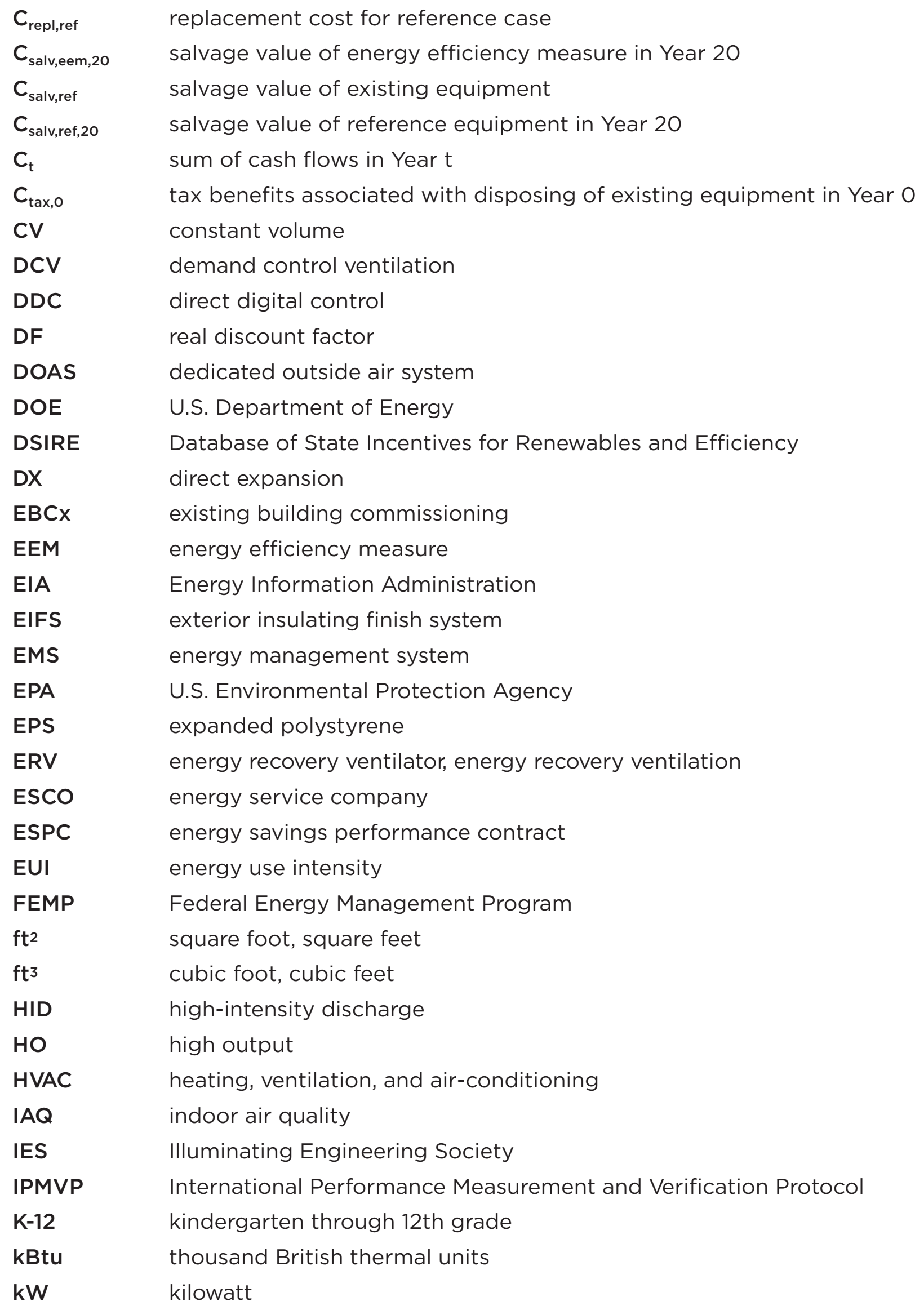




$\begin{array}{ll}\text { kWh } & \text { kilowatt-hour } \\ \text { LBNL } & \text { Lawrence Berkeley National Laboratory } \\ \text { LCC } & \text { life cycle costs } \\ \text { LED } & \text { light-emitting diode } \\ \text { LEED } & \text { Leadership in Energy and Environmental Design } \\ \text { MH } & \text { metal halide } \\ \text { M\&V } & \text { measurement and verification } \\ \text { MACRS } & \text { Modified Accelerated Cost Recovery System } \\ \text { MMBtu } & \text { million British thermal units } \\ \text { N } & \text { number of years in analysis period } \\ \text { NEED } & \text { National Energy Education Development } \\ \text { NEMA } & \text { National Electric Manufacturers Association } \\ \text { NPV } & \text { net present value } \\ \text { NREL } & \text { National Renewable Energy Laboratory } \\ \text { O\&M } & \text { operations and maintenance } \\ \text { OA } & \text { outside air } \\ \text { OAT } & \text { outside air temperature } \\ \text { OMETA } & \text { Operations, Maintenance, Engineering Support, Training } \\ \text { OPR } & \text { and Administration } \\ \text { OV } & \text { Owner Project Requirements } \\ \text { PECI } & \text { operational verification } \\ \text { PNNL } & \text { Portland Energy Conservation Inc. } \\ \text { RCx } & \text { Pacific Northwest National Laboratory } \\ R_{\text {esc,elect }} & \text { retrocommissioning } \\ R_{\text {esc,gas }} & \text { fuel price escalation rate for electricity } \\ R_{\text {tax,inc }} & \text { fuel price escalation rate for natural gas } \\ \text { RTU } & \text { federal corporate income tax rate } \\ \text { SAT } & \text { rooftop unit } \\ \text { SHGC } & \text { supply air temperature } \\ \text { SV } & \text { solar heat gain coefficient } \\ \text { t } & \text { savings verification } \\ \text { TAB } & \text { years after initial investment } \\ \text { VAV } & \text { testing, adjusting, and balancing } \\ \text { VCSC } & \text { variable air volume } \\ \text { VFD } & \text { Vigo County School Corporation } \\ \text { VSD } & \text { variable frequency drive } \\ & \text { variable speed drive } \\ & \end{array}$




\section{Foreword: How To Use This Guide}

The Advanced Energy Retrofit Guide for K-12 Schools is one of five retrofit guides commissioned by the U.S. Department of Energy (DOE). By presenting general project planning guidance as well as more detailed descriptions and financial payback metrics for the most important and relevant energy efficiency measures (EEMs), we believe these guides provide a practical roadmap for effectively planning and implementing performance improvements in existing buildings.

The AERGs are designed to address key segments of the U.S. commercial building stock: retail stores, office buildings, K-12 schools, grocery stores, and healthcare facilities. The guides' general project planning considerations are applicable nationwide; the energy and cost savings estimates for recommended EEMs were developed based on energy simulations and cost estimates tailored to five distinct climate zones. The results of these analyses are presented for individual EEMs, and for packages of recommended EEMs for two project types: existing building commissioning and whole-building retrofits. An overview of the AERG structure is shown below.

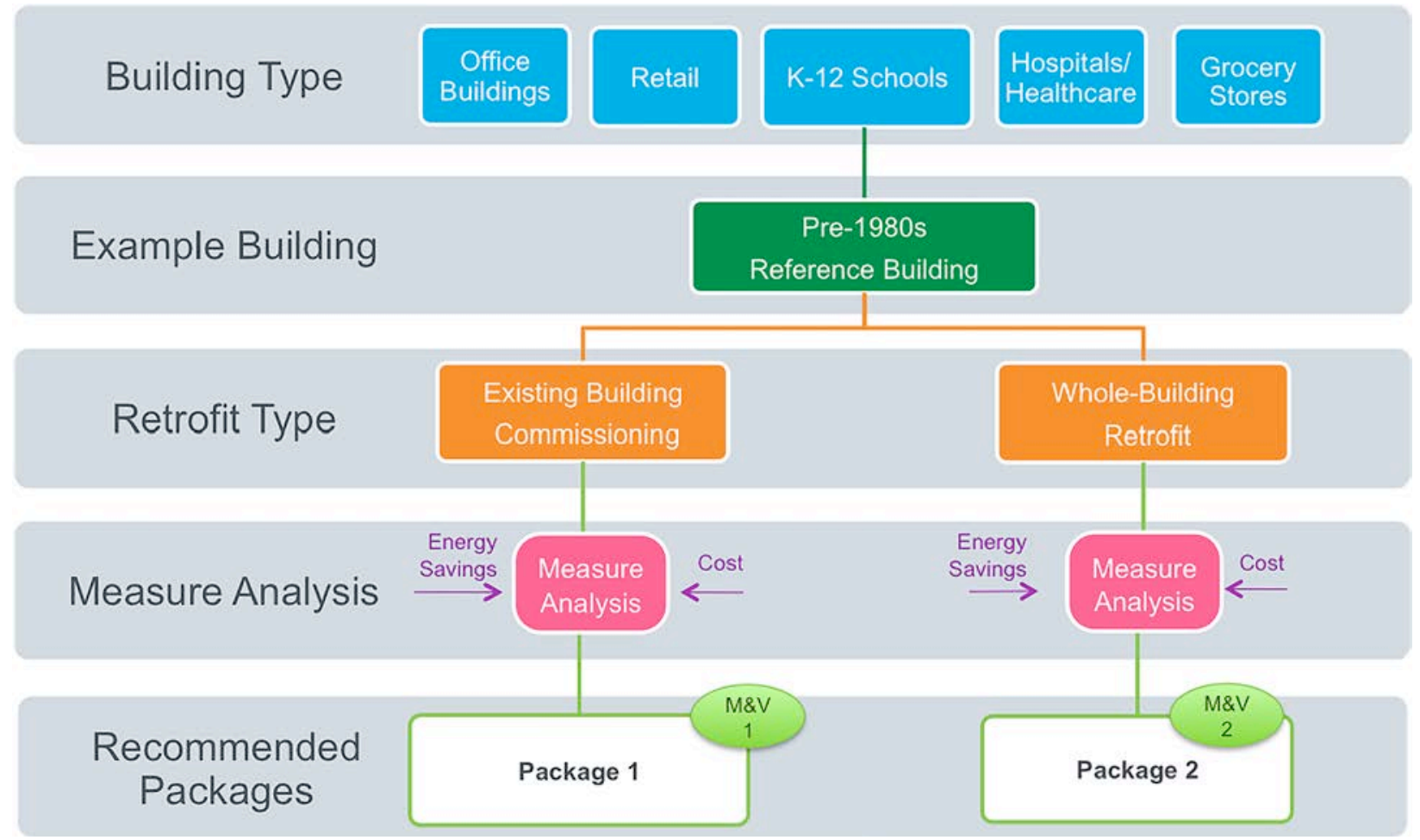

This guide was created to help school districts plan, design, and implement energy improvement projects in their facilities. It was designed with energy managers in mind, and presents practical guidance for kick starting the process and maintaining momentum throughout the project life cycle. The guide was developed primarily as a reference document, allowing energy managers to consult the sections that address the most pertinent topics, without reading the guide from cover to cover. Many other useful guides have been developed by other organizations, and are cited throughout this document when appropriate. This guide endeavors to provide a comprehensive range of information tailored specifically to the needs of K-12 schools, with an emphasis on the most effective retrocommissioning and 
retrofit measures as identified by experienced retrofit experts familiar with the special opportunities and challenges associated with schools. This guide presents a broad range of proven practices that can help energy managers take specific actions at any stage of the retrofit process, resulting in sustainable energy savings for many years to come.

The primary sections of the guide are shown in the figure below, along with indicators to help stakeholders determine the most relevant sections. Energy managers will find all sections helpful, as will other school district personnel who are responsible for planning and overseeing facility improvements that affect energy use. But an effective school retrofit project requires the support of many stakeholders, particularly when the project has the potential to enhance the learning environment for students. Nonenergy benefits are vital considerations when implementing energy efficiency projects in K-12 schools, and this guide demonstrates how to obtain strong financial returns from a project while supporting the education and well-being of our children.

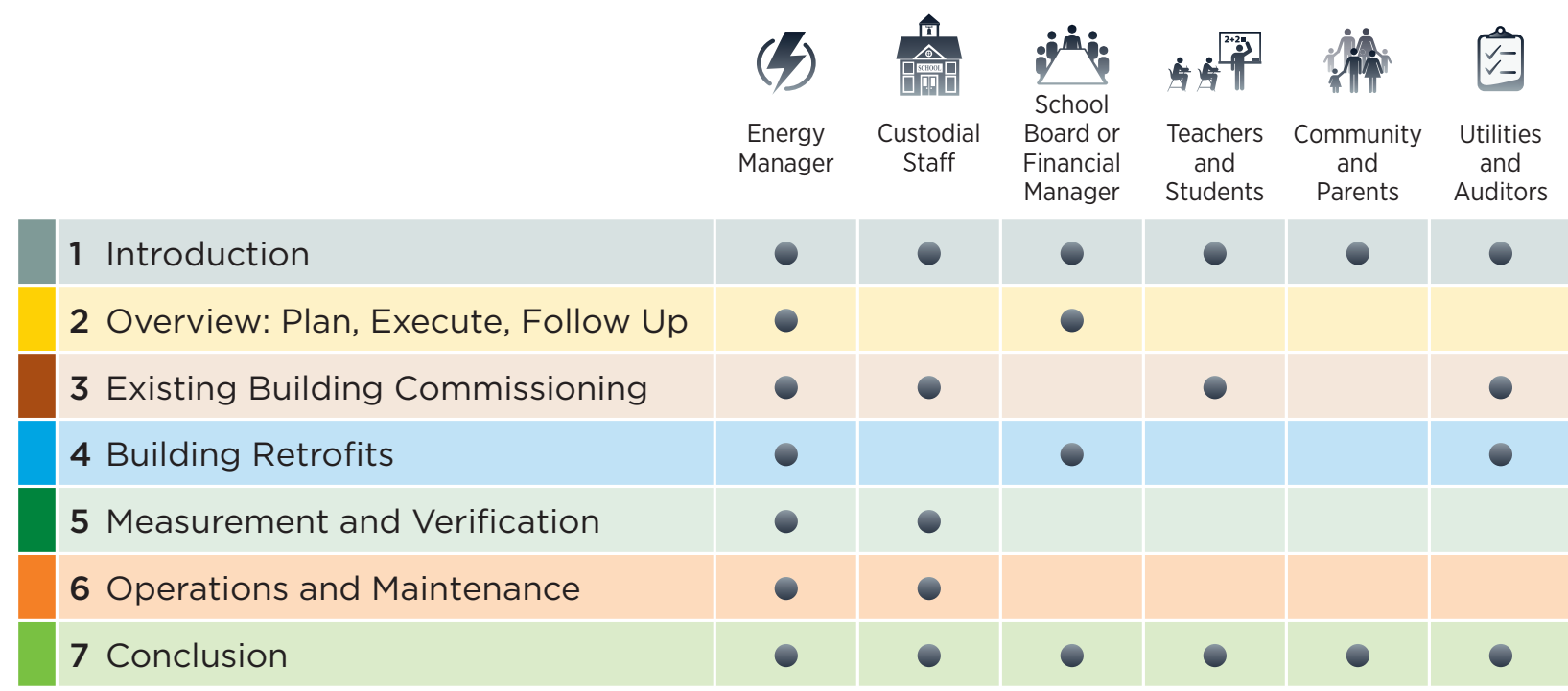

We hope this guide will be a valuable resource to all K-12 school districts, energy managers, facility managers, and other decision makers who seek to improve their buildings, save energy, reduce operating costs, and provide a comfortable environment for students and employees. 


\section{Introduction}

The U.S. Department of Energy (DOE) developed the Advanced Energy Retrofit Guides (AERGs) to provide specific methodologies, information, and guidance to help energy managers and other stakeholders plan and execute energy efficiency improvements. Detailed technical discussion is fairly limited. Instead, we emphasize actionable information, practical methodologies, diverse case studies, and unbiased evaluations of the most promising retrofit energy efficiency measures (EEMs) for each building type. A series of AERGs is under development, addressing key segments of the commercial building stock. K-12 schools were selected as one of the highest priority building sectors, because schools affect the lives of most Americans. They also represent approximately $8 \%$ of the energy use and $10 \%$ of the floor area in commercial buildings nationwide (see Figure 1-1 and Figure 1-2).

U.S. K-12 school districts spend more than $\$ 8$ billion each year on energy - more than they spend on computers and textbooks combined (EPA 2009). Most occupy older buildings that often have poor operational performance - more than 30\% of schools were built before 1960 (DOE 2003). The average age of a school is about 42 years - which is nearly the expected serviceable lifespan of the building (McGraw Hill 2011). K-12 schools offer unique opportunities for deep, cost-effective energy efficiency improvements, and this guide provides convenient and practical guidance for exploiting these opportunities in the context of public, private, and parochial schools.

Section 2 of this guide provides an overview of important steps to help energy managers identify energy efficiency improvement opportunities and to successfully plan, implement, and evaluate any level of energy upgrade project. We then address specific planning stages in subsections about performance assessment through benchmarking, identifying cost-effective EEMs (see sidebar) through energy auditing, and financing mechanisms.

Section 3 provides a detailed discussion of existing building commissioning (EBCx) EEMs that should be considered as the first step in almost any school upgrade project. The descriptions cover energy and cost savings, special opportunities and challenges, and climate-dependent considerations. Section 4 provides recommendations for going further with specific retrofit EEMs, addressing the strengths and weaknesses of each, and providing energy savings and cash flow analyses for recommended packages.
This guide to building energy retrofits offers practical methodologies, diverse case studies, and objective evaluations of the most promising retrofit measures for $K-12$ schools. By combining modeled energy savings and estimated costs, this guide presents cost-effectiveness metrics for individual EEMs and for recommended packages of EEMs. This information can be used to support a business case for energy retrofit projects and improve the energy performance of buildings nationwide.

On average, $\mathrm{K}-12$ schools spend more on energy bills than on computers and textbooks combined.

\section{Barriers addressed by this guide:}

- Difficulty getting started

- Limited capital and competition for resources

- Shortage of actionable information tailored to K-12 schools

- Failure to consider all benefits over project life

- Lack of specific integrated design methods adapted to K-12 schools

- Need for reliable data to support business case

- Desire to minimize risk 
Sections 5 and 6 provide guidance for verifying and sustaining energy savings through measurement and verification $(\mathrm{M} \& \mathrm{~V})$ and operations and maintenance $(\mathrm{O} \& \mathrm{M})$. The purpose of $\mathrm{M} \& \mathrm{~V}$ is to make sure the improvements were implemented properly, and achieve the expected level of energy savings. M\&V is usually performed by examining utility bills and making direct measurements of energy use for important subsystems. O\&M is a process for managing the operation of improved systems to ensure that the initial energy savings are not undermined over time through improper use or inadequate maintenance.

We also include case studies that show how other schools have implemented energy upgrades, the savings they have achieved, and the challenges they faced. These case studies are distributed throughout the guide to illustrate the application of key points.

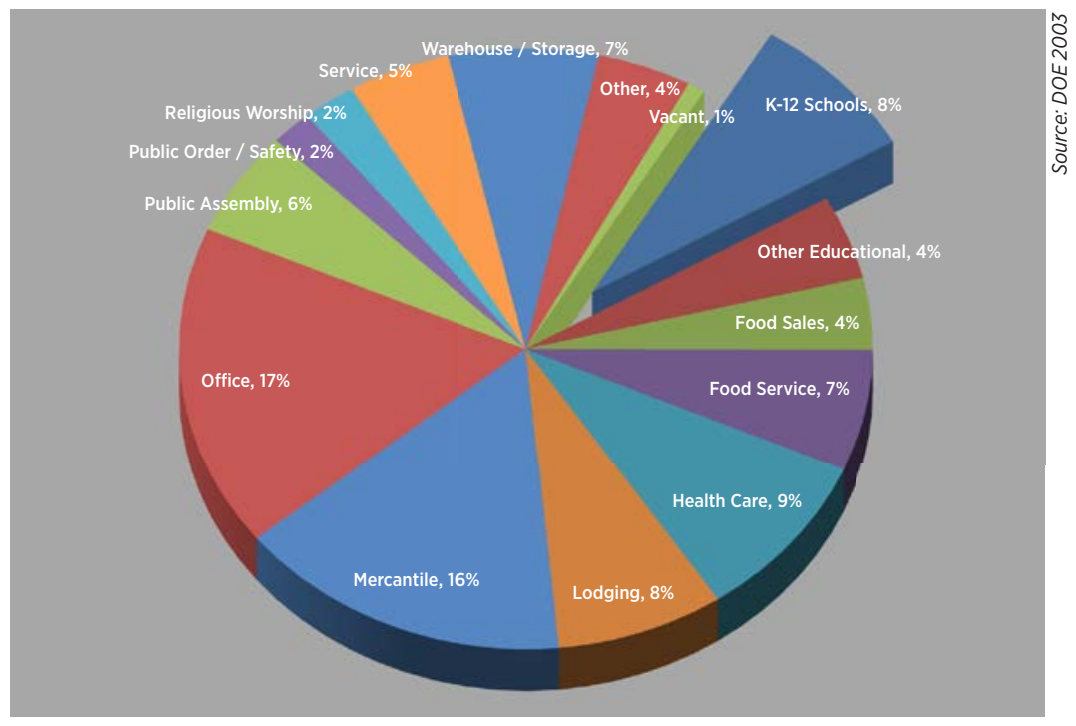

Figure 1-1 Distribution of commercial building energy use

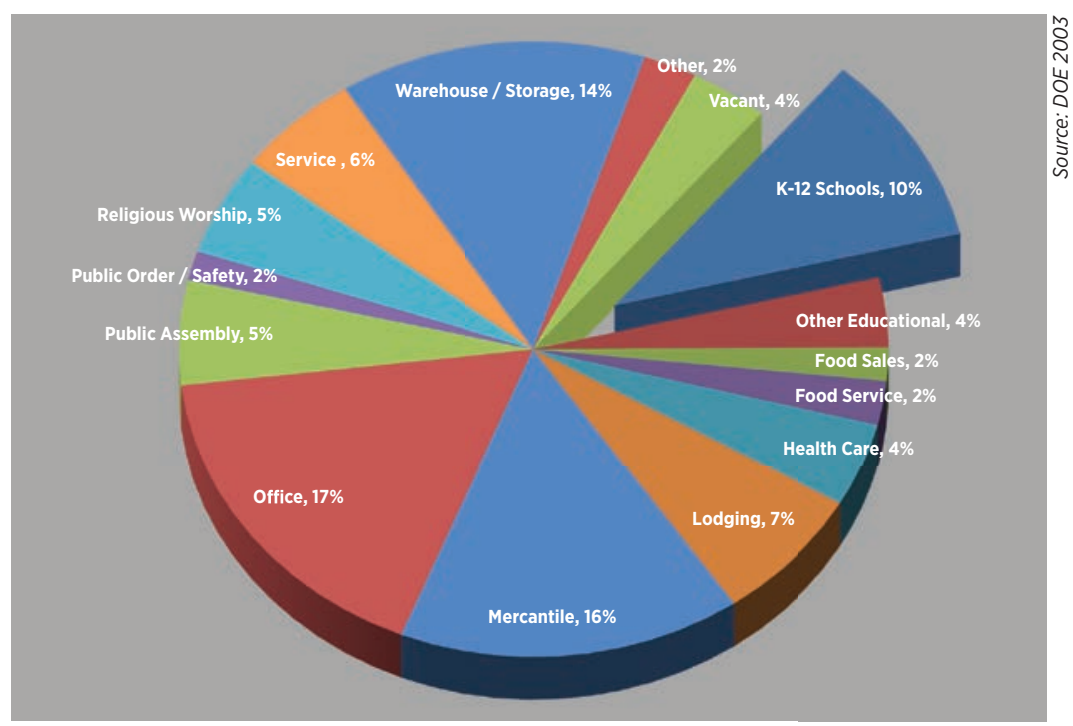

Figure 1-2 Distribution of commercial building floor area 
Why do we need another retrofit guide when a great deal of information is already available? Our goal is to address one of the biggest gaps in the literature: reliable and actionable cost- and energy-saving methods and data in the context of K-12 schools. This guide helps to fill that gap by providing comprehensive analytical methods for evaluating the cost effectiveness of potential retrofit EEMs. In the context of this guide, the term cost effective is synonymous with positive net present value (NPV) based on incremental cash flows over a 20-year analysis period, whether referring to a single EEM or to an EEM package. NPV analysis assumptions are discussed in greater detail in Section 2.6 and Appendix A. These analytical methods are supplemented with a comprehensive and detailed example using the Pre-1980s Secondary School Commercial Reference Building (CRB) developed by DOE (Deru et al. 2011). The example represents a relatively old elementary school, with equipment that has been replaced at least once since the school was built. The optimal packages for other schools would vary significantly, but the example illustrates the application of EEMs and methodologies described in the guide.

Because of the wide variation in school building conditions and financial constraints, we address three types of building upgrades in this guide: (1) low-cost and no-cost EBCx measures; (2) whole-building retrofits where a comprehensive package of measures is implemented in a short span of time using an integrated design approach (see sidebar); and (3) staged retrofit projects that leverage energy savings from each stage and more opportune timing of retrofits to achieve similar savings in an incremental fashion.

This approach broadens the applicability of the guide to a diverse set of situations, and each section builds on the recommendations of the

Integrated Design: A collaborative and iterative design process for building improvements in which a systems approach is employed to leverage multiple energy and nonenergy benefits from a capital improvement project, resulting in much higher energy savings than can be achieved using a piecemeal approach. previous one to create a logical progression. The guide addresses specific retrofit options and packages, along with the more general topics of project planning, financing mechanisms, investment analysis, O\&M, and M\&V within the framework of K-12 schools.

\subsection{Purpose and Audience}

This AERG will enhance the quality and depth of energy efficiency retrofit projects in existing schools. We recognize some schools and districts are financially constrained and that school characteristics vary widely; therefore, we address multiple levels of retrofit so you have greater flexibility to develop effective building improvement projects in a broad spectrum of situations. We also present holistic techniques for improving buildings so you can leverage synergistic opportunities.

The primary audience for this guide is school district energy managers who wish to significantly raise the efficiency of their K-12 school

Cost-effective measures: In the context of this guide, we define costeffective measures as those with a positive NPV, as discussed in Section 2.6 and Appendix A. buildings and generate a strong financial return that can be reinvested in the school or returned to the community through lower taxes or tuition rates. Other stakeholders will also benefit from specific sections (see Figure 1-3 and the following subsections). 


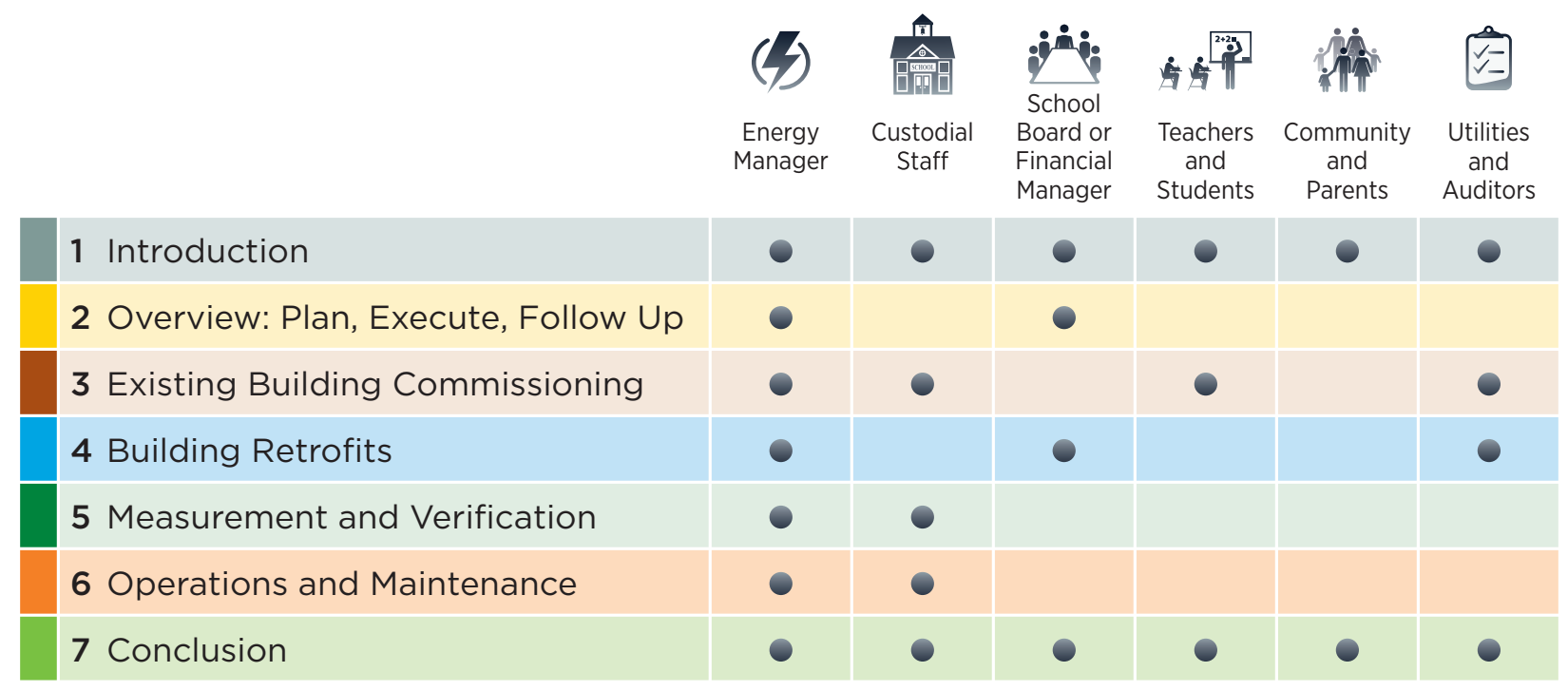

Figure 1-3 Relevant sections for K-12 school stakeholders

\section{Energy Manager}

The energy manager for a school district, or the staff member with equivalent responsibilities, must develop a strong justification for retrofit projects, and therefore requires sound economic and technical analysis methods and data before committing financial resources to a project. The energy manager is also responsible for overseeing the project's successful implementation. This guide is targeted to energy managers, and provides the practical guidance they need at each stage of the retrofit process.

\section{Custodial Staff}

The custodial staff has an important role in implementing, verifying, and maintaining the EEMs discussed in this guide. In fact, many commissioning measures described in Section 3 can be performed in the normal course of custodial activities, without any major capital investments that require special approval. The custodial staff may also be interested in the sections describing best practices for $\mathrm{M} \& \mathrm{~V}$ and $\mathrm{O} \& \mathrm{M}$.

\section{School Board or Financial Manager}

The school board has essential responsibilities for authorizing and overseeing major capital investment projects, ensuring the well-being and quality education of students, and interacting with the community. The school board members must make or approve many planning and financing decisions related to retrofit projects, and the information described in Section 2 is designed to assist with that process. The school board may also be cognizant of necessary building renovations or other leveraging opportunities that create the potential for whole-building retrofits (see Section 4).

\section{Teachers and Students}

An energy retrofit project offers a unique opportunity to teach students about how energy is used in schools and simple actions they can take to reduce energy use. Students can also learn how to predict energy savings mathematically, and how to use utility bills or metered data to verify savings. They can evaluate and implement many ideas in Section 3, with oversight from a science teacher or other qualified faculty member. 


\section{Community and Parents}

The local community in general, and parents in particular, have an important responsibility to ensure children spend their days in a safe environment that is conducive to effective learning. They also have an interest in how their tax dollars are being spent. The material in the introduction and conclusion presents ideas and principles that can be brought to the local school board for action.

\section{Utilities and Auditors}

The prioritized commissioning and retrofit EEM descriptions in Sections 3-4 and Appendices E-G can stimulate ideas for auditors, utility companies, and retrofit contractors. K-12 school retrofit experts from across the country provided their insights and knowledge to identify the most important EEMs that should be evaluated for each project, and to describe the strengths, weaknesses, climate considerations, and application issues for each EEM in the context of K-12 schools.

\subsection{Structure of the Guide}

This guide is most useful during the initial stages of a retrofit project, but it is also a valuable reference throughout the life of a project and beyond. It can stimulate ideas for additional retrofit EEMs, describes important performance and cost tradeoffs, and identifies reliable and cost-effective $M \& V$ protocols. Figure $1-4$ shows how each section fits into the general process of upgrading a K-12 school building. The sequencing illustrates a common approach to addressing retrofits, and is consistent with the order of topics in this guide, but alternate sequencing and additional steps may be included, depending on the situation. The planning and implementation processes are explained more fully in Section 2.

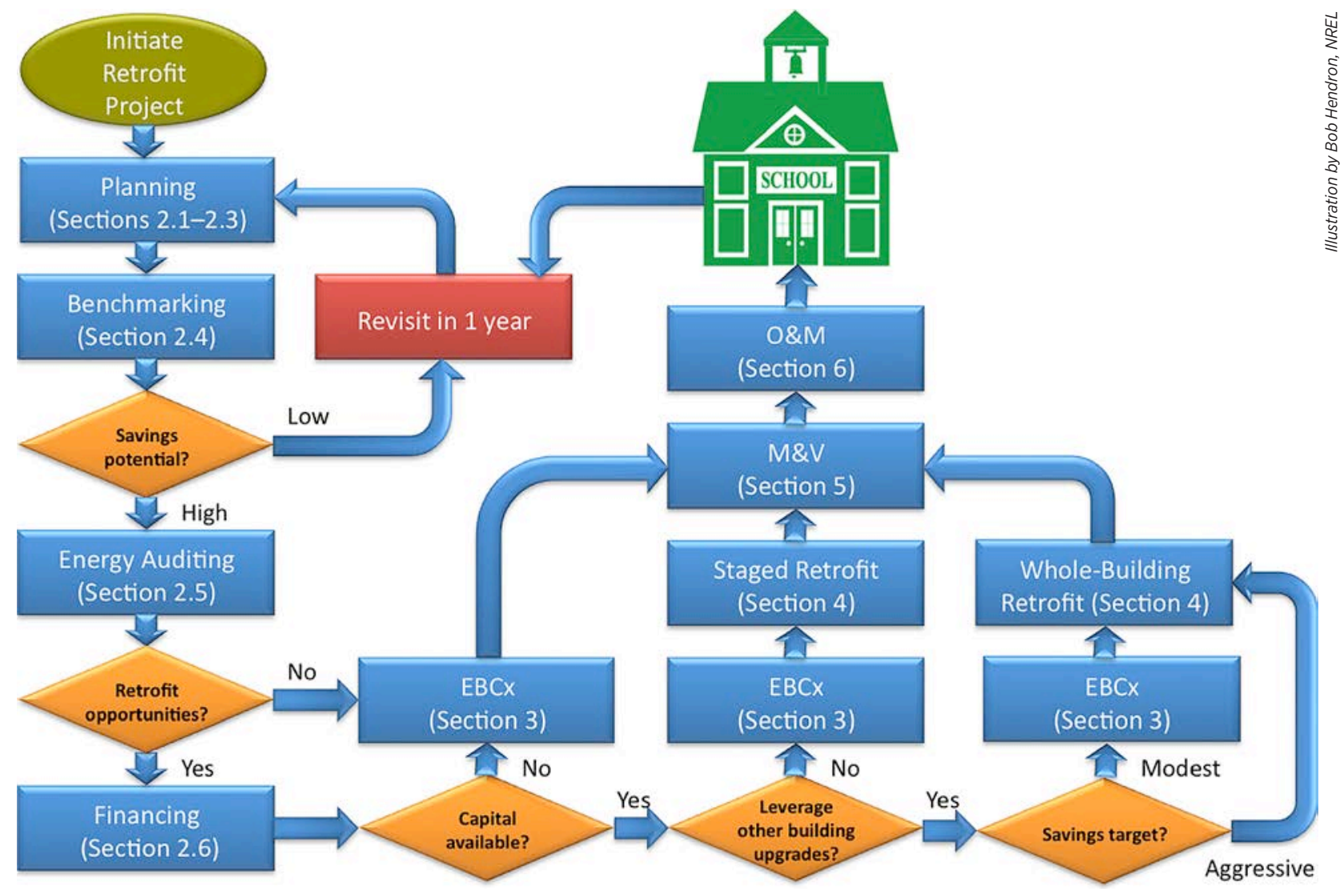

Figure 1-4 Structure of the guide relative to a typical retrofit decision-making process 
This AERG provides guidance and example energy efficiency packages for achieving a high level of energy savings in K-12 schools. A strict minimum energy savings cannot be guaranteed because of the range of potential starting points, but we identify multiple low-risk (see sidebar) EBCx and retrofit EEMs that are expected to meet strict cost-effectiveness requirements based on an example building that is representative of the stock of K-12 schools across the United States.
Risk: We define risk as uncertain return on investment caused by variations in energy savings, installation costs, useful life, or O\&M costs.

Three categories of retrofit are discussed in the following sections, and summarized in Table 1-1. Example EEMs for each category are provided in Figure 1-5.

\section{Table 1-1 Three Categories of Retrofit Discussed in This Guide}

\begin{tabular}{|c|c|}
\hline \multicolumn{2}{|c|}{$E B C x$} \\
\hline $\begin{array}{l}\text { Significant savings can often be achieved with minimal } \\
\text { risk and capital outlay by improving building operations } \\
\text { and restructuring maintenance procedures. This process } \\
\text { is generally recommended even when retrofits are being } \\
\text { considered, in order to determine the performance of } \\
\text { the existing building systems under the most favorable } \\
\text { conditions. A study of } 643 \text { commercial building } \\
\text { commissioning projects by Lawrence Berkeley National }\end{array}$ & $\begin{array}{l}\text { Laboratory (LBNL) indicated that approximately } 11 \% \\
\text { energy savings could be achieved in a typical educational } \\
\text { facility, with an average payback period of } 1.5 \text { years (Mills } \\
2009 \text { ). Savings well in excess of } 20 \% \text { are achievable } \\
\text { if a school has particularly severe O\&M weaknesses. } \\
\text { Additional savings are possible if cultural and behavioral } \\
\text { changes are included in the EBCx process. }\end{array}$ \\
\hline
\end{tabular}

\section{Whole-Building Retrofit}

Whole-building retrofit projects use an integrated design approach to develop a package of EEMs that can be implemented as a single project over a short time. Often this approach leverages a major remodeling effort or a similar opportunity to address many systems at once. Whole-building retrofits offer greater potential savings because the packages are optimized and all system interactions are considered. Systems interactions and equipment downsizing are important components of this approach, and broader ranges of equipment replacements and envelope upgrades are often possible. In many situations, the best packages for whole-building retrofits will be very similar to the prescriptive packages recommended for new construction in the Advanced Energy Design Guide for K-12 School Buildings developed by ASHRAE with funding from DOE (ASHRAE 2011c). The National Renewable Energy Laboratory's (NREL) work with two SuperTarget stores indicates that about
$15 \%$ additional savings could be achieved through an integrated design approach compared to a retrofit project where only component- and subsystem-level improvements were possible (DOE 2012). A similar impact for integrated design could be expected for K-12 schools. In an LBNL study of 178 school retrofit projects conducted by energy service companies (ESCOs) (Hopper et al. 2005), median energy savings of about $18 \%$ were documented, and savings beyond $28 \%$ were not uncommon. Simple payback was typically 15 years for K-12 school projects, which often include a significant number of nonenergy improvements that are valuable to the school district but decrease the rate of return on investment. If nonenergy improvements are excluded, the simple payback can be less than 10 years. In addition, many projects in the LBNL study were targeted systemor component-level retrofits that did not include an integrated whole-building approach.

\section{Staged Retrofit}

Staged retrofits are implemented in several steps over a longer time than whole-building retrofits. This approach allows retrofits to be aligned more closely with the school's capital improvement plans, reducing the incremental cost of the upgrades because equipment replacements occur near the end of useful life. An integrated design approach is recommended even for staged retrofits, but it can be more challenging to properly exploit system interactions when time passes between stages. It is important to plan all retrofits early in the process, even though they are implemented over time. This will help mitigate inefficiencies created if new contracts must be placed and different personnel are involved later. Some potential energy savings are delayed in a staged retrofit, but the economics can be much better than for a whole-building retrofit, where equipment may be replaced with a significant amount of useful life remaining. 


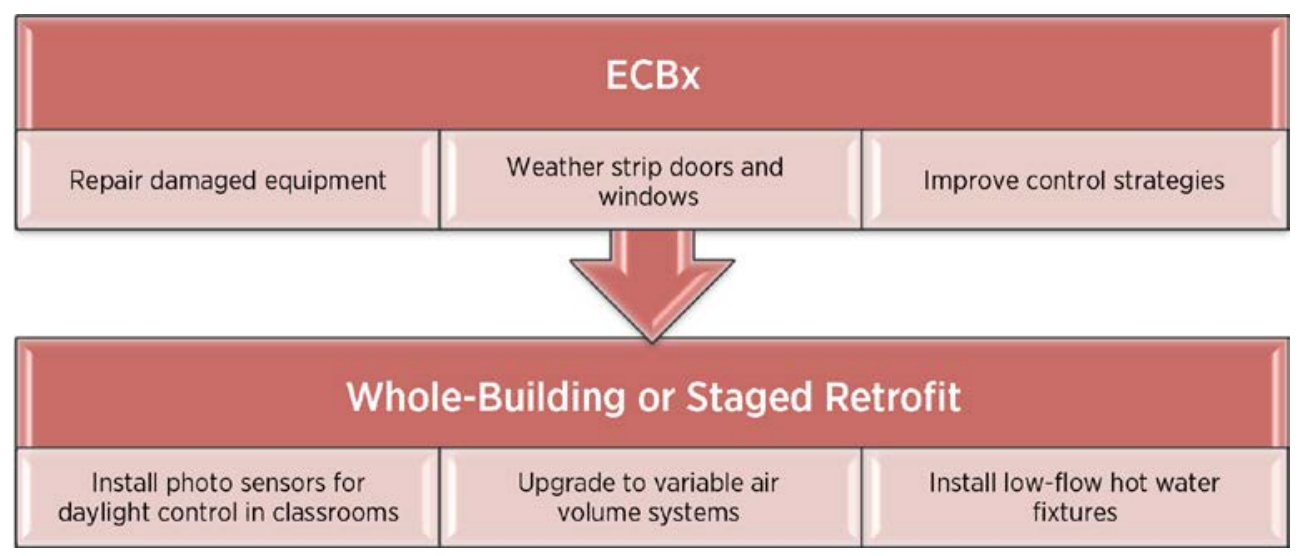

Figure 1-5 Example EEMs for the two categories of retrofit addressed in this guide

A school district can use several core elements of the guide as components of a comprehensive plan for upgrading a single school or an entire portfolio:

- General guidance describing the process and steps necessary to identify opportunities and to successfully plan, design, implement, and verify the energy savings for retrofit projects in K-12 schools. Because other organizations have provided this type of guidance, we provide only a concise summary of best practices. Helpful handbooks, standards, websites, and software tools are referenced extensively.

- Descriptions of approximately 70 promising EEMs, including a short overview of each and how it can be applied to a K-12 school. Many additional EEMs are addressed in the context of integrated subsystem improvements for whole-building retrofits. Climate-specific considerations are discussed, along with other factors such as building size, hours of operation, mechanical system type, and vintage. Special opportunities related to the age, condition, and efficiency of existing equipment are also discussed.

- Recommended packages of energy efficiency improvements for a representative public high school, tailored to five important U.S. climate regions.

- Key leverage points during the life cycle of a building that offer special opportunities to cost-effectively achieve more aggressive energy savings targets. These catalyst opportunities include any situation that leads to major changes in building systems for nonenergy reasons, such as a change in building use (e.g., an office building converted to a school), replacement of malfunctioning equipment, or major remodeling for cosmetic reasons.

- Techniques to ensure the expected level of energy savings is achieved after the retrofit, and persists throughout the life of the equipment. These strategies include post-retrofit commissioning, optimizing control logic, establishing equipment set points, involving and educating building occupants, best practices for ongoing commissioning and maintenance, and the most appropriate $M \& V$ protocols at each energy savings level.

- A diverse set of case studies that provide real-world examples of how these recommendations have been implemented in actual retrofit projects. The case studies are accessible and objective, offering insights into opportunities, tradeoffs, and potential pitfalls. To the extent possible, actual cost, performance, and utility billing data have been included. Detailed case studies are a valuable component of an effective business case, because evidence that similar projects have been successful enables financial decision makers to fund projects with greater confidence. 


\subsection{Business Case}

Among the investments a school district may consider, energy efficiency upgrades are likely to offer some of the highest returns with the lowest risks. The direct cost reductions provided through reduced energy use are complemented by valuable nonenergy benefits. The primary drivers for most school districts to invest in energy efficiency are to realize the direct benefits of reduced utility costs, while improving the learning environment for students. Nonenergy benefits may in fact be dominant project drivers in situations where energy costs are less important to the bottom line. For example, daylighting can improve student performance, and providing sufficient ventilation with demand control may reduce absenteeism (NRC 2006). These benefits are hard to quantify and are often omitted from financial analysis, but should be considered in the business case because they support the overall educational mission.

Funding is often the primary barrier to the implementation of retrofit projects in K-12 schools. Reliable cost and energy savings data enable the financial decision maker to evaluate the cost effectiveness and risk of a project as part of a solid business case. Practical analysis techniques and meaningful data are not easily found in the literature, especially in the context of specific building types such as schools, but are essential tools for robust and accurate analysis of energy and cost tradeoffs. In contrast, this guide provides a "best practice" methodology for performing accurate economic analysis of building improvement options. It uses both NPV and simple payback period, supplemented with example calculations based on a typical high school building, and detailed case studies with welldocumented project cost and energy savings data.

The guide provides detailed methods for accurately quantifying multiyear cash flows, including energy costs, demand reduction, replacement costs (including reduced energy savings if more efficient equipment would have been required by code), salvage value (if any), $O \& M$ costs, $M \& V$ costs, and tax implications. Techniques and references are also provided for capturing the effects of temporary financial incentives offered by government agencies or utilities (rebates, low-interest loans, tax credits, etc.) on multiyear cash flows. Indirect benefits such as productivity improvements and reduction in sick days are discussed qualitatively, but are not quantified in the cash flow analysis. Advice is provided for developing a comprehensive capital replacement plan, which is a necessary component of any multiyear cash flow analysis.

This guide does not provide comprehensive instructions for developing an effective business case for a retrofit project. Instead, we focus on specific EEMs, methodologies, and examples that contribute to a strong business plan. ASHRAE (2009b) recently published an informative resource for business case development. It is the first of a series of three technical guides that describe best practices for planning and implementing successful energy retrofit projects. Other valuable tools and resources for developing a business case and analyzing the economics of a retrofit project are discussed in Section 2.6.

\subsection{Recommended Packages}

We developed EEM packages for $\mathrm{EBCx}$ and for whole-building retrofit projects in the context of an example high school. To be selected, EEMs had to have a positive NPV when cash flows were analyzed over a 20 -year analysis period. A spreadsheet tool was created by NREL and Pacific Northwest National Laboratory (PNNL) to assist with the multiyear cash flow analysis needed for NPV and simple payback calculations. A public version of the tool with greater flexibility and a simpler interface is under development and will be made available on the DOE Commercial Building Initiative website in 2013.

A 20-year time horizon was selected because we encourage decision makers to take a long-term approach to energy efficiency improvements. Because most equipment improvements have lifetimes shorter than 20 years, this analysis period includes at least one replacement of each EEM except envelope improvements, resulting in a more stable projection of NPV than would result from a short-term analysis. Energy and maintenance savings often extend far beyond the simple payback period, which may be as short as $3-5$ years. The same methodology can be used even if 
stricter financial return and payback criteria must be used, with minor changes to the input parameters. It can also be applied to staged retrofits, although we did not develop recommended packages for the staged approach because the analysis is more complex and is highly dependent on the age of existing equipment and the capital improvement plan.

Packages range from low-cost/no-cost EBCx packages that are nearly always cost effective, to more capital-intensive standard retrofit packages with somewhat higher risks but larger life cycle returns, all the way to comprehensive retrofit packages that require an integrated design approach. These packages illustrate the analysis methodologies discussed in this guide, and provide some sense of the energy savings that are achievable in a typical school.

Unlike the recommended packages for new construction in the Advanced Energy Design Guides (AEDGs), ours are not prescriptive and are not evaluated against a code-minimum building. Because of the diverse range of starting points for retrofit projects and the limited applicability of building energy codes, prescriptive recommendations based on cost effectiveness are not possible. A recommended package might provide excellent financial returns in one situation, but would not be optimal—or even appropriate—in all situations. Your cost and energy savings will differ from the example, and you need to analyze the cost effectiveness of a particular set of EEMs in the context of the actual building, financing method, labor rates, rebates and tax credits, vendor prices, and utility rates.

Figure 1-6 illustrates the process used to narrow the original list of roughly 190 candidate EEMs to those included in the recommended packages. About 90 EEMs from the original list were deemed to save very little energy, or were considered unlikely to be cost effective, and are not included in this guide. Approximately 100 were considered high potential, and are addressed in Sections 3-4 and Appendices E-G. About 60 were considered for the recommended packages at one or more of the three levels of retrofit. The complete list of EEMs and their rankings is included in Appendix D.

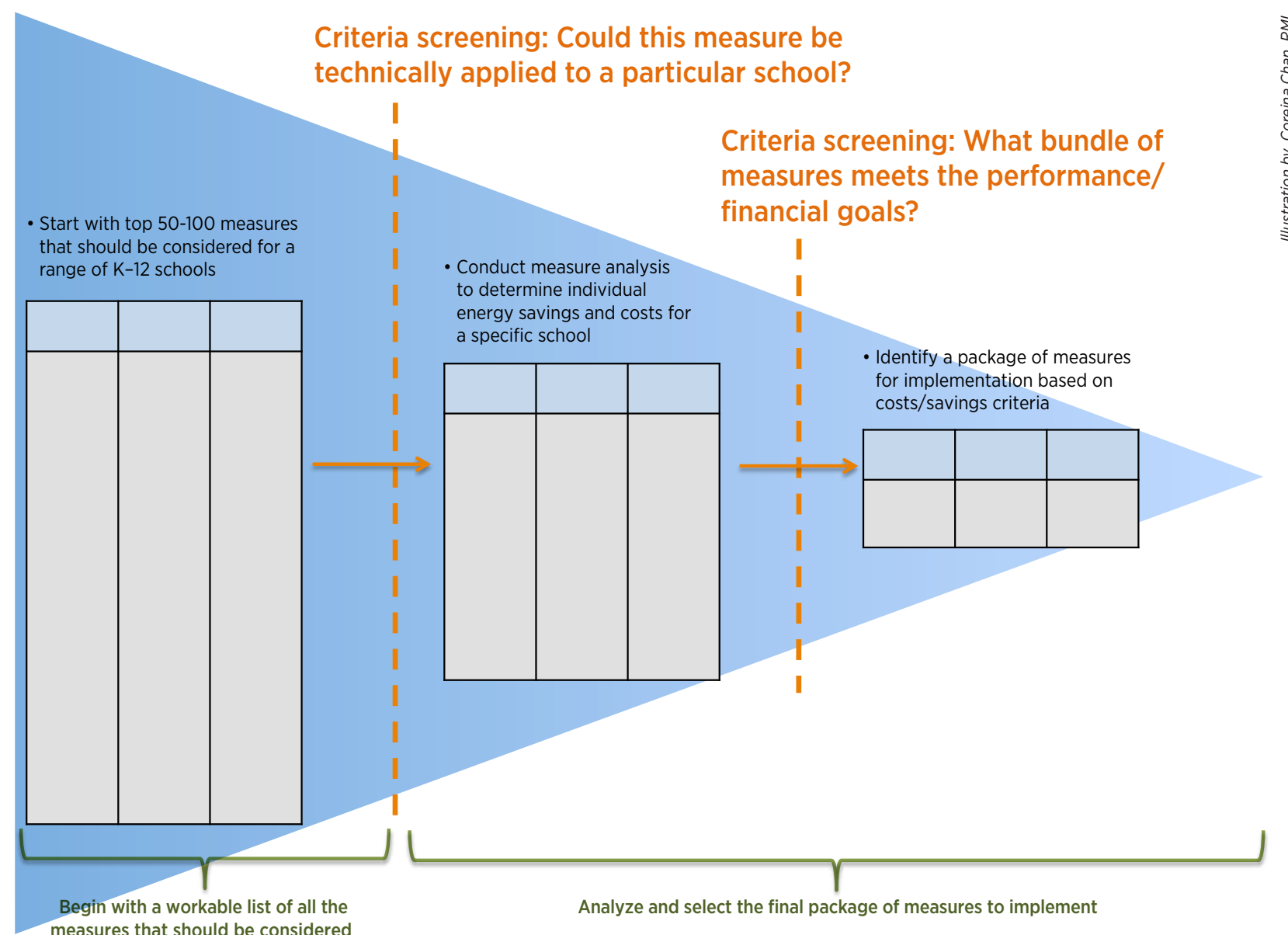

Figure 1-6 General process for selecting EEMs included in recommended packages 
The reference building for our example analysis is the Pre-1980s Secondary School CRB (Deru et al. 2011), which is one of a series of reference buildings developed by DOE to help standardize the analysis of EEMs when applied to specific building sectors. Details of the envelope characteristics and equipment included in the example building are presented in Appendix B.

The CRB and example packages are tailored to each of five important U.S. climate regions (see Figure 1-7), represented by the cities in parenthesis:

- Hot-humid (Miami, Florida)

- Hot-dry (Las Vegas, Nevada)

- Marine (Seattle, Washington)

- Cold (Chicago, Illinois)

- Very cold (Duluth, Minnesota)

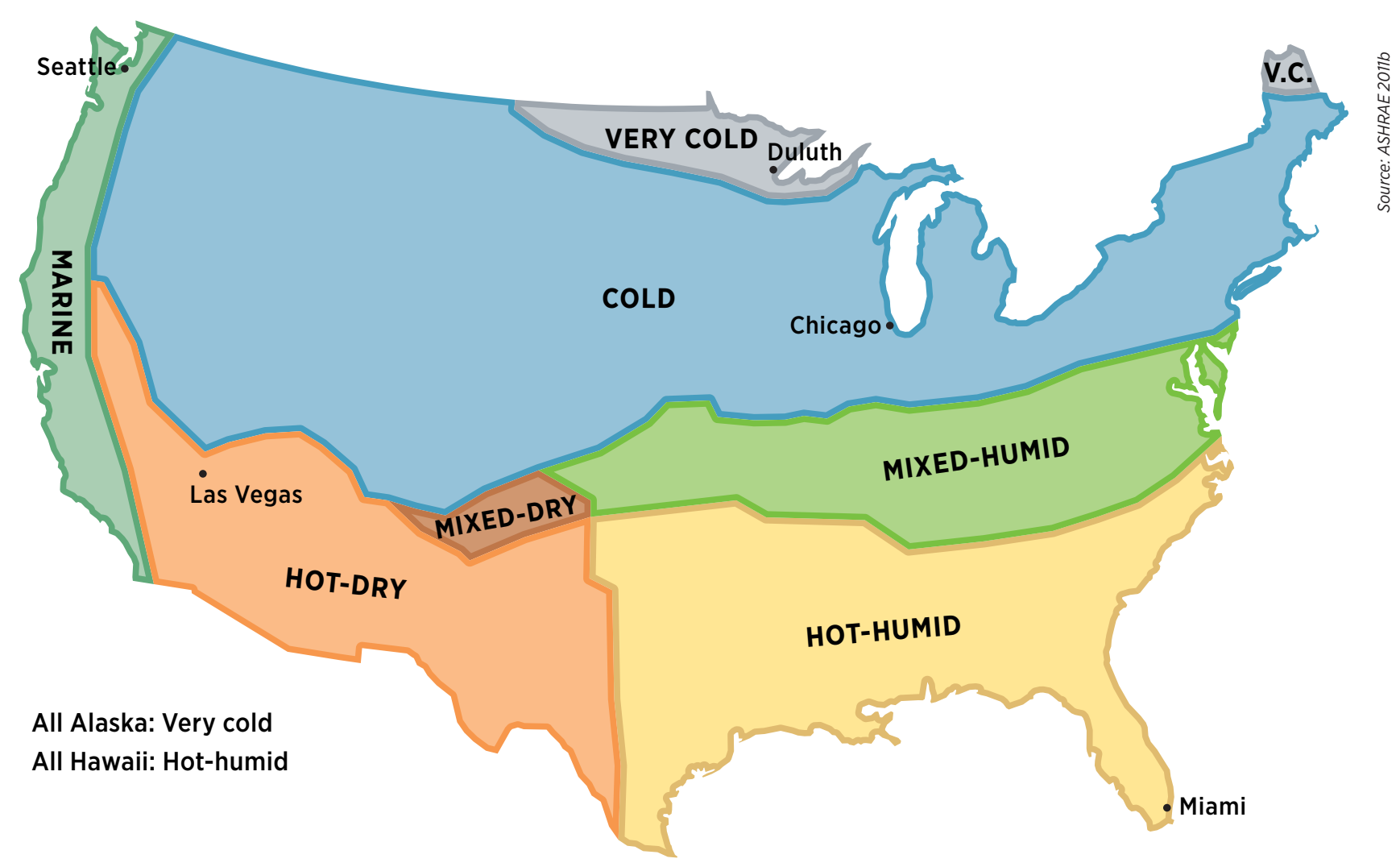

Figure 1-7 U.S. Climate Zone map 
The DOE CRBs are assumed to be well commissioned. The modeling inputs inherent in the CRBs are not consistent with suboptimal operating schedules, building controls that are no longer active, or degraded equipment performance caused by wear and tear. As a result, we did not try to model EBCx measures. Instead, the recommended EBCx packages were developed based on subjective estimates of the likely energy savings of each EEM considered. We estimated energy savings for the EBCx package based on data from actual projects, combined with the CRB physical characteristics and energy use. Further details of the process for selecting EBCx packages are provided in Appendix B.

The EEMs included in the recommended retrofit packages were chosen based on the cost effectiveness of each EEM when applied to the CRB model, using typical equipment costs and actual utility rates. Each EEM was analyzed individually and in combination with other EEMs when system interactions were significant. This sequencing allowed for the possibility of downsizing heating, ventilation, and air-conditioning (HVAC) equipment when heating and cooling loads were reduced. EEMs were selected for the recommended packages if their individual NPVs were greater than zero. Additional discussion of the process used for selecting retrofit EEMs for the recommended packages is included in Appendix B. 


\section{Overview: Plan, Execute, Follow Up}

Leaders in K-12 school administration, design, and facilities management have long recognized the role that energy efficiency can play in reducing operating costs and improving the environment for students and teachers. Nearly every school presents opportunities for improved energy performance. These come in many forms, including improved O\&M practices, equipment retrofits, occupant behavioral changes, and building envelope modifications. Over the life of a school, different opportunities will be available at different times, depending on functional and cosmetic changes to the building, remaining life of the equipment and assemblies, and availability of improved technologies in the market.

Although the opportunities for energy efficiency improvements in existing schools are significant, the process of identifying, analyzing, and implementing those improvements is not always straightforward.

This section provides a general picture of energy use in K-12 schools and presents an overview of important steps to help identify energy efficiency improvement opportunities and plan their implementation. It addresses plotting an energy efficiency roadmap, available financing mechanisms, performance assessment through benchmarking, and identifying cost-effective EEMs through energy auditing (see sidebar in Section 1.1 for our definition of cost-effective EEMs). Each section includes links to the extensive body of literature about these topics to provide more details.

\subsection{Energy Picture}

The nation's K-12 school districts spend more than $\$ 8$ billion annually on energy. That is more than they spend on computers and textbooks combined, and follows salaries as the second-highest operating expense (EPA 2009). Efficiency improvements can reduce these costs, freeing up funds for other priorities such as maintenance, salaries, and supplies; however, implementing energy efficiency upgrade projects in schools while ensuring a safe and productive learning environment presents unique challenges and opportunities. Meeting these challenges requires knowledge of which aspects of energy use affect education, how and where energy is used, and options for reducing energy use.

\section{Opportunities and Challenges}

Energy upgrades for all types of buildings face numerous challenges:

- Establishing a baseline of energy use and tracking progress (see Sections 2.3 and 2.4).

- Training staff to properly maintain equipment so any gains from the upgrade will persist (see Section 6).

- Gaining familiarity with the latest technologies. No single resource covers all new energy technologies, but the Federal Energy Management Program's (FEMP) Technology Deployment List (FEMP 2011) is a good starting point.

- Dealing with the unpredictability of energy costs (for information about energy costs, visit the U.S. Energy Information Administration [EIA] website) (EIA 2011).

Schools also face specific challenges of their own. Perhaps the largest is the upfront capital required for energyefficient building upgrades. In many areas, school budgets are shrinking, and capital projects are often the first things to be cut (Raabe 2003). In one scenario, capital-intensive efficiency improvement projects are cut when budgets 
are tight, and school boards reduce maintenance funds to prevent salary and faculty cuts. The result is a negative feedback cycle in which a lack of preventative maintenance leads to inefficient equipment operation, higher energy costs, and equipment malfunctions. However, innovative, cost-effective financing mechanisms can help to provide the needed capital (see Section 2.5). These financing programs are feasible, even with rigid finance requirements and policies in place in many school districts.

The primary drivers for most school districts to invest in energy efficiency are to realize the direct benefits of reduced utility costs, while improving the learning environment for students. Nonenergy benefits may in fact be dominant project drivers in situations where energy costs are less important to the bottom line. For example, daylighting can improve student performance, and providing sufficient ventilation with demand control may reduce absenteeism (NRC 2006). These benefits are hard to quantify and are often omitted from financial analysis, but are important to consider because they support the overall educational mission.

Research suggests that aging school facilities and inefficient equipment have a detrimental effect on academic performance that can be reversed when schools are upgraded (NCEF 2001). Kats (2006) provides 17 studies that demonstrate an increase in performance ranging from $2 \%$ to more than $25 \%$ resulting from improved indoor air quality (IAQ), acoustically designed indoor environments, and high-performance lighting systems. IAQ, thermal comfort, acoustics, and lighting all have significant impacts on the learning environment.

\section{Better Indoor Air Quality}

IAQ has a big effect on student performance and health. It can be improved by upgrading ventilation and filtration systems, which are components of the HVAC system. Indoor pollutants include gases (radon and carbon dioxide $\left.\left[\mathrm{CO}_{2}\right]\right)$, mold, and particulates such as dust and pollen. According to the U.S. Environmental Protection Agency (EPA), $20 \%$ of schools report unsatisfactory IAQ, which affects children more than adults because children have higher breathing and metabolic rates. Poor IAQ is correlated with increased absences that result from respiratory infections, allergies, and asthma. In addition, adverse reactions to chemicals used in schools can affect attention and overall performance (EPA 2011c). IAQ problems often arise in portable classrooms, which are often constructed with pressed wood materials containing formaldehyde.

One IAQ success story occurred in Colorado Springs, Colorado. The local school district developed an integrated energy efficiency and IAQ management program that significantly improved IAQ, saved more than $\$ 900,000$ in annual energy costs, and helped the district reach its air quality goal of $700 \mathrm{ppm}$ of $\mathrm{CO}_{2}$ during occupied hours. The upgrades were implemented through an energy savings performance contract (ESPC) (see Section 2.5) that enabled the school district to use the energy cost savings to pay for the upgrades. The improvements included better distribution of outside air (OA) and control of airborne contaminants. EEMs included quick fixes such as installing pool covers and maximizing the use of daylight, as well as long-term investments such as replacing old boilers, implementing demand control ventilation (DCV), installing energy recovery ventilators (ERVs), and upgrading lighting systems (EPA 2011d).

\section{Improved Thermal Comfort}

Thermal comfort also has an impact on academic performance. If the environment is too warm, students become less alert; if it is too cold, they lose dexterity. Widely fluctuating temperatures caused by inefficient HVAC systems can cause them to lose focus (EPA 2008). Upgrading or replacing aging, inefficient HVAC systems can improve thermal comfort. 


\section{Enhanced Visual Comfort}

Visual comfort depends on evenly distributed illumination of the right quantity and quality. Old, inefficient lighting systems often provide insufficient light with poor color quality, impeding student performance. Adequate lighting in hallways and stairwells is also an important safety measure. Lighting system upgrades that provide better color quality, utilize indirect/direct lighting, and enhance daylight in the classroom can all improve visual comfort. The California Energy Commission (CEC 2003) suggests that daylighting improves learning by up to $21 \%$. Lighting controls that enable teachers to set appropriate light levels for different activities also boost visual comfort (CEC 2008).

\section{Better Acoustic Comfort}

Acoustic comfort is critical for an effective learning environment. Noise from inefficient or malfunctioning fans, boilers, compressors, etc., can be a significant distraction.

\section{End Use Categories}

To target energy-saving upgrades, it helps to know where most energy is used. For individual schools this is best done by benchmarking and auditing (see Sections 2.4 and 2.5). For schools in general, lighting, ventilation, heating, and cooling account for $80 \%$ of energy consumption (see Figure 2-1), and typically represent the largest cost-saving opportunities. Water heating, computers, and other plug loads account for another $15 \%$ of energy use.

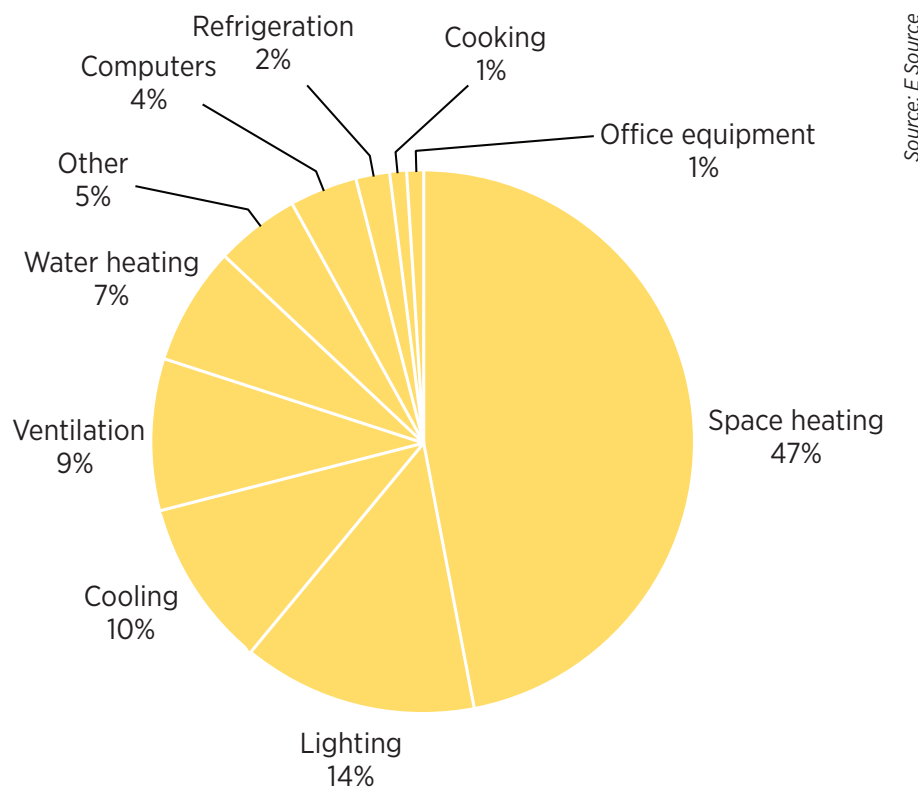

Figure 2-1 Average energy use profile of schools

Energy use varies widely with the specific school and climate region. For example, in hot dry climates, cooling accounts for as much as $38 \%$ of total energy consumption, whereas a northern school with a cool and dry climate consumes $21 \%$ for cooling (see Table 2-1). As a result, northern schools should focus more on saving energy through improvements to their heating and hot water systems, rather than cooling. 
Table 2-1 National Average of School Energy End Use by Climate Region

\begin{tabular}{|c|c|c|c|c|c|}
\hline Climate & Heating & Cooling & Lighting & Hot Water & Miscellaneous \\
\hline Cold and humid & 40 & 12 & 30 & 11 & 7 \\
\hline Cool and humid & 23 & 30 & 30 & 10 & 7 \\
\hline Cool and dry & 32 & 21 & 30 & 10 & 7 \\
\hline Temperate and humid & 14 & 41 & 30 & 8 & 7 \\
\hline Temperate and mixed & 30 & 23 & 30 & 10 & 7 \\
\hline Hot and humid & 18 & 35 & 30 & 10 & 7 \\
\hline Hot and dry & 16 & 38 & 29 & 10 & 7 \\
\hline
\end{tabular}

\subsection{Planning Retrofit Projects}

A successful energy efficiency upgrade depends on well-defined goals and a carefully constructed scope. If the goal is simply to cut energy costs by $5 \%-10 \%$, an $\mathrm{EBCx}$ (Section 3) program will probably be sufficient, but even that effort will require benchmarking (Section 2.4) to determine a baseline, a walk-through audit (Section 2.5) to identify the most promising EEMs for your situation, and M\&V (Chapter 6) to determine whether you have reached your goal. If the goal is to be the top performer in the district, or to have your district outperform other similar districts, the picture is more complicated, as illustrated by the example decision process flowchart in Figure 2-2.

The retrofit process typically begins with an assessment of the potential energy savings for a single school or the entire district (benchmarking), followed by an evaluation of the cost effectiveness of possible retrofit EEMs (energy audit). If significant savings are achievable and cost effective, financing sources should be evaluated and energy savings targets should be set. Opportunities for leveraging planned school upgrades should also be considered. Depending on the results of these steps, some combination of $\mathrm{EBCx}$, whole-building retrofits, and staged retrofits are selected. After the retrofit project is implemented, appropriate $\mathrm{M} \& \mathrm{~V}$ and $\mathrm{O} \& \mathrm{M}$ programs are undertaken to ensure the target energy savings are achieved and persist over time.

Although EBCx is often skipped in a comprehensive retrofit, you may still want to perform this step because it will provide quick savings and will help you determine how existing systems are performing under the most favorable conditions. That information will give you a better handle on what else needs to be done to meet your goals. If, for example, a lighting retrofit is called for, it may be worthwhile to precede the retrofit with $\mathrm{EBCx}$ measures to determine which lighting systems are already performing well. If it is apparent from the start that a major retrofit effort will be undertaken (for example, a new central refrigeration system will be installed in the near future), it may make sense to postpone some of the EBCx measures - a testing, adjustment, and balancing (TAB) project for examplebecause the new equipment will have to be commissioned anyway.

The benchmarking effort will help you to quantify your goals by showing you how well the competition is faring. A more comprehensive audit will help you determine which retrofit EEMs (Section 4) are appropriate for your school. In all cases, the most effective program will also include reviewing for continuous improvement:

- Management review of project results

- Modification of energy plan as needed

- Recognition of success 


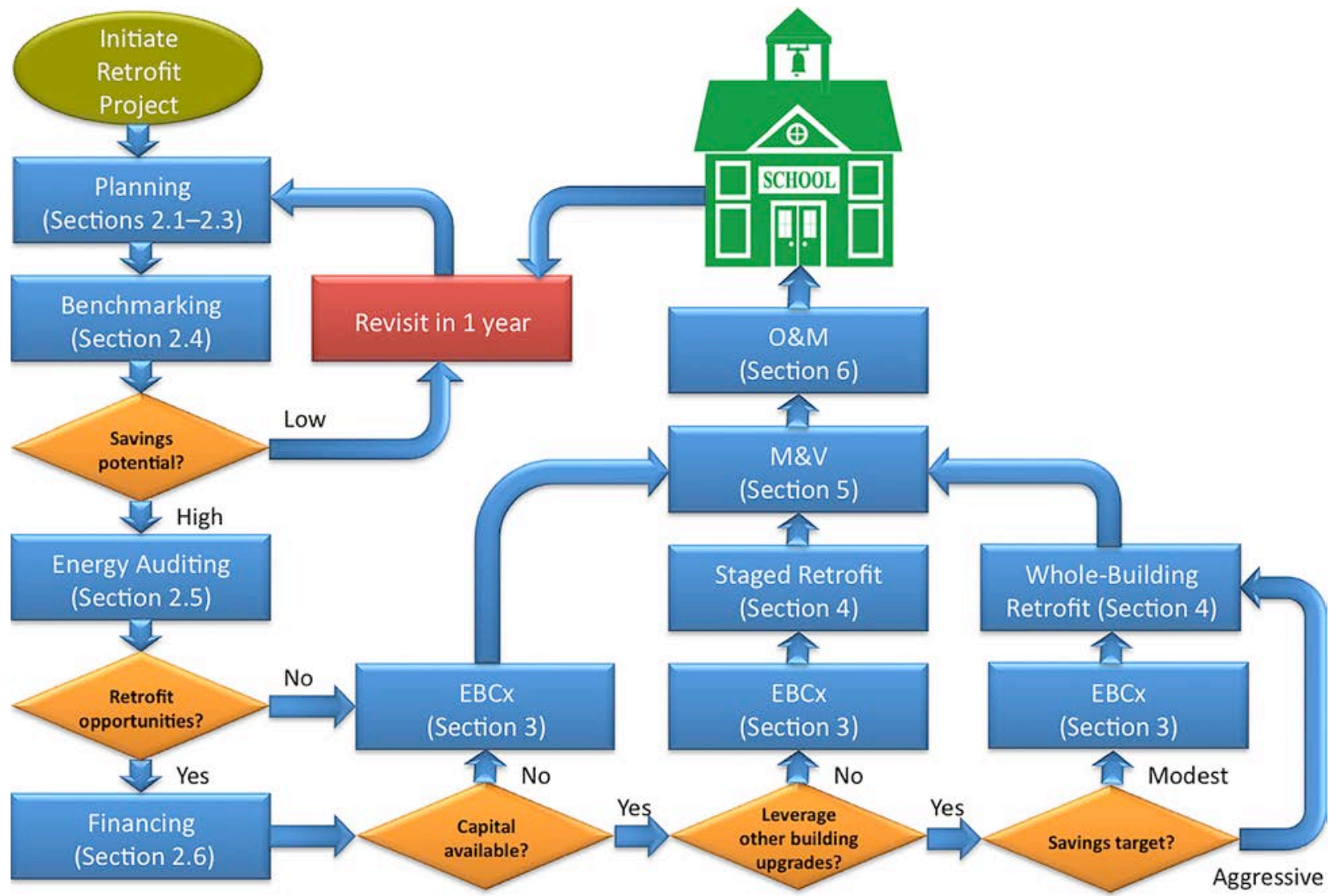

Figure 2-2 Example decision process for a retrofit project

School upgrades can be approached on an individual basis, but the most effective way to reduce school district energy consumption is to develop a system-wide approach for setting goals and assessing and improving energy efficiency in all school facilities. This results in greater cost and energy savings than improvements to single buildings and enables school districts to offset the costs of comprehensive energy efficiency projects in buildings that have higher upfront costs with the savings from projects in other buildings.

A system-wide approach also generates greater momentum for energy efficiency activities, which can lead to sustained commitment and continued savings. Raising community awareness about the environmental and cost-saving benefits of a project will help gain additional support and move the project forward. Improving energy efficiency across an entire district can also be incorporated as part of a larger community or state-wide goal. For example, in 2008, the State of Wisconsin (2009) implemented a statewide ENERGY STAR ${ }^{\circledR}$ challenge for all school districts to increase in energy efficiency by $10 \%$ within one year. Participants received guidance tools and support. Wisconsin met its goal by enrolling 127 school districts in the challenge.

Coordinating energy efficiency upgrades with any other maintenance and equipment upgrade plans also improves cost effectiveness and minimizes disruptions. For example, a roof can be insulated at the same time the membrane is replaced; or a low-temperature hot water distribution system with condensing boilers can replace a steam heating system that is on its last legs.

The optimal timing of efficiency upgrades depends on several factors, including size and scope, availability of capital, financing, and financial incentives. An EBCx project is relatively simple and low cost, and likely would not need to be coordinated with any existing capital project. On the other hand, a larger project such as roof insulation may make better economic and planning sense to implement before an impending boiler replacement, as the heating load would be reduced (which would mean the boiler could be smaller and less expensive). Also, government and local utility incentives are typically time dependent and could drive efficiency planning. 
A school district might also implement upgrades in stages to leverage cost savings from initial energy efficiency improvements to pay for additional EEMs. If funding and personnel are severely limited, school districts can focus on upgrading just a few schools. Successful outcomes can then be used to make a business case for further improvements, covering a broader range of buildings, when support and resources become available.

\section{Whole-Building Versus Staged Approach}

Whole-building retrofit projects most often use an integrated design approach to develop an EEM package that can be implemented as a single project over a short period of time. Often this approach leverages a major remodeling effort or a similar opportunity to address many systems at once. Further discussion of the whole-building retrofit approach is provided in Section 4.1.

Staged retrofits are implemented in several steps over a longer period of time than whole-building retrofits. This approach allows retrofits to be aligned more closely with the school's capital improvement plans, reducing the incremental cost of the upgrades because equipment is most often replaced near the end of their useful lives. An integrated design approach is recommended even for staged retrofits, but it can be more challenging to properly exploit system interactions when a period of time passes between stages. Additional guidance for implementing a staged retrofit is presented in Section 4.2.

\section{Additional Resources}

Advanced Energy Design Guidelines for K-12 Schools. This guide for new construction provides the tools, including recommendations for practical products and off-the-shelf technology, needed for achieving a 30\% energy savings compared to schools that meet the minimum requirements of ANSI/ASHRAE/IESNA Standard 90.1-1999 (ASHRAE 1999). Although aimed at new construction, many EEMs are applicable to existing buildings. www. ashrae.org/publications/page/1604

Alliance to Save Energy Green Schools Program. The Green Schools Program is an effort to educate and involve students in establishing energy efficient practices within their school. http://ase.org/programs/green-schools-program

EnergySmart Schools Design Guidelines for High Performance Schools: Each guide provides step-by-by step, detailed information on building EnergySmart Schools in specific climates, and for specific applications. www.nrel. gov/docs/fy02osti/29105.pdf

ENERGY STAR Building Upgrade Manual, K-12 Schools: The building upgrade manual provides technical recommendations for improvements to existing buildings, with a specific chapter dedicated to K-12 schools. www.energy star.gov/index.cfm?c=business.bus_upgrade_manual

ENERGY STAR for K-12 School Districts: The ENERGY STAR program provides a strategic approach that helps in measuring current energy performance, setting goals, tracking savings, and rewarding improvements, with focus on specific industries, including K-12 schools (EPA 2011b). www.energystar.gov/index.cfm?c=k12_schools. bus_schoolsk12

Indoor Air Quality tools for schools program: The IAQ Tools for Schools Program is a comprehensive resource to help schools maintain a healthy environment in school buildings by identifying, correcting, and preventing IAQ problems. www.epa.gov/iaq/schools/

School Operations and Maintenance: Best Practices for Controlling Energy Costs. This Guidebook for K-12 Schools provides detailed and practical guidance on how K-12 school districts can plan and implement enhancements to their current O\&M programs that can successfully maintain their facilities while also reducing energy costs up to $20 \%$. www.azdeg.gov/function/about/download/greenguide2.pdf 


\subsection{Key Steps in the Retrofit Process}

Planning and implementing a successful upgrade project involves several steps: making a commitment, assessing performance through energy audits and benchmarking, evaluating financing options, implementing the project, evaluating its progress, and developing an O\&M program to ensure savings persist.

\section{Get Started}

Efficiency upgrade projects will have the greatest chance for success if senior school officials and decision makers are committed. Officials should incorporate energy efficiency into the school district's overarching policy for improvement. Many efficiency upgrades not only reduce energy costs, but also increase visual and thermal comfort, improve student performance, and provide other benefits (USGBC 2011). Commitment to a policy that meets a broad set of objectives that include — but are not limited to - efficiency helps to secure adequate funding and gain staff support for efficiency-related projects.

A committed team or individual champion can initiate, lead, and guide implementation of the energy efficiency plan. This person or team will help keep the plan on track and ensure there are no bureaucratic roadblocks, and will provide access to data, justify the project to decision makers, and oversee implementation. Identifying qualified and experienced team members from throughout the school district will help to ensure quality and broad support. The team in Colorado's Poudre School District included representatives from facility services departments, planning, design and construction, and various external organizations (Poudre 2011). The district has won numerous awards for energy efficiency. Defining and implementing an energy policy with clearly stated goals can help secure support from elected officials and is valuable in tracking and verifying efficiency improvements. Communicating success, rewarding top achievers, and demonstrating money saved can ensure continued support for a successful program and provide momentum for further accomplishments.

\section{Conduct an Energy Review}

An energy upgrade plan begins with an assessment of how and where energy is used. To conduct this assessment, you need to identify and prioritize the most effective energy-saving opportunities and conduct interviews or surveys to understand occupant needs and comfort issues. The process requires data collection and analysis in support of benchmarking and energy auditing.

- Benchmarking enables you to compare your school's baseline energy use with that of similar school buildings. This information can help you target buildings for energy audits and energy efficiency investments. Many tools and methods are available to help identify energy use patterns. EPA's Portfolio Manager (EPA 2011a) is an online tool that can help you assess baseline energy performance in existing school buildings, and compile data across a school district. A more detailed discussion of best practices for benchmarking is outlined in Section 2.4.

- An energy audit examines how energy is used in a facility, and identifies the most cost-effective improvements. Audits range from a simple in-house inspection to complex data gathering and analysis by a certified auditor. A comprehensive audit, sometimes called an investment-grade audit, accounts for all system interactions and provides a detailed, accurate analysis of project costs and savings for available energy technology improvements. An audit report is essential for a strong business case. A well-designed business case will highlight the financial and educational benefits and make a compelling argument for implementing the upgrades. A detailed discussion of the various types of energy audits is presented in Section 2.5.

Based on results from these steps, you can set goals for improving energy efficiency. These can be established at different levels and over varying periods, from a short-term project for a single school building to multiyear improvements for an entire district. Many school districts have established short- and long-term goals that include quick cost savings that continue to accrue over time, helping to fund the longer term improvements. 


\section{Identify Sources of Financing}

When coordinated with current upgrade plans, the added cost of efficiency may be minimal. In most cases, however, more financing is required and a range of options is available. Involving the finance and legal departments in the early stages can help identify these sources and prevent delays. Although policies vary widely, many states administer programs that provide incentives for energy efficiency investments. Many school districts have identified and arranged for funding resources through external sources such as ESPCs. These contracts can be used to implement comprehensive energy efficiency upgrades at no upfront cost, usually with the assistance of an ESCO. Further discussion of project financing options is provided in Section 2.6.

Public benefit funds, government funds, and utility incentive programs are also viable funding sources. Some states require utilities to provide energy efficiency assistance through public benefit funds collected from taxpayers; other have implemented energy efficiency programs targeted at school districts. For example, the New Hampshire EnergySmart Schools program helps K-12 public and private schools across the state pursue energy efficiency initiatives.

The program is sponsored by the New Hampshire Public Utilities Commission in collaboration with the New Hampshire Department of Education (2010). Many federal programs provide information and assistance for improving energy efficiency targeted to school districts. These include EPA's ENERGY STAR for K-12 School Districts, the DOE EnergySmart Schools program, and the EPA's Healthy School Environments Program (EPA 2011c). The Database of State Incentives for Renewables and Efficiency (DSIRE 2011) is a comprehensive source of information about state, local, utility, and federal incentives and policies that promote renewable energy and energy efficiency.

\section{Implement Energy Management}

The shape of the implementation phase depends on how extensive the upgrade is. Simple EBCx measures are straightforward, but more comprehensive efforts require a methodical approach. We recommend either a staged or a whole-building approach that accounts for all system interactions in a building (integrated design), setting up an overall process to achieve the greatest energy and cost savings over the life of the project. See Section 2.3 and the EPA’s ENERGY STAR Building Upgrade Manual for more information about project implementation.

\section{Measure Project Results}

Measuring performance involves gathering energy use and cost data and analyzing the data to quantify savings. These performance metrics can be compared with the project's baseline energy use and against established goals for energy and financial savings to determine project success. This can be done by a third party to verify that the energy efficiency improvements have achieved their performance targets. This approach is common when schools are involved in an ESPC with an ESCO, and the ESCO must provide unbiased proof of the promised cost and energy savings. A detailed discussion of $M \& V$ protocols is provided in Section 5.

Energy upgrades provide an initial efficiency boost, and a good O\&M program will ensure the savings persist. All building systems degrade over time - light output decreases through natural lumen depreciation and dirt buildup and control systems drift from set points. A good O\&M program anticipates all the expected degradations and monitors building status to catch the unexpected ones. The action items can be proactive, such as prescheduled preventative maintenance plans, or reactive, responding to problems as they arise. Details on developing an O\&M plan are covered in Section 6.

\section{Review for Continuous improvement}

Once the retrofit project has been implemented, it is important to continually review the building's performance and to identify new opportunities as they arise. Building systems that were working properly at the time of the retrofit may have degraded, new technologies may be available, and evolving educational needs may lead to remodeling 
efforts to improve or adapt the learning environment. Poorly performing retrofit EEMs should be re-evaluated and modified if necessary. Successful projects should be recognized by the school district, so the lessons learned can be applied to other local schools. Individuals who contributed to the project should also be recognized.

\section{Additional Resources}

Database of State Incentives for Renewables and Efficiency (DSIRE). DSIRE is a comprehensive source of information on state, local, utility, and federal incentives and policies that promote renewable energy and energy efficiency. www.dsireusa.org/

Energy Efficiency Guide for Existing Commercial Buildings: The Business Case for Building Owners and Managers (ASHRAE 2009b) is the first of a series of three guides developed to assist building owners and facility managers with the development of a strong business case for energy efficiency projects. The guide focuses on economically based decision making and includes a variety of useful information needed to identify opportunities, arrange financing, and make sound decisions that will result in a successful project. www.ashrae.org/resources-publications/ bookstore/Energy-Efficiency-Guides-for-Existing-Commercial-Buildings

Energy Efficiency in K-12 Schools. EPA's Local Government Climate and Energy Strategy Guides provide a comprehensive, straightforward overview of local government greenhouse gas emissions reduction strategies that local governments can employ for specific sectors. www.epa.gov/statelocalclimate/resources/strategy-guides.htm/

ENERGY STAR for K-12 School Districts. The ENERGY STAR program provides a strategic approach that helps in measuring current energy performance, setting goals, tracking savings, and rewarding improvements, with focus on specific industries, including K-12 schools. www.energystar.gov/index.cfm?c=k12_schools.bus_schoolsk12

EPA Healthy School Environments website. The healthy school environments website is designed to provide one-stop access to the many programs and resources available to help prevent and resolve environmental issues in schools. www.epa.gov/schools/

Natural Resources Canada. Natural Resources Canada offers a variety of data and statistics on energy use in schools, including The Benchmarking Guide for School Facility Managers, which helps facility managers calculate their schools' energy performance. oee.nrcan.gc.ca/home

\subsection{Benchmarking Current Performance}

Energy performance benchmarking provides baseline information that will help you formulate energy management plans and strategies and identify upgrade opportunities. As the benchmarking effort moves forward, it will also provide metrics to gauge program effectiveness and evaluate upgrade alternatives.

The benchmarking process compares the energy use of one school building or group of buildings with that of other schools, or looks at how energy use varies from a baseline. It shows how energy is used and helps to identify the influences on that use. As part of the benchmarking process, energy managers establish the best metrics for evaluating performance, select appropriate baselines to use for comparisons, and set their energy performance goals. For example, one common metric is energy use intensity (EUI), which provides an energy use per square foot value. According to the EIA's Commercial Building Energy Consumption Survey (CBECS) data, the national average EUI for educational buildings is $83.1 \mathrm{kBtu} / \mathrm{ft}^{2}$ (DOE 2003). Benchmarking can also encourage ongoing improvement as performance is periodically compared to established baselines. The most appropriate benchmark used for making energy comparisons varies with project goals. The most commonly used metrics are listed in Table 2-2. 


\section{Table 2-2 Common Benchmarking Baselines}

\begin{tabular}{|l|l|}
\hline \multicolumn{1}{|c|}{ Benchmark Type } & \multicolumn{1}{c}{ Description } \\
\hline $\begin{array}{l}\text { Best in class } \\
\text { Performance goal }\end{array}$ & $\begin{array}{l}\text { The performance level of the top performer sets the bar when comparing buildings } \\
\text { be measured }\end{array}$ \\
\hline Baseline & $\begin{array}{l}\text { An initial performance baseline of the building, which is established before any } \\
\text { commissioning or other EEMs are taken, can be used to track improvements over time }\end{array}$ \\
\hline Above average & Percentages above an average can be used to establish a benchmark \\
\hline $\begin{array}{l}\text { Commissioned } \\
\text { performance level }\end{array}$ & The performance level of a commissioned building can be used as a benchmark \\
\hline National ratings & $\begin{array}{l}\text { National performance ratings, such as those established by ENERGY STAR, can be used as } \\
\text { performance targets for specific buildings }\end{array}$ \\
\hline
\end{tabular}

In certain areas, energy benchmarking is mandated by local government. Cities such as Washington, D.C., New York, and San Francisco further require that benchmarking data be disclosed on a public website. Whether the process is required or optional, you can use the benchmarking data to determine best practices in your school district and beyond, and identify schools where those practices can be implemented. These data also help you identify topperforming schools so those responsible can earn recognition for their efforts; and to find poorly performing schools that can be prioritized for improvement.

Benchmarking can be a complicated process, but tools are available to help. The most prominent is the ENERGY STAR Portfolio Manager (EPA 2011a), a free, comprehensive, interactive online tool that provides a set of benchmarks developed specifically for K-12 schools that can be used to assess energy performance. These benchmarks are developed from a national survey conducted every four years by the EIA (DOE 2003). You can set up private accounts to rate your buildings, set baselines, share information, and document results.

Other software products and consulting services are also available. For example, ENERGY STAR's Target Finder (EPA 2011i) can help you select a target EPA energy performance score or a percentage energy reduction target. LBNL (2011) offers an online benchmarking tool called EnergyIQ. It is an action-oriented tool used to assess

Seaford School District, a rural school system in southwestern Delaware, implemented an energy management plan to help reduce its overall energy consumption. The district used the Portfolio Manager tool to establish a baseline and track performance for each school. This process helped the energy team identify the least efficient buildings and focus on the most important efficiency projects. These efforts led to a $16 \%$ annual reduction in energy consumption across Seaford's six-building portfolio, and saved about $\$ 100,000$ in energy costs each year (EPA 2011e). opportunities and lay the groundwork for investment-grade audits. The Collaborative for High Performance Schools (CHPS 2006), a nonprofit organization originally formed to address energy efficiency in schools, offers benchmarking assistance and an Operations Report Card. 


\section{Categories of Benchmarking}

Energy benchmarking can be categorized in several ways: as internal or external (or sometimes a combination), and as qualitative or quantitative (see Table 2-3). Internal benchmarking keeps comparisons and data within a school district. The data are used to compare energy performance among the district's buildings, identifying the top performers and the best practices that can be applied to lower performing buildings in the district. External benchmarking includes school buildings outside the district, which allows energy managers to compare the energy performance of their schools against national performance ratings. Broadening the scope in this manner helps energy managers find new energy management practices and strategies and increases their understanding of how to evaluate energy performance. Striving to become an ENERGY STAR school building would be considered external benchmarking.

\section{Table 2-3 Four Major Categories of Benchmarking}

\begin{tabular}{l|l|l}
\hline Quantitative & $\begin{array}{l}\text { Compare calculated metrics of your building's } \\
\text { performance against its own historical perform- } \\
\text { ance or against other buildings in your portfolio. }\end{array}$ & $\begin{array}{l}\text { Compare calculated metrics of your building's } \\
\text { performance against similar buildings in a } \\
\text { defined geographic area. }\end{array}$ \\
\hline Qualitative & $\begin{array}{l}\text { Compare management and operational practices } \\
\text { in your building over time or against other } \\
\text { buildings in your portfolio. }\end{array}$ & $\begin{array}{l}\text { Compare management and operational practices } \\
\text { in your building against similar buildings in a } \\
\text { defined geographic area. }\end{array}$ \\
\hline
\end{tabular}

Whether internal or external, benchmarking may be either quantitative or qualitative. The quantitative approach compares numerical measures of performance, looking at how performance changes over time, or how a building's performance compares to other similar buildings. The qualitative approach analyzes management and operational practices across the entire building portfolio to identify best practices and needs for improvement. Benchmarking projects typically include quantitative and qualitative measures. Case Study \#1 shows how external benchmarking motivated an Indiana school district to enter a performance contract resulting in $\$ 35$ million of projected energy cost savings.

\section{Developing a Benchmarking Plan}

A benchmarking plan begins with a definition of goals for the benchmarking process, which defines the scope of the effort, determines the metrics and the data needed, and identifies partners who may be asked to participate in the project.

1. Set goals. Benchmarking goals should be consistent with the overall project goals set forth by the school or school district. Guidelines, such as those established by the ENERGY STAR program, suggest evaluating energy use across the entire organization; for example, all K-12 school buildings within a school district. The data can then be used to establish a baseline against which energy performance goals can be set and measured. These goals also help you identify areas for improvements and target energy-saving opportunities.

2. Define scope. Once you define your goals, you can address the scale, organizational focus, and time frame of the benchmarking effort. You might focus on the entire district or on a subset of schools; establish an internal or external organizational emphasis; and establish a weekly to annual time frame.

3. Identify data requirements. The data collection requirements depend on the selected benchmarking metrics and the scope of the benchmarking analysis. Table 2-4 shows some common EUI metrics used when comparing buildings. The choice of metrics depends on the goals of the benchmarking project and the type of facility. Btu per square foot is the metric most commonly used for schools; energy use or cost per student is often used. 


\section{Case Study 1: Vigo County School Corporation}

\section{Quick Facts}

- Facility Name: Vigo County School Corporation

- Facility Type: K-12 Schools

- Location: Terre Haute, Indiana

- Number of Buildings: 29

\section{Project Description}

The Vigo County School Corporation (VCSC) in Terre Haute, Indiana, and under the leadership of Superintendent Daniel Tanoos, partnered with Energy Systems Group to develop and implement comprehensive energy savings performance contracts. VCSC is made up of 3 high schools, 2 alternative schools, 6 middle schools, and 18 elementary schools.

In 1999, VCSC decided to take control over rising operating costs with an assessment of its utility costs, which at the time averaged $\$ 0.845 / \mathrm{ft}^{2}$. This was compared to other Indiana school facilities that had installed energy retrofits resulting in energy costs as low as $\$ 0.65 / \mathrm{ft}^{2}$. Of the 19 VCSC schools surveyed, 9 were operating at more than $\$ 0.90 / \mathrm{ft}^{2}$.

In 2000, VCSC and Energy Systems Group entered into an initial agreement to provide energy-related upgrades at 20 of its facilities. This initial project resulted in a

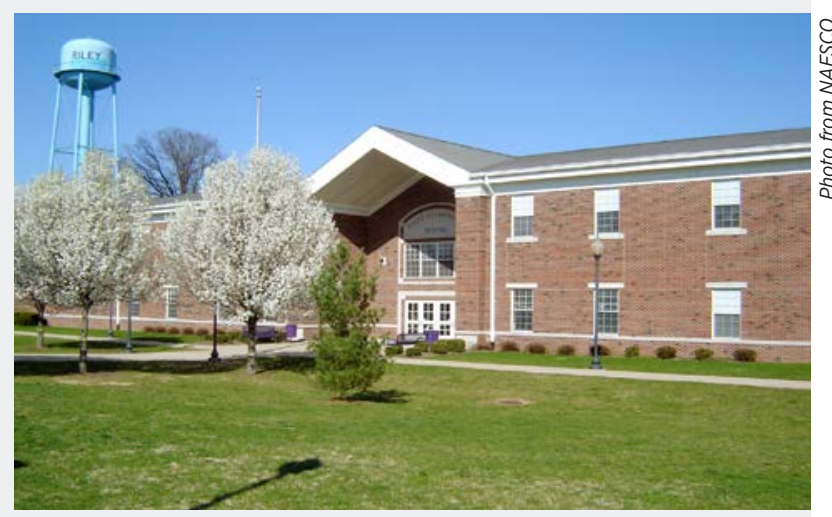

guaranteed cost reduction of more than $\$ 1$ million per year over the term of the agreement. To date, Energy Systems Group has met its savings guarantee.

VCSC has implemented more than $\$ 29$ million in comprehensive energy improvements and renovation projects in six phases which are estimated to save close to $\$ 35$ million over the terms of the contracts.

\section{Environmental Benefits}

1. Removes emissions equivalent to more than 5,200 passenger vehicles per year.

2. Creates enough electricity to provide power for more than 3,800 homes per year.

3. Planting more than 6,500 acres of forests annually.

Key EEMs:

- Comprehensive HVAC improvements and replacements

- Lighting systems redesigns and retrofits

- First school in Indiana to be $100 \%$ retrofitted with lightemitting diodes (LEDs)

- Electrical system upgrades

- District-wide EMS

\begin{tabular}{|c|c|c|c|c|c|c|}
\hline Installation Costs & M\&V Costs & \multicolumn{2}{|c|}{$\begin{array}{l}\text { Total Cost Without } \\
\text { Incentives }\end{array}$} & \multicolumn{2}{|c|}{ Financial Incentives } & Actual Project Costs \\
\hline$\$ 29,922,466$ & $\$ 75,477$ & \multicolumn{2}{|c|}{$\$ 29,977,943$} & $\$ 60,000$ & & $\$ 29,862,466$ \\
\hline Energy \$ Savings & \multicolumn{2}{|c|}{ O\&M \$ Savings } & \multicolumn{2}{|c|}{ Capital Cost Avoidance } & \multicolumn{2}{|r|}{ Total Annual \$ Savings } \\
\hline$\$ 592,321 /$ year & \multicolumn{2}{|c|}{$\$ 1,395,838 /$ year } & \multicolumn{2}{|c|}{$\$ 1,206,457 /$ year } & & $\$ 3,194,616$ \\
\hline $\begin{array}{c}\text { Energy Cost Intensity } \\
\text { Pre-Retrofit }\end{array}$ & \multicolumn{2}{|c|}{$\begin{array}{l}\text { Energy Cost Intensity } \\
\text { Post-Retrofit }\end{array}$} & \multicolumn{2}{|c|}{$\begin{array}{l}\text { Energy Cost Intensity } \\
\text { ASHRAE 90.1-2004 }\end{array}$} & & $\begin{array}{l}\text { Simple Payback } \\
\text { (years) } \\
\text { Excluding Incentives) }\end{array}$ \\
\hline$\$ 0.84 / \mathrm{ft}^{2}$ & \multicolumn{2}{|c|}{$\$ 0.70 / \mathrm{ft}^{2}$} & \multicolumn{2}{|r|}{$\$ 1.40 / \mathrm{ft}^{2}$} & & $9.3(9.4)$ \\
\hline
\end{tabular}

- Window replacements

- Hot water pump replacements

- 1.5-kW wind turbine with curriculum for science students

- High school pool improvements. 


\section{Table 2-4 Common EUI Metrics}

\begin{tabular}{|l|c|}
\multicolumn{1}{c|}{ Metric } & Application \\
\hline Btu/ft ${ }^{2}$ & Any building \\
\hline Btu/employee & Office building \\
\hline Btu/unit of product & Assembly plant \\
\hline Btu/lb of product & Manufacturer \\
\hline Btu/lb of product processed & Refinery \\
\hline Btu/number of beds occupied & Hotel or hospital \\
\hline $\mathrm{kWh} / \mathrm{ft}^{2}$ & Lighting \\
$\mathrm{kW} / \mathrm{ton}$ & Chilled water efficiency \\
\hline $\mathrm{W} / \mathrm{ft}^{3}$ airflow/min & HVAC systems \\
\hline
\end{tabular}

A wide range of variables influences energy use, and you should consider as many as possible in your comparisons. For example, a high school in Alabama with 2000 students cannot be directly compared to a high school in Vermont with 600 students without adjusting for certain factors, such as climate conditions and occupancy levels. The process of accounting for the important variables is called normalizing, and it enables apples-to-apples comparisons. Although this can be a complicated task, Portfolio Manager automatically normalizes energy use metrics based on key variables for K-12 schools.

Tracking a benchmarking project and calculating the normalized benchmark require gathering a variety of data points. Data such as energy purchases and hours of operations may already be recorded. Other types of data require specific investigation or even additional measurements. Some school systems use energy tracking software that automatically uploads utility data to Portfolio Manager.

Common data types include energy use and cost information, physical building design, operational statistics, and climate variables. To start out, ENERGY STAR's Portfolio Manager requires the following information for a K-12 school:

- Zip code

- Gross floor area

- Whether the school is open on weekends

- Percent of the gross floor area that is cooled

- Percent of the gross floor area that is heated

- Number of personal computers

- Presence of cooking facilities

- Whether it is a high school.

4. Engage partners. Other departments or utilities, especially those that own the data needed for benchmarking, can often help the benchmarking process run more smoothly. In a school system, this might be the school district's main office, the buildings' facility managers and architects, or the utility providers. For external benchmarking, look for other school districts or systems with active energy management plans in place. These partners should be involved from the beginning so they understand the objectives, anticipated outcomes, and schedule. This step also helps all parties better understand the nature and importance of their roles. 
The motivation behind an internal benchmarking project must be transparent so participants do not feel threatened by the process of monitoring their energy use and operations. Emphasizing the positive effects of benchmarking on the budget and quality of education can be helpful. Expanded awareness helps everyone involved understand the importance of the process and the positive contribution that energy efficiency has on the school's performance, and the environmental benefits to the community. For example, school systems often pay utility bills through a central point (finance office, maintenance operations, etc.), which can leave individual building administrators unaware of the amount of energy used by their buildings, and how it compares to other buildings in the district. Giving administrators information and sharing success stories is one way to involve the stakeholders in conservation efforts.

\section{Implementing the Benchmarking Plan}

Implementing the plan begins with a data collection effort, proceeds with an evaluation of benchmarking metrics, and concludes with the application of the findings. A variety of software and online tools are available to help with this process. Teams can also design custom spreadsheets to help in the analysis.

1. Collect data. Participants in the data collection effort need a common platform to share the data. Portfolio Manager allows users to share information easily, but schools can also develop their own spreadsheets and report cards. Developing unique spreadsheets enables schools to quickly evaluate performance based on metrics they deem to be high priority. The National Energy Education Development (NEED 2007) Project has some sample worksheets and data collection guides in its Energy Management Guide for Schools. The Utility Report Cards program in Florida is another good example of tailoring spreadsheets and report cards to school district goals.

2. Evaluate benchmarks and apply the results. With data in hand, the project team can calculate metrics for each school under the project scope and analyze the results. The benchmarking results can be used for a variety of purposes, from ranking facilities and setting goals to recognizing achievements in improving building performance (Table 2-5). For example, benchmarking information may be used to define a goal of bringing below-average buildings up to the average performance, or to strive for a $10 \%$ decrease in energy use for all buildings.

\section{Table 2-5 Applying Benchmarking Results}

\begin{tabular}{l|l|}
\hline \multicolumn{1}{|c}{ Purpose } & \multicolumn{1}{c}{ Description } \\
\hline Rank facilities & Use data to compare or rank buildings \\
\hline Set goals & Use initial results to set new goals at either the building or the organizational level \\
\hline $\begin{array}{l}\text { Identify and share best } \\
\text { practices }\end{array}$ & Look at top performers to identify best practices and apply to lower performing facilities \\
\hline Take action & $\begin{array}{l}\text { Use the data to develop action plans across the facility portfolio, identifying sites with } \\
\text { the most potential return }\end{array}$ \\
\hline Track progress & $\begin{array}{l}\text { Use data to track progress toward organizational management goals and identify the } \\
\text { organization's best practices }\end{array}$ \\
\hline Recognize achievements & $\begin{array}{l}\text { Give internal awards that recognize superior performance to encourage further efforts } \\
\text { and build support for an energy management plan. A variety of organizations also } \\
\text { provide external opportunities. }\end{array}$
\end{tabular}


Benchmarking data also help you to identify best practices and decide on next steps - determine where to do onsite audits, determine which sites would benefit most from tune-ups and retrofits, and remind school personnel and students about energy-efficient behaviors. Benchmarking efforts can be repeated to track progress against goals and to encourage continuous improvement. Tracking progress will also help to inform decisions about how to regularly set and achieve new goals to create an environment of continuous improvement. By tracking progress, you can also recognize individual achievements. For example, the school with the greatest energy use reductions over the past academic year may receive an award; individuals can also be recognized for their efforts. The data can also be used for a variety of external awards.
In 2009, 34 schools in Colorado's

Poudre School District received ENERGY STAR awards for energy efficiency; and the entire district received a Leadership in Energy and Environmental Design (LEED) Gold rating from the U.S. Green Building Council. These awards, and many earlier commendations, have helped to build support for a continuous stream of improvements in the district.

\section{Additional Resources}

Use these resources for more detailed information about benchmarking K-12 school energy use.

Benchmarking Building Energy Performance: A website from Oak Ridge National Laboratory's Buildings Technology Center that includes sections on benchmarking high schools and elementary/middle schools for a handful of states. http://eber.ed.ornl.gov/benchmark/homepage.htm

Collaborative for High Performance Schools: A national effort to improve student performance by building schools that provide the best education environment. A variety of assessment tools are available. www.chps.net/dev/Drupal/

ENERGY STAR for K-12 School Districts: The ENERGY STAR program provides a strategic approach that helps measure current energy performance, setting goals, tracking savings, and rewarding improvements, with focus on specific industries, including K-12 schools. www.energystar.gov/index.cfm?c=k12_schools.bus_schoolsk12

ENERGY STAR Portfolio Manager: A comprehensive, interactive tool that provides a set of benchmarks developed specifically for K-12 schools that can be used to assess energy performance. www.energystar.gov/index.cfm?c= evaluate_performance.bus_portfoliomanager

ENERGY STAR Target Finder: A no-cost online tool that enables architects and building owners to set energy targets. www.energystar.gov/index.cfm?c=new_bldg_design.bus_target_finder

EPA Building Upgrade Manual: A strategic guide for planning and implementing a profitable energy saving building upgrade following a five-stage process. Chapter 2 focuses on benchmarking. www.energystar.gov/index. cfm?c=business.bus_upgrade_manual

NEED Energy Management Guide for Schools: A tool from the NEED Project (www.need.org) that is designed to assist school leaders in making decisions about energy use in their buildings. www.need.org/needpdf/Energy ManagementGuide2007FINAL.pdf

Utility Report Cards Program: A Florida program that provides spreadsheets and report cards to school district to help them achieve their energy performance goals. http://utilityreportcards.com/ 


\subsection{Energy Audits}

An energy audit is a systematic assessment of a building's energy use that identifies how and where energy enters the building or piece of equipment, how it is used, and where it can be used more efficiently. Performing an energy audit at a K-12 school is straightforward and less complex than doing so at other specialty facilities such as hospitals and laboratories. If you are considering major investments, however, you may want to hire a professional auditor who can perform a high-quality audit and provide detailed project cost and savings calculations with a high level of confidence. Outside resources, such as utility programs, are often available to help schools conduct and finance audits.

There are several types of audits, which vary in the level of effort and detail required. ASHRAE (2004b) designates a preliminary analysis and three levels of energy audit, each expanding on the previous level: walk-through analysis (Level I), single system or targeted audits (Level II), and investment-grade audits (Level III). For each successive audit level both the quality and the cost of the audit increases, as shown in Figure 2-3. Only investment-grade audits account for the interactions among building systems when estimating energy savings (Table 2-6). Posing the right questions can help you select the right type of audit (Table 2-7) (CEC 2000).

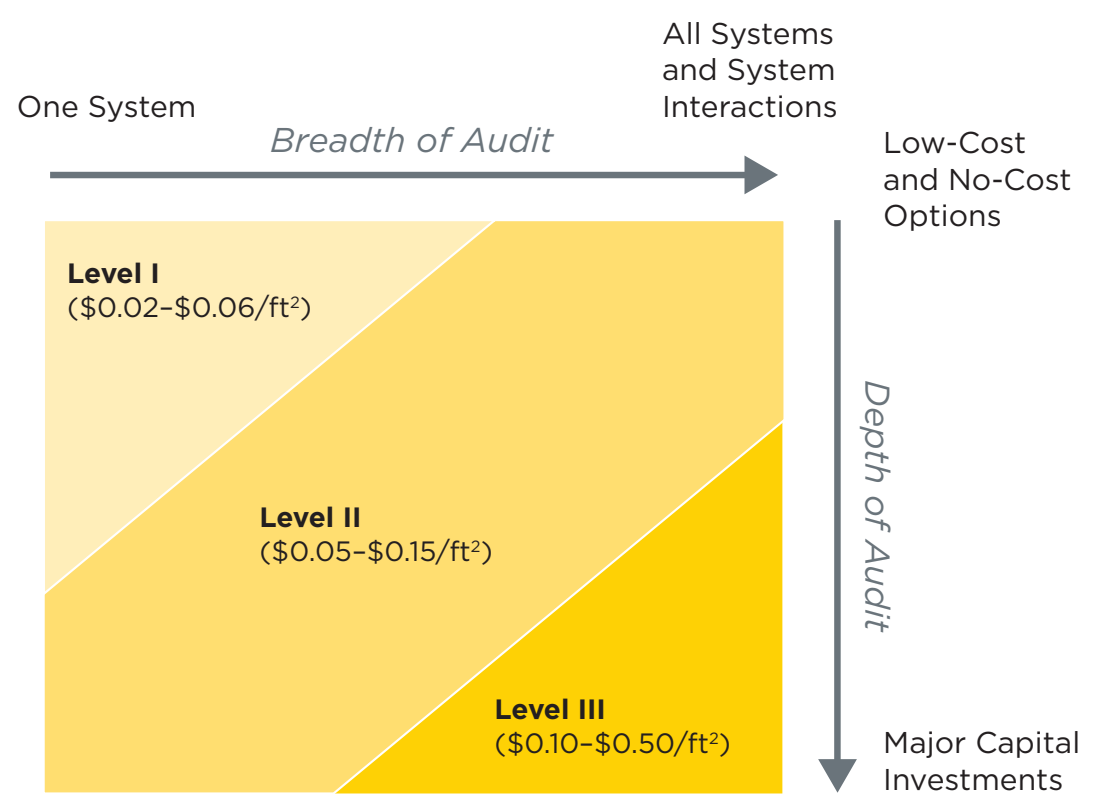

Figure 2-3 Cost and quality of the three levels of energy audits beyond preliminary analysis

Table 2-6 Types of Energy Audits

\begin{tabular}{|l|c|c|}
\hline \multicolumn{1}{|c|}{ Audit Type } & Accounts for Interactions? & Application Notes \\
\hline Preliminary analysis & No & Indicates overall potential for improvement \\
\hline Walk-through analysis & No & Identifies no-cost and low-cost EEMs \\
\hline Single system/targeted audit & No & Considers single systems in detail \\
\hline Investment-grade audit & Yes & Accounts for interactions between building systems \\
\hline
\end{tabular}


Table 2-7 Choosing the Right Energy Audit

\begin{tabular}{|c|c|c|}
\hline Question & If "Yes" & If “No" \\
\hline $\begin{array}{l}\text { Do you want a brief analysis of the energy } \\
\text { savings potential in your facility? }\end{array}$ & Walk-through analysis & Targeted or investment-grade audit \\
\hline Do you already have an energy audit? & Update your studies & $\begin{array}{l}\text { Walk-through analysis, targeted, or } \\
\text { investment-grade audit }\end{array}$ \\
\hline $\begin{array}{l}\text { Have some energy efficiency projects } \\
\text { been implemented? }\end{array}$ & $\begin{array}{l}\text { Target audit focusing on specific } \\
\text { areas not previously analyzed }\end{array}$ & $\begin{array}{l}\text { Walk-through analysis, targeted, or } \\
\text { investment-grade audit }\end{array}$ \\
\hline Do you have limited funding for an audit? & $\begin{array}{l}\text { Walk-through analysis or targeted } \\
\text { audit }\end{array}$ & $\begin{array}{l}\text { Walk-through analysis or } \\
\text { investment-grade audit }\end{array}$ \\
\hline $\begin{array}{l}\text { Do you know which projects you want to } \\
\text { implement? }\end{array}$ & Targeted audit & $\begin{array}{l}\text { Walk-through analysis or } \\
\text { investment-grade audit }\end{array}$ \\
\hline $\begin{array}{l}\text { Do you want a document that will serve as } \\
\text { an energy plan for your facility? }\end{array}$ & Investment-grade audit & $\begin{array}{l}\text { Walk-through analysis or targeted } \\
\text { audit }\end{array}$ \\
\hline $\begin{array}{l}\text { Are you concerned about the accuracy of } \\
\text { predicted savings and costs? }\end{array}$ & Investment-grade audit & Targeted audit \\
\hline $\begin{array}{l}\text { Do you want to add significant value } \\
\text { to your facility by creating a better } \\
\text { educational environment? }\end{array}$ & Investment-grade audit & $\begin{array}{l}\text { Walk-through analysis or targeted } \\
\text { audit }\end{array}$ \\
\hline $\begin{array}{l}\text { Do you have major building systems or } \\
\text { components that need to be replaced or } \\
\text { overhauled? }\end{array}$ & Investment-grade audit & $\begin{array}{l}\text { Walk-through analysis or targeted } \\
\text { audit }\end{array}$ \\
\hline $\begin{array}{l}\text { Does your facility use more energy than a } \\
\text { typical similar-type facility? }\end{array}$ & Investment-grade audit & $\begin{array}{l}\text { Walk-through analysis or targeted } \\
\text { audit }\end{array}$ \\
\hline $\begin{array}{l}\text { Do you want to identify a set of measures } \\
\text { tailored to your school district? }\end{array}$ & Investment-grade audit & $\begin{array}{l}\text { Walk-through analysis or targeted } \\
\text { audit }\end{array}$ \\
\hline
\end{tabular}

\section{Designating a Project Advocate}

Before initiating any plans for energy audits or building upgrades, it is important to designate an employee (or group) as the project advocate who will have the time and dedication to ensure the project receives adequate attention. He or she will provide the necessary resources to an energy auditor to streamline the process and communicate the audit results to decision makers. Projects with an advocate are more likely to proceed through actual implementation of an auditor's recommendations (E Source 1999).

\section{Preliminary Analysis-Benchmarking}

A preliminary or benchmarking analysis before the actual energy audit will show a building's current energy use and cost relative to other similar buildings and will indicate the overall potential for improvement. This is a critical step because it is necessary to understand how much energy a building is consuming in order to estimate how much energy can be saved. This step can also help to identify which buildings should be audited, in what order, and the appropriate audit level. Refer to Section 2.4 for more detail.

\section{Walk-Through Analysis (ASHRAE Level I)}

A walk-through analysis includes a study of utility bills and a visual survey of the facility. This process is simple, low-cost, and usually takes less than a day. The goal is to identify low- or no-cost energy savings opportunities and estimate their potential. The walk-through analysis can highlight simple O\&M EEMs such as turning off lights in 
unoccupied areas, performing regular equipment maintenance, and checking that automatic thermostat controls are working properly. This type of audit will also help managers decide if a more detailed energy audit is worth pursuing.

ESCOs or energy consultants often use the walk-through analysis as a marketing tool, but a facility manager can use it to decide whether to hire a professional consultant or auditor.

Reports from a walk-through audit typically provide rough estimates of energy savings and project costs based on back-of-the-envelope calculations. They do not take into account interactions between systems, such as the reduced HVAC load that results from more efficient lighting. Energy savings estimates based on walk-throughs are not necessarily accurate and should not be used in financing decisions.

Some schools have educational programs that incorporate walkthrough audits and EEMs into their classroom learning, and have found that actively engaging students can substantially lower energy use. Students are given hands-on experience by participating in walkthrough audits that identify simple EEMs to reduce energy consumption. Students help analyze building use and occupancy schedules, classroom lighting levels and controls, thermostat controls, computer controls, vending machines, and other electrical loads, and the condition of the building envelope, windows, and weather-stripping (DOE 2009). They create an "audit report card" and present their findings to school administrators, who can then include the results in a business case for building upgrades.

\section{Single System or Targeted Audits (ASHRAE Level II)}

The next level up in complexity is a single system audit, which provides a more detailed building survey and energy analysis. This type of audit yields a robust analysis of one or more improvement EEMs. It may also recommend additional capital-intensive energy efficiency improvements that require more in-depth engineering analysis to estimate potential savings.

A targeted audit identifies energy use issues and provides a cost and savings analysis that meets a decision maker's budget criteria. It does not account for system interactions and the resulting potential savings and upgrades that might be beneficial for other systems. Typically, this type of audit comes about based on recommendations of a walk-through audit or the near-term need to repair or upgrade specific pieces of equipment. Specialty equipment vendors with a focus on lighting, HVAC, thermal storage systems, or energy management systems (EMSs) can perform these types of audits.

Targeted audits focus on specific areas of need, and are less costly than more comprehensive audits. They do not provide a management plan for future improvements, may miss nontargeted opportunities, and can be biased, especially if the recommendations are provided by a vendor marketing the system in question.

\section{Comprehensive Investment-Grade Audits (ASHRAE Level III)}

The most comprehensive and accurate type of audit is an investment-grade audit, performed by a qualified energy auditor. It uses computer models to simulate building and equipment operations and covers the building envelope, lighting, hot water systems, and HVAC systems. It might also consider demand response, thermal energy storage, and combined heat and power opportunities. 
The unique feature of an investment-grade audit is that it accounts for the interactive effects of all building systems improvements. This information allows for a rigorous total system engineering analysis that details the estimated cost and savings with a level of confidence sufficient for making financial decisions. Taking interactions into account may also lead to opportunities to reduce equipment size. For example, if an HVAC retrofit is planned, energy-efficient lighting and spectrally selective windows may reduce cooling loads enough to downsize the equipment. The audit produces a detailed implementation plan for single or multiphase energy upgrades.

This type of audit provides a comprehensive analysis of project costs and savings for all potential energy technology improvements available to the facility, accounts for all system interactions, and should provide a rational, unbiased plan for implementation. It is costly, however, and may identify more improvements than can be immediately implemented. In some cases, an ESCO can create a financially beneficial project plan and help secure financing to overcome this barrier as part of performance contract. (see Section 2.6 for more information about financing options).
Comprehensive audits played a role in a unique program, designed to reduce overall auditing costs, in Hamilton, Ontario's Hamilton-Wentworth School District. Engineering students and faculty from the nearby McMaster University, with assistance from Union Gas utility, developed a screening method to effectively conduct energy audits on 129 elementary and 24 secondary schools over a two-year period. The method involved classifying schools on the basis of building characteristics, operation, electrical, and HVAC system properties. Nine classifications covered elementary schools; secondary schools fit into seven categories. Comprehensive audits were performed on one school representing each classification and the recommendations for energy efficiency improvements for each were applied to the rest of the schools with the same classification. Although the school district had been working for years to improve school energy efficiency, the resulting audits highlighted dozens of additional EEMs, including upgrading lighting, ensuring proper maintenance or replacement of HVAC components, improving the air distribution systems, installing building automation systems (BASs), and implementing weatherization EEMs (McMaster University 2011).

\section{Covering the Cost of an Energy Audit}

The cost of an energy audit varies with audit type and the complexities of a specific facility. Schools have more basic energy equipment and are less costly to analyze than, for example, healthcare facilities and supermarkets. Many state and local incentive programs offer substantial rebates or even free energy audits. Check with your local utility to learn more about the programs for which you may qualify. Many school districts have incorporated energy audits into ESPCs, in which the school contracts with an ESCO, which provides an energy audit as part of its design and planning services (see Section 2.6).

\section{Presenting Audit Results}

A completed audit can be a valuable tool for creating a business case for energy upgrades, if the audit results are presented in the right way. A well-designed business case will highlight the financial and educational benefits and make a compelling case for implementing the upgrades. Decision makers will be more interested in current and historical energy costs, the benefits to student learning, and the effect of improvements on the operating budget than in technical details of equipment and systems. A comparison of energy use and costs with other school districts in the area along with success stories from other schools will help to get the attention of decision makers. It is important to present various financing options, along with economic calculations expressed in terms the decision makers expect. For some, simple payback will be appropriate, but for others life cycle costs (LCC) and NPV will be more meaningful. Refer to Section 2.6 for more information about innovative new financing mechanisms and investment analysis. 


\section{Additional Resources}

Use these resources for more detailed information on energy audits.

Energy Audit Workbook: A workbook from the Washington State University Energy Program that provides instructions, checklists, and worksheets for conducting an energy audit. www.energy.wsu.edu/Documents/audit2.pdf

ENERGY STAR for K-12 School Districts. The ENERGY STAR program provides a strategic approach that helps in measuring current energy performance, setting goals, tracking savings, and rewarding improvements, with focus on specific industries, including K-12 schools. www.energystar.gov/index.cfm?c=k12_schools.bus_schoolsk12

How to Hire an Energy Auditor to Identify Energy Efficiency Projects: A report from the California Energy Commission. www.energy.ca.gov/reports/efficiency_handbooks/400-00-001C.PDF

Procedures for Commercial Building Audits. A report from ASHRAE that provides purchasers and providers of energy audit services with a complete definition of good procedures for an energy survey and analysis. www.tech street.com/cgi-bin/detail?product_id=1703613\&ashrae_auth_token=

U.S. Department of Energy, Building Energy Software Tools Directory, Whole-Building Analysis: Retrofit Analysis. This website describes a series of software tools that can aid the energy auditing and analysis process. Links to the tools - some available free of charge, some for purchase - are included. $h$ ttp://appst.eere. energy.gov/buildings/tools_directory/subjects.cfm/pagename=subjects/pagename_menu=whole_building_analysis/ pagename_submenu=retrofit_analysis

\subsection{Financing Options}

School administrators and financial managers face many challenges during the financial decision-making process when considering building upgrades for energy efficiency improvements. Even though the short-term savings and long-term economic benefits of energy efficiency improvements are well understood, schools struggle with the upfront capital required, because available capital is almost always limited and must be balanced against other priorities. Innovative financing approaches are available that lower upfront costs to schools, but these mechanisms can be complicated and usually involve third parties. School administrators also face challenges in getting approval from local voters to spend tax dollars on the investment.

Most school districts can expect to use their facilities for at least 40 years, so they have the flexibility to take full consideration of LCC when implementing upgrades. This long-term perspective provides the opportunity to minimize operating expenses and maximize energy efficiency. It also promotes a wider variety of energy efficiency improvements than other commercial facilities are prepared to undertake, because schools may accept payback periods of 5 years, 10 years, or longer. And most schools are tax exempt, so they can take advantage of lower interest rates. 
The best financing choice depends on many factors, including debt capacity, creditworthiness, risk level, in-house expertise, and project term. Financial analysis will provide insight into the financial mechanism to fund and implement an energy efficiency project. The nature and timing of cash flows will vary for every project and funding mechanism, and the resulting NPV should be used to assess the profitability of the energy upgrade investment. Financing categories include capital budget, issuing of bonds, bank loans, performance contracting, leasing, and on-bill financing.

\section{Investment Analysis}

NPV is the most accurate tool for assessing the financial worth of a building upgrade project, but financial managers often use a simple payback period to justify the investment. Simple payback is defined as the number of years required for an investment's cumulative cash flow, including upfront costs, to break even. Usually simple payback assumes that the first year of cost savings continues into the future, and does not include avoided costs for eventual equipment replacement. For example, a project that costs $\$ 50,000$ up front but immediately saves $\$ 10,000$ year in energy and O\&M costs would have a simple payback of 5 years. Simple payback does not provide an accurate measure of the long-term value of an investment, because it does not account for cash flows that occur after payback has been reached.

NPV is a measure of investment worth that explicitly accounts for the time value of money and is used to compare the profitability of multiple financing strategies. NPV is computed from the stream of cash flows that result from the investment. These cash flows are adjusted using a discount rate to increase the value of upfront costs and near-term savings while reducing the value of future costs or benefits. A higher NPV indicates a more profitable investment, so when comparing project financing options, the one with the higher NPV should be chosen. Public facility finance managers can use the ENERGY STAR Cash Flow Opportunity Calculator (http://www.energystar.gov/ia/business/ cfo_calculator.xls?ae04-3a39) to analyze the NPV of energy efficiency projects.

The discount rate is an interest rate used to adjust a future cash flow to its present value. As the starting point, most school districts use their cost of capital - the rate of return that must be earned to pay interest on debt from loans, bonds, leases, or other financial mechanisms. For example, suppose a school district could obtain a loan to finance the entire cost of a building upgrade with an interest rate of 5\%. The cost of capital for this project would be 5\%. If the $5 \%$ discount rate results in an NPV greater than zero, the project would be financially worthwhile because the excess cash flow would be sufficient to repay the loan. Often a somewhat higher discount rate will be used to account for project risk or to provide a return on investment.

In general, if the discount rate and initial costs are high and the cost savings are more stretched out, the NPV of that investment will be lower. Projects with low initial costs and greater initial savings yield higher NPVs.

Consider two energy efficiency project options. One is a noncomprehensive retrofit project involving only lighting; the second is a more complex and comprehensive retrofit project that involves a mix of small and large EEMs. The simpler project has an initial capital cost of $\$ 100,000$ and a simple payback of 2.5 years. The comprehensive project has an initial capital cost of $\$ 400,000$, which is paid off after 4 years. Table 2-8 illustrates the NPV calculation for both scenarios, assuming a discount factor (DF) of 3.5\%. At first glance, the simpler project appears to be the better investment because it has a shorter simple payback period. The NPV calculation shows that the more comprehensive project is actually the more profitable because it has a higher overall NPV (DOE 2008b). More detailed information about NPV analysis in the context of a school retrofit project can be found in Appendix A. 
Table 2-8 Comparison of NPV for Two Projects

\begin{tabular}{|c|c|c|c|c|c|c|}
\hline \multirow[b]{2}{*}{ Year } & \multicolumn{3}{|c|}{ Noncomprehensive Project } & \multicolumn{3}{|c|}{ Comprehensive Project } \\
\hline & $\begin{array}{l}\text { Cash Flow } \\
\quad(\$ 0)\end{array}$ & $\begin{array}{l}\text { Discount Factor } \\
(3.5 \%)\end{array}$ & $\begin{array}{l}\text { NPV } \\
(\$ 0)\end{array}$ & $\begin{array}{l}\text { Cash Flow } \\
(\$ 0)\end{array}$ & $\begin{array}{c}\text { Discount Factor } \\
(3.5 \%)\end{array}$ & $\begin{array}{l}\text { NPV } \\
(\$ 0)\end{array}$ \\
\hline 0 & $-100,000$ & 1.000 & $-100,000$ & $-400,000$ & 1.000 & $-400,000$ \\
\hline 1 & 40,000 & 0.966 & 38,647 & 100,000 & 0.966 & 96,618 \\
\hline 2 & 40,000 & 0.902 & 36,078 & 100,000 & 0.902 & 90,194 \\
\hline 3 & 40,000 & 0.814 & 32,540 & 100,000 & 0.814 & 81,350 \\
\hline 4 & 40,000 & 0.709 & 28,357 & 100,000 & 0.709 & 70,892 \\
\hline 5 & 40,000 & 0.597 & 23,876 & 100,000 & 0.597 & 59,689 \\
\hline 6 & 40,000 & 0.486 & 19,423 & 100,000 & 0.486 & 48,557 \\
\hline 7 & 40,000 & 0.382 & 15,266 & 100,000 & 0.382 & 38,165 \\
\hline 8 & 40,000 & 0.290 & 11,593 & 100,000 & 0.290 & 28,983 \\
\hline 9 & 40,000 & 0.213 & 8,506 & 100,000 & 0.213 & 21,266 \\
\hline 10 & 40,000 & 0.151 & 6,030 & 100,000 & 0.151 & 15,076 \\
\hline 11 & 40,000 & 0.103 & 4,130 & 100,000 & 0.103 & 10,326 \\
\hline 12 & 40,000 & 0.068 & 2,733 & 100,000 & 0.068 & 6,834 \\
\hline 13 & 40,000 & 0.044 & 1,748 & 100,000 & 0.044 & 4,369 \\
\hline 14 & 40,000 & 0.027 & 1,080 & 100,000 & 0.027 & 2,699 \\
\hline 15 & 40,000 & 0.016 & 644 & 100,000 & 0.016 & 1,611 \\
\hline 16 & 40,000 & 0.009 & 372 & 100,000 & 0.009 & 929 \\
\hline 17 & 40,000 & 0.005 & 207 & 100,000 & 0.005 & 518 \\
\hline 18 & 40,000 & 0.003 & 111 & 100,000 & 0.003 & 279 \\
\hline 19 & 40,000 & 0.001 & 58 & 100,000 & 0.001 & 145 \\
\hline 20 & 40,000 & 0.001 & 29 & 100,000 & 0.001 & 73 \\
\hline Total* & 700,000 & & 131,430 & $1,600,000$ & & 178,575 \\
\hline
\end{tabular}

*Totals may not equal sums due to independent rounding.

\section{Financing Mechanisms}

Financing mechanisms for schools range from traditional forms of financing, such as available capital and in-house resources, to approaches that involve third party financing. Choosing the right financing mechanism depends on the specific needs, budget, and budget policies of a school or school system. DOE published a comprehensive financing guide titled "Financing Energy Upgrades for K-12 School Districts," which provides a more detailed analysis of financing options in the context of public schools (Borgeson and Zimring 2013).

\section{Capital Budget}

The simplest and most direct way to finance energy efficiency improvements is to use available capital, or internal funds. With internal financing, projects are paid for directly with available cash drawn from the school's current capital funds. Upfront capital investments almost always result in a short-term negative cash flow, but the resulting savings in energy use and O\&M costs eventually result in a neutral or positive net cash flow. 
This approach presents a simple process that avoids complex contract negotiations or transaction delays and requires no financing costs (interest or transaction fees) paid to third parties. The school retains all energy cost savings immediately, which decreases operating expenses in future years. However, there are several disadvantages. Schools often have limited capital, which can prevent them from implementing comprehensive energy efficiency improvements that could provide greater long-term cost savings. In addition, using capital funds normally requires approval within a school's budgeting process. Most schools have tight budget constraints, so the competition for alternative operating and capital investments is tough. In-house expertise on energy audits, project design, cost estimation, and project management are required, and the school assumes all risks associated with the investment.

\section{Revolving Investment}

Some organizations use revolving investment funds, which involve investing capital in energy efficiency projects, with some or all of the savings from avoided energy costs used to repay the revolving fund. Excess savings allow the fund to grow and be reinvested in additional phases of energy efficiency improvements. With revolving funds it can take a relatively long time to realize the full savings of energy upgrades, but schools often have leeway to take advantage of such opportunities (DOE 2008b).

\section{Bank Loan}

The private sector often uses bank loans to finance small energy efficiency improvements such as equipment upgrades, but schools may find these difficult to use. There are several benefits to using a traditional loan. The payments are fixed and structured to be lower than the anticipated energy savings, resulting in positive cash flow, and the depreciation and interest are tax deductible for private schools. The cost savings of the upgrades are realized immediately, and the school owns the equipment from the start. Loans are a simple mechanism to fund smaller projects, are quick to obtain, and do not involve complexities such as voter approval.

Loans do, however, typically require a substantial down payment, which can be difficult for schools with already strained resources. In addition, lenders usually do not cover the "soft costs" of a project, such as consulting and installation fees. For larger and more complicated projects, schools usually turn to the bond market, discussed in the next section.

\section{Bond Issue}

Bonds are sold by public and private sector organizations to borrow money from capital markets. Municipal bonds are long-term debt obligations of states, local governments, and their authorities and agencies. They are usually exempt from federal and state taxes. They are most commonly issued to finance public buildings and schools and may be used to finance capital improvements such as energy efficiency projects.

Bonds usually have a low, tax-exempt interest rate compared to other financing options. They also avoid the need to rely on precious internal capital and operating budgets, and the financing costs can be structured to be repaid from energy savings.

Bonds are, however, complex agreements that often require input from attorneys, accountants, and investment bankers. This adds administrative costs and fees to the original financing cost. In addition, bonds incur a debt that is reflected on the school's balance sheet, and issuing bonds is a lengthy process that requires multiple levels of approval from legislative bodies and voters. Additional discussion of bond options available to school districts can be found in "Financing Energy Upgrades for K-12 School Districts" (Borgeson and Zimring 2013). 


\section{Energy Savings Performance Contract}

Though not a financing mechanism, an ESPC can help identify and facilitate appropriate financing for large-scale energy efficient building upgrades in both the private and public sectors. An ESPC is often the most effective solution for energy efficiency upgrades in schools because it provide the opportunity to make upgrades that limited capital would make impossible. It is a good approach for school systems that lack the necessary technical expertise, are budget constrained and need their resources for other priorities, and do not have the time or experience to manage complex improvement projects. An ESPC is an agreement with a private ESCO to deliver a group of EEMs with no capital investment by the building owner. The ESCO develops, installs, and manages the project from start to finish and works with the school system to identify sources of financing - unless the school arranges for its own tax-exempt source of funds. This financing is typically in the form of an operating lease or a municipal lease (EPA 2007c). Florida's Miami-Dade County Public Schools district used ESPCs with three ESCOs to install energy-efficient equipment. The district attached the project to a tax-exempt master lease-purchase agreement, which lowered the investment cost. The school district invested $\$ 9.5$ million in energy efficiency, which produced $\$ 3.5$ million in operational cost savings in the first three years (EPA 2003b).

The ESCO manages the project from analysis through construction and may provide some maintenance services along with ongoing $\mathrm{M} \& \mathrm{~V}$. The ESCO guarantees performance of the project within the defined parameters of each party's contractual obligations.

The energy savings generated by the upgrades are used to repay the entire cost of the projects. Any excess savings are distributed between the contracting organization and the ESCO as defined in the contract (Figure 2-4).

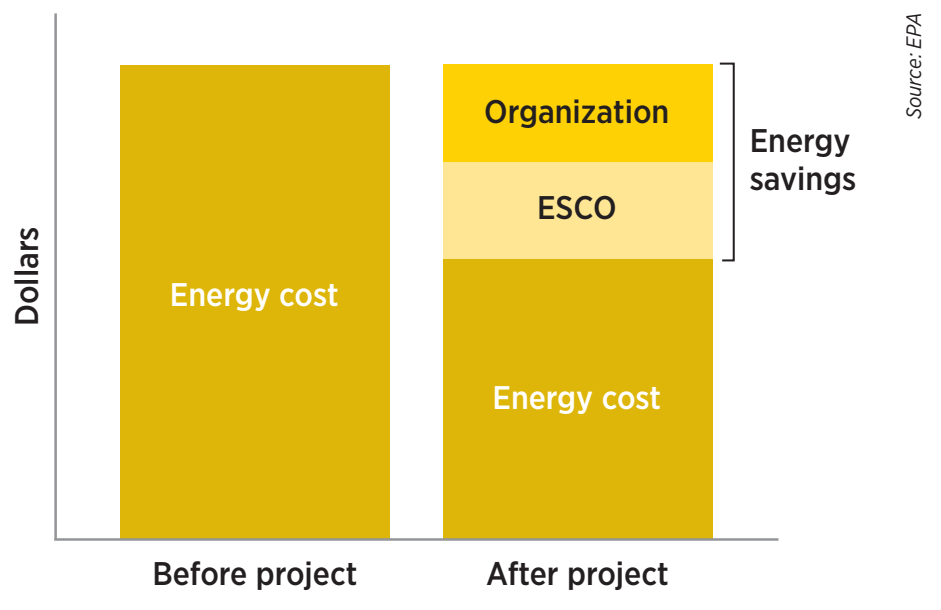

Figure 2-4 Performance contract economics

On the downside, the negotiations can be long and complex; and part of the savings generated by the project goes to payments to the financier, which can make the project more costly than doing it in house. However, the cost of delay by waiting for cash or a lower interest rate may make up for that expense. The Cash Flow Opportunity Calculator (http://www.energystar.gov/ia/business/cfo_calculator.xls?ae04-3a39) is available to help you make the right choice.

Borgeson and Zimring (2013) provide the following six guidelines to school districts and energy managers to help ensure a successful performance contract using an ESCO:

1. Look for more than the low bid. Select an ESCO with a good track record that can provide other necessary services, such as project design, installation, and maintenance. Get references.

2. Consider hiring a third party consultant to guide you through the ESPC process, especially if you lack previous experience or significant expertise on staff, to ensure creating a contract that meets the need of the school district. 
3. Require the ESCO to take a comprehensive approach rather than a cream-skimming.

4. Ask the ESCO to incorporate product warranties and personnel training into the bid.

5. When the contract is signed, organize an in-house team tow work with the ESCO to choose energy measures, prepare bid specs, qualify prospective bidders, and perform other tasks.

6. Document both the energy and non-energy benefits of the project and publicize its success widely. Case Study \#2 shows how a school district in Virginia was able to use an ESPC to make significant investments in energy efficiency despite declining operating budgets.

\section{Lease Purchase}

A lease is a loan in which the lender retains legal title to the property being leased. Leases tend to be quick and easy to implement compared to other forms of financing. Municipal leases are often used to finance comprehensive energy efficiency upgrades for schools, whereas operating and capital leases are better for funding smaller projects such as equipment replacements.

Municipal leases. Municipal leases, also known as tax-exempt purchase agreements, were developed as an alternative to debt or internal financing. They are a favorable approach for tax-exempt entities, such as school districts, for financing building upgrades over long terms. They use operating budget dollars rather than capital budget dollars. School districts are eligible for lower financing rates than borrowers from the private sector because the interest part of the lease payment, which is income to the lessor, is exempt from federal taxation. Rates can thus be set lower than for bonds that generate taxable interest income; and the lessee (the school or municipality) gains significant savings. With a municipal lease, the school district holds title to the leased equipment and the lessor maintains a security interest. As payments are made, the school district gains an equity interest in the equipment. When the lease term is up, the school district gains title to the equipment and the security interest is removed.

Municipal leases boast several advantages. They offer a fast approval process - typically weeks instead of the months required for a bond referendum. Transaction costs are also lower because the school district borrows only the cost of the assets, without the additional fees associated with issuing bonds. Municipal leases enable full project financing; for projects that need progress payments, funding into an escrow account ensures the school district can take advantage of any discounts that the vendor offers. Lease terms also match the useful life of the asset. The leases also do not require a large capital outlay — project costs are paid as they arise. Finally, with municipal leases there are no return provisions, run-on rent, stipulated loss values, and asset management, so hidden liability issues are avoided.

Municipal leases are a good choice for schools and other tax-exempt public sector organizations if the projected energy savings will be greater than the cost of the equipment plus financing, especially when a reputable ESCO guarantees the savings through an ESPC.

Operating leases. In an operating lease, the lessee rents equipment from the lender for a fixed monthly fee. At the end of the lease, the lessee has the option to purchase the equipment for fair market value, extend the lease, or return the equipment. Operating leases are simple and funded through operations budgets and are a good choice for shortterm projects. The payments tend to be smaller than for capital leases and are tax deductible - with a capital lease, only the interest on the payment is deductible. Possible changes from the Financial Accounting Standards Board may eliminate the category of operating lease (FASB 2011).

Capital leases. Under a capital lease, the lender owns the equipment until the end of the lease term, when the title passes to the lessee. These types of leased assets are depreciated, so the depreciation and interest portion of the lease payment is tax deductible. Compared to a traditional bank loan, capital leases require little or no down payment, involve little paperwork, and are approved more quickly. In addition, they can be used to finance soft costs that are hard to fund through a bank loan. More than $100 \%$ of the value of equipment can be leased and the excess used to fund the soft costs. 


\section{Case Study 2: Virginia Beach City Public Schools}

\section{Quick Facts}

- Facility Name: Virginia Beach City Public Schools

- Facility Type: K-12 Schools

- Number of Buildings: 90

- Gross Floor Area: 10.6 million $\mathrm{ft}^{2}$

- Energy Savings Contract Term: 13 yrs

\section{Project Description}

Virginia Beach City Public Schools is the largest school division in southeastern Virginia with 69,365 students and 15,750 employees. The this school division includes 56 elementary schools, 14 middle schools, 11 high schools, and 9 auxiliary buildings and specialty centers.

"Not only are we saving money, but our schools look better as a result of this work. It's a win-win situation for our budget and more importantly, our 'clients' who work and study in these buildings."

- Jim Morris, Assistant Director of Environmental and Energy Management

Like many schools throughout Virginia and the United States, Virginia Beach City Public Schools has experienced declining enrollment and budget cuts. Since the 2005-2006 school year, the division has seen a decline in enrollment of 5,152 students, which impacts the sources of funds for the schools. Budgeted revenues have decreased from a high of $\$ 721$ million in the 2008-2009 school year to $\$ 649$ million in the 2011-2012 school year. Faced with these challenges, VBCPS has undertaken an aggressive efficiency program that has reached across all aspects of school administration, including energy conservation and performance contracting.

The project was installed by NORESCO in less than 18 months, and was well coordinated with division staff. The work was done with the buildings in both occupied and unoccupied modes, and was scheduled for night and weekend work. The division has seen a significant and measureable reduction in utilities since the installation of the systems.

\section{Nonenergy Benefits}

1. Improved light levels in classroom

2. Higher level of comfort in the classroom and school

3. More reliable systems, resulting in an improved ability to respond to internal client demands.

4. Behavioral change initiative used as curriuculum for multiple grade levels

\section{Key EEMs}

- LEDs

- Portable heat pump controls

- Water conservation
- Computer power controls

- Ground source heat pumps

- EMS upgrades
- Rooftop air-conditioning unit replacements

- Behavioral change initiatives

\begin{tabular}{|c|c|c|c|c|c|}
\hline Audit Costs & Equipment Costs & Installation Costs & M\&V Costs & $\begin{array}{l}\text { Financial } \\
\text { Incentives }\end{array}$ & Total Costs \\
\hline$\$ 420,854$ & $\$ 1,943,515$ & $\$ 3,485,288$ & $\$ 18,971$ & $\$ 0$ & $\$ 5,849,657$ \\
\hline Energy \$ Savings & O\&M \$ Savings & Total \$ Savings & NPV & \multicolumn{2}{|c|}{ Simple Payback (yrs) } \\
\hline$\$ 6,626,322$ & $\$ 697,670$ & $\$ 7,323,992$ & $\$ 7,381,691$ & \multicolumn{2}{|c|}{10} \\
\hline \multicolumn{2}{|c|}{ Energy Use } & \multicolumn{3}{|c|}{ EUI } & \\
\hline Before & After & Before & After & ASHRAE 90.1-2004 & Savings \\
\hline 131,921 MMBtu/yr & 111,916 MMBtu/yr & $52.4 \mathrm{kBtu} / \mathrm{ft}^{2}$ & $43.1 \mathrm{kBtu} / \mathrm{ft}^{2}$ & $65.0 \mathrm{kBtu} / \mathrm{ft}^{2}$ & $15.2 \%$ \\
\hline
\end{tabular}




\section{On-Bill Financing}

On-bill financing through local utilities is another way to fund energy efficiency improvements without heavy upfront capital spending. It is applicable to small and medium-sized projects in the private and public sectors. A utility or other third-party financial institution incurs the upfront costs of improvements and recoups the investment by incorporating the loan repayment into future energy bills. This approach eliminates upfront costs, and the repayment schedule is structured so the energy savings are greater than the payment. On-bill repayment is simple to initiate, as utilities already have established billing and access to information about a school's energy use patterns and payment history. Utilities are often reluctant to take on the role of financing, however, and agreements can be complex to set up.

\section{Additional Resources}

Use these resources for more detailed information on financing options for K-12 schools energy efficiency upgrades.

Easy Access to Energy Improvement Funds in the Public Sector, Government Finance Review: An article that shows how the money saved from increased energy efficiency can be used to finance efficient equipment. www.energystar. gov/ia/business/government/Financial_Energy_Efficiency_Projects.pdf

Energy Efficiency Programs in K-12 Schools: An EPA document that discusses energy efficiency in schools in the context of clean energy strategies for local governments.

Energy Savings Performance Contracts. This webpage from FEMP provides guidance on energy performance contracts. wwwl.eere.energy.gov/femp/financing/espcs.html

Energy Services Coalition. This group provides resources for energy performance contracting. www.energyservices coalition.org

ENERGY STAR Building Upgrade Manual: A strategic guide for planning and implementing a profitable energy saving building upgrade following a five-stage process. Chapters 3 and 4 focus on investment analysis and financing. www.energystar.gov/index.cfm?c=business.bus_upgrade_manual

ENERGY STAR Cash Flow Opportunity Calculator: A spreadsheet designed to help decision makers quantify the costs of delaying an energy efficiency project. www.energystar.gov/index.cfm?c=business.bus_financing

eValuator. This financial analysis software can be downloaded for free from the Energy Design Resources website. It calculates life cycle benefits of improved building design investments and provides financial information necessary for making sound building upgrade decisions. www.energydesignresources.com/resources/software-too/s/evaluator.aspx

Financing Energy Upgrades for K-12 School Districts: A DOE publication that specifically addresses the pros and cons of a variety of financing mechanisms in the context of K-12 schools, focusing on comprehensive energy upgrades. It also provides six detailed case studies illustrating the successful application of financing principles described in the guide. www.eere.energy.gov/wip/solutioncenter/pdfs/financing_energy_upgrades_K-12.pdf.

Greening Schools. This website lists funding options, from a variety of sources for energy-efficient school projects. www.greeningschools.org/resources/funding_opportunities.cfm

Guide to Financing EnergySmart Schools: This guide from the DOE Energy Efficiency and Renewable Energy

Building Technologies Office summarizes methods of financing and looks at innovative approaches. It also describes the nonenergy benefits that affect the economic viability of a project. http://apps1.eere.energy.gov/buildings/ publications/pdfs/energysmartschools/ess_financeguide_0708.pdf

National Association of Energy Service Companies provides background information and helps users find providers of energy service contracts. www.naesco.org 


\section{Existing Building Commissioning}

Significant savings can often be achieved in K-12 schools with minimal risk and capital outlay by improving building operations and restructuring maintenance procedures. This process, commonly known as $\mathrm{EBCx}$, tunes up building performance. $\mathrm{EBCx}$ can take the form of retrocommissioning $(\mathrm{RCx})$ when performed for the first time in an existing building, or recommissioning when it is performed as a follow-up to the original commissioning process. Besides being a highly cost-effective strategy for reducing energy use, EBCx can help reduce O\&M costs and ensure the persistence of proper operation. It is typically a good first step on the road to increased energy performance with either a staged or an integrated approach.

An EBCx process usually consists of four phases: planning, investigation, implementation, and hand-off. The EPA's "A Retrocommissioning Guide for Building Owners" includes a detailed discussion of the activities that take place in each phase (PECI 2007b). This process may vary slightly for specific projects, but most EBCx projects follow the process shown in Figure 3-1.

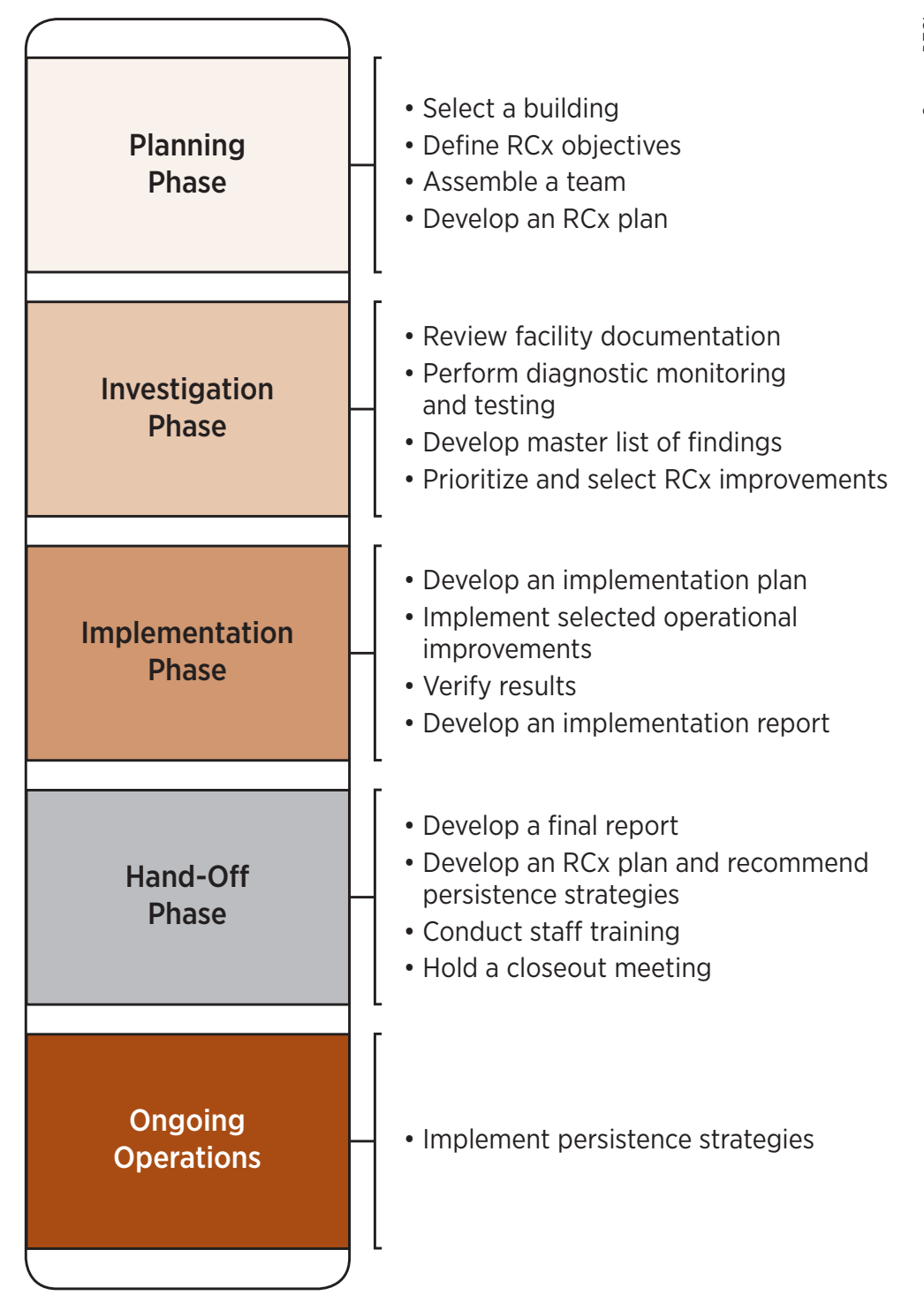

Figure 3-1 Phases of an effective EBCx project 
Much of the effort and cost of EBCx are applied during the investigation phase. An outside EBCx provider, or perhaps an experienced energy manager for larger school districts, works with the facility manager to conduct an in-depth investigation into building operations. This provides a detailed understanding of the systems and assemblies and identifies operational improvements. About half the overall project cost is usually devoted to the $\mathrm{EBCx}$ provider's work on the project, which includes this in-depth investigation. The other half is devoted to implementing the EEMs. Further considerations for cost and the choice of an EBCx provider are presented in Section 3.3.

EBCx is generally recommended even when retrofits are being considered, to optimize building system operations before the retrofits are designed and implemented. This approach also enables savings to accrue even while planning proceeds for more comprehensive upgrades. However, if a facility has scheduled retrofits in the near future, it may make sense to delay implementation of some $\mathrm{EBCx}$ measures until those retrofits have occurred. Aside from being a highly cost-effective strategy for reducing energy use, EBCx can help reduce nonenergy costs, and help ensure that proper operation persists. It provides a good first step on the road to increased energy performance with either a staged or an integrated approach.

This section begins with an EBCx measure summary table that provides a list of the highest priority EEMs that should be considered as part of an EBCx project. The EEMs were identified by evaluating the most common and cost-effective EEM options being implemented in K-12 schools. More detailed information about the application of each EBCx measure to schools is provided in Appendix E, which presents a brief technical overview, addresses strengths and weaknesses, and discusses special considerations related to building vintage, size, and climate. It also presents a second tier of EBCx measures that may be worth exploring, depending on the current state of the school.

This section continues with a set of recommended packages of EBCx measures that were selected based on their appropriateness for the example high school building in each climate region. Details of the approach used for costeffectiveness analysis are provided in Appendices A and B. Our analysis indicates that implementing the recommended packages can produce a large positive NPV and payback periods of less than 2 years in all regions of the country.

This section concludes with considerations for the EBCx process that address factors that can influence cost effectiveness, and aspects to consider when evaluating EEMs. Because all buildings are unique and have particular needs and opportunities for energy upgrades, building owners are encouraged to think about how these aspects will influence their projects.

\subsection{Existing Building Commissioning Energy Efficiency Measure Summary Table}

Approximately 30 EBCx measures suitable for K-12 schools are presented in this section, and described in more detail in Appendix E. These EEMs were carefully selected by retrofit experts based on the likelihood that they will yield significant energy savings in typical K-12 schools at little or no cost. Table 3-1 provides a summary of these EEMs and their applicability to each climate region. Note that most $\mathrm{EBCx}$ measures are worthwhile in all climates because a low threshold of energy savings is necessary to pay for the low cost of implementation. 


\section{运}

\section{Table 3-1 EBCx Measure Summary Table}

\begin{tabular}{|c|c|c|c|c|c|c|c|c|}
\hline \multirow[b]{2}{*}{ System } & \multirow[b]{2}{*}{ Measure Description } & \multicolumn{5}{|c|}{ Applicable to: } & \multirow[b]{2}{*}{$\begin{array}{l}\text { Stage } \\
\text { (see } \\
\text { Section } \\
4.2 \text { ) }\end{array}$} & \multirow[b]{2}{*}{ Section } \\
\hline & & $\stackrel{\bar{\varepsilon}}{\bar{\Sigma}}$ & 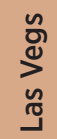 & 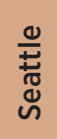 & $\begin{array}{l}\text { 을 } \\
\text { 은 }\end{array}$ & $\frac{\text { 들 }}{\frac{5}{3}}$ & & \\
\hline \multirow{2}{*}{ Lighting } & $\begin{array}{l}\text { Calibrate any existing lighting controls and } \\
\text { optimize settings based on building usage } \\
\text { patterns and daylight availability }\end{array}$ & $\checkmark$ & $\checkmark$ & $\checkmark$ & $\checkmark$ & $\checkmark$ & 1 & E.1.1 \\
\hline & $\begin{array}{l}\text { Improve janitorial workflow to consolidate } \\
\text { activities in each area, allowing a reduction } \\
\text { in operating hours for lighting }\end{array}$ & $\checkmark$ & $\checkmark$ & $\checkmark$ & $\sqrt{ }$ & $\checkmark$ & 1 & E.1.2 \\
\hline \multirow{5}{*}{$\begin{array}{l}\text { Plug and } \\
\text { process loads }\end{array}$} & $\begin{array}{l}\text { Provide power strips in easy-to-access } \\
\text { locations to facilitate equipment shutdown }\end{array}$ & $\checkmark$ & $\checkmark$ & $\checkmark$ & $\checkmark$ & $\checkmark$ & 1 & E.2.1 \\
\hline & $\begin{array}{l}\text { Control computer power management } \\
\text { settings facility wide through software or } \\
\text { logon scripts }\end{array}$ & $\checkmark$ & $\sqrt{ }$ & $\checkmark$ & $\sqrt{ }$ & $\sqrt{ }$ & 1 & E.2.2 \\
\hline & $\begin{array}{l}\text { Use timers or occupancy sensors for } \\
\text { compressors and turn off lights on vending } \\
\text { machines }\end{array}$ & $\sqrt{ }$ & $\sqrt{ }$ & $\checkmark$ & $\sqrt{ }$ & $\checkmark$ & 1 & E.2.3 \\
\hline & $\begin{array}{l}\text { Verify or establish an effective maintenance } \\
\text { protocol for cooking equipment in kitchen } \\
\text { areas and break rooms, including cleaning } \\
\text { exhaust vents, heating coils, and burners }\end{array}$ & $\checkmark$ & $\checkmark$ & $\checkmark$ & $\sqrt{ }$ & $\checkmark$ & 1 & E.2.4 \\
\hline & $\begin{array}{l}\text { Use a pool cover when the pool is not in use } \\
\text { for an extended period }\end{array}$ & $\checkmark$ & $\checkmark$ & $\checkmark$ & $\sqrt{ }$ & $\checkmark$ & 1 & E.2.5 \\
\hline Envelope & $\begin{array}{l}\text { Repair broken windows and weather-strip/ } \\
\text { caulk windows and doors where drafts can } \\
\text { be felt }\end{array}$ & $\checkmark$ & $\sqrt{ }$ & $\checkmark$ & $\sqrt{ }$ & $\checkmark$ & 1 & E.3.1 \\
\hline $\begin{array}{l}\text { Service water } \\
\text { heating }\end{array}$ & $\begin{array}{l}\text { Repair any damaged or missing pipe and } \\
\text { tank insulation }\end{array}$ & $\checkmark$ & $\sqrt{ }$ & $\checkmark$ & $\sqrt{ }$ & $\checkmark$ & 1 & E.4.1 \\
\hline \multirow{7}{*}{$\begin{array}{l}\text { HVAC: Heating } \\
\text { and cooling }\end{array}$} & $\begin{array}{l}\text { TAB chilled water pumps and valves, } \\
\text { refrigerant lines, air handlers, and flow } \\
\text { modulation devices to ensure heating and } \\
\text { cooling loads are met }\end{array}$ & $\checkmark$ & $\sqrt{ }$ & $\checkmark$ & $\sqrt{ }$ & $\checkmark$ & 1 & E.5.1 \\
\hline & $\begin{array}{l}\text { Verify or establish a comprehensive } \\
\text { maintenance protocol for HVAC equipment, } \\
\text { including cleaning cooling and heating coils, } \\
\text { cooling towers, burners, radiators, and filters }\end{array}$ & $\sqrt{ }$ & $\sqrt{ }$ & $\sqrt{ }$ & $\sqrt{ }$ & $\sqrt{ }$ & 1 & E.5.2 \\
\hline & Verify correct operation of OA economizer & & $\checkmark$ & $\checkmark$ & $\sqrt{ }$ & $\sqrt{ }$ & 1 & E.5.3 \\
\hline & $\begin{array}{l}\text { Increase thermostat setback/setup when } \\
\text { building is unoccupied }\end{array}$ & $\sqrt{ }$ & $\sqrt{ }$ & $\checkmark$ & $\checkmark$ & $\sqrt{ }$ & 1 & E.5.4 \\
\hline & $\begin{array}{l}\text { Precool spaces to reduce peak demand } \\
\text { charges }\end{array}$ & $\sqrt{ }$ & $\sqrt{ }$ & $\checkmark$ & $\sqrt{ }$ & & 1 & E.5.5 \\
\hline & $\begin{array}{l}\text { Reset supply air temperature (SAT) } \\
\text { based on building loads or outdoor air } \\
\text { temperature (OAT) }\end{array}$ & $\sqrt{ }$ & $\sqrt{ }$ & $\checkmark$ & $\sqrt{ }$ & $\checkmark$ & 1 & E.5.6 \\
\hline & $\begin{array}{l}\text { Reset boiler temperature based on building } \\
\text { loads or OAT }\end{array}$ & & & $\checkmark$ & $\sqrt{ }$ & $\checkmark$ & 1 & E.5.7 \\
\hline
\end{tabular}


Table 3-1 EBCx Measure Summary Tab (cont'd)

\begin{tabular}{|c|c|c|c|c|c|c|c|c|}
\hline \multirow[b]{2}{*}{ System } & \multirow[b]{2}{*}{ Measure Description } & \multicolumn{5}{|c|}{ Applicable to: } & \multirow[b]{2}{*}{$\begin{array}{l}\text { Stage } \\
\text { (see } \\
\text { Section } \\
4.2 \text { ) }\end{array}$} & \multirow[b]{2}{*}{ Section } \\
\hline & & $\stackrel{\bar{\varepsilon}}{\overline{\frac{\pi}{\Sigma}}}$ & $\begin{array}{l}\text { סू } \\
\text { jo } \\
\tilde{J}\end{array}$ & 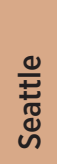 & 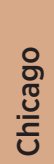 & $\frac{\text { 돌 }}{\text { 몸 }}$ & & \\
\hline \multirow{3}{*}{$\begin{array}{l}\text { HVAC: Heating } \\
\text { and cooling } \\
\text { (continued) }\end{array}$} & $\begin{array}{l}\text { Verify adequate deadband between heating } \\
\text { and cooling }\end{array}$ & $\sqrt{ }$ & $\sqrt{ }$ & $\checkmark$ & $\checkmark$ & $\checkmark$ & 1 & E.5.8 \\
\hline & $\begin{array}{l}\text { Optimize equipment staging/sequence of } \\
\text { operation }\end{array}$ & $\checkmark$ & $\checkmark$ & $\sqrt{ }$ & $\checkmark$ & $\sqrt{ }$ & 1 & E.5.9 \\
\hline & Optimize equipment start/stop procedures & $\sqrt{ }$ & $\sqrt{ }$ & $\checkmark$ & $\checkmark$ & $\sqrt{ }$ & 1 & E.5.10 \\
\hline \multirow{3}{*}{$\begin{array}{l}\text { HVAC: } \\
\text { Ventilation }\end{array}$} & $\begin{array}{l}\text { Suspend ventilation during unoccupied } \\
\text { periods }\end{array}$ & $\sqrt{ }$ & $\sqrt{ }$ & $\checkmark$ & $\checkmark$ & $\checkmark$ & 1 & E.6.1 \\
\hline & $\begin{array}{l}\text { Test and adjust ventilation flow rates as } \\
\text { needed to meet ASHRAE } 62.1 \text { requirements }\end{array}$ & $\checkmark$ & $\checkmark$ & $\checkmark$ & $\sqrt{ }$ & $\sqrt{ }$ & 1 & E.6.2 \\
\hline & Replace or repair leaky and broken dampers & $\checkmark$ & $\checkmark$ & $\checkmark$ & $\checkmark$ & $\checkmark$ & 1 & E.6.3 \\
\hline
\end{tabular}

\subsection{Recommended Packages}

\section{At-a-Glance Results}

Table 3-2 shows a summary of estimated energy savings for the EBCx measures selected for the example high school (see Section 1.4). Eight of the EEMs from Section 3.1 that were deemed to be the largest energy savers and that could be applied to the example building have been recommended as an example package, but as discussed in Section 3.3, other EEMs may also be cost effective depending on the site specifics. Certain EEMs are not in the package because the example building does not have relevant equipment or envelope characteristics. For example, calibration of lighting controls is not included because the example building does not have automatic lighting controls, though we assume it does have a basic EMS. (See Appendix B for an explanation of the EEM selection process for EBCx projects and for further information about the example building.)

Table 3-2 EBCx Recommended Packages-Results of Common Metrics

\begin{tabular}{|l|c|c|c|c|c|c|c|}
\hline \multirow{2}{*}{\multicolumn{1}{c|}{ Location }} & \multicolumn{3}{|c|}{ EUI (kBtu/ft2)* } & \multicolumn{3}{c|}{ Energy Cost/ft2* } \\
\cline { 2 - 7 } & Baseline & Post-EBCx & $\begin{array}{c}\text { \% Reduction } \\
\text { From Baseline }\end{array}$ & Baseline & Post-EBCx & From Baseline \\
\hline Miami (Hot \& Humid) & 84 & 77 & $8 \%$ & $\$ 2.58$ & $\$ 2.43$ & $6 \%$ \\
\hline Las Vegas (Hot \& Dry) & 86 & 77 & $10 \%$ & $\$ 2.58$ & $\$ 2.40$ & $7 \%$ \\
\hline Seattle (Marine) & 82 & 70 & $15 \%$ & $\$ 1.91$ & $\$ 1.74$ & $9 \%$ \\
\hline Chicago (Cold) & 103 & 86 & $16 \%$ & $\$ 2.52$ & $\$ 2.28$ & $9 \%$ \\
\hline Duluth (Very Cold) & 124 & 102 & $18 \%$ & $\$ 2.38$ & $\$ 2.13$ & $11 \%$ \\
\hline Average & 96 & 82 & $14 \%$ & $\$ 2.39$ & $\$ 2.19$ & $8 \%$ \\
\hline
\end{tabular}

*Annual cost and energy savings are first year values. Cost savings are expressed in 2011 dollars, and include the effect of annual M\&V costs. 
The measures included in the EBCx packages are shown in Table 3-3.

Table 3-3 EBCx Measures in Recommended Package

\begin{tabular}{|c|c|c|c|}
\hline System & Measure Description & Climate Zone & Section \\
\hline $\begin{array}{l}\text { Plug and process } \\
\text { loads }\end{array}$ & $\begin{array}{l}\text { Provide power strips in easy-to-access locations to facilitate } \\
\text { equipment shutdown }\end{array}$ & All & E.2.1 \\
\hline Building enclosure & Repair broken and visibly damaged windows & All & E.3.1 \\
\hline $\begin{array}{l}\text { Service water } \\
\text { heating }\end{array}$ & Repair any damaged or missing pipe and tank insulation & All & E.4.1 \\
\hline \multirow{5}{*}{ HVAC } & $\begin{array}{l}\text { TAB of chilled water pumps and valves, refrigerant lines, air } \\
\text { handlers, and flow modulation devices }\end{array}$ & All & E.5.1 \\
\hline & $\begin{array}{l}\text { Verify or establish a comprehensive maintenance protocol for } \\
\text { HVAC equipment }\end{array}$ & All & E.5.2 \\
\hline & Verify correct operation of OA economizer & All & E.5.3 \\
\hline & Apply thermostat setback/setup when building is unoccupied & All & E.5.4 \\
\hline & $\begin{array}{l}\text { Decrease ventilation flow rates to meet ASHRAE 62-1999 } \\
\text { requirements }\end{array}$ & All & E.6.2 \\
\hline
\end{tabular}

\section{Rationale for Recommended Energy Efficiency Measures}

The EEMs in the EBCx package were chosen based on their frequency of occurrence on EBCx projects, ease of implementation in the example building, and likelihood of implementation. Further discussion of the process for developing recommended packages can be found in Appendix B.

The EEMs included in the recommended package are only a subset of the EEMs listed in Table 3-1. An EBCx process typically identifies many opportunities for improved O\&M and energy performance. Often, some of those opportunities are not implemented, for reasons such as budgeting, scheduling, and planned work that would affect the EEM. In addition, the auditing process may indicate that some EEMs are unnecessary because O\&M are already adequate. The EEMs in the EBCx package were chosen as a representative mix of EEMs that could be implemented as part of an EBCx process in a typical high school.

\section{Energy Savings}

The detailed energy and demand savings for the recommended EBCx packages are shown in Table 3-4. These values were determined by applying the EEMs to the example high school building described in Appendix B. 


\section{Table 3-4 EBCx Recommended Package Energy Savings Results}

\begin{tabular}{|c|c|c|c|c|c|c|c|}
\hline Location & $\begin{array}{l}\text { Electricity } \\
\text { Savings } \\
\text { (annual } \\
\text { kWh) }\end{array}$ & $\begin{array}{l}\text { Electric } \\
\text { Demand } \\
\text { Savings } \\
\text { (peak kW) }\end{array}$ & $\begin{array}{c}\text { Gas Savings } \\
\text { (annual } \\
\text { therms) }\end{array}$ & $\begin{array}{c}\text { Site EUI } \\
\text { Savings } \\
\left(\mathrm{kBtu} / \mathrm{ft}^{2}\right)\end{array}$ & $\begin{array}{c}\text { Savings as \% } \\
\text { of Total Site } \\
\text { Usage }\end{array}$ & $\begin{array}{c}\text { Source EUI } \\
\text { Savings } \\
\left(\mathrm{kBtu} / \mathrm{ft}^{2}\right)\end{array}$ & $\begin{array}{c}\text { Savings as \% } \\
\text { of Total } \\
\text { Source Use }\end{array}$ \\
\hline $\begin{array}{l}\text { Miami (Hot } \\
\text { \& Humid) }\end{array}$ & 378,586 & 86 & 1,819 & 7 & $8 \%$ & 22 & $8 \%$ \\
\hline $\begin{array}{l}\text { Las Vegas } \\
\text { (Hot \& Dry) }\end{array}$ & 344,999 & 107 & 6,811 & 9 & $10 \%$ & 23 & $9 \%$ \\
\hline $\begin{array}{l}\text { Seattle } \\
\text { (Marine) }\end{array}$ & 242,401 & 58 & 16,900 & 12 & $15 \%$ & 22 & $11 \%$ \\
\hline $\begin{array}{l}\text { Chicago } \\
\text { (Cold) }\end{array}$ & 271,960 & 79 & 24,664 & 16 & $16 \%$ & 28 & $11 \%$ \\
\hline $\begin{array}{l}\text { Duluth } \\
\text { (Very Cold) }\end{array}$ & 256,225 & 68 & 38,521 & 22 & $18 \%$ & 34 & $13 \%$ \\
\hline
\end{tabular}

As shown in Table 3-4, EBCx measures can yield significant energy savings. The overall reductions in building energy use shown in the table are based on actual EBCx projects across a range of building types, and may not be representative of K-12 schools (Mills 2009). The site-to-source conversion factors for electricity and gas are calculated using a nationwide average based on an NREL study of transmission and distribution losses (Deru and Torcellini 2007).

\section{Financial Analysis}

The cost of individual EEMs can vary greatly, depending on the baseline condition of the school and the work involved in implementing the EEMs. Studies have shown that the average cost for an EBCx project, including commissioning and minor repairs, is $\$ 0.30 / \mathrm{ft}^{2}$ (Mills 2009). Applying this value to the example high school and applying inflation rates for the past 2 years gives an overall EBCx package cost of $\$ 0.31 / \mathrm{ft}^{2}$ (see Table 3-5). As shown, EBCx is projected to have a fast simple payback (1.2-2.0 years) and a positive NPV, making it an attractive method to achieve energy savings in a typical school.

Table 3-5 EBCx Recommended Package Financial Analysis Results

\begin{tabular}{|l|c|c|c|c|}
\hline \multicolumn{1}{|c|}{ Location } & Total Measure Costs & $\begin{array}{c}\text { Total Energy Cost } \\
\text { Savings }\end{array}$ & $\begin{array}{c}\text { Simple Payback } \\
\text { (Years) }\end{array}$ & NPV \\
\hline Miami (Hot \& Humid) & $\$ 64,456$ & $\$ 34,309$ & 2.0 & $\$ 101,417$ \\
\hline Las Vegas (Hot \& Dry) & $\$ 64,456$ & $\$ 38,890$ & 1.7 & $\$ 124,606$ \\
\hline Seattle (Marine) & $\$ 64,456$ & $\$ 39,087$ & 1.7 & $\$ 127,995$ \\
\hline Chicago (Cold) & $\$ 64,456$ & $\$ 51,639$ & 1.3 & $\$ 189,626$ \\
\hline Duluth (Very Cold) & $\$ 64,456$ & $\$ 57,131$ & 1.2 & $\$ 218,031$ \\
\hline
\end{tabular}

Nonenergy benefits, such as improved thermal comfort and extended equipment life, can also be achieved by the EBCx process. The estimated median nonenergy impact of $\mathrm{EBCx}$ across a variety of building types is about $\$ 0.18 / \mathrm{ft}^{2}$. This is significant, when compared to the median energy savings of $\$ 0.29 / \mathrm{ft}^{2}$ related to EBCx (Mills 2009). For K-12 schools specifically, these values may be higher or lower, because typical equipment and HVAC systems are not necessarily representative of all commercial buildings. Although savings may be realized beyond the energy savings 
reported in Table 3-5, some costs may also increase. For example, energy use will increase in some schools that were operating with insufficient lighting levels or ventilation rates. Additional O\&M expenses may be required to maintain optimal energy performance after the EBCx process. For this analysis, the additional nonenergy costs and benefits were assumed to cancel out.

To maintain the energy benefits related to EBCx measures, the performance of the related equipment and systems must be maintained through periodic monitoring. The financial analysis assumes that the EEM life of EBCx is 5 years, with ongoing maintenance of the improvements. Full recommissioning should be performed every few years so the benefits persist over a longer time horizon. The cost of recommissioning is usually less than the cost of initial EBCx.

The EBCx measures proposed in the recommended packages above and comprehensive $\mathrm{EBCx}$ measure discussions in Appendix E provide a starting point for EEM options to be considered for most K-12 schools. However, not all EEMs will be applicable to all schools, because every school building is unique. Other EEMs not included in the preceding discussion may be applicable to a specific building. Some of these additional ideas are listed at the end of Appendix E. The EBCx process, which includes an in-depth investigation into building operations, identifies opportunities for improved performance, including energy performance, occupant comfort, O\&M, and equipment performance. The extent of the opportunities identified will be partly dependent on the comprehensiveness of the EBCx scope.

Facility managers considering implementing the EBCx process will benefit from consulting the detailed EEM descriptions in Appendix E to gain an understanding of the types of EEMs typically implemented as part of an EBCx project. Appendix E includes a discussion of each EEM's technical characteristics, special considerations, and technical assumptions for implementing the EEM in the context of a typical school.

\subsection{Additional Considerations}

An experienced $\mathrm{EBCx}$ provider can help determine if a building is a good candidate for $\mathrm{EBCx}$. In addition, an ASHRAE Level I energy audit can help determine a building's suitability for $\mathrm{EBCx}$ and give greater confidence in proceeding with an EBCx project. Some indicators of a school that is a good candidate for EBCx include (EPA 2007b):

- High, unjustified energy use

- Low-performing building equipment or control systems

- High equipment failure rates

- The presence of electronic controls, or an EMS, which makes it easier to implement many of the EEMs

- Experienced and available in-house staff

- Up-to-date building documentation.

Employees, students, and teachers can also signal the need for EBCx. A school with many occupant complaints is often a good candidate for EBCx. The building commissioning industry suggests that it is good practice to engage building occupants during investigation and persistence phases of commissioning (Building Commissioning Association 2008). Case Study \#3 describes how comfort complaints led to a number of efficiency improvements in a Colorado middle school.

When evaluating $\mathrm{EBCx}$ measures to apply in a specific school, the following questions should be considered to help narrow the options to a manageable number:

- Is the EEM applicable to the systems and assemblies in the building? Certain EEMs may not be feasible due to the constraints of the installed systems. For example, adding equipment lockouts based on OAT may not be 
feasible for some types of HVAC systems.

- Is the EEM relevant to the operations of the building? EEMs that affect IAQ should be closely evaluated and considered, as they may impact occupant health and comfort. Also, the capabilities of the service contractors and operations staff should be considered when evaluating EEMs. Do the contractors and staff have the necessary skills and knowledge to support the EEM? If not, is there additional training that they can receive?

- How difficult will it be to ensure that the EEM persists? After EEMs are implemented, they require periodic monitoring to ensure that the benefits of the EEMs are realized over time. Sufficient resources and strategies must be put into place to ensure EEM persistence.

- Are there planned retrofits that may nullify the benefits of the EBCx measure? If a facility has scheduled retrofits in the near future, it may make sense to delay implementation of $\mathrm{EBCx}$ measures until those retrofits have occurred. For example, if the exterior lighting will soon be upgraded to more efficient fixtures, it may not be worth calibrating the lighting controls before the retrofit.

- The cost of EBCx is an important consideration for most energy managers. Much of the cost of EBCx relates to the provider cost—-for the planning, investigation, and hand-off phases of a typical project (Mills 2009). And most of the provider cost is spent during the in-depth investigation phase of the project. Although the cost of implementing EBCx measures is typically low, it is important to also consider this provider effort, which is necessary to identify the best opportunities. In-house staff or service contractors may be used, but EBCx providers are typically better suited for managing the process for the following reasons:

- The in-house staff or service contractors may not have the resources to lead the process, or the skills to perform the in-depth investigation.

- A third-party EBCx provider offers a "second set of eyes," with significant experience to draw upon and without biased notions about how the building should perform.

- EBCx providers have the specialized tools for performing the work- e.g., data loggers, functional test forms, and power monitors

- EBCx providers have the necessary analytic skills and resources for diagnosing performance issues and determining the cost effectiveness of identified improvements.

These are just a few of the factors that should be considered. An experienced EBCx provider can help determine if a building is a good candidate for EBCx. To help determine a building's suitability for EBCx and to give greater confidence in proceeding with an EBCx project, an ASHRAE Level I energy audit can be conducted. Case Study \#4 shows how energy audits were used in a California elementary school to identify several quick payback HVAC scheduling improvements.

\subsection{Additional Resources}

ENERGY STAR Building Upgrade Manual, K-12 Schools: The building upgrade manual provides technical recommendations for RCx measures in existing buildings, with a specific chapter dedicated to retrofits in $\mathrm{K}-12$ schools. www.energystar.gov/index.cfm?c=business.bus_upgrade_manual

School Operations and Maintenance: Best Practices for Controlling Energy Costs. This Guidebook for K-12 schools provides detailed and practical guidance on how K-12 school districts can plan and implement enhancements to their current O\&M programs that can successfully maintain their facilities while also reducing energy costs up to 20\%. www.azdeq.gov/function/about/download/greenguide2.pdf

Advanced Variable Air Volume System Design Guide from the California Energy Commission provides general guidelines for optimizing systems (CEC 2005a) 


\section{Case Study 3: Century Middle School Retrocommissioning}

\section{Quick Facts}

- Facility Name: Century Middle School

- Owner: Adams Twelve Five Star School District

- Location: Thornton, Colorado

- Gross Floor Area: 75,000 ft²

- Energy Use Intensity: 128.7 kBtu/ft²

\section{Project Description}

Soon after the Century Middle School of Adams Twelve Five Star School District in Thornton, Colorado, opened, school district personnel decided to retrocommission the building because it had the highest energy utilization index $\left(\$ / \mathrm{ft}^{2} / \mathrm{yr}\right)$ in the district and generated numerous and consistent occupant complaints. The poor comfort conditions and high energy use were due to poor control of the mechanical systems and broken mechanical devices.
"...it is clear that the comfort of the school has been greatly improved, and the students' learning environment has improved as a result of this project."
-Architectural Energy Corporation
Century Middle School
Retro-Commissioning Report

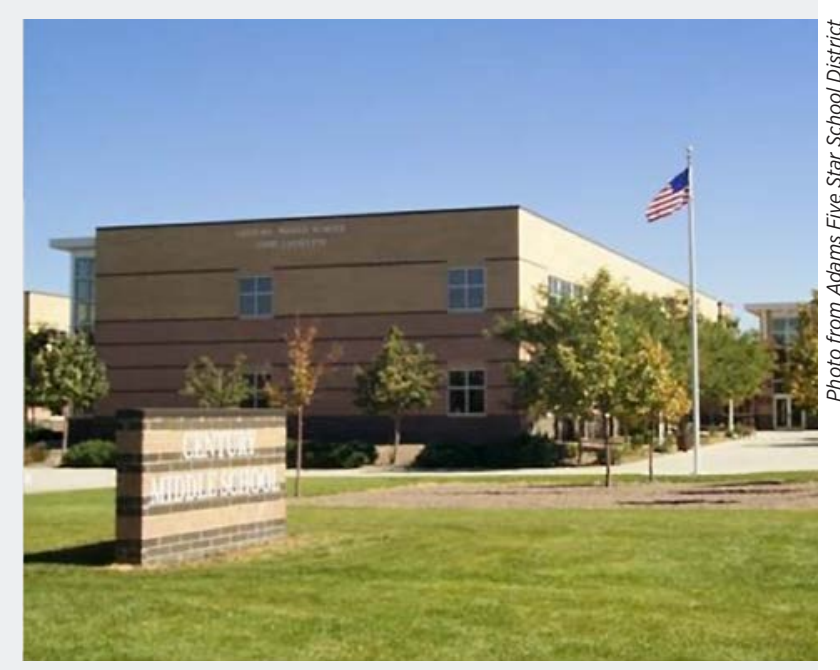

The RCx study targeted large systems, including air handling units (AHUs), the boiler and chiller plants, and the building automation system. As a result of the measures implemented, comfort complaints were significantly reduced; also in a six-month period, natural gas consumption decreased by $46 \%$ and electricity consumption decreased by $22 \%$.

Further information: www.cacx.org/database/data/ AEC_century.pdf

\section{Key EEMs}

1. An outside contractor, Architectural Energy Corporation, performed TAB analysis on the AHUs. Six AHU hot water valves were found to be fully open during unoccupied hours, resulting in a large, unnecessary heating load on the boilers.

2. AHU schedules were reset and optimized after it was found that they were running four hours/day longer than necessary.

3. Temperature set points and deadband of the OA economizer were optimized-the chiller had been running when airside free cooling should have been used.
4. The AHUs did not have a proper reset control strategy and were set to a constant $55^{\circ} \mathrm{F}$ discharge air temperature all year, resulting in increased cooling and reheating loads. The discharge air temperature set point now resets based on OAT, with a small variation from the average zone temperature.

5. Numerous AHU valves and dampers were broken and all pneumatic transducers were configured incorrectly. All these items were repaired.

\begin{tabular}{|c|c|c|c|c|c|}
\hline \multicolumn{3}{|c|}{ Energy \$ Savings } & \multicolumn{2}{|c|}{ Total Costs } & $\begin{array}{c}\text { Simple Payback } \\
\text { (years) }\end{array}$ \\
\hline \multicolumn{2}{|r|}{$\$ 55,831$} & & \multicolumn{2}{|c|}{$\$ 41,875$} & 0.75 \\
\hline \multicolumn{2}{|c|}{ Energy Use } & \multicolumn{3}{|c|}{ EUI } & \% Sito \\
\hline Before & After & Before & After & ASHRAE 90.1-2004 & Energy Savings \\
\hline 16,514 MMBtu/yr & 9,654 MMBtu/yr & $220.1 \mathrm{kBtu} / \mathrm{ft}^{2}$ & $128.7 \mathrm{kBtu} / \mathrm{ft}^{2}$ & $63.7 \mathrm{kBtu} / \mathrm{ft}^{2}$ & $42 \%$ \\
\hline
\end{tabular}


Functional Performance Test, Air-Side Economizer: PECI provides this free checklist for economizers. www.peci. org/ftguide/ftg/SystemModules/AirHandlers/AHU_ReferenceGuide/CXTestProtocolLib/Documents/econtest.doc

General Commissioning Procedure for Economizers: Pacific Gas \& Electric developed these guidelines for commissioning economizers. www.peci.org/ftguide/ftg/SystemModules/AirHandlers/AHU_ReferenceGuide/CXTestProtoco/Lib/ Documents/EconomizerProcedure.doc

Assessing Economizer Performance: An application note from Pacific Gas \& Electric's Pacific Energy Center providing guidance on how to identify problem areas for economizers. $h$ ttp://handbook2.com/a/assessingeconomizer-performance-w8817

EPA, "A Retrocommissioning Guide for Building Owners," 2007: A comprehensive guide to the EBCx process. Also includes case studies, sections on lease structures and impacts to building financial metrics. Available for free download online; www.peci.org/sites/default/files/documents/epaguide.pdf

Mills (LBNL), "Building Commissioning: A Golden Opportunity for Reducing Energy Costs and Greenhouse Gas Emissions", 2009: An investigation of the cost-effectiveness of EBCx that leverages past EBCx project data. Available for free download online. $w w w . / b l . g o v$

California Commissioning Collaborative: A source for case studies, tools, and templates related to EBCx projects; www.cacx.org

BetterBricks: A source for advice and resources related to building operations; www.betterbricks.org (NEEA 2011).

PECI, A Study on Energy Savings and Measure Cost Effectiveness of Existing Building Commissioning, 2009: A cost-effectiveness analysis of EBCx on a measure by measure basis. Available for free download online; www.peci.org

PECI, Functional Testing Guide, 2006: Guidance and sample tests for HVAC systems, as well as advice on how to achieve integrated operation. Available for free download online; www.peci.org

Building Operator Certification: A nationally recognized training and certification program for building operators. The Building Operator Certification training focuses on improving an operator's ability to operate and maintain comfortable, energy-efficient facilities. More information available at www.theboc.info 


\section{Case Study 4: Mountain View Elementary School Retrocommissioning}

\section{Quick Facts}

- Facility Name: Mountain View Elementary School

- Owner: Clovis Unified School District

- Location: Fresno, California

- Gross Floor Area: 53,070 ft²

- Energy Use Intensity: $45.2 \mathrm{kBtu} / \mathrm{ft}^{2}$

\section{Project Description}

The Clovis Unified School District in Fresno, California, initiated a pilot program to reduce energy costs, and improve comfort, IAQ, and the learning environment through RCx. Energy audits identified a number of steps that could be taken to increase efficiency, and led to an $\mathrm{RCx}$ effort at eight schools in the district. One school was Mountain View Elementary.

"By better controlling our energy use with these changes, we're saving money on our energy costs-money that can be put into the classroom where it belongs."

-John Poytress

Director of Plan Operations

Clovis Unified School Distri ct

The district worked with the local utility provider through its RCx program to qualify for incentives throughout the project. The measures implemented at Mountain View

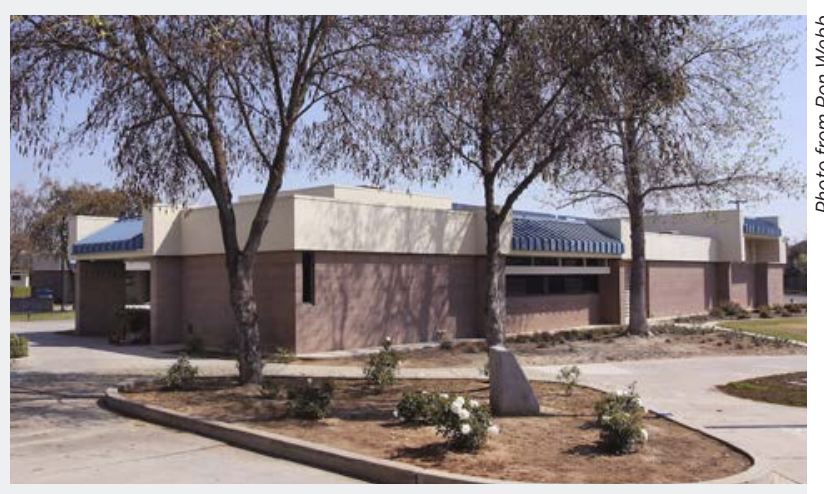

focused on upgrading the EMSs and tying them to the HVAC system to optimize scheduling.

By focusing on the two most energy-intensive systems -lighting and HVAC-Mountain View Elementary saved more than 100,000 kWh and 1,600 therms annually. Across the eight pilot schools, the RCx projects produced annual savings of almost $600,000 \mathrm{kWh}$ and 9,000 therms. The district received $\$ 105,115$ in rebates from the local utility, and with the energy cost savings, the payback was approximately 1.2 years.

Nonenergy benefits included a more comfortable environment and better operational control, which allowed most problems to be handled remotely, minimizing maintenance dispatch.

Further information: www.pge.com/includes/docs/pdfs/ mybusiness/energysavingsrebates/analyzer/retro commissioning/RCx_clovis_unified_case_study.pdf

\section{Key EEMs}

1. Installed relays on all 24 pneumatically controlled unit ventilators, tying them into the EMS and giving the EMS control of individual units for each room. Previously, these ventilators stayed on all day.
2. Installed start/stop scheduling controls on three heat pumps (4 tons each).

3. Installed start/stop scheduling controls on two package units (4 tons each).

\begin{tabular}{|c|c|c|c|c|c|c|}
\hline Energy $\$$ Sa & fings & Total Costs & \multicolumn{2}{|c|}{ Energy \$ Savings } & \multicolumn{2}{|c|}{ Simple Payback (years) } \\
\hline \multicolumn{2}{|c|}{$\$ 14,850$} & $\$ 27,410$ & \multicolumn{2}{|c|}{$\$ 6,354 / y r$} & \multicolumn{2}{|r|}{1.97} \\
\hline \multicolumn{2}{|c|}{ Energy Use } & \multicolumn{4}{|c|}{ EUI } & \multirow{2}{*}{$\begin{array}{c}\% \text { Site } \\
\text { Energy Savings }\end{array}$} \\
\hline Before & After & Before & After & ASHRA & $.1-2004$ & \\
\hline 16,514 MMBtu/yr & 9,654 MMBtu/yr & $220.1 \mathrm{kBtu} / \mathrm{ft}^{2}$ & $128.7 \mathrm{kBtu} / \mathrm{ft}^{2}$ & 63.7 & $\mathrm{u} / \mathrm{ft}^{2}$ & $42 \%$ \\
\hline
\end{tabular}




\section{Building Retrofits}

Building retrofit EEMs include equipment, system, and assembly enhancements or replacements. This section provides guidance for selecting the right package of retrofits, proven practices for implementing those EEMs in a K-12 school, and case studies that apply the EEMs in real-world situations.

\subsection{Whole-Building Approach}

A whole-building approach to energy efficiency upgrades focuses on the retrofits of multiple building systems, with a package of EEMs of varying financial benefits being installed at the same time. For example, an energy manager may complete a lighting system retrofit at the same time roof insulation and the HVAC system are improved.

The whole-building approach is well suited to energy managers who either have ambitious energy savings goals to be met in a short period of time, or have the opportunity to install comprehensive retrofit EEMs because of planned changes in a building's systems, such as those that occur when a building undergoes a major renovation. From a financial perspective, implementing multiple EEMs simultaneously has two distinct benefits:

- The overall economics of the project are often improved. Cumulative project costs can be reduced compared to the staged approach, due to efficiencies from installing multiple EEMs at once. Life cycle benefits may be simultaneously increased, as energy savings begin at a high level, rather than phasing in over time as stages are completed.

- The whole-building approach allows for optimization of equipment sizes when multiple building systems and assemblies are replaced simultaneously. For example, if lighting and HVAC systems are replaced, the HVAC system designer can take into account the reduced cooling load achieved by the lighting retrofit, resulting in a smaller cooling system. Though this can also occur in the staged approach, the whole-building approach is generally more conducive to identifying such opportunities.

The whole-building approach typically involves architects, design engineers, and potentially commissioning providers working together as part of an integrated design process, where the various design disciplines coordinate closely to design and specify systems and assemblies that will meet the project needs as well as result in minimal energy use (Energy Design Resources 2002). Retrofit systems are designed in concert, rather than as a sum of individual parts, and the final design is evaluated using life cycle economics. This process aligns well with aggressive energy savings targets.

A whole-building retrofit often involves an ESPC, in which an ESCO works with a school district to develop and implement a comprehensive retrofit package that can be financed by a third party and whose costs are repaid from energy and maintenance savings and available utility rebates. An ESPC often helps schools address critical facility modernization requirements without requiring new tax levies. This path accounts for about $\$ 2$ billion in projects annually.

\subsection{Staged Approach}

The key to the staged upgrade approach is to complete improvements to buildings systems in the order that reflects the influence of one system on another. For example, waste heat from lighting systems adds cooling loads to spaces that must be met by the cooling equipment during the summer. By first upgrading the lighting systems, future cooling system improvements can be properly sized and better optimized in a subsequent stage of the project. Under the staged 
approach, projects are usually implemented in the order shown in Figure 4-1. It may be appropriate to skip EBCX for subsystems or components that will be replaced during Step 2, if the time between the two steps is short (less than 1 year), because the energy savings will likely be small over such a short timeframe. It may also be valuable to install an EMS during Step 1 to add flexibility in the selection of future retrofit EEMs and to increase their effectiveness.

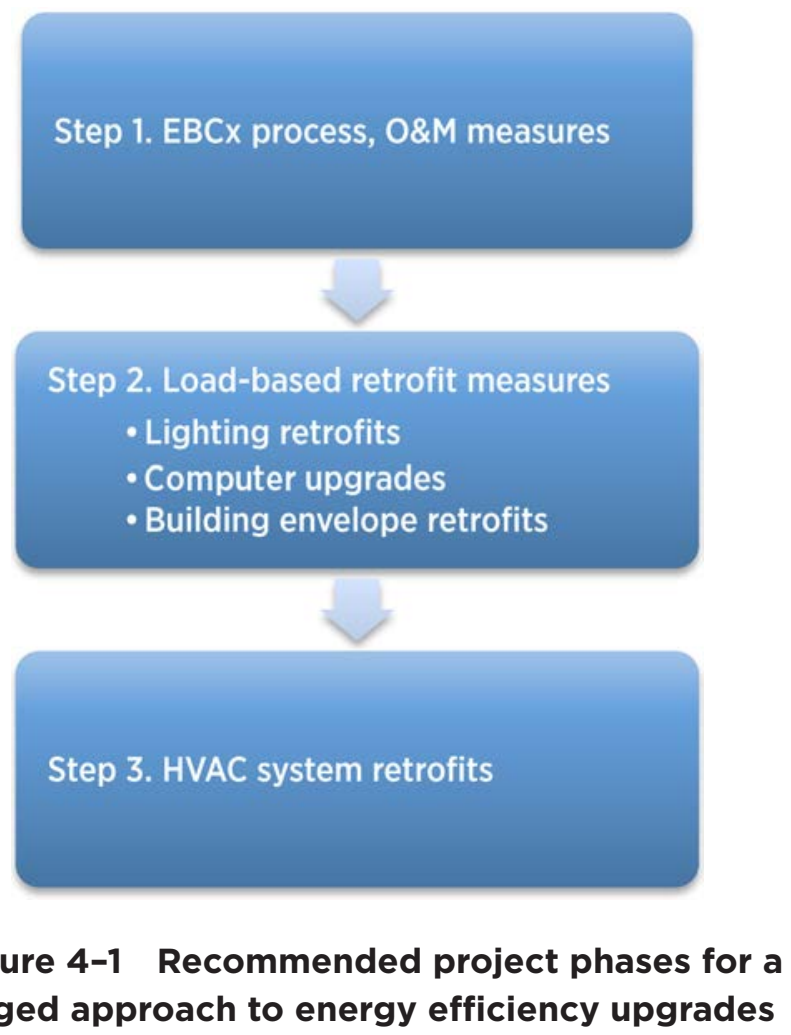

EBCx optimizes the performance of existing equipment, which provides a better baseline for determining which retrofits will be cost effective. In some cases, EBCx can improve the cost effectiveness of subsequent EEMs by showing where systems can be downsized when operated efficiently. In addition, the typically low-cost and quick returns of O\&M EEMs make them an obvious first step for energy managers who want to see immediate results with limited capital expense. The risk to completing EBCx first is that the system optimization may need to be repeated as subsequent retrofits are completed. Carefully documenting EBCx measures can reduce this effort. A more detailed discussion of EBCx is presented in Section 3.

After EBCx, EEMs that affect heating and cooling loads should be considered. A variety of EEMs fall into this category. Some directly reduce energy consumption with cooling savings as an indirect benefit, such as replacement of inefficient lighting. Others, such as sealing compressor room leaks, solely reduce energy through indirect means. What they have in common is that they all have an impact on the building's heating and cooling demands. The more efficient lights will emit less wasted energy into the building as heat; they therefore reduce the building's cooling needs and may increase its heating needs. The envelope improvements may reduce solar heat gain and thereby lower cooling needs. By first completing retrofits to these systems, the next stage of retrofits can be optimized for the new heating and cooling demands.

In typical retrofit projects, it may be standard practice to progress from the EEMs affecting heating and cooling loads to a one-to-one replacement of components in the heating and cooling system. A 10-ton rooftop unit (RTU) is replaced with a more efficient 10-ton RTU. In this common approach, efficiency is no doubt improved, but a big cost-saving opportunity is missed. A carefully planned approach will look deeper to identify where the heating and 
cooling system can be resized to meet the demand of the optimized building. An engineering analysis may show that the 10-ton RTU could be replaced with an efficient 71/2-ton RTU. Not only does the smaller RTU cost less, but it also performs better because it is a better match to the optimized building's load.

Energy managers must tailor their plans to match the needs of the school, so the staged approach presented here may not always fit. Departing from the stages shown here may be necessary at times, to deal for example with financial constraints or school operations. It is a good idea for energy managers to at least investigate the potential for implementing retrofit EEMs that will impact heating and cooling loads before embarking on a large-scale HVAC system retrofit. That way, the tradeoffs can be clearly examined.

The primary benefit of the staged approach is that the upfront project costs can be spread over a longer period. Retrofits with quick paybacks are typically completed first, and it may be possible to use the savings from these early projects to justify the costs of subsequent stages. For this reason, the staged approach may be ideal for organizations that cannot justify one large upfront cost for a whole-building retrofit project.

\subsection{Leveraging Opportunities for Higher Savings}

Several key leverage points during a building's life cycle offer opportunities to achieve much higher energy savings, regardless of whether a whole-building or a staged approach is being applied. Table 4-1 lists some of these key opportunities that can fundamentally change the economics for a retrofit project, helping to meet more aggressive energy savings targets of $50 \%$ and beyond. Some of the opportunities apply only to private schools.

Table 4-1 Special Opportunities for Achieving Higher Energy Savings

\begin{tabular}{|c|c|}
\hline Point in Building Life Cycle & Opportunity \\
\hline $\begin{array}{l}\text { Redevelopment or market } \\
\text { repositioning }\end{array}$ & $\begin{array}{l}\text { Redevelopment or market repositioning will require (perhaps over several years) } \\
\text { significant capital expense to which the cost of a retrofit would be incremental and } \\
\text { likely small in comparison. }\end{array}$ \\
\hline $\begin{array}{l}\text { Roof, window, or siding } \\
\text { replacement }\end{array}$ & $\begin{array}{l}\text { Planned roof, window, and siding replacements provide opportunities for significant } \\
\text { improvements in daylighting and efficiency at small incremental cost, providing the } \\
\text { leverage for envelope improvements that reduce loads and therefore the cost of } \\
\text { replacing major equipment such as HVAC systems and lighting. }\end{array}$ \\
\hline $\begin{array}{l}\text { End (or near end) of life } \\
\text { HVAC, lighting or other major } \\
\text { equipment replacement }\end{array}$ & $\begin{array}{l}\text { Major equipment replacements provide opportunities to address the envelope and } \\
\text { other building systems as part of a comprehensive retrofit package. After reducing } \\
\text { thermal and electrical loads, the marginal cost of replacing the major equipment with } \\
\text { much smaller equipment (or no equipment at all) can be negative. }\end{array}$ \\
\hline Upgrades to meet code & $\begin{array}{l}\text { Life safety upgrades may require substantial disruption and cost, enough that } \\
\text { the incremental investment and effort to radically improve the building efficiency } \\
\text { become both feasible and profitable. }\end{array}$ \\
\hline New owner or refinancing & $\begin{array}{l}\text { New ownership or refinancing can put in place attractively financed building upgrades } \\
\text { as part of the transaction, which may not have been possible at other times. }\end{array}$ \\
\hline Major occupancy change & $\begin{array}{l}\text { A company or tenant moving a significant number of people or products into a } \\
\text { building, or a major turnover in square footage, presents a prime opportunity for a } \\
\text { comprehensive retrofit, because (1) a comprehensive retrofit can generate layouts } \\
\text { that improve energy and space efficiency, and can create more leasable space } \\
\text { through downsizing mechanical equipment; and (2), ownership can leverage tenant } \\
\text { investment in the fit-out. }\end{array}$ \\
\hline Building greening & $\begin{array}{l}\text { An owner- or tenant-driven desire to achieve green building or energy certification } \\
\text { may require significant work on the building and its systems, which may then make a } \\
\text { more aggressive retrofit economical. }\end{array}$ \\
\hline
\end{tabular}


Table 4-1 Special Opportunities for Achieving Higher Energy Savings (cont'd)

Point in Building Life Cycle

Large utility incentives

Fixing an "energy hog"

Portfolio planning

\section{Opportunity}

Many utilities will subsidize the cost for a retrofit project, covering initial evaluations through construction. In some regions, the incentives might be large enough to make more retrofit EEMs economical.

There are buildings, often unnoticed, with such high energy use or high energy prices (perhaps after a major rate increase), that comprehensive retrofits have good economics without leveraging any of the factors above.

As part of an ongoing energy management plan for a portfolio of buildings, an owner may desire a set of EEMs to be replicated across the portfolio. These can be developed from a comprehensive retrofit of a typical building.

In addition to identifying solutions that create educational value, the whole-building retrofit process reveals ways to piggyback EEMs onto planned building equipment or component replacements, thereby reducing the cost and inconvenience of standalone EEMs. For example, the high capital cost of adding insulation to a school roof often creates negative NPV, but if the roof must be replaced anyway, the cost of adding insulation is much less. Case Study \#5 shows how a middle school in California leveraged a planned expansion to greatly increase the efficiency of the entire school.

A well-planned whole-building retrofit project can identify several piggybacking opportunities that are less straightforward than the preceding example. For example, if a school's roof needs replacement in five years but the boiler is slated for replacement now, it probably makes the most economic sense to move that roof replacement up and add insulation to reduce the heating load and the size and cost of the boiler. The boiler will last 25 years, so this move would capture a rare opportunity to downsize. Only the deliberate and rigorous process of a whole-building retrofit can identify these opportunities that make efficiency more cost effective and valuable.

A retrofit project can also be used as a tool for identifying EEMs that are tailored to the entire school district. Key elements to such an approach are grouping similar buildings together and conducting a pilot whole-building retrofit of the typical buildings. The more similar the typical buildings are to the group of buildings they represent, the more informative the findings will be and the less analysis will be needed later.

To create groups of similar school buildings, you should sort all the buildings in the district by factors such as:

- Age and condition of building systems and components

- Building size and shape

- HVAC system and envelope type

- Building functions.

One typical school building from the group of similar buildings should then be selected for the pilot renovation. This retrofit will address the following questions for all the buildings it represents:

\section{Which groups of integrated EEMs were particularly cost effective?}

The pilot retrofit team will identify the specifications, capital costs, and returns on investment for one or more groups of integrated EEMs. This information will be critical for planning a larger long-term investment across the rest of the schools. Case Study \#6 shows how a California school district conducted a successful pilot project before initiating a large-scale retrofit effort at 10 schools.

\section{Which groups of integrated EEMs will require further design work to be replicated?}

A subset of the total identified EEMs may require tailoring to specific schools. It will be important to indicate in the overall plan which EEMs will require this extra design work. For instance, an EEM that links the heating controls 
Case Study 5: Georgina Blach Intermediate School

\section{Quick Facts}

- Facility name: Georgina Blach Intermediate School

- Facility type: Middle School

- Owner: Los Altos School District

- Location/climate zone: San Francisco Peninsula/Marine

- Year finished: 2002

- Gross floor area: $61,500 \mathrm{ft}^{2}$

\section{Project Description:}

A pilot project for CHPS, the Georgina Blach School project in Los Altos, California, consists of an expansion of $27,500 \mathrm{ft}^{2}$ and renovation of the $34,000 \mathrm{ft}^{2}$ facility. Los Altos School District and Gelfand Partners leveraged the planned expansion to create an energy-efficient facility that would provide a more nurturing environment for the students and cost savings for the district. CHPS and PG\&E, through their Savings By Design Program, provided funding and consultation on the new design features.

"There is no better example of a win-win... high achieving students, learning and working in a high performing, energy efficient environment. It will be a model for hundreds of schools in California."

- Margo Harrigan, President

Board of Trustees, Los Altos School District

By emphasizing integrated design features, such as north-facing clerestories in classrooms to allow indirect

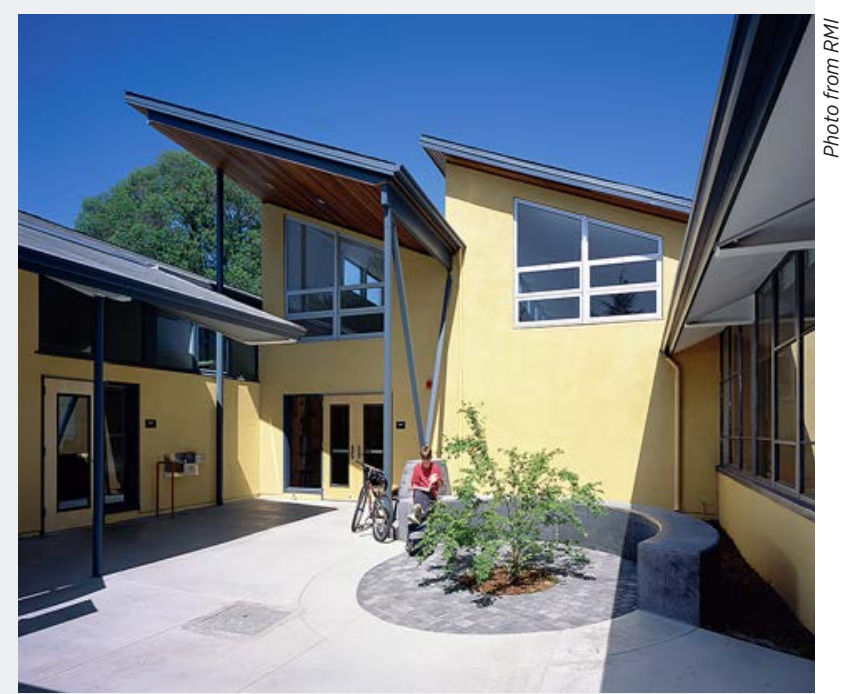

daylighting combined with intelligent light dimming technology to provide only as much electric light as is necessary, and doors and windows that, when opened, communicate to the HVAC fans to turn off to save energy, while providing natural ventilation to allow for a stronger connection with the outdoors and a richer learning environment, the school was able to drastically reduce their energy requirements, outperforming California's Title 24 requirements by as much as $38 \%$. The school saw a net decrease in energy requirements after nearly doubling the square footage of the facility.

Through integrated design, higher energy performance required no net increase in budget. The school saves $\$ 23,000 /$ year over a similar school built at the same time and renovated at the same time but without highperformance EEMs. The energy performance of Georgina Blach has remained consistent for almost 10 years.

\section{Key EEMs}

1. Daylighting strategies (clerestories at classrooms, daylighting dimming controls)

2. Efficient lighting design (reduced footcandles, direct/ indirect lighting fixtures, occupancy sensors)
3. Efficient ventilation solutions (low-energy fans, natural ventilation, door contacts connected to local HVAC system that turn fans off when doors are opened to allow for natural ventilation)

\begin{tabular}{|c|c|c|c|c|}
\hline \multicolumn{3}{|c|}{ Energy \$ Savings } & \multicolumn{2}{|c|}{ \% Site Energy Savings } \\
\hline \multicolumn{2}{|c|}{$\$ 23,000 /$ year } & & \multicolumn{2}{|c|}{$40.5 \%$} \\
\hline \multicolumn{2}{|c|}{ Energy Use } & \multicolumn{3}{|c|}{ EUI } \\
\hline Before & After & Before & After & ASHRAE 90.1-2004 \\
\hline 16,514 MMBtu/yr & 9,654 MMBtu/yr & $220.1 \mathrm{kBtu} / \mathrm{ft}^{2}$ & $128.7 \mathrm{kBtu} / \mathrm{ft}^{2}$ & $63.7 \mathrm{kBtu} / \mathrm{ft}^{2}$ \\
\hline
\end{tabular}




\section{Case Study 6: Orange County Unified School District}

\section{Quick Facts}

- Facility name: Orange County Unified School District (3 phases of work)

- Location: Orange, California

- Number of buildings: $100+$ school buildings

- Gross floor area: 1,023,915 ft²

\section{Project Description}

The Orange County Unified School District (the District) serves more than 31,300 students and includes 29 elementary schools, five middle schools, four high schools, a continuation high school, a K-8 math and science magnet school, and two special schools.

In 2003, the District selected Chevron Energy Solutions to perform an energy audit on a middle school and install $\$ 1.74$ million in improvements to the school's mechanical and electrical systems as Phase I of the project. Following the successful completion of work on Phase I the District awarded Chevron Energy Solutions two additional phases to perform work at nine sites. Phases II and III audits identified approximately $\$ 21.2$ million in retrofit and modernization opportunities at five high schools, three intermediate schools, and two elementary schools.

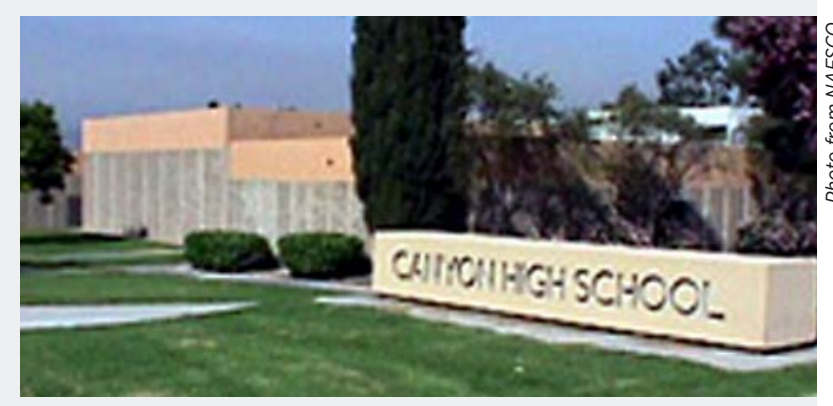

As a result of the energy efficiency upgrades, the District is expected to save more than $\$ 684,511$ in annual cost savings. Chevron Energy Solutions worked closely with the District throughout the three phases of the project, ensuring favorable results for both parties. Coordinated planning and scheduling resulted in a project that was completed on schedule, with no change orders and with the least disruption to campus activities.

\section{Nonenergy Benefits}

1. Cleaner, safer, more comfortable learning environments

2. Improved staff efficiency

3. Equipment standardization and lower maintenance and replacement costs.

4. Project fully funded with minimal budget impact

\section{Key EEMs}

1. Interior and exterior lighting retrofits

2. Comprehensive HVAC upgrades

3. EMS

4. Controls/motion sensors
5. New/replacement motors
6. Variable-speed drives (VSDs)
7. Evaporative coolers
8. Economizers

\begin{tabular}{|c|c|c|c|c|}
\hline Energy \$ Savings & \multicolumn{2}{|c|}{ Total Savings } & $\begin{array}{c}\text { Simple Payback } \\
\text { (Excluding Incentives) }\end{array}$ & Actual Project Costs \\
\hline$\$ 684,511 /$ year & \multicolumn{2}{|c|}{$\$ 684,511 /$ year } & 16.9 years (17.2 years) & $\$ 22,741,596$ \\
\hline Equipment Costs & Installation Costs & M\&V Costs & Financial Incentives & $\begin{array}{c}\text { Total Costs } \\
\text { Without Incentives }\end{array}$ \\
\hline$\$ 14,057,198$ & $\$ 8,852,407$ & $\$ 22,500$ & $\$ 190,509$ & $\$ 22,932,105$ \\
\hline
\end{tabular}


to the lighting occupancy sensors may not require electrical design work, because the wiring is similar across all the schools. On the other hand, replicating an EEM to install skylights may require some lighting design work to ensure correct placement for optimal light distribution.

\section{Which implementation team members were particularly creative or integrative?}

The retrofit project can also be a proving ground for the team charged with reducing energy across all schools in the district. The team should include talented people who are not afraid to be unconventional and who want to go beyond incremental energy savings.

\section{What institutional policies would help or hinder implementation of the EEMs?}

In many cases, decision makers for a school district may not realize that their policies can hinder or encourage efficiency. A thorough examination of a single school can reveal institutional impediments and enablers.

\subsection{Retrofit Energy Efficiency Measure Summary Table}

The EEMs in Table 4-2 were identified as the best retrofit options for K-12 schools, and are described in detail in Appendix F. These EEMs were carefully selected based on input from experts in energy retrofits for K-12 schools. Handbooks, manuals, technical papers, and other external resources were consulted extensively, along with available case studies describing successful retrofit projects in K-12 schools. Additional EEMs may be appropriate for specific projects; many of these ideas are also presented for consideration at the end of Appendix F.

\section{Table 4-2 Retrofit EEM Summary Table}

\begin{tabular}{|c|c|c|c|c|c|c|c|c|}
\hline \multirow[b]{2}{*}{ System } & \multirow[b]{2}{*}{ EEM Description } & \multicolumn{5}{|c|}{ Applicable to: } & \multirow[b]{2}{*}{$\begin{array}{l}\text { Stage } \\
\text { (see } \\
\text { Section } \\
4.2 \text { ) }\end{array}$} & \multirow[b]{2}{*}{ Section } \\
\hline & & 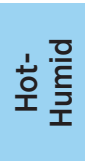 & $\begin{array}{l}\text { 추 } \\
\stackrel{0}{0} \\
\text { 오 }\end{array}$ & $\stackrel{\substack{c \\
\frac{\pi}{2}}}{\sum}$ & 흥 & 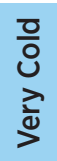 & & \\
\hline \multirow{7}{*}{ Lighting } & $\begin{array}{l}\text { Replace incandescent lamps in exit signs } \\
\text { with LEDs }\end{array}$ & $\checkmark$ & $\checkmark$ & $\checkmark$ & $\checkmark$ & $\checkmark$ & 2 & F.1.1 \\
\hline & $\begin{array}{l}\text { Replace T12 fluorescent lamps and magnetic } \\
\text { ballasts with high- efficiency T8 lamps and } \\
\text { instant-start electronic ballasts }\end{array}$ & $\checkmark$ & $\checkmark$ & $\checkmark$ & $\checkmark$ & $\checkmark$ & 2 & F.1.2 \\
\hline & $\begin{array}{l}\text { Replace incandescent lamps with compact } \\
\text { fluorescent lamps (CFLs) }\end{array}$ & $\checkmark$ & $\checkmark$ & $\checkmark$ & $\checkmark$ & $\checkmark$ & 2 & F.1.3 \\
\hline & $\begin{array}{l}\text { Install wireless motion sensors for lighting in } \\
\text { rooms that are used intermittently }\end{array}$ & $\checkmark$ & $\checkmark$ & $\checkmark$ & $\checkmark$ & $\checkmark$ & 2 & F.1.4 \\
\hline & $\begin{array}{l}\text { Install photosensors and dimming ballasts } \\
\text { to dim lights when daylighting is sufficient }\end{array}$ & $\checkmark$ & $\checkmark$ & $\checkmark$ & $\checkmark$ & $\checkmark$ & 2 & F.1.5 \\
\hline & $\begin{array}{l}\text { Replace high intensity discharge (HID) lights } \\
\text { with T5 high- output (HO) fluorescents in } \\
\text { gymnasiums }\end{array}$ & $\checkmark$ & $\checkmark$ & $\checkmark$ & $\checkmark$ & $\checkmark$ & 2 & F.1.6 \\
\hline & $\begin{array}{l}\text { Install more efficient exterior lighting for } \\
\text { façades and parking lot }\end{array}$ & $\checkmark$ & $\checkmark$ & $\checkmark$ & $\checkmark$ & $\checkmark$ & 2 & F.1.7 \\
\hline \multirow{2}{*}{$\begin{array}{l}\text { Plug and } \\
\text { process loads }\end{array}$} & $\begin{array}{l}\text { Replace cafeteria appliances with ENERGY } \\
\text { STAR models }\end{array}$ & $\checkmark$ & $\checkmark$ & $\checkmark$ & $\checkmark$ & $\checkmark$ & 2 & F.2.1 \\
\hline & $\begin{array}{l}\text { Install VSD demand control for kitchen hood } \\
\text { exhaust fans }\end{array}$ & $\checkmark$ & $\checkmark$ & $\checkmark$ & $\checkmark$ & $\checkmark$ & 2 & F.2.2 \\
\hline
\end{tabular}


Table 4-2 Retrofit EEM Summary Table (cont'd)

\begin{tabular}{|c|c|c|c|c|c|c|c|c|}
\hline \multirow[b]{2}{*}{ System } & \multirow[b]{2}{*}{ EEM Description } & \multicolumn{5}{|c|}{ Applicable to: } & \multirow[b]{2}{*}{$\begin{array}{l}\text { Stage } \\
\text { (see } \\
\text { Section } \\
\text { 4.2) }\end{array}$} & \multirow[b]{2}{*}{ Section } \\
\hline & & 호를 을 & $\begin{array}{l}\text { 호 } \\
\text { 후 } \\
\text { 오 }\end{array}$ & 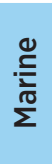 & 흥 & $\begin{array}{l}\frac{0}{0} \\
\frac{\pi}{0} \\
\end{array}$ & & \\
\hline Envelope & Add reflective roof covering & $\checkmark$ & $\checkmark$ & & $\checkmark$ & & 2 & F.3.1 \\
\hline $\begin{array}{l}\text { Service water } \\
\text { heating }\end{array}$ & $\begin{array}{l}\text { Install low-flow showerheads in locker } \\
\text { rooms }\end{array}$ & $\checkmark$ & $\checkmark$ & $\checkmark$ & $\checkmark$ & $\checkmark$ & 2 & F.4.1 \\
\hline \multirow{8}{*}{$\begin{array}{l}\text { HVAC Heating } \\
\text { and cooling }\end{array}$} & $\begin{array}{l}\text { Add evaporative precooling of condenser } \\
\text { supply air }\end{array}$ & & $\checkmark$ & & & & 3 & F.5.1 \\
\hline & $\begin{array}{l}\text { Add a small condensing boiler to handle the } \\
\text { base load and summer load, with current } \\
\text { inefficient boiler operating when heating } \\
\text { loads are highest }\end{array}$ & $\checkmark$ & $\checkmark$ & $\checkmark$ & $\checkmark$ & $\checkmark$ & 3 & F.5.2 \\
\hline & $\begin{array}{l}\text { Install VSDs on chilled-water and hot water } \\
\text { pumps }\end{array}$ & $\checkmark$ & $\checkmark$ & $\checkmark$ & $\checkmark$ & $\checkmark$ & 3 & F.5.3 \\
\hline & $\begin{array}{l}\text { Replace standard furnace with a high- } \\
\text { efficiency condensing furnace }\end{array}$ & $\checkmark$ & $\checkmark$ & $\checkmark$ & $\checkmark$ & $\checkmark$ & 3 & F.5.4 \\
\hline & $\begin{array}{l}\text { Install an EMS and replace pneumatic } \\
\text { controls with direct digital controls (DDCs) }\end{array}$ & $\checkmark$ & $\checkmark$ & $\checkmark$ & $\checkmark$ & $\checkmark$ & 3 & F.5.5 \\
\hline & $\begin{array}{l}\text { Replace oversized, inefficient fans and } \\
\text { motors with rightsized National Electric } \\
\text { Manufacturers Association (NEMA) premium } \\
\text { efficiency models }\end{array}$ & $\checkmark$ & $\checkmark$ & $\checkmark$ & $\checkmark$ & $\checkmark$ & 3 & F.5.6 \\
\hline & $\begin{array}{l}\text { Convert CV or dual-duct air handling system } \\
\text { to variable air volume (VAV) (add dampers, } \\
\text { VSD fan motors) }\end{array}$ & $\checkmark$ & $\checkmark$ & $\checkmark$ & $\checkmark$ & $\checkmark$ & 3 & F.5.7 \\
\hline & Install VSDs on cooling tower fans & $\checkmark$ & $\checkmark$ & $\checkmark$ & $\checkmark$ & $\checkmark$ & 3 & F.5.8 \\
\hline \multirow{3}{*}{$\begin{array}{l}\text { HVAC } \\
\text { Ventilation }\end{array}$} & Install a dry-bulb airside economizer & $\checkmark$ & $\checkmark$ & $\checkmark$ & $\checkmark$ & $\checkmark$ & 2 & F.6.1 \\
\hline & $\begin{array}{l}\text { Upgrade to DCV to reduce OA flow during } \\
\text { partial occupancy }\end{array}$ & $\checkmark$ & $\checkmark$ & $\checkmark$ & $\checkmark$ & $\checkmark$ & 2 & F.6.2 \\
\hline & $\begin{array}{l}\text { Add heat/energy recovery to the ventilation } \\
\text { system }\end{array}$ & $\checkmark$ & $\checkmark$ & $\checkmark$ & $\checkmark$ & $\checkmark$ & 2 & F.6.3 \\
\hline
\end{tabular}

LBNL and the National Association of Energy Service Companies partnered to develop a very large database of ESCO projects around the country. This database allows us to identify the most common retrofit EEMs implemented by ESCOs in K-12 schools. Assuming ESCOs generally choose the optimal EEM combination, with simple payback well within the contract period, this database provides useful information about the likelihood that specific EEMs will be cost effective in a typical school. Figure 4-2 shows the estimated frequency at which most of the EEMs listed above are included in ESCO projects in K-12 schools. 


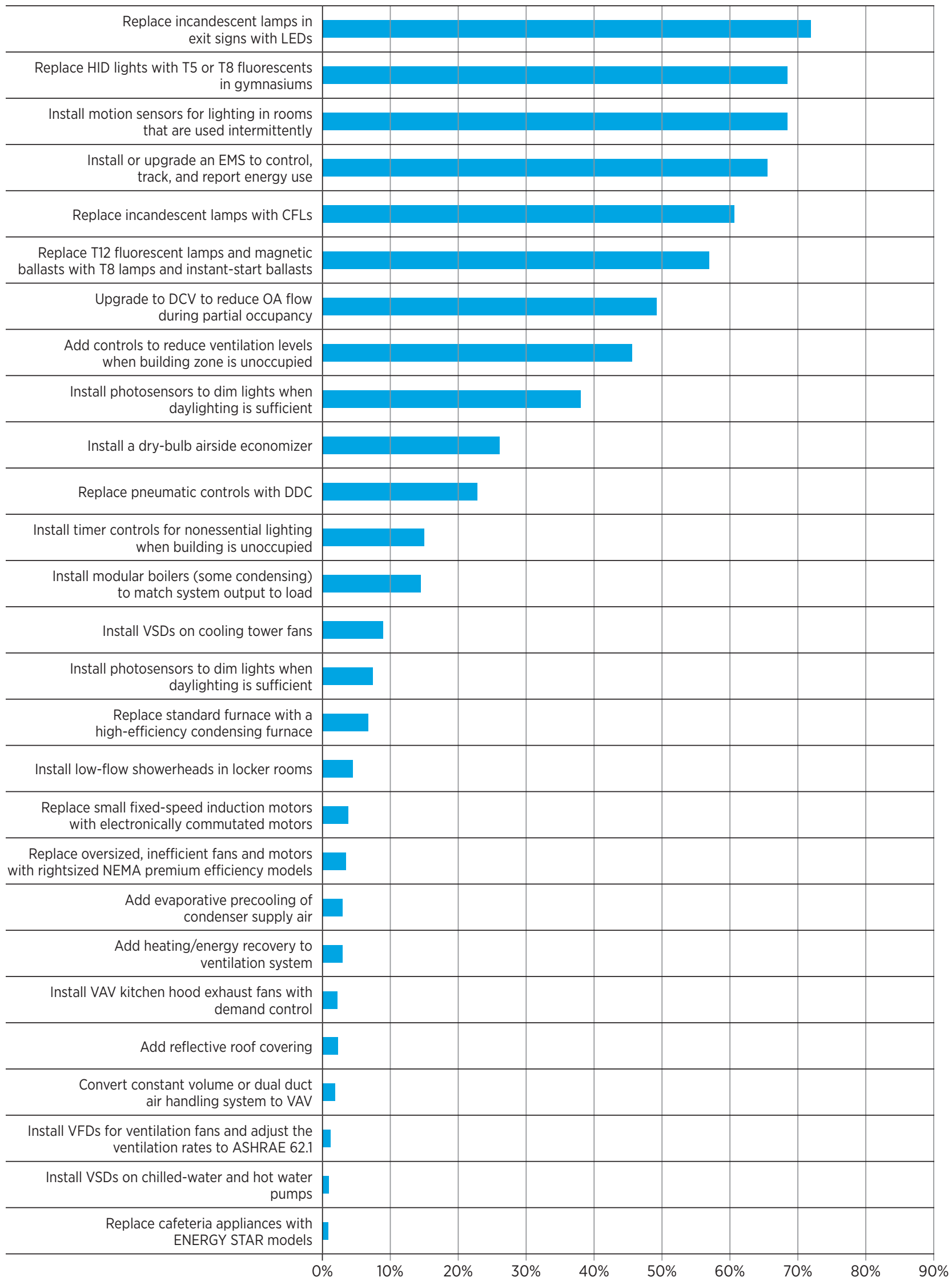

Figure 4-2 Retrofit EEM frequency in ESCO projects 


\subsection{Recommended Retrofit Packages}

The following sections identify cost-effective (positive NPV) retrofit packages for the example high school building in each of five geographic locations. All EEMs were selected from those listed in Table 4-2 and are discussed in detail in Appendix F. The analysis was performed in the context of a whole-building retrofit, with all EEMs implemented in the first year. These packages are not necessarily optimal, but are representative of the type of package that can be very cost effective in a typical school even before financial incentives are considered. Energy savings are based on analytical projections, and actual savings can be less if high-quality workmanship is not enforced. The process for selecting the EEMs for inclusion in each package is described in Appendix B.

\section{At-A-Glance Results}

Table 4-3 summarizes the results of the energy and financial analysis of the recommended packages of retrofit EEMs.

Table 4-3 Recommended Retrofit Packages-Results of Common Metrics*

\begin{tabular}{|l|c|c|c|c|c|c|}
\hline & \multicolumn{3}{|c|}{ EUI (kBtu/ft2) } & \multicolumn{3}{c|}{ Energy Cost/ft2 } \\
\hline \multicolumn{1}{|c|}{ Location } & Baseline & $\begin{array}{c}\text { Post- } \\
\text { Retrofit }\end{array}$ & $\begin{array}{c}\text { Percent } \\
\text { Reduction }\end{array}$ & Baseline & $\begin{array}{c}\text { Post- } \\
\text { Retrofit }\end{array}$ \\
\hline Reduction \\
\hline Miami (Hot \& Humid) & 84 & 65 & $22.2 \%$ & $\$ 2.28$ & $\$ 1.79$ & $21.3 \%$ \\
\hline Las Vegas (Hot \& Dry) & 86 & 62 & $27.7 \%$ & $\$ 2.19$ & $\$ 1.56$ & $28.7 \%$ \\
\hline Seattle (Marine) & 82 & 56 & $31.7 \%$ & $\$ 3.18$ & $\$ 2.41$ & $24.1 \%$ \\
\hline Chicago (Cold) & 103 & 70 & $31.5 \%$ & $\$ 5.72$ & $\$ 4.37$ & $23.6 \%$ \\
\hline Duluth (Very Cold) & 124 & 84 & $32.4 \%$ & $\$ 2.08$ & $\$ 1.55$ & $25.3 \%$ \\
\hline Average & 96 & 67 & $29.1 \%$ & $\$ 3.09$ & $\$ 2.34$ & $24.6 \%$ \\
\hline
\end{tabular}

${ }^{*}$ Energy savings for retrofit packages do not include the effects of EBCX.

The retrofit EEMs included in the recommended packages are shown in Table 4-4.

Table 4-4 EEMs Included in the Recommended Retrofit Packages

\begin{tabular}{|c|c|c|c|}
\hline System & EEM Description & Climate Zone & Section \\
\hline \multirow{6}{*}{ Lighting } & Replace incandescent lamps in exit signs with LEDs & All & F.1.1 \\
\hline & $\begin{array}{l}\text { Replace T12 fluorescent lamps and magnetic ballasts with high- } \\
\text { efficiency T8 lamps and instant-start electronic ballasts }\end{array}$ & All & F.1.2 \\
\hline & Replace incandescent lamps with CFLs & All & F.1.3 \\
\hline & $\begin{array}{l}\text { Install wireless motion sensors for lighting in rooms that are used } \\
\text { intermittently }\end{array}$ & All & F.1.4 \\
\hline & Replace HID lights with T5 HO fluorescents in gymnasiums & All & F.1.6 \\
\hline & Install more efficient exterior lighting for façades and parking lot & All & F.1.7 \\
\hline $\begin{array}{l}\text { Plug and } \\
\text { process loads }\end{array}$ & Replace kitchen appliances with ENERGY STAR models & $\begin{array}{l}\text { All, except } \\
\text { Very Cold }\end{array}$ & F.2.1 \\
\hline $\begin{array}{l}\text { Service water } \\
\text { heating }\end{array}$ & Install low-flow showerheads in locker rooms & All & F.4.1 \\
\hline
\end{tabular}


Table 4-4 EEMs Included in the Recommended Retrofit Packages (cont'd)

\begin{tabular}{|l|l|c|c|}
\hline \multirow{2}{*}{ System } & \multicolumn{1}{|c|}{ EEM Description } & Climate Zone & Section \\
\hline & Add evaporative precooling of condenser supply air & Hot-Dry & F.5.1 \\
\hline \multirow{2}{*}{ HVAC } & Install VSDs on chilled-water and hot water pumps & All & F.5.3 \\
\hline & $\begin{array}{l}\text { Replace oversized, inefficient fans and motors with rightsized } \\
\text { NEMA premium efficiency models }\end{array}$ & Cold & F.5.6 \\
\hline & Upgrade to DCV to reduce OA flow during partial occupancy & All & F.6.2 \\
\hline
\end{tabular}

\section{Rationale for Recommended Energy Efficiency Measures}

The EEMs were chosen for inclusion in each retrofit package based on their high energy savings potential, cost effectiveness, and relatively simple implementation in the context of the example high school. These are representative of EEMs that energy managers typically implement solely to realize energy cost savings. These EEMs may be very cost effective to implement when equipment is being replaced anyway, but energy managers also often find it pays to implement these EEMs before the affected equipment has reached the end of its useful life - that way they may have more time to consider multiple options. Note that other EEMs from Table 4-2 could be included as part of a retrofit package, depending on the particular school being retrofit. Additional EEMs that may be considered are included at the end of Appendix F.

The EEMs included in each retrofit package may add functionality, replace a system component with a more efficient version, or modify a system to operate more efficiently. These typically do not require an integrated design process as part of implementation, and usually do not represent changes to system types. They can be implemented with minimal disruption to the school's normal operations. A more integrated design approach would be likely to reveal more opportunities and achieve higher savings. Further discussion of the process for selecting retrofit packages can be found in Appendix B.

\section{Energy Savings}

The recommended retrofit packages are estimated to result in savings of $22 \%-32 \%$ of site energy use, based on an analysis of each package when applied to the example high school. As shown in Table 4-5, each climate zone shows significant energy savings, with the highest savings achievable in the coldest climates based on the financial constraints imposed in the example analysis. For the energy savings and NPV of retrofit EEMs applied individually, see the detailed analytical results in Appendix C.

Table 4-5 Recommended Retrofit Package Energy Savings Results*

\begin{tabular}{|c|c|c|c|c|c|c|}
\hline Location & $\begin{array}{c}\text { Electricity } \\
\text { Savings } \\
\text { (annual } \\
\text { kWh) }\end{array}$ & $\begin{array}{l}\text { Electric } \\
\text { Demand } \\
\text { Savings } \\
\text { (peak kW) }\end{array}$ & $\begin{array}{c}\text { Gas Savings } \\
\text { (annual } \\
\text { therms) }\end{array}$ & $\begin{array}{c}\text { Site EUI } \\
\text { Savings } \\
\left(\mathrm{kBtu} / \mathrm{ft}^{2}\right)\end{array}$ & $\begin{array}{l}\text { Savings as } \\
\% \text { of Total } \\
\text { Site Usage }\end{array}$ & $\begin{array}{c}\text { Savings as } \\
\% \text { of Total } \\
\text { Source } \\
\text { Usage }\end{array}$ \\
\hline Miami (Hot \& Humid) & $1,107,191$ & 315 & 1,577 & 18.7 & $22.2 \%$ & $22.2 \%$ \\
\hline Las Vegas (Hot \& Dry) & $1,149,463$ & 680 & 10,802 & 23.7 & $27.7 \%$ & $26.1 \%$ \\
\hline Seattle (Marine) & 669,115 & 233 & 32,175 & 26.1 & $31.7 \%$ & $25.5 \%$ \\
\hline Chicago (Cold) & 764,357 & 385 & 42,134 & 32.4 & $31.5 \%$ & $25.9 \%$ \\
\hline Duluth (Very Cold) & 639,525 & 294 & 63,187 & 40.3 & $32.4 \%$ & $25.9 \%$ \\
\hline
\end{tabular}

* Energy savings for retrofit packages do not include the effects of EBCx. 


\section{Financial Analysis}

The financial metrics associated with the retrofit packages for each climate zone are shown in Table 4-6. For the financial metrics of all individual retrofit EEMs, see Appendix C. Each retrofit package has a fast, simple payback and positive NPV. We recognize that these packages are very aggressive, and it may be challenging for a school board to raise the initial capital even if the EEMs are cost effective.

Table 4-6 Retrofit Recommended Package Financial Analysis Results*

\begin{tabular}{|l|c|c|c|c|c|c|}
\hline \multicolumn{1}{|c|}{ Location } & $\begin{array}{c}\text { Total Measure } \\
\text { Costs }\end{array}$ & $\begin{array}{c}\text { Total Energy } \\
\text { Cost Savings }\end{array}$ & $\begin{array}{c}\text { O\&M Cost } \\
\text { Savings }\end{array}$ & $\begin{array}{c}\text { Total Annual } \\
\$ \text { Savings }\end{array}$ & $\begin{array}{c}\text { Simple } \\
\text { Payback } \\
\text { (Years) }\end{array}$ \\
\hline Miami (Hot \& Humid) & $\$ 829,394$ & $\$ 102,469$ & $\$ 7,047$ & $\$ 109,516$ & 7.6 & $\$ 901,098$ \\
\hline Las Vegas (Hot \& Dry) & $\$ 1,165,461$ & $\$ 132,267$ & $(\$ 13,318)$ & $\$ 118,949$ & 9.8 & $\$ 764,048$ \\
\hline Seattle (Marine) & $\$ 1,022,096$ & $\$ 161,932$ & $\$ 8,087$ & $\$ 170,019$ & 6.0 & $\$ 1,744,787$ \\
\hline Chicago (Cold) & $\$ 1,089,271$ & $\$ 285,400$ & $\$ 3,544$ & $\$ 288,944$ & 3.8 & $\$ 3,577,302$ \\
\hline Duluth (Very Cold) & $\$ 877,669$ & $\$ 111,169$ & $\$ 9,310$ & $\$ 120,479$ & 7.3 & $\$ 1,126,919$ \\
\hline
\end{tabular}

*Energy savings for retrofit packages do not include the effects of EBCX.

\subsection{Additional Considerations}

The retrofit EEMs included in the recommended packages, along with the additional EEMs discussed in Appendix F, provide a starting point for retrofit options that should be considered for most K-12 schools. However, not all EEMs will be applicable to all schools, and additional EEMs may be applicable in certain situations. Some are listed at the end of Appendix F.

Energy managers considering implementing specific retrofit EEMs should consult the detailed description of the retrofit EEMs in Appendix F to gain an understanding of the application of each EEM to schools in various climate zones.

When evaluating retrofit EEMs for application to a specific school, the following questions should be considered to help narrow the options to a manageable number:

- Are the equipment and assemblies in the school nearing the end of their useful lives? By identifying and evaluating equipment that is nearing the end of its life before it has failed, energy managers can evaluate multiple retrofit options considering all potential costs and benefits instead of just replacing the equipment with like equipment once it fails.

- Is the EEM relevant to school operations? The capabilities of the facility manager should be considered when evaluating EEMs.

- Does the staff have the necessary skills and knowledge to support the EEM? If not, is there additional training that they can receive?

- Are there load-based retrofits that can be considered and implemented before HVAC retrofits? Using a staged approach for retrofits can produce greater savings and increased performance than just replacing systems and components with like-sized equipment. Implementing load-based retrofits first, which have an impact on the heating and cooling loads, can help lower the cost of subsequent HVAC retrofits, improve the performance of HVAC systems, and reduce overall energy use. 


\section{Case Study 7: The Pingry School-The Carol \& Park B. Smith Middle School}

\section{Quick Facts}

- Facility name: The Carol \& Park B. Smith Middle School

- Owner: The Pingry School

- Location/climate zone: Bernards Township, New Jersey

- Year completed: 2007

- Gross floor area: $280,474 \mathrm{ft}^{2}$

\section{Project Description:}

When the Pingry School decided to add a 30,000- $\mathrm{ft}^{2}$ addition to its school to combine the middle and high schools, it had an opportunity for deep energy savings.

\section{"We had to force a conversation and} fundamentally change the engineering approach in order to capture the savings that we did."

- Mike Virzi, Director of Facilities

The design team's original plan was to serve the new building with standalone heating and cooling systems, which would have required a major electrical upgrade along with increased energy consumption. Director of Facilities Mike Virzi thought there could be a better solution and his colleague Mark Lyons of The Fulcrum Group recommended that the design team consider retrofitting the central HVAC system.

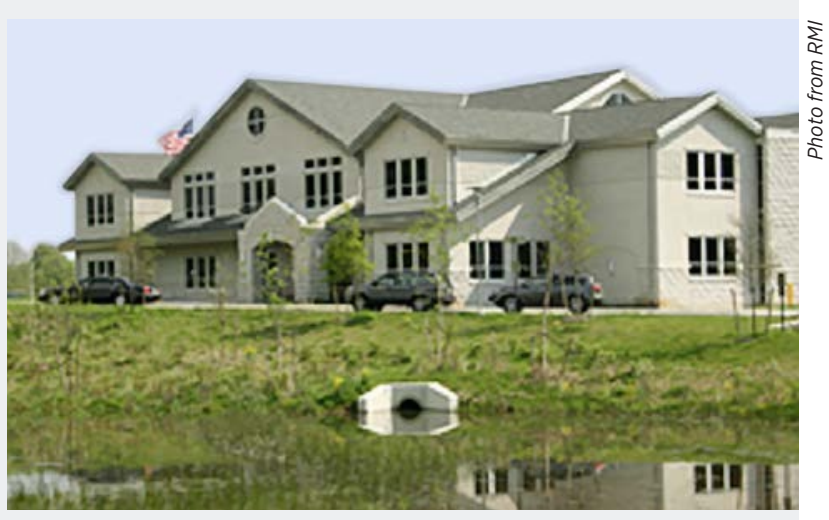

After a daylong workshop, the design team decided that retrofitting the central system was the better option. They tied a new heat recovery chiller and highefficiency condensing boilers to the old peak-load sized conventional boilers in an innovative and operationally simple manner. In this new design, the heat recovery system and small high-efficiency condensing boilers can handle the building loads for all but 10-14 weeks of the year.

Even though the campus added $30,000 \mathrm{ft}^{2}$ of conditioned floor area, the overall energy consumption was reduced by $30 \%$. When considering how much energy the school would have consumed using conventional energy systems, the savings are $40 \%$. In addition to the significant annual operating savings related to energy reductions, The Pingry School also received $\$ 200,000$ in New Jersey State Rebates-the story of which is told in the $M \& V$ case study.

\section{Key EEMs}

1. Installed two 2-MMBtu condensing hot water boilers. 3. Installed premium efficiency motors, variable frequency

2. Installed lighting controls and high-performance lighting. drives (VFDs), and VAV units in each classroom.

\begin{tabular}{|c|c|c|c|c|c|}
\hline Gross Cost & \multicolumn{2}{|c|}{ Incremental Project Cost } & \multicolumn{2}{|c|}{ Financial Incentives } & Net Incremental Cost \\
\hline$\$ 2,870,000$ & \multicolumn{2}{|c|}{$\$ 955,000$} & \multicolumn{2}{|c|}{$\$ 200,000$} & $\$ 755,000$ \\
\hline Energy \$ Savings & \multicolumn{2}{|c|}{$\begin{array}{c}\text { ROI } \\
\text { (Excluding Incentives) }\end{array}$} & \multicolumn{2}{|c|}{$\begin{array}{c}\text { Simple Payback } \\
\text { (Excluding Incentives) }\end{array}$} & \% Site Energy Savings \\
\hline$\$ 215,000 /$ year & \multicolumn{2}{|c|}{$28 \%(23 \%)$} & \multicolumn{2}{|c|}{3.5 years ( 4.4 years) } & $39 \%$ \\
\hline \multicolumn{2}{|c|}{ Energy Use } & & \multicolumn{3}{|c|}{ EUI } \\
\hline Before & After & \multicolumn{2}{|c|}{ Before } & After & ASHRAE 90.1-2004 \\
\hline 16,514 MMBtu/yr & 9,654 MMBtu/yr & \multicolumn{2}{|c|}{$220.1 \mathrm{kBtu} / \mathrm{ft}^{2}$} & $128.7 \mathrm{kBtu}$ & $63.7 \mathrm{kBtu} / \mathrm{ft}^{2}$ \\
\hline
\end{tabular}


- Have the school characteristics changed over time in a way that could impact the retrofit? When replacing equipment, it is important to evaluate whether the equipment should be replaced with like-sized equipment. As load-based retrofits occur over time in a school (e.g., envelope, lighting), the load on the HVAC and refrigeration equipment can change, which can impact the necessary size of the equipment. Also, if school operating criteria have changed over time, this can also impact the new equipment. Case Study \#7 illustrates how a facility expansion that combined a middle school and high school in New Jersey resulted in major improvements to the central heating and cooling systems.

- Do energy codes apply to the retrofit? Energy codes have minimum efficiency standards for most equipment installed in schools. Before embarking on a retrofit project, it is important to ensure that the equipment being installed as part of the retrofit meets or exceeds local energy efficiency codes.

- Are there incentives that can help increase the cost effectiveness of a particular retrofit? Many electric and gas utilities offer incentives for replacing old, inefficient equipment with new equipment that exceeds the code energy efficiency requirement. The local utility can provide information about incentive programs.

- Do school operations need to continue during the retrofit period? Retrofits often include major renovations to building systems and assemblies. Impact on the operation of the school must be considered, and this aspect can be a limiting factor in the depth that a retrofit can go. If the retrofit can be performed during the summer months when school activities are limited, the level of retrofit can be deeper than if classes are in session during the retrofit construction period.

- Will the project be commissioned? Commissioning is highly recommended for all retrofits. It provides assurance that the project was designed and constructed to meet the stated requirements. The commissioning program can start during a retrofit's design phase and proceed through construction, to help the project team match the design with the needs of the school, and to help ensure the long term maintainability of the facility. Commissioning is often most useful at the start of a project, when it can have the biggest impact.

\subsection{Additional Resources}

Use these resources for more detailed information about retrofit strategies for K-12 schools.

ENERGY STAR Building Upgrade Manual, K-12 Schools: The building upgrade manual provides technical recommendations for retrofits to existing buildings, with a specific chapter dedicated to K-12 schools. www.energystar.gov/ index.cfm?c=business.EPA_BUM_CH10_Schools

ENERGY STAR for K-12 School Districts: The ENERGY STAR program provides a strategic approach that helps in measuring current energy performance, setting goals, tracking savings, and rewarding improvements, with a focus on specific industries, including K-12 schools. www.energystar.gov/index.cfm?c=k12_schools.bus_schoolsk12

Indoor Air Quality tools for schools program: The IAQ Tools for Schools Program is a comprehensive resource to help schools maintain a healthy environment in school buildings by identifying, correcting, and preventing IAQ problems. www.epa.gov/iaq/schools/

Indoor Air Quality Tools for Schools Kit: This set of tools from the EPA provides guidance for establishing and implementing an effective indoor air quality management program. www.epa.gov/iaq/schools/index.htm/

School Advance Ventilation Engineering Software (SAVES): This tool from the EPA helps assess the payback and air quality benefits of various ventilation systems. www.epa.gov/iaq/schooldesign/saves.htm/ 
The Advanced Energy Design Guide (AEDG) for K-12 School Buildings (ASHRAE 2008) developed by DOE, ASHRAE, and other stakeholders provides best practices for achieving more than 30\% energy savings compared to ASHRAE Standard 90.1-1999. Although this guide was developed for new construction, most of the design approaches and principles are also relevant for whole-building retrofits. A new AEDG targeting 50\% energy savings in K-12 schools is currently under development by ASHRAE. www.ashrae.org/technology/page/938

Technical Support Document: Development of the Advanced Energy Design Guide for K-12 Schools-30\% Energy Savings. (Pless et al. 2007) NREL published this report for the K-12 AEDG to provide further documentation of the assumptions and analytical results that led to the recommendations in the AEDG. The TSD presents detailed analysis of three typical K-12 school buildings, including a "new construction" version of the pre-1980s example high school we used for this guide.

Buys, A.; Bendewald, M.; Tupper, K. Life Cycle Cost Analysis: Is it Worth the Effort? Boulder, CO: Rocky Mountain Institute. http://rmi.org/rmi/

Collaborative for High Performance Schools, Volume II, Design. Best Practices Manual. 2006 Edition.

Rocky Mountain Institute's RetroFit Depot. Online resource for case studies, advice, and tools and resources for deep retrofits. www.retrofitdepot.org/

Rose, W.B. Water in Buildings: an Architect's Guide to Moisture and Mold. Hoboken, NJ: John Wiley \& Sons, 2005. Print.

Torcellini, Paul, Shanti Pless, Chad Lobato, David Okada, Tom Hootman. "Main Street Net Zero Energy Buildings: The Zero Energy Method in Concept and Practice.” Proceedings of ASME 2010 4th International Conference on

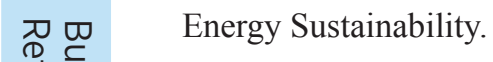




\section{Measurement and Verification}

Determining the actual savings from an energy efficiency retrofit project is often important to prove the effectiveness of a project. Savings represent the absence of energy use, so they cannot be directly measured. Although preand post-retrofit measurements are used, simple comparisons of energy use before and after a retrofit are typically insufficient to accurately estimate energy savings, because they do not account for routine fluctuations in weather and building occupancy. $\mathrm{M} \& \mathrm{~V}$ is the practice of measuring, computing, and reporting savings for energy-savings projects. Proven $M \& V$ strategies provide a means to accurately calculate the energy savings by making adjustments to account for these fluctuations, allowing the comparison of baseline and post-installation energy use under the same conditions.

$\mathrm{M} \& \mathrm{~V}$ activities include conducting site surveys, metering energy use, monitoring independent variables, executing engineering calculations, and reporting. The industry has several application guidebooks available; their foundation is the International Performance Measurement and Verification Protocol (IPMVP) (EVO 2010). It defines practices for conducting site-specific $\mathrm{M} \& \mathrm{~V}$ and outlines four general approaches or options. These establish a range of methods that can be applied as part of a site-specific measurement plan to determine verified savings. The measurement plan describes the data that will be gathered and how it will be processed to determine changes in energy use from the retrofit. As such, the measurement plan is a key document in the retrofit process and should meet the needs of all concerned. Many of the key terms discussed in the IPMVP are defined in Table 5-1. See the IPMVP sponsor's website (www.evo-world.org) for detailed definitions of M\&V concepts and copies of the IPMVP.

\section{Table 5-1 M\&V Terminology}

\section{Key IPMVP M\&V Terminology}

\begin{tabular}{l|l}
\hline EEM & $\begin{array}{l}\text { A design or operational improvement made to a facility, system, or piece of equipment that } \\
\text { reduces energy use or peak demand. }\end{array}$ \\
$\begin{array}{l}\text { Measurement } \\
\text { boundary }\end{array}$ & $\begin{array}{l}\text { A hypothetical boundary drawn around equipment and/or systems to isolate energy or mass } \\
\text { flows relevant for determining energy savings. }\end{array}$ \\
$\begin{array}{l}\text { Independent } \\
\text { variable }\end{array}$ & $\begin{array}{l}\text { A parameter that is expected to change regularly and have a measurable impact on the energy } \\
\text { use of the facility, system, or piece of equipment. }\end{array}$ \\
\hline Baseline period & $\begin{array}{l}\text { The period of time chosen to represent operation of the facility or system before implementation } \\
\text { of the energy efficiency project. }\end{array}$ \\
\hline Baseline energy & $\begin{array}{l}\text { The energy use occurring during the baseline period, and its relation to driving independent } \\
\text { variables. }\end{array}$ \\
\hline $\begin{array}{l}\text { Adjusted baseline } \\
\text { energy }\end{array}$ & $\begin{array}{l}\text { The energy use of the baseline period, adjusted using regression analysis or simulation modeling } \\
\text { to a different set of operating conditions, typically those of the post-install conditions. }\end{array}$ \\
\hline Savings & \begin{tabular}{l} 
Typically, the adjusted baseline energy costs minus the post-installation energy costs. \\
\hline
\end{tabular}
\end{tabular}

The selected M\&V approach should take into account the objectives for conducting M\&V and the value that it can provide. Some retrofit projects may have an explicit need to include a savings verification (SV) component as part of their M\&V efforts, such as those using ESPCs, pursuing LEED New Construction M\&V credits, or participating in utility incentive programs. Projects without this requirement may focus their M\&V activities on ensuring the building is performing as intended and has a high potential to achieve savings. Such projects would place less emphasis on quantifying savings. The methods used for $\mathrm{M} \& \mathrm{~V}$ are flexible and can accommodate differing objectives. 


\subsection{Planning}

An owner needs to determine early in the planning process whether $\mathrm{M} \& \mathrm{~V}$ will be part of the project. If savings are to be verified, special planning is required and may involve metering and measurement activities before any changes are implemented. The baseline energy use and costs are established through metering and utility bill analysis. Before energy savings can be determined, the baseline energy use is adjusted to represent energy costs that would occur under the same conditions as the post-retrofit costs. Savings are the difference between the adjusted baseline energy use and the post-retrofit energy use.

A key issue is the accuracy of the reported savings, which influences the scope and level of rigor of M\&V activities. Proper planning can help integrate these activities into the project and may leverage related tasks, such as commissioning. A key goal is to keep the cost of $\mathrm{M} \& \mathrm{~V}$ activities in line with the scope and needs of the project. Figure 5-1 shows a typical M\&V timeline.
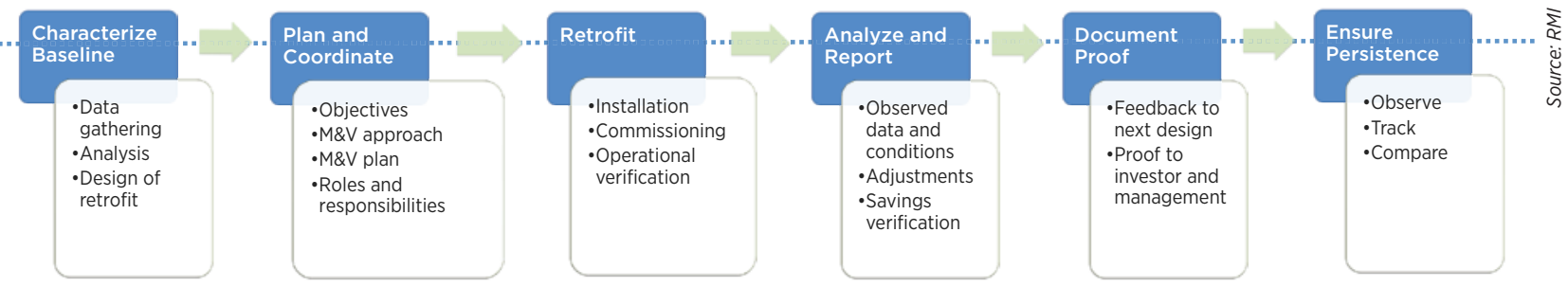

Figure 5-1 M\&V timeline

\subsection{Overview of Approaches}

There are two essential components of $\mathrm{M} \& \mathrm{~V}$ for any energy efficiency project:

- Operational verification (OV). This verifies that the EEMs are installed and operating properly. Activities include visual inspection, data trending, and functional testing. This is accomplished through comprehensive commissioning of all affected systems and supplemental data-driven activities (e.g., monitoring and tracking). Setting clear expectations for equipment or system performance is helpful for directing effective OV efforts. OV should be conducted even if SV activities are not.

- SV. This involves the calculation of energy savings resulting from the installed EEMs. Industry-accepted SV procedures are covered by the IPMVP.

$\mathrm{OV}$ and commissioning should be completed before the start of the M\&V period for which savings are determined. This ensures the full savings attributed to EEMs and control and operational improvements are captured.

The four SV options defined by the IPMVP include:

- Option A-Retrofit isolation with partial measurement. Equipment is isolated; key parameters affected, such as load and hours of operation, are spot measured before and after the retrofit.

- Option B-Retrofit isolation with full measurement. Equipment is isolated and energy use is measured across all operating conditions before and after the retrofit. This strategy is preferred over Option A when the energy use varies widely depending on operating conditions.

- Option C-Whole building. Utility data from the whole building are correlated with independent variables such as OAT, and baseline and post-retrofit energy uses are adjusted to the same set of conditions and compared to determine energy savings. 
- Option D-Calibrated simulation. Specialized software is used to model energy use before and after the retrofit and the models are adjusted so they accurately predict building energy use. The before and after models are adjusted to represent the same set of conditions and compared to determine energy savings.

These options fall into two general categories: retrofit isolation (Options A and B) and whole building (Options C and D). A fundamental difference between these approaches is where the savings boundary is drawn (see Figure 5-2). Retrofit isolation strategies focus on the individual retrofit, and ensure the energy performance of a specific piece of equipment or system. Whole-building methods are based on either utility billing analysis or a calibrated whole-building simulation. Whole-building approaches are most appropriate for comprehensive retrofits when savings are expected to be greater than $10 \%$ of total electricity or gas use, and report on the building's overall energy performance. In addition to measurement boundary, these methods vary in their requirement for measured data, their application appropriateness, and the level of effort and cost to implement. Table 5-2 summarizes the characteristics of each M\&V option.

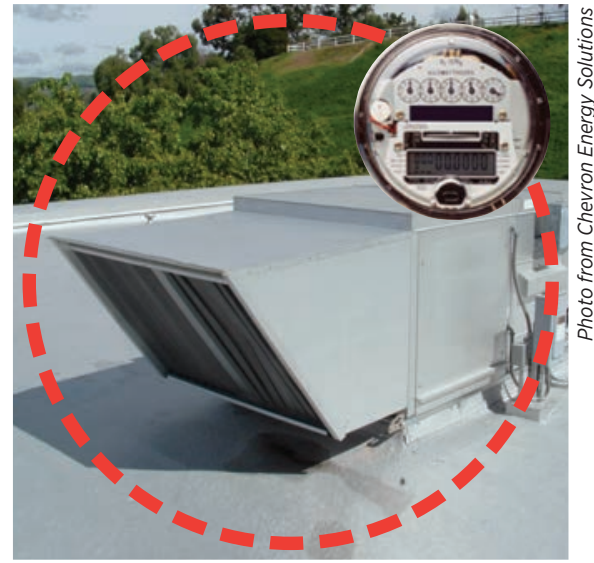

Retrofit-Isolation Measurement Boundary

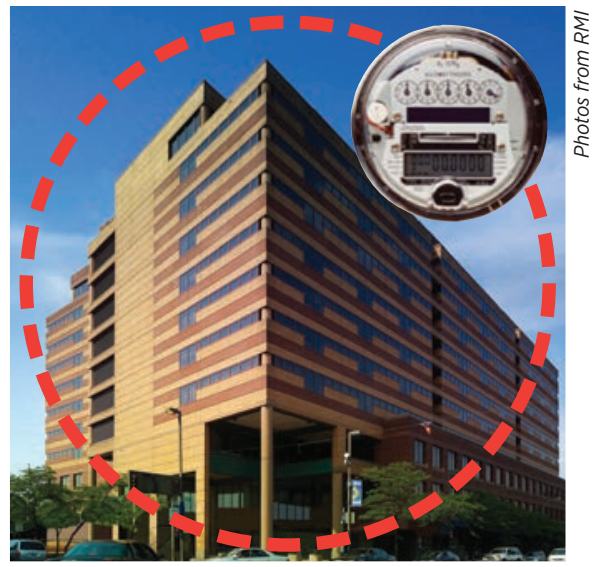

Whole-Building

Measurement Boundary

Figure 5-2 Measurement boundary for M\&V options

Table 5-2 Overview of IPMVP Options

\begin{tabular}{|l|c|c|c|c|}
\hline \multicolumn{1}{|c|}{ Method } & Option A & Option B & Option C & Option D \\
\hline Boundary & Retrofit isolation & Retrofit isolation & Whole building & Whole building \\
\hline Measured data & Key parameters & All parameters & Utility bills & $\begin{array}{c}\text { Utility bills, end use, } \\
\text { system, equipment }\end{array}$ \\
\hline Analysis & $\begin{array}{c}\text { Engineering } \\
\text { calculations }\end{array}$ & Regression analysis & Regression analysis & Calibrated simulation \\
\hline Applications & $\begin{array}{c}\text { Limited variation of } \\
\text { some parameters } \\
\text { impacting EEM savings }\end{array}$ & $\begin{array}{c}\text { Individual EEM } \\
\text { assessment }\end{array}$ & $\begin{array}{c}\text { Estimated savings } \\
\text { > 10\% of total use, } \\
\text { existing building projects, } \\
\text { interacting EEMs }\end{array}$ & $\begin{array}{c}\text { Estimated savings } \\
>10 \% \text { of total use, } \\
\text { interacting EEMs }\end{array}$ \\
\hline
\end{tabular}

The appropriateness of the $M \& V$ approach varies from project to project. Larger projects with larger savings can justify higher M\&V expenses and more rigorous methods. Projects with a few EEMs, or EEMs with little interaction, may opt for a retrofit isolation approach instead of evaluating whole-building impacts. Utility data analysis using Option $\mathrm{C}$ can be a simple method for buildings undergoing whole-building retrofits whose energy use is stable and has a strong correlation to weather. Alternatively, projects that have developed a detailed energy simulation model as a part of the retrofit evaluation process may be best suited to use Option D. Case Study \#8 shows how a school in New Jersey used utility bills and other data to verify energy savings in accordance with Option C. 


\section{Case Study 8: M\&V for the Pingry School Retrofit}

\section{Quick Facts}

- Facility Name: The Carol \& Park B. Smith '50 Middle School

- Owner: The Pingry School

- Location/climate zone: Bernards Township, New Jersey

- Year completed: 2007

- Gross floor area: $280,474 \mathrm{ft}^{2}$

\section{M\&V Implementation Description:}

The Pingry School retrofit project (see Case Study 7) measured and verified its nearly $40 \%$ energy savings using an Option C approach, comparing whole-facility utility bills before and after the retrofit, accounting for changes in square footage, climate, and sometimes other factors.

By completing an M\&V protocol, the project qualified for New Jersey's SmartStart Buildings Program and received $\$ 200,000$ in rebates. The program, like many other incentive programs, provides rebates for purchasing efficient equipment, typically requiring EEM-by-EEM savings verification, or an Option B approach.
Understanding that projects that include EEMs with significant interactions are better assessed using a whole-building SV approach (Option C or Option D), the project team proactively worked with TRC Energy Services, a SmartStart Program manager, to develop an M\&V Plan that would best meet project needs while satisfying program requirements. By explaining the benefit of using Option C M\&V and finding an internal champion in TRC, Dr. Ron Maslo, the team's approach was accepted as meeting the M\&V requirements of the SmartStart program.

The project team began the M\&V process by creating a baseline energy usage for the site using the utility billing data for a one-year period prior to renovation. The team also collected utility cost data from the year after the expansion and retrofit. Savings were determined after adjustments were made for climate and increased facility size.

The verified savings showed a $39 \%$ reduction in total annual energy use, achieved primarily through improvements in boiler efficiency and sequencing, as well as lighting reductions and reduced loads from more efficient air handling equipment.

M\&V may include several verification methods. EEMs with little impact, uncertainty, or variation in performance may require a less rigorous M\&V approach. Low-cost or no-cost EEMs may rely solely on OV methods that identify their potential to save energy. If a retrofit isolation approach is chosen, some EEMs within the project might follow Option A and others Option B. A project that uses Option C to determine whole-building savings with utility billing analysis might be supported with submetering and trend analysis of individual retrofits to ensure all systems perform as expected and savings are realized. If Option $\mathrm{C}$ savings fall below their anticipated level, trending from individual retrofits and/or Option B activities can help identify performance issues. For large projects following Option D, calibration might be supported with submetering and conducted at the utility, electricity end use, and equipment levels. Smaller projects may calibrate at the utility level only.

The IPMVP puts forward several general requirements to ensure the adequacy of an M\&V effort. These include:

- Develop a complete M\&V plan.

- Measure baseline energy use for all operating modes of the building or systems.

- Adjust energy use to the same set of conditions before calculating savings.

- Report savings for the post-installation measurement period only; do not extrapolate beyond this period.

- Establish the acceptable savings accuracy during the M\&V planning process. 


\subsection{Developing the Plan}

An effective verification effort must be planned in advance by developing a detailed $\mathrm{M} \& \mathrm{~V}$ plan during the project planning phase. Each project must establish its own specific $M \& V$ plan that outlines all activities that will be conducted. The $\mathrm{M} \& \mathrm{~V}$ plan should address the project's unique characteristics and be crafted to balance the cost of $\mathrm{M} \& \mathrm{~V}$ with the value it provides.

Adherence to the IPMVP requires preparation of a project specific M\&V Plan that is consistent with IPMVP terminology. It must name the IPMVP Option(s); metering, monitoring, and analysis methods to be used; quality assurance procedures to be followed; and person or persons responsible for the M\&V. Key components of the M\&V Plan are outlined in Table 5-3.

\section{Table 5-3 Components of an M\&V Plan}

\begin{tabular}{|l|l|}
\hline \multicolumn{1}{c}{ Basic M\&V Plan Components } \\
\hline Project description & $\begin{array}{l}\text { - Relevant site characteristics } \\
\text { - Measurement boundary and metering requirements } \\
\text { - Details and data of baseline conditions }\end{array}$ \\
\hline Project savings and costs & $\begin{array}{l}\text { - A description of the EEMs and performance expectations } \\
\text { - Estimated energy and cost savings } \\
\text { - All relevant utility rates } \\
\text { - Expected M\&V cost and accuracy }\end{array}$ \\
\hline - Schedule for obtaining baseline information \\
\hline - Schedule for all post-installation M\&V activities \\
\hline Reporting & $\begin{array}{l}\text { - All assumptions and sources of data } \\
\text { - Identification of deviations from expected conditions } \\
\text { - Delineation of post-retrofit period } \\
\text { - Documentation of the design intent of the EEMs } \\
\text { - Calculation method to be used (all equations shown) }\end{array}$ \\
\hline - Selected option(s) (A, B, C, D) \\
\hline - Details on approach for baseline adjustments \\
- Savings calculation details \\
- OV strategies \\
- Responsibilities for M\&V activities and reporting \\
- Content and format of M\&V reports \\
- Quality control/quality assurance procedures
\end{tabular}

\section{Goals and Objectives}

The first step in developing the M\&V Plan is to identify the goals and objectives for M\&V activities. The value that $\mathrm{M} \& \mathrm{~V}$ provides and costs that can be justified vary based on a project's objectives. For example, $\mathrm{M} \& \mathrm{~V}$ cost savings used to determine payments within an ESPC will need to be more rigorous than an M\&V effort conducted to meet LEED certification requirements. In many projects, $M \& V$ equipment and activities may have other uses, such as tenant submetering or continuous optimization of building or system energy performance, which can help offset costs.

Verification activities can overlap with other project efforts (e.g., commissioning, energy modeling, and installation of energy information systems). If the commissioning agent is developing Owner Project Requirements (OPR), the $\mathrm{M} \& \mathrm{~V}$ goals and objectives should also be stated in the OPR to promote a coordinated team approach early on, which promotes leveraging complementary or overlapping efforts. 


\section{Determining the Best Approach}

The basic purpose of $M \& V$ is to ensure the predicted energy savings are realized. Not achieving expected energy savings may be due to inadequate $M \& V$ methods, faulty engineering assumptions or analysis, uncertainty introduced from sampling or meter accuracy, or from EEMs being disabled (e.g., overriding controls for VFDs). The M\&V approach needs to be adequate but not cost prohibitive. In general, the cost for verification should not exceed about $10 \%$ of the annual savings from a project. Using this cost cap as a rule of thumb can help bound the verification activities. In general, the cost for $M \& V$ increases with the accuracy of the savings determination, which is impacted by the $M \& V$ approach specified and by the number of metering points, metering duration, measurement sample size, and analysis requirements.

SV plans may call for a single whole-building approach addressing all EEMs for the project, or several M\&V options to jointly cover the different EEMs of the project. Before deciding which M\&V options to use, you need to assess how a specific option will meet the project's goals and constraints, address savings risk, and fall within an acceptable budget. The cost of using a proposed $\mathrm{M} \& \mathrm{~V}$ approach must be determined and compared to the risk of not achieving savings. If the project's goals and savings risk do not justify the $M \& V$ expenses, the $M \& V$ approach should be reconsidered. All M\&V plans should include OV activities for all EEMs. For low-cost and no-cost EEMs that have lower savings impacts, additional SV activities may not be warranted.

\section{Plan for Ongoing Monitoring}

For the full value of the retrofit efforts to be realized, ongoing $M \& V$ activities should be included in the plan. Some EEMs can be overridden or disabled, so ongoing $M \& V$ activities will help to ensure savings persist for the life of the equipment. With this in mind, the team should specify periodic performance verification activities. This effort may be composed of OV activities or a combination of operational and SV activities. Ongoing M\&V activities may overlap with performance tracking efforts or any ongoing commissioning activities (see Section 7 for more discussion of O\&M). Often, these efforts can be combined and may be automated into the BAS or into an energy information system or fault detection and diagnosis system.

\subsection{Recommendations for Specific Energy Efficiency Measures}

Effective M\&V methods appropriate for the EEMs discussed in Sections 3 and 4 are listed in Table 5-4. Included for each EEM are estimated cost savings, performance variability, OV activities, SV approach, SV activities, and suggestions for ongoing performance assurance. The methods listed are illustrative in the context of the example building and should not be broadly applied to other projects because of possible differences in the nature and scope of the EEMs installed. Further explanation of the methods used to develop the recommended M\&V protocols is provided in the following sections. 
Table 5-4 M\&V Measures for Common EBCX (Tier 1) and Retrofit (Tier 2) Improvements

\begin{tabular}{|c|c|c|c|c|c|c|c|}
\hline \multirow[b]{2}{*}{ Tier } & \multirow[b]{2}{*}{ Description } & \multicolumn{2}{|c|}{ EEM Information } & \multirow[b]{2}{*}{ OV Activities } & \multirow[b]{2}{*}{ SV Approach } & \multirow[b]{2}{*}{ SV Activities } & \multirow{2}{*}{$\begin{array}{l}\text { Ongoing } \\
\text { Performance } \\
\text { Assurance }\end{array}$} \\
\hline & & $\begin{array}{l}\text { Savings } \\
\text { Impact }\end{array}$ & $\begin{array}{l}\text { Performance } \\
\text { Variability }\end{array}$ & & & & \\
\hline 1 & $\begin{array}{l}\text { Calibrate any existing lighting } \\
\text { controls and optimize settings } \\
\text { based on building use patterns } \\
\text { and daylight availability }\end{array}$ & Medium & High & $\begin{array}{l}\text { Short-term } \\
\text { testing }\end{array}$ & $\begin{array}{l}\text { Option B - } \\
\text { Fully measured } \\
\text { retrofit isolation }\end{array}$ & $\begin{array}{l}\text { Measure } \\
\text { wattages and } \\
\text { run hours }\end{array}$ & $\begin{array}{l}\text { Short-term } \\
\text { testing }\end{array}$ \\
\hline 1 & $\begin{array}{l}\text { Improve janitorial workflow to } \\
\text { consolidate activities in each } \\
\text { area, allowing a reduction in } \\
\text { operating hours for lighting }\end{array}$ & Low & Medium & $\begin{array}{c}\text { Verify } \\
\text { implementation } \\
\text { of procedures }\end{array}$ & None & None & $\begin{array}{l}\text { Verify } \\
\text { implementation } \\
\text { of procedures }\end{array}$ \\
\hline 1 & $\begin{array}{l}\text { Provide power strips in easy- } \\
\text { to-access locations to facilitate } \\
\text { equipment shutdown }\end{array}$ & Medium & Medium & $\begin{array}{c}\text { Visual } \\
\text { inspection }\end{array}$ & None & None & $\begin{array}{l}\text { Verify imple- } \\
\text { mentation of } \\
\text { procedures }\end{array}$ \\
\hline 1 & $\begin{array}{l}\text { Control computer power } \\
\text { management settings facility } \\
\text { wide through software or logon } \\
\text { scripts }\end{array}$ & Medium & Medium & $\begin{array}{l}\text { BAS control } \\
\text { logic and/or } \\
\text { data trending } \\
\text { and review }\end{array}$ & $\begin{array}{l}\text { Option C or D - } \\
\text { Whole-building } \\
\text { approach }\end{array}$ & $\begin{array}{l}\text { Utility data } \\
\text { analysis <or> } \\
\text { building } \\
\text { simulation }\end{array}$ & $\begin{array}{l}\text { Verify imple- } \\
\text { mentation of } \\
\text { procedures }\end{array}$ \\
\hline 1 & $\begin{array}{l}\text { Repair broken windows and } \\
\text { weather-strip/caulk windows } \\
\text { and doors where drafts can } \\
\text { be felt }\end{array}$ & Low & Low & $\begin{array}{c}\text { Visual } \\
\text { inspection }\end{array}$ & None & None & $\begin{array}{l}\text { Regular } \\
\text { maintenance }\end{array}$ \\
\hline 1 & $\begin{array}{l}\text { TAB chilled water pumps and } \\
\text { valves, and refrigerant lines to } \\
\text { ensure that SATs meet cooling } \\
\text { loads and no unnecessary flow } \\
\text { restrictions are present }\end{array}$ & Low & Medium & $\begin{array}{l}\text { Verify existence } \\
\text { of test reports }\end{array}$ & None & None & $\begin{array}{l}\text { Regular } \\
\text { maintenance }\end{array}$ \\
\hline 1 & $\begin{array}{l}\text { Verify correct operation of OA } \\
\text { economizer }\end{array}$ & Low & Medium & $\begin{array}{l}\text { BAS control } \\
\text { logic and/or } \\
\text { data trending } \\
\text { and review }\end{array}$ & None & None & $\begin{array}{l}\text { BAS control } \\
\text { logic and/or } \\
\text { data trending } \\
\text { and review }\end{array}$ \\
\hline 1 & $\begin{array}{l}\text { Precool spaces to reduce peak } \\
\text { demand charges }\end{array}$ & Low & Medium & $\begin{array}{l}\text { BAS control } \\
\text { logic and/or } \\
\text { data trending } \\
\text { and review }\end{array}$ & $\begin{array}{l}\text { Option C or D - } \\
\text { Whole-building } \\
\text { approach }\end{array}$ & $\begin{array}{l}\text { Utility data } \\
\text { analysis <or }> \\
\text { building } \\
\text { simulation }\end{array}$ & $\begin{array}{l}\text { BAS control } \\
\text { logic and/or } \\
\text { data trending } \\
\text { and review }\end{array}$ \\
\hline 1 & $\begin{array}{l}\text { Reset boiler temperature based } \\
\text { on current building loads and } \\
\text { usage patterns }\end{array}$ & Medium & Medium & $\begin{array}{l}\text { BAS control } \\
\text { logic and/or } \\
\text { data trending } \\
\text { and review }\end{array}$ & $\begin{array}{l}\text { Option A - } \\
\text { Partially } \\
\text { measured } \\
\text { retrofit isolation }\end{array}$ & $\begin{array}{c}\text { Measure } \\
\text { wattage, } \\
\text { estimate run } \\
\text { hours }\end{array}$ & $\begin{array}{l}\text { BAS control } \\
\text { logic and/or } \\
\text { data trending } \\
\text { and review }\end{array}$ \\
\hline 2 & $\begin{array}{l}\text { Replace T12 fluorescent lamps } \\
\text { and magnetic ballasts with } \\
\text { high-efficiency T8 lamps and } \\
\text { instant-start electronic ballasts }\end{array}$ & Medium & Low & $\begin{array}{l}\text { Sample spot } \\
\text { measurement }\end{array}$ & $\begin{array}{l}\text { Option A - } \\
\text { Partially } \\
\text { measured } \\
\text { retrofit isolation }\end{array}$ & $\begin{array}{c}\text { Measure } \\
\text { wattage, } \\
\text { estimate run } \\
\text { hours }\end{array}$ & $\begin{array}{l}\text { Visual } \\
\text { inspection }\end{array}$ \\
\hline 2 & $\begin{array}{l}\text { Install wireless motion sensors } \\
\text { for lighting in rooms that are } \\
\text { used intermittently }\end{array}$ & Medium & Medium & $\begin{array}{l}\text { Sample spot } \\
\text { measurement }\end{array}$ & $\begin{array}{l}\text { Option A - } \\
\text { Partially } \\
\text { measured } \\
\text { retrofit isolation }\end{array}$ & $\begin{array}{l}\text { Measure run } \\
\text { hours, estimate } \\
\text { wattages }\end{array}$ & $\begin{array}{c}\text { Visual } \\
\text { inspection }\end{array}$ \\
\hline 2 & $\begin{array}{l}\text { Install photosensors and } \\
\text { dimming ballasts to dim lights } \\
\text { when daylighting is sufficient. }\end{array}$ & Medium & High & $\begin{array}{l}\text { Short-term } \\
\text { testing }\end{array}$ & $\begin{array}{l}\text { Option B - } \\
\text { Fully measured } \\
\text { retrofit isolation }\end{array}$ & $\begin{array}{l}\text { Measure } \\
\text { wattage over } \\
\text { time }\end{array}$ & $\begin{array}{l}\text { Visual } \\
\text { inspection }\end{array}$ \\
\hline 2 & $\begin{array}{l}\text { Replace cafeteria appliances } \\
\text { (refrigerators, freezers, dish- } \\
\text { washers, ovens, fryers, griddles, } \\
\text { steam cookers, ice machines, } \\
\text { hot food holding cabinets) with } \\
\text { ENERGY STAR models }\end{array}$ & Low & Low & $\begin{array}{l}\text { Visual } \\
\text { inspection }\end{array}$ & $\begin{array}{l}\text { Option A - } \\
\text { Partially } \\
\text { measured } \\
\text { retrofit Isolation }\end{array}$ & $\begin{array}{l}\text { Measure } \\
\text { wattage, } \\
\text { estimate run } \\
\text { hours }\end{array}$ & $\begin{array}{l}\text { Visual } \\
\text { inspection }\end{array}$ \\
\hline
\end{tabular}


Table 5-4 M\&V Measures for Common EBCx (Tier 1) and Retrofit (Tier 2) Improvements (cont'd)

\begin{tabular}{|c|c|c|c|c|c|c|c|}
\hline \multirow[b]{2}{*}{ Tier } & \multirow[b]{2}{*}{ Description } & \multicolumn{2}{|c|}{ EEM Information } & \multirow[b]{2}{*}{ OV Activities } & \multirow[b]{2}{*}{ SV Approach } & \multirow[b]{2}{*}{ SV Activities } & \multirow{2}{*}{$\begin{array}{l}\text { Ongoing } \\
\text { Performance } \\
\text { Assurance }\end{array}$} \\
\hline & & $\begin{array}{l}\text { Savings } \\
\text { Impact }\end{array}$ & $\begin{array}{l}\text { Performance } \\
\text { Variability }\end{array}$ & & & & \\
\hline 2 & $\begin{array}{l}\text { Install VSDs and demand } \\
\text { control for kitchen hood } \\
\text { exhaust fans }\end{array}$ & Low & Medium & $\begin{array}{l}\text { Short-term } \\
\text { testing }\end{array}$ & $\begin{array}{l}\text { Option A- } \\
\text { Partially } \\
\text { measured } \\
\text { retrofit isolation }\end{array}$ & $\begin{array}{l}\text { Measure } \\
\text { wattage, } \\
\text { estimate run } \\
\text { hours }\end{array}$ & $\begin{array}{l}\text { Visual } \\
\text { inspection }\end{array}$ \\
\hline 2 & $\begin{array}{l}\text { Add reflective roof covering } \\
\text { (hot climates only) }\end{array}$ & Medium & Low & $\begin{array}{l}\text { Visual } \\
\text { inspection }\end{array}$ & $\begin{array}{l}\text { Option C or D - } \\
\text { Whole-building } \\
\text { approach }\end{array}$ & $\begin{array}{l}\text { Utility data } \\
\text { analysis <or }> \\
\text { building } \\
\text { simulation }\end{array}$ & $\begin{array}{l}\text { Visual } \\
\text { inspection }\end{array}$ \\
\hline 2 & $\begin{array}{l}\text { Add a small condensing boiler } \\
\text { to handle the base load and } \\
\text { summer load, with current } \\
\text { inefficient boiler operating } \\
\text { when heating loads are highest }\end{array}$ & High & Medium & $\begin{array}{l}\text { Visual } \\
\text { inspection }\end{array}$ & $\begin{array}{l}\text { Option B- } \\
\text { Fully measured } \\
\text { retrofit isolation }\end{array}$ & $\begin{array}{l}\text { Measure } \\
\text { wattages and } \\
\text { run hours }\end{array}$ & $\begin{array}{l}\text { BAS control } \\
\text { logic and/or } \\
\text { data trending } \\
\text { and review }\end{array}$ \\
\hline 2 & $\begin{array}{l}\text { Replace pneumatic controls } \\
\text { with DDC (enabling } \\
\text { technology) }\end{array}$ & Low & Low & $\begin{array}{l}\text { Visual } \\
\text { inspection }\end{array}$ & $\begin{array}{l}\text { Option C or D - } \\
\text { Whole-building } \\
\text { approach }\end{array}$ & $\begin{array}{l}\text { Utility data } \\
\text { analysis <or }> \\
\text { building } \\
\text { simulation }\end{array}$ & $\begin{array}{l}\text { Visual } \\
\text { inspection }\end{array}$ \\
\hline 2 & $\begin{array}{l}\text { Install a dry-bulb airside } \\
\text { economizer (differential } \\
\text { enthalpy in humid climates) }\end{array}$ & Medium & Low & $\begin{array}{l}\text { Short-term } \\
\text { testing }\end{array}$ & $\begin{array}{l}\text { Option A- } \\
\text { Partially } \\
\text { measured } \\
\text { retrofit isolation }\end{array}$ & $\begin{array}{l}\text { Measure } \\
\text { wattage, } \\
\text { estimate run } \\
\text { hours }\end{array}$ & $\begin{array}{l}\text { BAS control } \\
\text { logic and/or } \\
\text { data trending } \\
\text { and review }\end{array}$ \\
\hline 2 & $\begin{array}{l}\text { Upgrade to DCV to reduce OA } \\
\text { flow during partial occupancy }\end{array}$ & Medium & High & $\begin{array}{l}\text { Sample spot } \\
\text { measurement }\end{array}$ & $\begin{array}{l}\text { Option C or D - } \\
\text { Whole-building } \\
\text { approach }\end{array}$ & $\begin{array}{l}\text { Utility data } \\
\text { analysis <or }> \\
\text { building } \\
\text { simulation }\end{array}$ & $\begin{array}{l}\text { Visual } \\
\text { inspection }\end{array}$ \\
\hline 2 & $\begin{array}{l}\text { Convert constant volume } \\
\text { (CV) or dual duct air handling } \\
\text { system to VAV (add dampers, } \\
\text { VSD fan motors) }\end{array}$ & Medium & Medium & $\begin{array}{l}\text { BAS control } \\
\text { logic and/or } \\
\text { data trending } \\
\text { and review }\end{array}$ & $\begin{array}{l}\text { Option C or D - } \\
\text { Whole-building } \\
\text { approach }\end{array}$ & $\begin{array}{l}\text { Utility data } \\
\text { analysis <or }> \\
\text { building } \\
\text { simulation }\end{array}$ & $\begin{array}{l}\text { Visual } \\
\text { inspection }\end{array}$ \\
\hline 2 & $\begin{array}{l}\text { Replace lighting system with } \\
\text { a more efficient approach } \\
\text { (reduced ambient light, greater } \\
\text { use of task lighting, indirect T5 } \\
\text { fixtures in place of direct T12 } \\
\text { fixtures) }\end{array}$ & Medium & Low & $\begin{array}{c}\text { Visual } \\
\text { inspection }\end{array}$ & $\begin{array}{l}\text { Option C or D - } \\
\text { Whole-building } \\
\text { approach }\end{array}$ & $\begin{array}{l}\text { Utility data } \\
\text { analysis or } \\
\text { Building } \\
\text { simulation }\end{array}$ & $\begin{array}{l}\text { Visual } \\
\text { inspection }\end{array}$ \\
\hline 2 & $\begin{array}{l}\text { Add an exterior insulating finish } \\
\text { system (EIFS) to exterior walls }\end{array}$ & Medium & Low & $\begin{array}{l}\text { Sample spot } \\
\text { measurement }\end{array}$ & $\begin{array}{l}\text { Option C or D - } \\
\text { Whole-building } \\
\text { approach }\end{array}$ & $\begin{array}{l}\text { Utility data } \\
\text { analysis <or } \\
\text { building } \\
\text { simulation }\end{array}$ & $\begin{array}{l}\text { Visual } \\
\text { inspection }\end{array}$ \\
\hline 2 & $\begin{array}{l}\text { Replace windows and frames } \\
\text { with double-paned, low-e, } \\
\text { aluminum framed windows } \\
\text { with reduced air leakage }\end{array}$ & Medium & Low & $\begin{array}{l}\text { Visual } \\
\text { inspection }\end{array}$ & $\begin{array}{l}\text { Option C or D - } \\
\text { Whole-building } \\
\text { approach }\end{array}$ & $\begin{array}{l}\text { Utility data } \\
\text { analysis or } \\
\text { building } \\
\text { simulation }\end{array}$ & $\begin{array}{l}\text { Regular } \\
\text { maintenance }\end{array}$ \\
\hline 2 & $\begin{array}{l}\text { Install exterior automated } \\
\text { louver shading systems on all } \\
\text { sun-exposed windows }\end{array}$ & Medium & Low & $\begin{array}{l}\text { Short-term } \\
\text { testing }\end{array}$ & $\begin{array}{l}\text { Option C or D - } \\
\text { Whole-building } \\
\text { approach }\end{array}$ & $\begin{array}{l}\text { Utility data } \\
\text { analysis or } \\
\text { building } \\
\text { simulation }\end{array}$ & $\begin{array}{l}\text { Regular } \\
\text { maintenance }\end{array}$ \\
\hline 2 & $\begin{array}{l}\text { Supplement direct expansion } \\
\text { (DX) cooling system with an } \\
\text { indirect evaporative cooler sized } \\
\text { to meet small and medium cool- } \\
\text { ing loads (in dry climates only) }\end{array}$ & Medium & Medium & $\begin{array}{l}\text { Visual } \\
\text { inspection }\end{array}$ & $\begin{array}{l}\text { Option B- } \\
\text { Fully measured } \\
\text { retrofit isolation }\end{array}$ & $\begin{array}{c}\text { Measure } \\
\text { wattage, } \\
\text { estimate run } \\
\text { hours }\end{array}$ & $\begin{array}{l}\text { Regular } \\
\text { maintenance }\end{array}$ \\
\hline 2 & $\begin{array}{l}\text { Replace single large boiler } \\
\text { with several smaller, staged } \\
\text { standard efficiency boilers }\end{array}$ & Medium & Low & $\begin{array}{l}\text { Visual } \\
\text { inspection }\end{array}$ & $\begin{array}{l}\text { Option A - } \\
\text { Partially } \\
\text { measured } \\
\text { retrofit Isolation }\end{array}$ & $\begin{array}{c}\text { Measure } \\
\text { wattage over } \\
\text { time }\end{array}$ & $\begin{array}{c}\text { Regular } \\
\text { maintenance }\end{array}$ \\
\hline
\end{tabular}


Table 5-4 M\&V Measures for Common EBCx (Tier 1) and Retrofit (Tier 2) Improvements (cont'd)

\begin{tabular}{|c|c|c|c|c|c|c|c|}
\hline \multirow[b]{2}{*}{ Tier } & \multirow[b]{2}{*}{ Description } & \multicolumn{2}{|c|}{ EEM Information } & \multirow[b]{2}{*}{ OV Activities } & \multirow[b]{2}{*}{ SV Approach } & \multirow[b]{2}{*}{ SV Activities } & \multirow{2}{*}{$\begin{array}{c}\text { Ongoing } \\
\text { Performance } \\
\text { Assurance }\end{array}$} \\
\hline & & $\begin{array}{l}\text { Savings } \\
\text { Impact }\end{array}$ & $\begin{array}{l}\text { Performance } \\
\text { Variability }\end{array}$ & & & & \\
\hline 2 & $\begin{array}{l}\text { Replace DX cooling system } \\
\text { with more efficient rightsized } \\
\text { model with evaporative } \\
\text { condenser }\end{array}$ & Medium & Low & $\begin{array}{c}\text { Visual } \\
\text { inspection }\end{array}$ & $\begin{array}{l}\text { Option A - } \\
\text { Partially } \\
\text { measured } \\
\text { retrofit isolation }\end{array}$ & $\begin{array}{c}\text { Measure } \\
\text { wattage, } \\
\text { estimate run } \\
\text { hours }\end{array}$ & $\begin{array}{c}\text { Regular } \\
\text { maintenance }\end{array}$ \\
\hline 2 & $\begin{array}{l}\text { Install dedicated outside air } \\
\text { system (DOAS) with high- } \\
\text { efficiency heat recovery, } \\
\text { reducing the heating, cooling, } \\
\text { and dehumidification loads }\end{array}$ & Medium & Medium & $\begin{array}{l}\text { Short-term } \\
\text { testing }\end{array}$ & $\begin{array}{l}\text { Option C or D - } \\
\text { Whole-building } \\
\text { approach }\end{array}$ & $\begin{array}{l}\text { Utility data } \\
\text { analysis <or }> \\
\text { building } \\
\text { simulation }\end{array}$ & $\begin{array}{c}\text { Regular } \\
\text { maintenance }\end{array}$ \\
\hline 2 & $\begin{array}{l}\text { Convert to displacement } \\
\text { ventilation system (where } \\
\text { ceilings are higher than } 9 \text { feet) }\end{array}$ & Medium & Low & $\begin{array}{c}\text { Visual } \\
\text { inspection }\end{array}$ & $\begin{array}{l}\text { Option C or D - } \\
\text { Whole-building } \\
\text { approach }\end{array}$ & $\begin{array}{l}\text { Utility data } \\
\text { analysis <or> } \\
\text { building } \\
\text { simulation }\end{array}$ & $\begin{array}{c}\text { Regular } \\
\text { maintenance }\end{array}$ \\
\hline
\end{tabular}

\section{Measure Characterization}

Before the verification approach and supporting activities are specified, the characteristics of the individual EEMs as well as the overall package are considered. As previously discussed, the ultimate aim of M\&V is to effectively balance the risk of losing savings against the cost needed to verify them. This risk is tied to the amount of anticipated energy cost savings as well as the performance variability of the measures.

- Energy cost savings impact has been defined as low $(0 \%-1 \%)$, medium $(1 \%-3 \%)$, and high $(>3 \%)$ based on the overall retrofit cost savings.

- Performance variability has been defined as low, medium, and high, and is based on the level of variability in the performance of the EEM, which may be influenced by hours of operation, user interaction, control sequences, or part-load performance. This criterion defines the likelihood of savings varying from expectations due to performance-related assumptions being different from actual. The performance of certain EEMs, such as envelope improvements, is static and should be as anticipated if properly installed. These EEMs are ranked as low. EEMs that could vary in performance due to differences in operating hours or efficiency, but not likely both, are ranked as medium. These EEMs include automated measures that could be disabled or changed, such as adjustments to control set points. EEMs that could perform with a wide range of efficiency and associated operating hours, such as VSDs, are ranked as high.

\section{Operational Verification}

OV should be performed as part of any project $M \& V$ program. It serves as a low-cost initial step for realizing savings potential and should precede SV activities. A range of OV methods can be applied, as outlined in Table 5-5. Selection of a given approach depends on the EEM's characteristics. However, it can also be influenced by the SV approach taken. For example, if Option B is being used to verify savings, a more simple visual inspection may suffice for OV. However, if Option A is applied, short-term testing might be conducted so that the EEM's performance characterization is complete. 
Table 5-5 OV Approach and Application

\begin{tabular}{|l|l|l|}
\hline \multicolumn{1}{|c|}{ OV Approach } & \multicolumn{1}{c|}{ Typical EEM Application } & \multicolumn{1}{c}{ Activities } \\
\hline Visual inspection & $\begin{array}{l}\text { EEM will perform as anticipated when } \\
\text { properly installed; direct measurement } \\
\text { of EEM performance is not possible. } \\
\text { Examples: wall insulation, windows. }\end{array}$ & $\begin{array}{l}\text { View and verify the physical installation of } \\
\text { the EEM. }\end{array}$ \\
\hline Sample spot measurements & $\begin{array}{l}\text { Achieved EEM performance can vary } \\
\text { from published data based on installation } \\
\text { details or component load. Examples: } \\
\text { fixtures, lamps, ballasts, fans, pumps. }\end{array}$ & $\begin{array}{l}\text { Measure single or multiple key energy-use } \\
\text { parameters for a representative sample of } \\
\text { the EEM installations. }\end{array}$ \\
\hline Short-term testing & $\begin{array}{l}\text { EEM performance may vary depending on } \\
\text { actual load, controls, and interoperability } \\
\text { of components. Examples: daylighting } \\
\text { sensors and lighting dimming controls, } \\
\text { VSD fans. }\end{array}$ & $\begin{array}{l}\text { Test for functionality and proper control } \\
\text { Measure key energy use parameters. } \\
\text { May involve conducting tests designed } \\
\text { to capture the component operating } \\
\text { over its full range or performance data } \\
\text { collection over a sufficient period of time to } \\
\text { characterize the full range of operation. }\end{array}$ \\
\hline $\begin{array}{l}\text { BAS control logic and/or } \\
\text { data trending and review }\end{array}$ & $\begin{array}{l}\text { EEM performance may vary depending on } \\
\text { actual load and controls. Component or } \\
\text { system is being monitored and controlled } \\
\text { through the BAS. Examples: DCV, boiler } \\
\text { staging. }\end{array}$ & $\begin{array}{l}\text { Set up and review BAS data trends and } \\
\text { BAS control logic.. Measurement period } \\
\text { may last for a few days to a few weeks, } \\
\text { depending on the period needed to } \\
\text { capture the full range of performance. }\end{array}$ \\
\hline
\end{tabular}

\section{Savings Verification}

Including an SV component as part of the project $\mathrm{M} \& \mathrm{~V}$ is critical for some applications (e.g., ESPCs or LEED 2009 Design \& Construction Energy \& Atmosphere Credit 5 adherence). For small projects and EEMs with little savings potential or variability, only the simplest SV methods may be justified. Typically, SV is not conducted for maintenance type EEMs or EEMs with small savings, especially those that are challenging to measure or where it is difficult to define their baseline.

\section{Retrofit Isolation Approach}

Option A-Retrofit isolation approach is less rigorous than Option B and is applied to EEMs that have low savings and low performance variability. Post-installation, either performance (e.g., wattage) or operation (e.g., operating hours) is measured. The value for the unmeasured parameter is estimated or based on baseline measurements. School EEMs that would use an Option A SV approach include those that involve replacing equipment that maintains the same operating schedule: appliances, furnaces, boilers, and on/off lighting systems.

Option B-Retrofit isolation approach fully characterizes the post-installation EEM by measuring all energy-use parameters (e.g., wattage and operating hours). It is most appropriate for EEMs with higher savings and/or higher performance/operating variability. School EEMs assigned an Option B SV approach include those involving equipment change outs accompanied by changes in controls or part-load performance, such as active daylighting controls, VSD chilled water pumps, VSD chillers, and supplementing DX cooling with indirect evaporative cooling.

\section{Whole-Building Approach}

A whole-building SV approach is most appropriate for projects that include interactive EEMs or those for which performance improvements are challenging to directly measure. If a whole-building approach is followed, the retrofit isolation methods are generally not implemented but might be conducted for select EEMs to verify savings at the EEM level. When relying on a whole-building approach, it is critical to include a strong OV component, including ongoing, data-driven activities. 
Option C-Utility billing analysis is generally selected as the whole-building approach for projects where the energy cost savings are not large enough to justify the higher costs associated with implementing Option D.

Option D-Whole-building calibrated simulation analysis can be justified if the project savings are high and results from the simulation can be used to evaluate and inform the building's optimized performance.

\section{Approach for Retrofit Packages}

The M\&V approach for the three tiers of retrofit discussed in this guide should include an OV component. This will ensure energy efficiency improvements are installed correctly and have the potential to save energy. Because of the relatively low savings associated with a Tier-1 type package, the M\&V will probably not include a verified savings component due to the added expense. Of course, rough savings calculations can be made to see if estimates are close to expectations, but the methods will not be considered to be IPMVP adherent.

For school projects that can justify spending $\$ 5,000$ or more on $M \& V$ (e.g., at least $\$ 50,000$ in savings), verified savings can be determined by following either a retrofit isolation approach (Options A and B) or a whole-building Option C approach. Projects with less savings or smaller M\&V budgets will need to be more targeted in their efforts For example, these projects can focus on the EEMs that have higher impact and/or more variable performance. It is also possible to follow Option C but also include Option A and Option B on select EEMs. This may be particularly warranted if Option $\mathrm{C}$ reveals lower savings than anticipated. If Option $\mathrm{C}$ is the primary method selected for verifying savings, ongoing performance monitoring should occur during the $\mathrm{M} \& \mathrm{~V}$ period.

For school projects that can justify spending at least $\$ 15,000$ on M\&V (e.g., at least $\$ 150,000$ in savings), verified savings might be determined through an Option $\mathrm{D}$ approach. This approach is most feasible if an energy model of the project is available to support M\&V. The benefit of using Option D instead of Option C is that one can compare expected and actual performance for major building end uses and systems. Some discrepancies will be due to modeling operating assumptions. Others can reveal shortcomings in actual operation that can be rectified for improved performance.

\section{Persistence}

Performance assurance activities are conducted to ensure EEM savings persist once the M\&V period has passed. These activities follow the same categories as those described for OV.

\subsection{Additional Resources}

Use these resources for more detailed information about $\mathrm{M} \& \mathrm{~V}$ best practices for existing buildings:

The International Performance Measurement and Verification Protocol (IPMVP) is available at www.evo_world.org. (EVO 2010)

The Building Performance Tracking Handbook was developed by PECI for the California Energy Commission (CEC 2011). www.cacx.org/PIER/documents/bpt-handbook.pdf

California Commissioning Collaborative, "Building Performance Tracking Handbook", 2011: Includes a discussion of performance tracking tools relevant to $\mathrm{M} \& \mathrm{~V}$ activities. Available for free download online; www.cacx.org.

DOE, "M\&V Guidelines: Measurement and Verification for Federal Energy Projects, Version 3.0”, 2008: Guidelines and methods for measuring and verifying energy, water, and cost savings associated with federal energy savings performance contracts (ESPCs); much of the content is relevant to $\mathrm{M} \& \mathrm{~V}$ activities in private sector buildings. Available for free download online; wwwl.eere.energy.gov/femp/pdfs/mv_guidelines.pdf

ASHRAE, "Guideline 14", 2008: A standard set of energy (and demand) savings calculation procedures for M\&V activities. More information available at www.ashrae.org. 


\section{Continuous Improvement Through Operations and Maintenance}

\subsection{What Is Operations and Maintenance?}

$\mathrm{O} \& \mathrm{M}$ is the combination of mental (operations) and physical (maintenance) activities that are required to keep a building and its energy systems functioning at peak performance. Operations focus on the control and performance optimization of equipment, systems, and assemblies. Proper operations help ensure that equipment produces the required capacity when needed, and that it produces this capacity efficiently. Maintenance typically refers to routine, periodic physical activities conducted to prevent the failure or decline of building equipment and assemblies. Proper physical care helps ensure that equipment maintains its required capacity and that assemblies maintain their integrity. O\&M is an activity that almost all facility management staff members engage in, but the nature of that engagement varies. Some engage in reactive O\&M, primarily responding to complaints and breakdowns; those with a well-planned comprehensive O\&M program work proactively to prevent complaints and failures.

Implementing a comprehensive O\&M program with limited resources is a common challenge. All too often, lack of sufficient funding, time, manpower, or even training prevents holistic and optimized O\&M implementation. Dedicating the resources can be advantageous, though, as a well-run O\&M program can result in the following benefits (DOE 2010):

- Energy savings of 5\%-20\% of whole-building energy use

- Minimal comfort complaints

- Equipment that operates adequately until the end of its planned useful life, or beyond

- IAQ maintenance

- Safe working conditions for the school's operating staff.

Optimizing a building's O\&M program is one of the most cost-effective approaches to ensure reliability and energy efficiency, as these practices can often be significantly enhanced with only minor initial investments (DOE 2010). Case Study \#9 illustrates how an RCx project in a Montana middle school unveiled a number of operational issues that could have been avoided with greater attention to the initial commissioning process and an ongoing O\&M program.

When planning for energy upgrades, a building owner needs to evaluate how each retrofit will impact the O\&M program, and if current O\&M practices are adequate. Additional training or resources may be required to maintain the systems and/or assemblies affected by the upgrade, or to maintain the benefits associated with the upgrade. For more modest retrofits, the O\&M program may not be affected, as these retrofits usually replace systems and components with similar but more efficient systems and components. However, even in these instances it is important to evaluate the sufficiency of the current O\&M program and consider devoting additional planning and resources to maintain the performance and benefits of these retrofits. 


\section{Case Study 9: East Valley Middle School Retrocommissioning}

\section{Quick Facts}

- Facility Name: East Valley Middle School

- Owner: East Helena Public Schools

- Location: East Helena, Montana

- Gross Floor Area: 64,000 ft²

- Energy Use Intensity: 59.4 kBtu/ft²

\section{Project Description:}

East Valley Middle School of East Helena, Montana, serves as an educational tool for both students and school officials. Not long after the school opened, energy bills were much higher than expected and occupants lodged numerous complaints about comfort, averaging 12 complaints per day. Things reached the point of litigation between the school and building contractors that installed the equipment. Looking back, these difficulties could have been avoided if the building had been commissioned before being occupied. But in the world of commissioning, it's never too late, and school officials turned to RCx to solve their problems.

\section{As a result of commissioning, the original contractors have corrected the problems and we now enjoy a comfortable building with efficient heating, ventilation, and cooling systems. \\ - Ron Whitmoyer, \\ Superintendent of E. Helena Public Schools}

Focusing on the operation and controls of the building's HVAC systems, school officials found many deficiencies that were deteriorating the quality of the building's

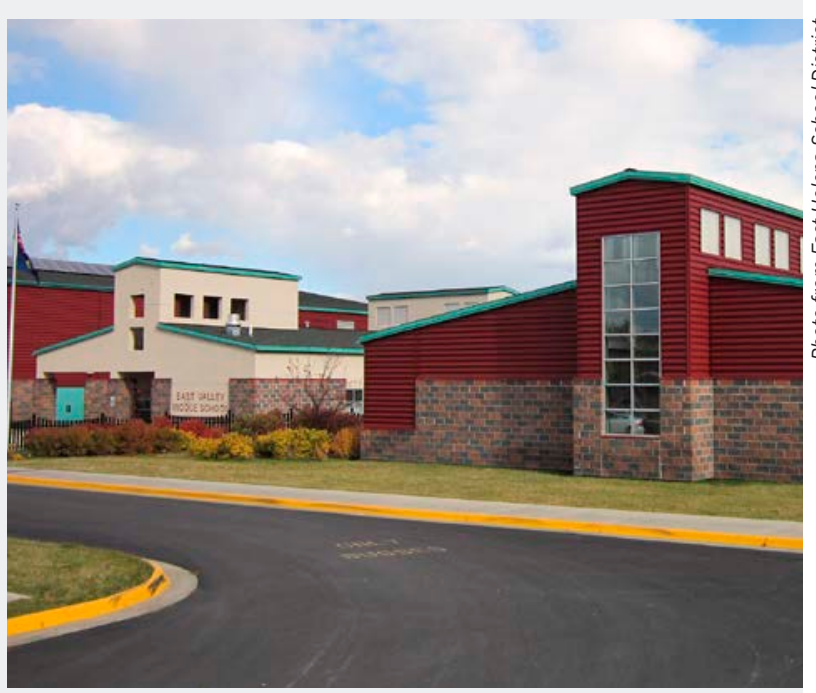

learning environment. The $\mathrm{RCx}$ process allowed them to lower their energy bills and dramatically reduce occupant comfort complaints. The payback period was less than five years and the intangible benefits from a comfortable indoor learning environment were more than worth the wait to school officials. www.cacx.org/ database/data/BB_HelenaMS.pdf

\section{Key EEMs}

1. Hot water pump lockout set points were reprogrammed from $60^{\circ} \mathrm{F}$ to $50^{\circ} \mathrm{F}$.

2. Boilers were staged based on OAT, shutting the boiler off when OAT exceeded $60^{\circ} \mathrm{F}$.

3. Control systems were re-programmed for several HVAC units to operate according to ASHRAE Cycle II instead of ASHRAE Cycle III.

4. Malfunctioning heating valves and dampers were repaired.

\begin{tabular}{|c|c|c|c|c|}
\hline Audit Costs & Energy \$ Savings & $\begin{array}{c}\text { Simple Payback } \\
\text { (years) }\end{array}$ & Total Costs & $\begin{array}{l}\text { \% Site Energy } \\
\text { Savings }\end{array}$ \\
\hline$\$ 8,700$ & $\$ 2,828$ in 1st year & 4.8 & $\$ 13,700$ & $10 \%$ \\
\hline \multicolumn{2}{|c|}{ Energy Use } & \multicolumn{3}{|c|}{ EUI } \\
\hline Before & After & Before & After & ASHRAE $90.1-2004$ \\
\hline 4,244 MMBtu/yr & 3,801 MMBtu/yr & $66.0 \mathrm{kBtu} / \mathrm{ft}^{2}$ & $59.4 \mathrm{kBtu} / \mathrm{ft}^{2}$ & $72.6 \mathrm{kBtu} / \mathrm{ft}^{2}$ \\
\hline
\end{tabular}




\subsection{Management System}

Successful O\&M practices require the support and coordination of many people besides the operations staff. Integration across all levels of an organization is vital to empowering the right people at the right time to produce and sustain an energy-efficient building. Five key elements of a management system that can produce a comprehensive and optimized O\&M strategy are represented by the acronym "OMETA" (Operations, Maintenance, Engineering Support, Training and Administration) (Meador 1995).

- Operations. Effective operations plans and protocols to maximize building systems' efficiency.

- Maintenance. Effective maintenance plans and protocols to maximize building systems' efficiency.

- Engineering support. Availability of technical personnel who can effectively carry out an O\&M program.

- Training. Adequate training facilities, equipment, and materials to develop and improve the knowledge and skills necessary to perform assigned job functions.

- Administration. Effective establishment and implementation of policies and planning related to O\&M activities.

OMETA describes the key elements of O\&M management. It is also vital to establish a clear framework for communication and cooperation among the various groups included in an O\&M management structure. For a school building, these groups can include:

- School board

- In-house custodial staff

- Service contractors

- Energy managers

- Teachers and students.

An individual responsible for maintaining the lines of communication between the various groups, referred to as an in-house champion, is a critical part of this framework. This champion must be knowledgeable about the building systems and involved in decision making related to operations. The role of champion is vital to the O\&M process, as lack of support from any element of the structure can greatly reduce the benefits of O\&M and limit the ability to achieve and retain a fully optimized building.

When implementing the EBCx process or retrofits in a building, it is important to obtain buy-in from all parties associated with an O\&M program to maximize the persistence of upgrade-related benefits. The O\&M team needs to be closely involved in all core building-related upgrades, because its members will maintain the systems and assemblies and ultimately define the sustainability of upgrades.

An additional O\&M management consideration is how O\&M can be affected if a building outsources O\&M responsibilities to a maintenance management firm, as is often the case with retail buildings. These firms are often highly skilled and capable of implementing advanced O\&M programs, but will do so only if it is specified in the service agreement. Building owners can review their service agreements and talk to their service providers to determine what level of O\&M activity is currently contracted and what may be lacking. When entering into a new service agreement, building owners are encouraged to seek out vendors that offer comprehensive O\&M. 


\subsection{Program Development}

Implementing an O\&M program serves a crucial role in an energy upgrade - upgrades provide an initial efficiency boost, and a good O\&M program will ensure the savings persist. All building systems degrade over time- light output decreases through natural lumen depreciation and dirt buildup, control systems drift from set points or occupants override or disable the optimum settings, heat exchangers become fouled, and motors and drives wear out. Dozens of other problems can also arise.

A good O\&M program anticipates all the expected degradations and monitors building status to catch the unexpected. The action items can be proactive, such as prescheduled preventative maintenance plans, or reactive, responding to problems as they arise.

For an O\&M program to be successful, planners and participants must understand all the building systems and equipment and how they are operated and maintained. Most building systems interact with each other, so if one is operating inefficiently, others may follow suit. For example, if a building's lighting system is providing more light than necessary, the HVAC system will have to compensate for the additional heat added. These kinds of interactions can be hard to detect without a comprehensive approach to O\&M.

\section{Developing an Effective Plan}

Successful O\&M starts with the energy upgrade plan-O\&M is easier if it is planned. A good program also requires defining and communicating the goals, and identifying partners who may either participate in, or contribute to, the program.

Design for maintenance. The best results come about when maintenance is addressed from the start of the energy upgrade process. For example, a lighting upgrade can include components that minimize lumen degradation, offer long lamp life, and minimize the number of lamp types that must be stocked. If upgraded HVAC equipment is different in shape or size from existing equipment, designers should make sure that there is still easy access for cleaning coils and filters. Coils and filters should be selected to minimize maintenance costs in the expected environment — dry versus humid, clean air versus dirty

Newark Public Schools, the largest school district in New Jersey, implemented a district-wide O\&M program that included energy use monitoring software at all its schools. After the software was installed (part of a complete BAS) at Weequahic High School, staff discovered that gas consumption was $7.9 \%$ above the baseline on weekends. They determined that boilers were on during weekends and heating appliances were not shutting down even though the building was unoccupied. Eliminating this waste saved the school $\$ 2,300$ per month on its energy bill (DOE 2009). air, and other factors.

Goals. O\&M program goals are to maintain the improved operational efficiency of building systems. Normal equipment degradation and building occupant adjustments can quickly reduce benefits after an upgrade. O\&M goals will guide building staff as they develop regularly scheduled maintenance activities to actively monitor building systems.

Communication. An O\&M program will be most successful if all parties are informed of the goals and expected benefits - from the principals and school board to the students and the community. It is also important to emphasize that savings might not be realized immediately but will accrue over time. A strong O\&M program is one of the most cost-effective methods for maintaining or boosting energy efficiency, as well as ensuring the reliability and safety of a building's systems. Communicating this fact early on is crucial to a program's success (PNNL 2010).

Engage partners. The right team members for an O\&M program increase its effectiveness. The facility manager, school maintenance staff, custodians, contractors, and any other parties involved in the operations of a school 
building should be represented. Staff members with extensive knowledge of the building and its systems can add tremendous value when determining the objectives of the program and the implementation schedules.

The participation of other parties outside the school often helps, particularly if staff members lack the expertise or time to carry out all aspects of the O\&M program. Contact local utilities early in the process to see what options are available for obtaining energy use data in the most useful format. Sometimes utilities offer technical assistance with issues that arise during O\&M implementation, such as interpreting submetered data and peak shaving impacts.

External consultants with O\&M program experience can help schools set up, implement, and manage an O\&M program. School systems can also look outside their own districts to find other schools with active O\&M programs and learn from their experiences.
The school system in Virginia Beach, Virginia, was concerned about the energy and maintenance costs of plug loads (microwaves, refrigerators, etc.) used outside of common areas and not for direct instructional support. Surveys showed thousands of these devices were in use, with energy costs exceeding $\$ 100,000$. To deal with this potentially sensitive issue, the school department shared the survey results to raise awareness, convened a group of building managers to discuss potential policies, and communicated and implemented the policies to minimize pushback. Through this measure the department saved $\$ 100,000 / \mathrm{yr}$, reduced classroom disruptions, and made classrooms safer (Morris 2011).

Be flexible. An O\&M program should be flexible enough to adapt to changes that occur to a building over time. These can include O\&M and retrofit EEMs that are implemented throughout the life of the school, such as those discussed in this guide. As EEMs are implemented, the O\&M program should be revised to address the equipment and assemblies related to these EEMs. This will help maintain the capacity, reliability, and performance, including energy performance, of all building systems in the school.

\section{Training}

School administration and maintenance staff need training on how to maintain optimum building operations after the upgrade; and on how they and their students can change their own behavior to reduce energy use. For major projects, the new systems will go through a commissioning process; the commissioning agent should also provide operator training. A hands-on workshop is an effective way of teaching staff members how to properly maintain and operate building equipment. By covering topics such as energy use and expected improvements, the training ties operations to maintenance. It is especially important that the maintenance and custodial staffs are trained in the operation of control systems and that they are properly motivated to optimize the system operations. Consider recording these training sessions as a resource for future training sessions.

Students and teachers must also be educated to understand how their actions impact the O\&M program. Their contributions made during daily activities in the building are important to the program's overall success. The most successful O\&M measures can be rendered ineffective by careless occupant behaviors; thus, training students and staff about the O\&M measures and how their actions can affect the measure effectiveness is vital.

Building Operator Certification (BOC 2011) courses provide training in many locations around the United States. This series is designed to help building operators improve their ability to operate and maintain comfortable, efficient facilities.

Training should cover maintenance requirements for all equipment and systems. Those requirements should be performance based rather than simple checklists - the intent is not to have maintenance personnel simply go through a set of steps, but to make sure that the desired performance result is achieved. 


\section{Recommissioning}

Regular recommissioning can serve as the foundation of a good O\&M program. An effective school upgrade begins with an $\mathrm{RCx}$ effort that identifies building equipment upgrades and finds areas where building systems are not operating as planned (see Section 3). O\&M programs identify low-cost and no-cost ways to maintain changes made as part of the RCx effort. Recommissioning will detect and correct any major systemic problems that develop over time, and ensure that savings persist. Timing for recommissioning will vary, but every three to five years is a typical recommendation. If utility bills are higher than expected, students and teachers complain about comfort, or O\&M staff members constantly repair the same equipment, it might be time to consider recommissioning. According to Mills (2009), RCx and recommissioning yielded average whole-building energy savings of $16 \%$ and a simple payback of 1.1 years. Seventy-seven percent of problems identified were related to the HVAC system (see Figure 6-1).

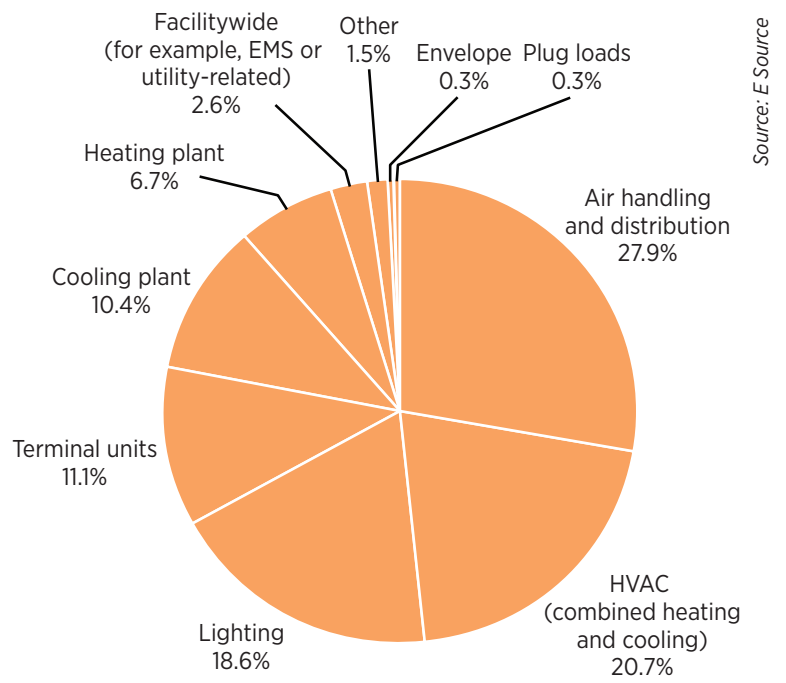

Figure 6-1 Breakdown of common commissioning problems by system type

\section{Good Operations and Maintenance Practices}

The O\&M program covers overall systems and building policies as well as specific areas, including lighting, HVAC, water heating, and miscellaneous systems.

\section{Overall Systems and Policies}

A good O\&M program starts with collecting and creating O\&M resource documents. It also covers BAS or EMS, and includes an O\&M-friendly purchasing policy.

Collect reference materials. O\&M staff members rely on equipment lists and reference manuals for the information they need to operate and maintain building systems and equipment. The upgrade process provides schools the opportunity to evaluate the status of O\&M documentation and update or create new references as needed. Equipment lists provide basic information about each piece of equipment in the school, including:

- Manufacturer's name

- Name plate information

- Unique name/number (if necessary)

- Vendor's name

- Installation date

- Location within building. 
Reference manuals should also be on file for all building systems. These could be equipment manuals from the manufacturers or system control documents explaining the new set points and operating sequences in place after the upgrade. The U.S. Department of Health and Human Services provides a blank template that O\&M staff can fill in for each building system and piece of equipment (HHS 2011). The template supplies sections for system descriptions, use, and maintenance, among other items. O\&M staff can use these sections to help guide them to all the information necessary for a reference manual. O\&M staff should also keep an open journal or log for each piece of equipment or building system to chronicle all maintenance activities.

Use a BAS. When introducing a new O\&M program, take advantage of any BAS or EMS that might be in place. One survey of 11 buildings with BASs in New England found that five were not fully utilizing their BASs, achieving only $55 \%$ of expected savings. Furthermore, one building realized no savings at all because operators never correctly implemented the BAS control strategies (Wortman et al. 1996). A BAS comprises automated systems that can be programmed to control setbacks, shutdowns, and startups, as well as other energy-saving actions. An EMS or BAS may have automated diagnostic capabilities to alert O\&M staff of impending operational issues or other problems that are difficult for staff to diagnose. It can also collect performance data that can be further analyzed for operational performance evaluation and benchmarking purposes. These systems can be costly and require intensive staff training, but when properly used, they help increase a building's efficiency.

Establish a green purchasing policy. Using inefficient replacement parts can undermine energy saving efforts. A purchasing policy that emphasizes efficiency can ensure that only the most efficient options are used. For example, if a building upgrade includes the installation of high-performance T8 lamps, the purchasing policy should ensure that only those lamps are in stock. That way, if a teacher reports a lamp burnout in a classroom, only the efficient version will be available to replace it.

The policy should also consider maintenance requirements for each item. Procurement staff should evaluate maintenance records and useful life of potential items and stock only those with proven track records. Procurement plans can decrease repair and replacement times by requiring the purchase of efficient items that need little to no maintenance. For example, purchasing air filters with three months of useful life that offer equivalent performance to filters with only one month of useful life will provide O\&M staff additional time for other priorities.

ENERGY STAR and FEMP provide purchasing and procurement resources that can help organizations find energyefficient products. These resources include lists of qualifying products, key product criteria, drop-in procurement language, and savings calculators. See the list of ENERGY STAR products (EPA 2011h) and visit the FEMP website (FEMP 2011) for products not covered under ENERGY STAR.

\section{Lighting}

Lighting systems lose efficiency over time. Some of these losses are inevitable - light sources naturally degrade as they age. But other efficiency losses - dirt accumulation on fixture lenses, reflectors, and lamps; or controls drifting out of calibration, can be minimized by regularly scheduled maintenance.

Clean. Lighting levels can decrease by as much as $15 \%$ without proper cleaning. Cleaning dirt and dust off lamps and their covers keeps light output at the maximum level. Lighting covers and diffusers darken with age and will eventually need replacement, but regular cleaning should extend their useful life. Cleaning is most efficient when built in with another O\&M program, such as group relamping.

Check light levels. Once lights have been replaced and cleaned, measure the lighting levels to determine whether they are appropriate for the tasks performed in that space. Overlit and underlit areas should be adjusted to provide appropriate light levels. 
Establish a group relamping program. A planned group relamping program is typically more cost effective than spot replacement of burned-out lamps. With group relamping, a number of lamps are replaced at the same timeusually at $60 \%-80 \%$ of rated lamp life. This process usually results in higher lamp costs, which are usually more than offset by lower labor costs. Schools will also enjoy brighter and more uniform lighting because all lights will be replaced at similar points in the degradation process, before their output fully degrades. Another benefit is that additional lighting O\&M activities, including cleaning and ballast inspection, can be coordinated with relamping.

Inspect controls. Inspect lighting control systems regularly to ensure lights are off when spaces are unoccupied or to take advantage of daylighting opportunities. Evaluate and adjust automatic timers as needed and push the start time back as late as possible. Nighttime and outdoor lighting should be minimized as much as safety and local ordinances allow.

\section{Heating, Ventilation, and Air-Conditioning}

O\&M activities for the HVAC system can have a large impact on building efficiency and comfort, considering that the heating and cooling systems typically account for more than half the energy consumed by school buildings.

Maintain boilers. Boilers usually consume more energy than any other piece of equipment in a school building. Boilers require regular maintenance throughout the year and some states require regular inspections. The operating manual should provide tests and procedures for scheduled maintenance. Other best practices for boilers include:

- Review boiler controls to identify unused efficiency strategies, such as OA reset, OA high temperature shutoff, and optimization for multiple boiler systems. If these strategies are not available in the onboard boiler controls, they can be added later as retrofits.

- Develop a program for treating makeup water to prevent equipment damage and efficiency losses.

- Install a boiler combustion monitoring system or have O\&M staff periodically check the air-fuel ratio.

- Inspect set point temperatures and reset the boiler to the minimum required pressure if no temperature or pressure reset controls are in use.

- Initiate a steam trap maintenance program to identify and repair steam trap leaks.

- Shut down boilers seasonally, if appropriate for the climate and equipment.

Maintain furnaces. O\&M programs for furnaces are similar to those for boilers. The operating manual should provide normal operation guidelines. O\&M staff should also check for gas leaks regularly, inspect limit devices and flame sensors, and check the flue for blockage. Installing controls to set back the supply temperatures during unoccupied periods will help save energy as well.

Inspect cooling equipment. Refrigerant charge should be checked regularly, as over- and undercharged systems can significantly reduce efficiency. Regular inspections should also help O\&M staff identify leaks.

Test AHUs. Airflow rates should be tested every few years to confirm that they meet minimum requirements. Lowering ventilation rates can save energy, but can also decrease IAQ. The right balance will depend on occupancy levels and climate. Desired airflow rates for each system should be stated in the O\&M reference documents.

Maintain economizers. Economizers use controlled dampers to automatically open and close as indoor and outdoor conditions dictate. By design, they house many moving parts. Cleaning, lubricating, and inspecting these parts three or four times per year can keep the dampers from being stuck in any position.

Inspect and clean coils. Dirty condenser and evaporator coils reduce airflow and cooling capabilities. Inspect both regularly and clean as necessary. 
Inspect and clean fans. Cleaning fan blades annually can extend the life of the fan and gives O\&M staff the chance to inspect for chips or cracks. Staff should inspect the bearings and lubricate as the manufacturer recommends, usually no longer than six-month intervals, and examine the belts for wear and appropriate tightness.

Replace air filters. Dirty air filters block the airflow through the system. This blockage requires more power from the fan motor to push the air through. Consider using filters with larger cross-sections because they use less energy to move air through the filter. Most filters need to be replaced every one to three months, as recommended by the manufacturer. O\&M staff should inspect filters regularly and replace as needed.

Inspect air ducts. Air leaks can drastically reduce cooling system efficiencies. O\&M staff should inspect all access panels and gaskets for leaks at regular intervals, at least once each year. The entire duct system should also be inspected regularly, although not as frequently. Look over appropriate areas to ensure nothing blocks access panels or air intakes.

Maintain controls. Regular maintenance of control systems is crucial because occupants may have changed settings or the systems may be defective or have drifted out of specification. System settings are determined with energy efficiency in mind and O\&M staff should test and verify all systems periodically, particularly those affected by seasonal changes.

\section{Water Heating}

Water heating is the next-largest energy consumer in schools behind lighting and HVAC. Inspecting and evaluating the water heater and delivery system will prevent energy losses and extend equipment life.

Check storage tank insulation. Storage type water heaters can lose efficiency through heat loss from the water stored in the tank. If insulation was added as part of an energy upgrade, check to make sure its integrity is maintained.

Check pipe insulation. Hot water delivery pipes, particularly those in unconditioned spaces, should be insulated to minimize uncontrolled loss of heat from the system and reduce wait time at the fixtures. O\&M staff should inspect this insulation regularly, because it will deteriorate over time.

Tune up burners. Gas- and oil-fired burners should be tested and adjusted annually to maintain optimum operating efficiency.

Flush hot water fixtures. Hot water fixtures should be flushed occasionally to control bacteria growth. Water heaters with storage tanks should be flushed out annually to remove any sediment that reduces the system's heat transfer efficiency.

Reduce water use. Reducing hot water use throughout the building will lessen the load on the water heater. Finding and repairing leaks will also reduce the water heater load.

\section{Miscellaneous}

The O\&M program should also cover a number of other areas, including the building envelope, plug loads, and kitchen equipment.

Seal the building envelope. Eliminate air and water leaks by sealing the building envelope. Inspect doors, windows, roofing, and the foundation for leaks and repair using caulking or weather-stripping. Complaints about drafty areas will help O\&M staff locate these leaks. Other signs, such as doors that do not fully close and water marks on walls or ceilings, are indicators of an inefficient or leaky envelope.

Manage plug loads. Plug loads refer to the electricity drawn by any device plugged into a wall outlet. These loads can be as much as $25 \%$ of a school's electricity use, so managing them is vital for the O\&M program (DOE 2009). Students and staff need to participate because they are the most aware of plug loads and have the greatest ability to 
limit them. Turning computers and monitors off when not in use can save significant energy. Even setting computers to "hibernate" mode after periods of inactivity will reduce their power draw. Using smart strip surge protectors in equipment-heavy rooms, such as computer rooms, will help eliminate phantom loads, the power drawn by certain appliances even when turned off or in standby mode. Simply unplugging devices when they are not in use can also help reduce energy consumption. McKenney et al. (2010) studied common plug loads in commercial buildings. This report can help O\&M staff estimate how much standby power is being consumed throughout the building.

Clean kitchen appliances. Cleaning vents and heating coils will increase the efficiency of kitchen equipment. Ensuring that condenser coils are clean and unobstructed can keep refrigerators and freezers operating at maximum efficiency.

\subsection{Additional Resources}

Consult these resources for more detailed information on O\&M programs for K-12 schools:

A Retrocommissioning Guide for Building Owners from PECI, a guide explaining the retrocommissioning process, including a section on maintaining benefits long after the commissioning process is complete. www.peci.org/ resources/library/retrocommissioning-guide-building-owners

BOMA's Preventative Maintenance Guidebook is a comprehensive guide to establishing and implementing a preventive maintenance program.

Building Operator Certification (BOC) courses provide training for building operators to improve their ability to operate and maintain comfortable, efficient facilities. www.theboc.info/

Building Upgrade Manual from ENERGY STAR, a strategic guide for energy saving building upgrades. www. energystar.gov/index.cfm?c=business.bus_upgrade_manual

Guide to Operating and Maintaining EnergySmart Schools from the Office of Energy Efficiency and Renewable Energy, a guide written specifically for developing and implementing O\&M programs for K-12 schools and districts. http://apps1.eere.energy.gov/buildings/publications/pdfs/energysmartschools/ess_o-and-m-guide.pdf

Operations and Maintenance Systems-A Best Practice for Energy-Efficient Building Operations from Portland Energy Conservation, Inc., explains where to begin the process of developing an O\&M program. www.energystar. gov/ia/business/assessment.pdf

Operations \& Maintenance Best Practices-A Guide to Achieving Operational Efficiency, Release 3.0 from FEMP, an extensive resource of best practices and O\&M tips for many types of building equipment and systems. www .eere. energy.gov/femp/pdfs/omguide_complete.pdf

PNNL report, "Maintaining the Solution to Operations and Maintenance efficiency improvement": defines the key elements of a holistic approach to O\&M management: Operations, Maintenance, Engineering Support, Training and Administration.

Procuring Energy-Efficient Products page from the Federal Energy Management Program, similar to the ENERGY STAR procurement page with more information on procurement policies and energy-efficient product categories outside of ENERGY STAR. www1.eere.energy.gov/femp/technologies/procuring_eeproducts.htm/

Purchasing \& Procurement page from ENERGY STAR, a compilation of ENERGY STAR qualified products as well as resources for developing efficient procurement policies. www.energystar.gov/index.cfm?c=bulk_purchasing. bus_purchasing

The BetterBricks website developed by the Northwest Energy Efficiency Alliance. It includes management advice, tools and technical advice, and training resources. www.betterbricks.org 


\section{Conclusion}

K-12 schools consume $8 \%$ of all commercial building energy use in the United States, and spend more than $\$ 8$ billion on energy costs. In addition, the average school is 42 years old, and 30\% were built before 1960. As a result, existing K-12 schools provide ample opportunity for energy efficiency improvements. This guide demonstrates that significant energy savings are relatively easy to achieve through $\mathrm{EBCx}$, and that much greater savings can be accessible for energy managers and school districts that are willing to invest in holistic retrofit projects using a wholebuilding or staged approach. The rigorous financial analysis methods presented in this guide show that the long-term benefits from these retrofits considerably outweigh the costs. Rising energy costs, climate risks, regulatory risks, and growing community support for sustainability are other drivers moving building energy upgrades from a niche activity to an essential activity to control costs and create a healthy, comfortable learning environment for our children.

When analyzed in the context of the example high school building, we were able to identify energy savings ranging from $12 \%$ for EBCx packages to more than $32 \%$ for whole-building retrofit packages (see Figure 7-1). Energy savings for retrofit packages are independent of $\mathrm{EBCx}$, and the combined package will result in even higher energy savings, though less than the sum of the two separate packages because the benefit of certain EBCx EEMs would be consumed by retrofit EEMs for the same system (such as cleaning or delamping lighting systems before replacing them entirely). For reference, the energy savings for the 50\% AEDG new construction packages are also shown in the graph (ASHRAE 2011c). The modeling of retrofits was very conservative for our example building, because many EEMs appropriate for comprehensive renovations (such as major equipment replacements and enhanced daylighting) were not considered, and an integrated design approach that considered the interactions among EEMs was not applied. Additional savings opportunities are very likely when applied to an actual K-12 school, when all retrofit EEMs are considered, and when available financial incentives are included.

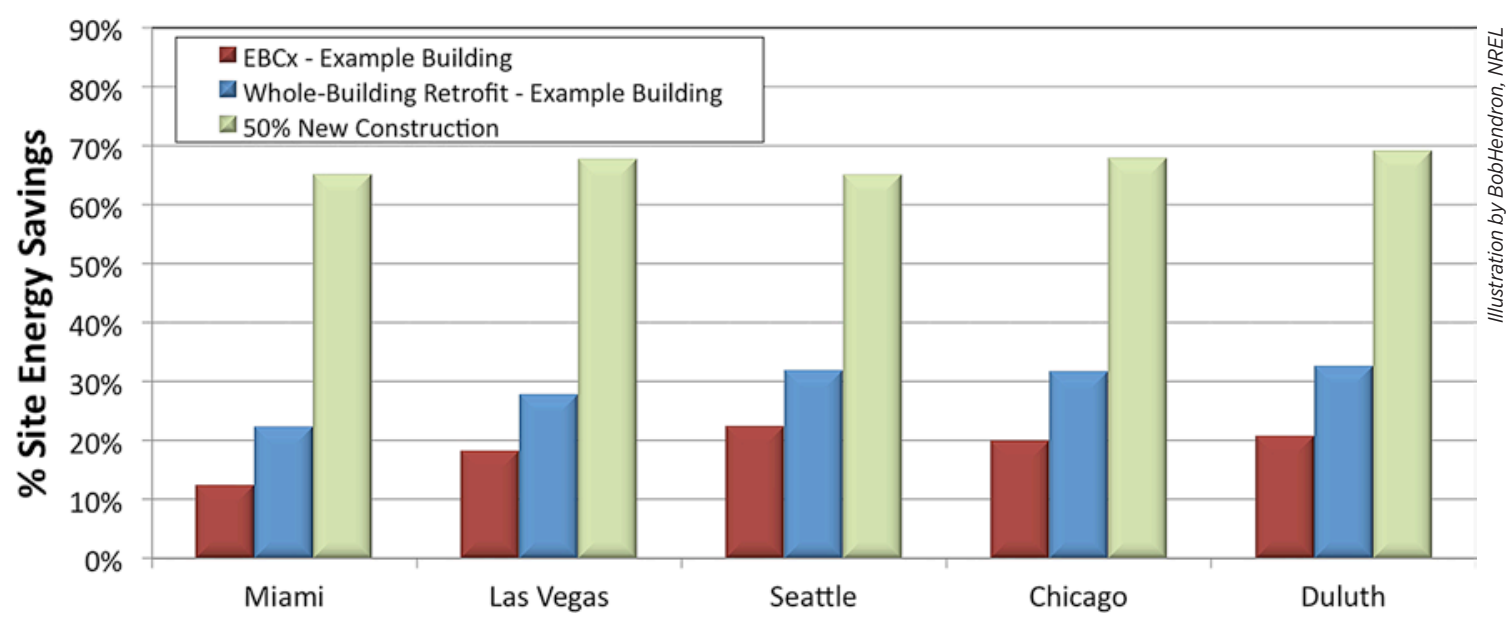

Figure 7-1 Site energy savings for example high school 
Policymakers may be interested in the source (or primary) energy savings associated with the recommended packages. Source energy includes the energy used on site, along with the energy lost or consumed during the generation, transmission, and distribution processes. The source energy multiplier for electricity is about 3.4, and the multiplier for natural gas is about 1.1 (Deru and Torcellini 2007). The energy savings expressed in terms of source energy are shown in Figure 7-2.

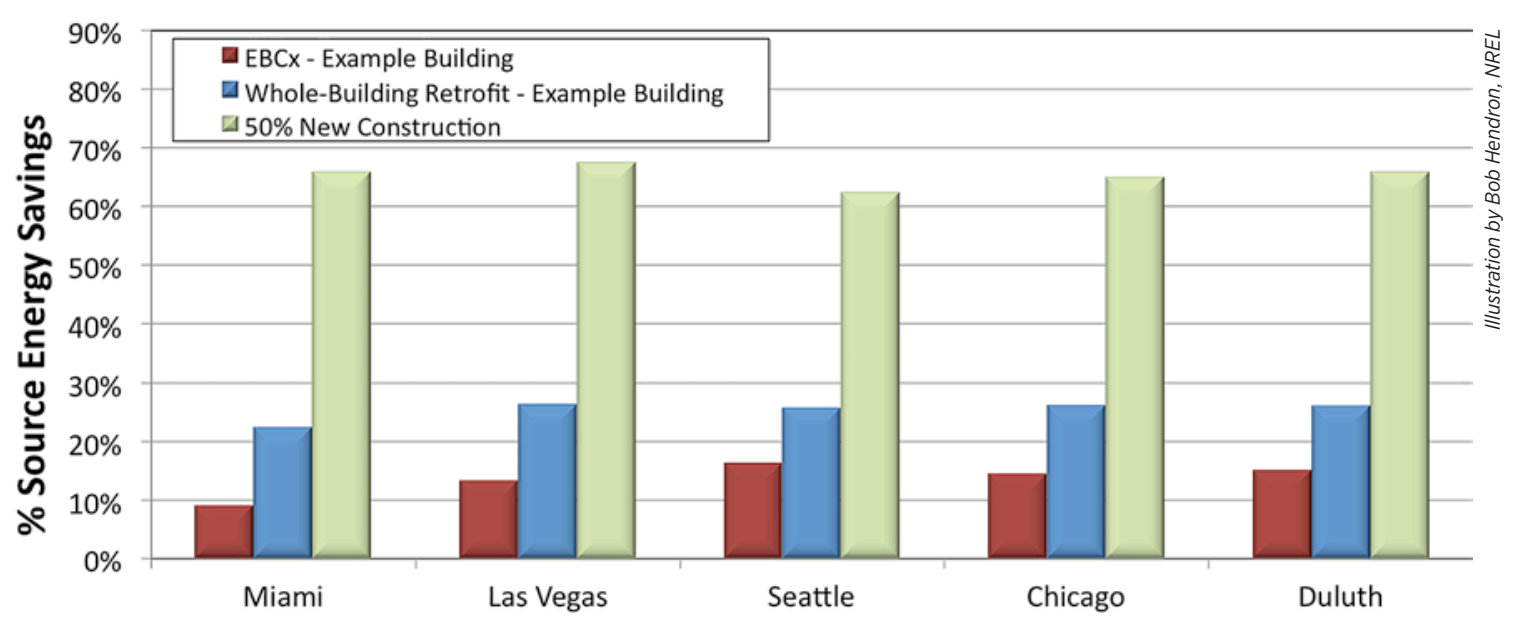

Figure 7-2 Source energy savings for the example high school

Although most would agree that improving building performance is the right thing to do, and acknowledge the wide range of options, navigating those options and developing a profitable long-term strategy have been far from easy. This guide breaks down the myriad options into prioritized retrofit EEMs and recommended packages based on a typical high school, providing a strong start to energy managers responsible for any K-12 school. The guide also presents cost-effectiveness metrics for each package that recognize the complexity of a school board's economic decisions.

Even the most compelling business case might fall short of success without sound planning and implementation. Therefore, this guide describes proven approaches to project planning and execution. Decision makers can drive their schools toward higher performance by setting goals, creating a long-term plan, and carefully tracking progress. The roadmap presented in this guide can help lead energy managers from recognition of the opportunity through the full journey that leads to high performance.

A wide array of resources is available to energy managers who seek to enhance building performance. This guide includes links to a host of other resources that energy managers may wish to consult. With the help of information and assistance offered by many government agencies, utility companies, and other organizations, nearly every energy manager, facility manager, or school board is within easy reach of an energy-saving project.

We hope this guide will give school district decision makers the confidence to take aggressive actions to improve the energy efficiency of their school buildings, and will be a valuable reference as building improvement projects are implemented. 


\section{References}

Apter, A.; Bracker, A.; Hodgson, M.; Sidman, J.; Leung, W. 1994. Epidemiology of the sick building syndrome. The Journal of Allergy and Clinical Immunology 94(2):277-288.

Arends, J.; Sandusky, W.F. 2010. American Recovery and Reinvestment Act (ARRA), FEMP Technical Assistance, U.S. General Services Administration - Project 195, John Seiberling Federal Office Building and U.S. Courthouse, Akron, Ohio.” Pacific Northwest National Laboratory Technical Report PNNL-19391. www.pnl.gov/main/ publications/external/technical_reports/PNNL-19391.pdf

ASE. 2009. Tips to Save Energy at School During the Holidays. Efficiency News, December 2009. http://ase.org/ efficiencynews/tips-save-energy-school-during-holidays

ASE. 2011. Energy Saving Tips for Schools. http://ase.org/resources/energy-saving-tips-schools. Accessed July 2011.

ASHRAE 1999. ANSI/ASHRAE/IESNA Standard 90.1-1999 Energy Standard for Buildings except Low-Rise Residential Buildings. American Society of Heating, Refrigerating and Air-Conditioning Engineers, Inc. Atlanta, Georgia. ASHRAE. 2004a. Thermal Environmental Conditions for Human Occupancy,” ASHRAE Standard 55-2004, Atlanta, GA: American Society of Heating, Refrigerating and Air-Conditioning Engineers, Inc.

ASHRAE. 2004b. Procedures for Commercial Building Audits. Atlanta, GA: American Society of Heating, Refrigerating and Air-Conditioning Engineers, Inc.

ASHRAE 2004c. ANSI/ASHRAE/IESNA Standard 90.1-2004 Energy Standard for Buildings except Low-Rise Residential Buildings. American Society of Heating, Refrigerating and Air-Conditioning Engineers, Inc. Atlanta, Georgia.

ASHRAE. 2008. Advanced Energy Design Guide for K-12 Schools: Achieving 30\% Energy Savings Toward a Net Zero Energy Building. Atlanta, GA: American Society of Heating, Refrigerating and Air-Conditioning Engineers, Inc.

ASHRAE. 2009a. Standard 189.1: Standard for the Design of High-Performance, Green Buildings Except Low-Rise Residential Buildings. Atlanta, GA: American Society of Heating, Refrigerating and Air-Conditioning Engineers, Inc. ASHRAE. 2009b. Energy Efficiency Guide for Existing Commercial Buildings: The Business Case for Building Owners and Managers. Atlanta, GA: American Society of Heating, Refrigerating and Air-Conditioning Engineers, Inc.

ASHRAE. 2010. Ventilation for Acceptable Indoor Air Quality. ANSI/ASHRAE Standard 62.1-2010. Atlanta, GA: American Society of Heating, Refrigerating and Air-Conditioning Engineers.

ASHRAE. 2011a. 2011 ASHRAE Handbook: HVAC Applications. Atlanta, GA: American Society of Heating, Refrigerating and Air-Conditioning Engineers, Inc.

ASHRAE. 2011b. Procedures for Commercial Building Energy Audits. Atlanta, GA: American Society of Heating, Refrigerating and Air-Conditioning Engineers, Inc.

ASHRAE. 2011c. Advanced Energy Design Guide for K-12 Schools: Achieving 50\% Energy Savings Toward a Net Zero Energy Building. Atlanta, GA: American Society of Heating, Refrigerating and Air-Conditioning Engineers, Inc.

Benya, J.; Clanton, N.; Lipstein, L.; Smith, L.; Mutmansky, M.; Miller, N.; English, C.; Lavoie, D.; Gibson, E. 2011. Joint IDA-IES Model Lighting Ordinance (MLO) With User's Guide. 
Borgeson, M.; Zimring, M. 2013. Financing Energy Upgrades for K-12 School Districts. LBNL-6133E. Berkeley, CA: Lawrence Berkeley National Laboratory. www.eere.energy.gov/wip/solutioncenter/pdfs/financing_energy_ upgrades_K-12.pdf.

Braun, J.E.; Lawrence, T.M. 2002. Demonstration of Load Shifting and Peak Load Reduction with Control of Building Thermal Mass. Commercial Buildings: Technologies, Design, Performance Analysis, and Building Industry Trends. http://eec.ucdavis.edu/ACEEE/2002/pdfs/pane/03/05_530.pdf

Callahan, M.; Parker, D.; Sherwin, J.; and Anello, M. 1999. "Evaluation of Energy Efficiency Improvements to Portable Classrooms in Florida." FSEC-CR-1133-99. Prepared for the Florida Department of Education. Cocoa, FL: Florida Solar Energy Center. www.fsec.ucf.edu/en/publications/html/FSEC-CR-1133-99/index.htm

CEC. 2000. "How to Hire an Energy Auditor to Identify Energy Efficiency Projects." www.energy.ca.gov/reports/ efficiency_handbooks/400-00-001C.PDF

CEC. 2003. "Summary Of Daylighting In Schools: Reanalysis Report". Prepared By New Buildings Institute. Technical Report 500-03-082-A-4. www.energy.ca.gov/2003publications/CEC-500-2003-082/CEC-500-2003082-A-04.PDF

CEC. 2005a. "Advanced Variable Volume Air Handler Design Guide." Public Interest Energy Research (PIER) Program http://uccsuiouee.org/seminars/UC\%20CSU\%20VAV\%20Design\%20Guide.pdf

CEC. 2005b. Design Guide: Big Savings on Small HVAC Systems, Public Interest Energy Research Program Tech Brief. www.energy.ca.gov/2005publications/CEC-500-2005-046/CEC-500-2005-046-FS.PDF

CEC. 2008. Integrated Classroom Lighting System: Light's Great, Less Billing. Public Interest Energy Research Program Tech Brief. www.esource.com/esource/getpub/public/pdf/cec/CEC-TB-1_ClassroomLighting.pdf

Cho, H.; Gowri, K.; and Liu, B. 2010. Energy Saving Impact of ASHRAE 90.1 Vestibule Requirements: Modeling of Air Infiltration through Door Openings. PNNL Technical Report PNNL-20026. Richland, WA: Pacific Northwest National Laboratory.

CHPS. 2006. Best Practices Manual. Sacramento, CA: Collaborative for High-Performance Schools. www.chps.net/ dev/Drupal/node/288

Cowan, A. 2004. "Review of Recent Commercial Roof Top Unit Field Studies in the Pacific Northwest and California,” New Buildings Institute. http://newbuildings.org/document-library?page=9

Deru, M., and Torcellini, P. 2007. Source Energy and Emission Factors for Energy Use in Buildings. NREL Technical Report TP-550-38617. www.nrel.gov/docs/fy07osti/38617.pdf

Deru, M.; Field, K.; Studer, D.; Benne, K.; Griffith, B.; Torcellini, P.; Liu, B.; Halverson, M.; Winiarski, D.; Rosenberg, M.; Yazdanian, M.; Huang, J.; Crawley, D. 2011. U.S. Department of Energy Commercial Reference Building Models of the National Building Stock. NREL/TP-5500-46861.

DiLaura, D.L. The Lighting Handbook. New York, NY: Illuminating Engineering Society, 2011.

DOE. 2002. "Industrial Wireless Technology for the 21st Century." Office of Energy Efficiency and Renewable Energy. Washington, DC: U.S. Department of Energy. www.energetics.com/resourcecenter/products/roadmaps/Pages/ wireless_roadmap.aspx

DOE. 2003. Commercial Buildings Energy Consumption Survey (CBECS). Washington, DC: U.S. Department of Energy. www.eia.gov/emeu/cbecs/ 
DOE. 2008a. "Goodyear Tire Plant Gains Traction on Energy Savings After Completing Save Energy Now Assessment." Save Energy Now case study. www.nrel.gov/docs/fy08osti/42328.pdf

DOE. 2008b. Guide to Financing Energy Smart Schools. http://apps1.eere.energy.gov/buildings/publications/pdfs/ energysmartschools/ess_financeguide_0708.pdf

DOE. 2008c. Energy Tips - Motor: Adjustable Speed Drive Part-Load Efficiency. DOE/GO-102008-2617. www1. eere.energy.gov/industry/bestpractices/pdfs/motor_tip_sheet11.pdf

DOE. 2009. Guide to Operating and Maintaining EnergySmart Schools. Washington, DC: U.S. Department of Energy. http://apps1.eere.energy.gov/buildings/publications/pdfs/energysmartschools/ess_o-and-m-guide.pdf

DOE. 2010. Operations \& Maintenance Best Practices: A Guide to Achieving Operational Efficiency. Washington, D.C.: U.S. Department of Energy. www1.eere.energy.gov/femp/pdfs/omguide_complete.pdf

DOE. 2011a. Annual Energy Outlook 2011. DOE/EIA-0383(2011). Washington, DC: U.S. Department of Energy. www.eia.gov/forecasts/aeo/pdf/0383(2011).pdf

DOE. 2011b. Estimating Swimming Pool Gas Heating Costs and Savings. Washington, DC: U.S. Department of Energy. www.energysavers.gov/your_home/water_heating/index.cfm/mytopic=13180

DOE. 2011c. Technology Specification Project: LED Site (Parking Lot) Lighting. http://apps1.eere.energy.gov/ buildings/publications/pdfs/alliances/techspec_ledparkinglot.pdf

DOE. 2012. Aiming for 50\% Energy Savings: Target takes efficiency to the next level in their design for a new store in Brookfield, Wisconsin. Draft Case Study.

DSIRE. 2011. Database of State Incentives for Renewable Energy. Washington, D.C.: U.S. Department of Energy. www.dsireusa.org/

E Source. 1997. "Low-Cost, No-Cost Efficiency Retrofits for Chilled Water Systems." TU-97-9. www.esource.com/ esource/getpub/members/e_cd/pdfs/TU9709.PDF

E Source. 1999. “Public-Sector Audit Programs: Lessons Learned.” ER-99-12. Boulder, CO: E Source.

E Source. 2005. "Making Daylighting Systems Work.” ER-05-9. Boulder, CO: E Source. E Source. 2009. “Airside Economizers.” E Source Resource Guide.

E Source. 2009. “Air-side Economizers.” E Source Resource Guide.

E Source. 2011. Saving Energy with Smart Strips. TAS-ASKES-30, January 04, 2011.

EVO. 2010. The International Performance Measurement and Verification Protocol (IPMVP): Concepts and Options for Determining Energy and Water Savings, Volume I. Efficiency Valuation Organization.

EWC. 2011. The Efficient Windows Collaborative Tools for Schools. www.efficientwindows.org/ToolsForSchools.pdf Egan, M.D., and Olgyay, V. 2002. Architectural Lighting. New York, NY: McGraw-Hill.

EIA. 2011. Total Energy. Washington, D.C.: Energy Information Administration. www.eia.gov/totalenergy/

Empire State Building Company L.L.C 2011. Empire State Building Retrofit. http://esbnyc.com/sustainability energy_efficiency.asp. Accessed July 2011.

EPA. 2003a. Energy Efficiency and Indoor Air Quality in Schools. EPA Working Paper. Washington, DC: U.S. Environmental Protection Agency. www.epa.gov/iaq/schools/pdfs/publications/ee_iaq.pdf 
EPA. 2003b. Financing Profile of Success: Miami-Dade County Public Schools. Energy Star Program. www.energy star.gov/ia/business/121202profile_MDCPS.pdf

EPA. 2003c. Save Energy, Money, and Prevent Pollution with Light-Emitting Diode (LED) Exit Signs. ENERGY STAR Fact Sheet. Washington, DC: U.S. Environmental Protection Agency. http://unix4.com/s/save-energy,-moneyand-prevent-pollution-with-light-emitting-diode-w1987.htm/

EPA. 2006. North Thurston Public Schools Will Save $\$ 45,000$ by Putting Computers To Sleep. Energy Star Case Study. Washington, DC: U.S. Environmental Protection Agency.

EPA. 2007b. A Retrocommissioning Guide for Building Owners. Washington, DC: U.S. Environmental Protection Agency www.peci.org/resources/library/retrocommissioning-guide-building-owners

EPA. 2007c. Introduction to Energy Performance Contracting. Washington, DC: U.S. Environmental Protection Agency. www.energystar.gov/ia/partners/spp_res/Introduction_to_Performance_Contracting.pdf

EPA. 2008. "ENERGY STAR Building Upgrade Manual.” Office of Air and Radiation. Washington, DC: U.S. Environmental Protection Agency. www.energystar.gov/index.cfm?c=business.bus_upgrade_manual

EPA. 2009. ENERGY STAR Computer Power Management Savings Calculator. www.energystar.gov/index.cfm?fuse action=find_a_product.showProductGroup\&pgw_code $=\mathrm{CO}$

EPA. 2011a. Portfolio Manager Overview. Washington, DC: U.S. Environmental Protection Agency. www.energystar. gov/index.cfm?c=evaluate_performance.bus_portfoliomanager

EPA. 2011b. Energy Star for K-12 School Districts website. Accessed June 2011. Washington, DC: U.S. Environmental Protection Agency. www.energystar.gov/index.cfm?c=k12_schools.bus_schoolsk12

EPA. 2011c. IAQ Tools for Schools program. Washington, DC: U.S. Environmental Protection Agency. www.epa. gov/iaq/schools/

EPA. 2011d. "Colorado Springs School District 11-Achieving Healthy Indoor Learning Environments Through Energy Efficiency Upgrades.” Energy Star Program Case Study. Washington, DC: U.S. Environmental Protection Agency. www.documbase.com/Colorado-Springs-School-District.pdf. Accessed July 2011

EPA. 2011e. "How Seaford School District Met the Mark for Energy Efficiency." Energy Star Program Case Study. Washington, DC: U.S. Environmental Protection Agency. www.energystar.gov/ia/business/k12_schools/ENERGY_ STAR_Case_Study-How_to_Meet_the_Mark_for_Energy_Efficiency_CG0807.pdf

EPA. 2011f. ENERGY STAR Commercial Kitchen Equipment Savings Calculator. www.energystar.gov/index. cfm?fuseaction=find_a_product.showProductGroup\&pgw_code $=\mathrm{COH}$

EPA. 2011g. Commercial Kitchen Package for Businesses and Operators: Qualified Products. Washington, DC: U.S. Environmental Protection Agency. www.energystar.gov/index.cfm?fuseaction=find_a_product.showProduct Group\&pgw_code $=C K P$

EPA. 2011h. Purchasing and Procurement Website. Washington, DC: U.S. Environmental Protection Agency. www. energystar.gov/index.cfm?c=bulk_purchasing.bus_purchasing

EPA. 2011i. ENERGY STAR EZ GPO.www.energystar.gov/index.cfm?c=power_mgt.pr_power_mgt_ez_gpo

Fairey, P. 1984. "Designing and Installing Radiant Barrier Systems," Design Note 7, Florida Solar Energy Center, Cape Canaveral, FL. 
FEMP. 2011. Technology Deployment List. Washington, D.C.: Federal Energy Management Program. www.eere. energy.gov/femp/technologies/newtechnologies_matrix.htm/

Fisher, D. 2008. Field Studies in Demand Control Ventilation. San Ramon, CA: Food Service Technology Center. Flexible Solutions. 2011. Personal communication with Monique Nelson, Sales \& Marketing Manager, June 2, 2011. Foster-Miller. 2002. Vending Machine Service Call Reduction Using the VendingMiser. www.usatech.com/energy management/downloads/Foster_Miller_Report_on_VM_Savings_Final.pdf

Guo, W.; Nutter, D.W. 2010. "Setback and Setup Temperature Analysis for a Classic Double-Corridor Classroom Building." Energy and Buildings 42:189-197.

HHS. O\&M Manual Template. Accessed July 2011. Washington, DC: U.S. Department of Health and Human Services. www.hhs.gov/ocio/ep/c/EPLC\%20Archive\%20Documents/40-Operations\%20and\%20Maintenance\%20Manual/ eplc_om_manual_template.doc

Hopper, N.; Goldman, C.; McWilliams, J.; Birr, D. McMordie K. 2005. Public and Institutional Markets for ESCO Services: Comparing Programs, Practices and Performance. Berkeley, CA: Ernest Orlando Lawrence Berkeley National Laboratory. http://eetd.Ibl.gov/ea/EMS/reports/55002.pdf

Hughes, P.J.; Shonder, J.A.; Sharp, T.; Madgett, M. 2003. Evaluation of Federal Energy Savings Performance Contracting-Methodology for Comparing Processes and Costs of ESPC and Appropriations-Funded Energy Projects. Oak Ridge, TN: Oak Ridge National Laboratory. ORNL/TM-2002/150. www.ornl.gov/sci/ees/etsd/btric/pdfs/com_ espc_lcc.pdf

IESNA. 2011. The IES Lighting Handbook, Tenth Edition. D. DiLaura, K. Houser, R. Mistrick, G. Steffy (eds.), Illuminating Engineering Society of North America.

Information \& Energy Services (IES). 2010. Engineering Measurement \& Verification Study: HeatSavr Liquid Swimming Pool Cover.

Itron, Inc. 2007. PECI San Diego Retrocommissioning Program EM\&V: SDG\&E Service Area: Final Report. www. nwcouncil.org/dropbox/6th\%20Plan\%2OIndustrial/Industrial\%20Conservation\%20Data\%20Catalogue/ISC\%20 Document \%20Catalogue_Public\%20Version-5\%20June\%202009/Documents/Tier\%202/SCE\%20EE\%20Work\%20 Papers\%20November\%202007\%20Final/References/PECI_SDGE_RCXProgram_Itron_FinalReport.pdf

Kats, G. 2006. Greening America's Schools Costs and Benefits. Capital E. www.leed.us/ShowFile.aspx?Document ID $=2908$

LBNL. 2011. EnergyIQ. Berkeley, CA: Lawrence Berkeley National Laboratory. http://energyiq.Ibl.gov/

Lee, K.; Braun, J. 2008. Model-Based Demand-Limiting Control of Building Thermal Mass. Building and Environment 43(10).

Lord, M. 2008. "Clean Up with Day Cleaning_In More Ways than One.” Buildings, November 2008. www.buildings. com/Magazine/ArticleDetails/tabid/3413/ArticlelD/6762/Default.aspx.

Lovins, A.; Lovins, H.; Hawken, P. 1999. Natural Capitalism, Chapter 6. New York, NY: Little, Brown, \& Co.

Maniccia, D.; Von Neida, B.; Tweed, A. 2000. "Effects of Changing Occupancy Sensor Timeout Setting on Energy Savings, Lamp Recycling, and Maintenance Costs.” IESNA Annual Conference Technical Papers, pp. 409-432

McKenney, K.; Guernsey, M.; Ponoum, R.; Rosenfeld, J. 2010. “Commercial Miscellaneous Electric Loads: Energy Consumption Characterization and Savings Potential in 2008 by Building Type. Lexington, MA: TIAX LLC. http:// zeroenergycbc.org/pdf/2010-05-26 TIAX CMELs Final Report.pdf 
McMaster University. 2011. "Energy Audits by McMaster Students Could Save Schools Millions." Faculty of Engineering News. www.eng.mcmaster.ca/news/2011/student_energy_audit.html. A fact sheet summarizes the outcomes of the project: $h t t p: / / w w w . e n g . m c m a s t e r . c a /$ news/2011/EnergyAuditFactSheet.pdf

Meyer, M.K. 1997. Available Equipment in School Foodservice. Publication No. NFSMI-R-27-97, National Food Service Management Institute. Hattiesburg, MS: University of Mississippi.

Meyers, S. 2003. "Advice On Easing The Transition To Team Cleaning." Health Facilities Management Magazine.

Mills, E. 2009. Building Commissioning: A Golden Opportunity for Reducing Energy Costs and Greenhouse Gas Emissions. Report to California Energy Commission. Berkeley, CA: Lawrence Berkeley National Laboratory.

NEMA. 2011. NEMA Premium Motors. www.nema.org/gov/energy/efficiency/premium/

New Hampshire Department of Education. 2010. Helping New Hampshire Schools Save Money and Energy. Portsmouth, NH: New Hampshire EnergySmart Schools Program. www.nhschoolbenchmarking.com/

NEEA. 2011. BetterBricks website. Portland, OR: Northwest Energy Efficiency Alliance. www.betterbricks.org

NEED. 2007. Energy Management Guide for Schools. Manassas, VA: National Education Energy Development Project. www.need.org/needpdf/EnergyManagementGuide2007FINAL.pdf

NYSERDA. 2004. Energy Smart Schools Program. Albany, NY: New York State Energy Research and Development Authority.

ORNL and LBNL. 2011. Roof Savings Calculator. www.roofcalc.com/index.shtm/

PECI. 2007b. “A Retrocommissioning Guide for Building Owners". Portland Energy Conservation, Inc. www.peci. $\mathrm{org} /$ sites/default/files/epaguide_0.pdf

PECI. 2011. Personal communication with Reid Hart, Associate Director, Technical Research.

PG\&E. 2002. Assessing Economizer Performance. PEC Tool Lending Library Application Note. www.pge.com/ includes/docs/pdfs/about/edusafety/training/pec/toolbox/tll/appnotes/assessing_economizer_performance.pdf

Plympton, P.; Conway, S.; Epstein, K. 2000. Daylighting in Schools: Improving Student Performance and Health at a Price Schools Can Afford. Presented at the 2000 American Solar Energy Society Conference in Madison, WI. Golden, CO: National Renewable Energy Laboratory. NREL/CP-550-28049. www.nrel.gov/docs/fy00osti/28049.pdf

PNNL. 2010. "Operations \& Maintenance Best Practices: A Guide to Achieving Operational Efficiency, Release 3.0.” Prepared for the U.S. Department of Energy Federal Energy Management Program. www1.eere.energy.gov/ femp/pdfs/omguide_complete.pdf

Poudre School District. 2011. Green Team, www.psdschoo/s.org/node/4176

Price, S.; Rosenow, L. 2009. "BPA RTU Puget Sound Pilot." Northwest Energy Efficiency Council. www.nwcouncil. org/energy/rtf/subcommittees/rtug/2010_01/BPA\%20RTU\%20Pilot\%2OFinal\%2OField\%20Report\%20NEEC.pdf

PERI. 2004. School Operations and Maintenance: Best Practices for Controlling Energy Costs: A Guidebook for K-12 School System Business Officers and Facilities Managers. Rockville, MD: Princeton Energy Resources International www.azdeg.gov/function/about/download/greenguide2.pdf

Quantec. 2007. "Characterization and Energy Efficiency Opportunities in Vending Machines for the Northwestern US Market." Prepared for the Northwest Power and Conservation Council. www.nwcouncil.org/energy/rtf/meetings/ 2007/08/RTF\%20Vending\%20Characterization\%20Study_Revised\%20Report_072407.pdf 
R.S. Means. 2009. Facilities Maintenance \& Repair Cost Data: 16th Annual Edition. Kingston, MA: R.S. Means Company, Inc.

Raabe, S., 2003, “Program Helps Pay for Capital Projects.” Denver Post.

Rose, W.B. Water in Buildings: an Architect's Guide to Moisture and Mold. Hoboken, NJ: John Wiley \& Sons, 2005.

Roth, K.W.; Westphalen, D.; Dieckmann, J.; Hamilton, S.D.; Goetzler. W. 2002. Energy Consumption Characteristics of Commercial Building HVAC Systems - Volume III: Energy Savings Potential. Final Report by TIAX LLC to U.S. Department of Energy, Office of Building Technology, State and Community Programs. http://apps1.eere.energy. gov/buildings/publications/pdfs/commercial_initiative/hvac_volume3_final_report.pdf

Sanchez, M.; Webber, C.; Brown, R.; Busch, J.; Pinckard, M.; Roberson, J. 2007. Space Heaters, Computers, Cell Phone Chargers: How Plugged In Are Commercial Buildings? Lawrence Berkeley National Laboratory. LBNL62397. http://enduse.Ibl.gov/info/LBNL-62397.pdf

Schneider, M. 2002. “Do School Facilities Affect Academic Outcomes?” Washington, DC: National Clearinghouse for Educational Facilities. www.ncef.org/pubs/outcomes.pdf

Siegenthaler, J. 2001. "Outdoor Reset Control - No Quality Hydronic System Should Be Without It.” PM Engineer. www.pmengineer.com/Articles/Feature_Article/cdd55d5472298010VgnVCM100000f932a8c0

State of Connecticut. 2009. "Maintaining Good IAQ While Conserving Energy.” Connecticut School Indoor Environment Resource Team.

Taylor, S.T. 2007. "Increasing Efficiency With VAV System Static Pressure Setpoint Reset.” ASHRAE Journal, June 2007, pp. 24-32. www.ashrae.org/File\%20Library/docLib/eNewsletters/Tay/or-0607--feature.pdf

Taylor, S.T. 2011. “Optimizing Design \& Control of Chilled Water Plants.” ASHRAE Journal, July, pp. 14-25. www. ashrae.org/File\%20Library/docLib/Journal\%20Documents/2012June/056-075_taylor.pdf

U.S. Army Corps of Engineers. 2010. High Performance Technology Strategy Templates: Daylighting Photosensor.

USGBC. 2011. LEED 2009 for Schools: New Construction and Major Renovations. www.usgbc.org/ShowFile. aspx?Document $I D=8872$

UT Austin. 2008. “Green Roofs Differ In Building Cooling, Water Handling Capabilities.” ScienceDaily, 13 August.

Vaidya, P.; McDougall, T.; Steinbock, J. Douglas, J.; Eijadi, D. 2004. "What's Wrong with Daylighting? Where It Goes Wrong and How Users Respond to Failure." American Council for an Energy-Efficient Economy's (ACEEE) Summer Study on Energy Efficiency in Buildings, Pacific Grove, CA.

Wortman, D.; Evans, E.; Porter, F.; Hatcher, A. 1996. “An Innovative Approach to Impact Evaluation of Energy Management System Incentive Programs." ACEEE Summer Study on Energy Efficiency in Buildings. American Council for an Energy-Efficient Economy.

Xu, P.; Yin, R.; Brown, C.; Kim, D. 2009. Demand Shifting with Thermal Mass in Large Commercial Buildings in a California Hot Climate Zone. LBNL-3898E. http://drrc.Ibl.gov/publications/demand-shifting-thermal-mass-largecommercial-buildings-california-hot-climate-zone

Yin, R.; Kiliccote, S.; Piette, M.A.; Parrish, K. 2010. Scenario Analysis of Peak Demand Savings for Commercial Buildings with Thermal Mass in California. Proceedings of the 2010 ACEEE Summer Study on Energy Efficiency in Buildings. LBNL-3636E. http://drrc.lbl.gov/sites/drrc.lbl.gov/files/lbnl-3636e.pdf 


\section{Appendix A}

\section{Cost-Effectiveness Analysis Methodology}

The economic analysis of retrofit EEMs is one of the most challenging topics to address in a guidebook, yet is essential for school boards or energy managers trying to develop a convincing business case for a retrofit project. This guide provides best practice methodologies for calculating both NPV and simple payback period. We recognize that NPV is the preferred metric because it better captures the full range of benefits and costs associated with an investment over time, but simple payback remains the most commonly used metric for quantifying the cost effectiveness of energy retrofit projects.

In this appendix, we address the economic analysis of retrofit EEMs in a much more practical manner than has been attempted in other retrofit guides. We provide methods for accurately quantifying multiyear cash flows, including energy costs, demand reduction, replacement costs (including reduced energy savings if more efficient equipment is required by code), salvage value, $O \& M$ costs, and $M \& V$ costs. Techniques and references are also provided for capturing the effect of temporary financial incentives offered by government agencies or utilities (such as rebates, low-interest loans, and tax credits) on multiyear cash flows. Although it can be challenging to quantify the cash flows associated with a project, many tools are available to assist with the calculation of both NPV and simple payback, including the free LCCAid tool developed by Rocky Mountain Institute (www.rmi.org/ModelingTools).

The recommended methodology described in this guide has been applied to an example building (see Appendix B), resulting in the selection of building improvement packages for retrofit projects in five locations. The purpose of the example is to illustrate the economic analysis and EEM-selection process in the context of a realistic scenario, and to provide an idea of the energy savings potential of the EEMs described in this guide. However, certain EEMs may be highly cost effective in the example building, but may be very poor choices in a different situation. Age of equipment, cost structure, financing terms, tax incentives, local weather conditions, and system interactions can have very large impacts on the cost effectiveness of a particular EEM.

\section{A.1 Overall Net Present Value Calculation}

As discussed in Section 2.6, NPV is the financial analysis metric that best captures the full economic value of a retrofit EEM or package of EEMs from the school's perspective, especially when evaluating a staged retrofit. NPV is an integral component of life cycle cost analysis, but we will limit our analysis to direct costs and benefits that impact a school's budget. Societal and environmental costs will not be addressed, except to the extent they are reflected in taxes, financial incentives, purchase costs, and disposal costs.

Equation A-1 provides the general definition of NPV used in this guide:

$$
\mathrm{NPV}=C_{0}+\sum_{t=1}^{N} \frac{C_{t}}{(1+D F)^{t}}
$$

Where:

$\mathrm{C}_{0}=$ initial investment and related cash flows in Year 0

$\mathrm{C}_{\mathrm{t}}=$ sum of cash flows in Year $\mathrm{t}$ (current year dollars)

$\mathrm{t}=$ years after initial investment

$\mathrm{N}=$ number of years in analysis period

$\mathrm{DF}=$ real discount factor (does not include inflation) 
We recommend a 20-year project analysis period. This is longer than the useful life of most of the EEMs that will be evaluated, and provides a fair cutoff point for energy savings and other benefits associated with an EEM. There is also likely to be major remodeling or other modifications to a building or its use beyond a 20-year timeframe, which would negate the value of many retrofit EEMs. Finally, cash flows beyond 20 years are significantly discounted in the NPV calculation, and no longer hold much weight in the analysis.

DF is defined as the minimum rate of return required by the building owner, and is usually equal to the return that can be expected from alternative investment opportunities with similar risk. The appropriate DF can vary wildly, depending on the risk tolerance of the building owner, type of financing, uncertainty in energy savings, and alternative investment options that may be available. Because most K-12 schools are owned by the local government, a religious institution, or some other nonprofit organization, a relatively small DF is usually appropriate. If the required simple payback is known for an organization, the corresponding DF can be estimated using the graph in Figure A-1. This correlation was developed by calculating the internal rate of return over a 20 -year period for a simple investment in Year 0 followed by a stream of equal positive cash flows consistent with the required payback period. The implied DF is that which, when applied to these cash flows, would result in an NPV of zero.

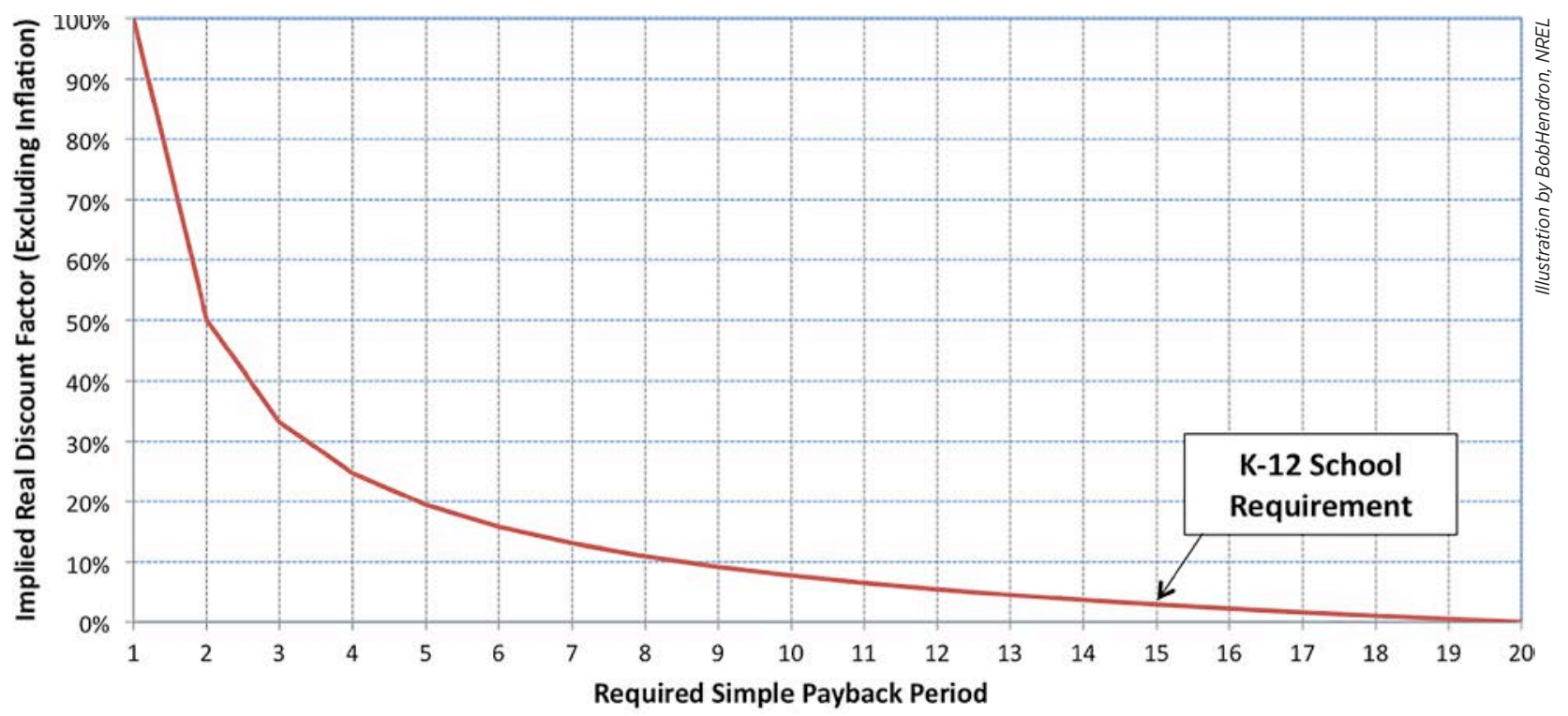

Figure A-1 Implied DF as function of required simple payback period
(assumes investment in Year 0 with constant return for 20 years)

Hopper et al. (2005) indicated that the median simple payback for retrofit projects in K-12 schools is approximately 15 years, and $25 \%$ of the projects in the study had simple paybacks exceeding 24 years. The study examined 1,634 retrofit projects performed by ESCOs throughout the United States, including 340 projects in K-12 schools. The simple payback for K-12 schools is much longer than for other building types, including those owned by other government and nonprofit entities, because school districts often include nonenergy-saving capital improvements in ESPCs as a way to address other infrastructure issues that cannot be addressed using the regular capital budget. Even though schools can tolerate simple paybacks well beyond 15 years for the entire project, it is probably most appropriate to use 15 years as the maximum simple payback for the energy-related improvements. According to Figure A-1, a required simple payback of 15 years is roughly equivalent to a $3 \%$ DF. 


\section{A.2 Components of Multiyear Cash Flows}

Many cash flows, both positive and negative, may be associated with a particular retrofit EEM. Positive cash flows represent net inflows of money; negative cash flows represent net outflows or costs. All cash flows are "net" cash flows relative to the reference case. A positive cash flow may be a direct inflow of cash to an organization, such as the sale of equipment or a rebate from the utility company, or it may represent an avoided expenditure, such as energy cost savings or not purchasing replacement equipment when the original equipment would have reached the end of its useful life. Equations A-2 and A-3 identify the cash flows that are the most important for a meaningful NPV calculation. The cash flows are assumed to be in current year dollars (they do not include the effects of inflation).

$$
C_{0}=-C_{\text {pur }}-C_{\text {inst }}+C_{\text {salv,ref }}+C_{\text {tax }, 0}+C_{\text {incent }}-\left[\left(C_{\text {disp }}+C_{\text {plan }}\right) \times\left(1-R_{\text {tax }, \text { inc }}\right)\right]
$$

Where:

$\mathrm{C}_{\mathrm{pu}}=$ purchase cost of equipment

$\mathrm{C}_{\text {inst }}=$ installation cost of EEM/package

$\mathrm{C}_{\text {salv,ref }}=$ salvage value of existing equipment

$\mathrm{C}_{\mathrm{tax}, 0}=$ tax benefits associated with disposing of existing equipment

$\mathrm{C}_{\text {incent }}=\mathrm{NPV}$ of financial incentives (rebates, tax credits, etc.)

$\mathrm{C}_{\text {disp }}=$ disposal cost of existing equipment

$\mathrm{C}_{\text {plan }}=$ cost of project planning $(=0$ for individual EEMs $)$

$\mathrm{R}_{\text {tax }, \text { inc }}=$ federal corporate income tax rate $(=0$ for most schools $)$

$$
\begin{gathered}
C_{t}=\left[C_{\text {energy,elec }} \times\left(R_{\text {escelecc }}\right)^{t}+C_{\text {energy,gas, } t} \times\left(R_{\text {esc,gas }}\right)^{t}-C_{\text {om }}-C_{m v}\right] \times\left(1-R_{\text {tax,inc }}\right) \\
-C_{\text {repl,eem }}+C_{\text {repl,ref }}+C_{\text {depr,eem }, t}-C_{d p r, \text { ref }, t}+C_{\text {rem,eem }, 20}-C_{\text {rem, ref }, 20}
\end{gathered}
$$

Where:

$$
\begin{aligned}
& \mathrm{C}_{\text {energy,elec, }}=\text { annual electricity cost savings in Year } \mathrm{t} \\
& \mathrm{C}_{\text {energy,gas, } \mathrm{t}}=\text { annual natural gas cost savings in Year } \mathrm{t} \\
& \mathrm{R}_{\text {escelect }}=\text { fuel price escalation rate for electricity }=0.5 \% \text { (DOE 2011a) } \\
& \mathrm{R}_{\text {esc,gas }}=\text { fuel price escalation rate for natural gas }=2.0 \%(\mathrm{DOE} 2011 \mathrm{a}) \\
& \mathrm{C}_{\mathrm{om}} \quad=\text { additional O\&M costs (negative if O\&M savings) } \\
& \mathrm{C}_{\mathrm{mv}} \quad=\text { additional } \mathrm{M} \& \mathrm{~V} \text { costs }(=0 \text { for individual EEMs }) \\
& \mathrm{C}_{\text {repl,eem }}=\text { replacement cost for EEM/package ( }=0 \text { except at end of useful life) } \\
& \mathrm{C}_{\text {repl,ref }}=\text { replacement cost for reference case (must meet code) }(=0 \text { except at end of useful life) } \\
& \mathrm{C}_{\text {depr,eem,t }}=\text { tax deduction for depreciation of EEM/package in Year } \mathrm{t} \\
& \mathrm{C}_{\text {depr,ref,t }}=\text { tax deduction for depreciation of existing equipment in Year } \mathrm{t} \\
& \mathrm{C}_{\text {rem,eem,20 }}=\text { remaining value of EEM }(=0 \text { except in year } 20) \\
& \mathrm{C}_{\text {rem,ref }, 20}=\text { remaining value of reference equipment }(=0 \text { except in year } 20)
\end{aligned}
$$

Guidance, assumptions, and technical resources for estimating each of these cash flows are presented in the following sections. 


\section{A.2.1 Purchase Cost $\left(C_{\text {pur }}\right)$}

The purchase cost of the EEM or package of EEMs includes the cost of equipment and associated materials. It does not include labor costs. If the purchase cost is financed over several years, it should be calculated as the NPV of the loan or lease payments over the term of the project. Purchase cost for a particular product or piece of equipment is relatively consistent from project to project, but may still vary depending on the financing mechanism, volume purchased, local competition, and any negotiated purchasing agreements with suppliers. For staged retrofit projects, there will be multiple purchase costs applied at several points during the 20 -year analysis period. For our example analysis, professional cost estimating software and databases were used to estimate purchase costs associated with each measure based on the building type (high school) and geographic location. We assume that the investment was funded using the school's capital budget, and no borrowing was necessary.

\section{A.2.2 Installation Costs $\left(\mathrm{C}_{\text {inst }}\right)$}

Unlike purchase cost, the installation costs associated with an EEM can vary dramatically depending on the building being modified and the capabilities of the contractor. Costs may be higher for a variety of reasons:

- Systems are difficult to access.

- Complex integration with existing systems and controls is necessary.

- The work must be done piecemeal or in stages to avoid disrupting building operations.

- Hazardous materials (asbestos, mold) must be removed or controlled.

The example analysis for this guide assumes that none of these complications are present, and that typical installation costs based on similar projects in K-12 schools can be used, with adjustments for local labor rates. We assume all installation costs occur in Year 0, consistent with a whole-building retrofit.

\section{A.2.3 Salvage Value of Existing Equipment $\left(\mathrm{C}_{\text {salv,ref }}\right)$}

For the most part, older equipment and materials removed from a building have very little salvage value. Newer equipment may have more value, but is less likely to be replaced as part of an energy retrofit. In most cases, we assume equipment cannot be reused, and the value of recyclable components (such as copper, aluminum, and glass) is approximately the same as the cost of hauling the equipment away.

\section{A.2.4 Tax Benefits Associated With Disposing of Existing Equipment $\left(C_{\text {tax }, 0}\right)$}

If capital equipment is replaced before it is fully depreciated, the difference between the undepreciated value of the equipment (or adjusted basis) and the salvage value (if any) is considered an operating loss, which can be deducted from corporate income taxes if the school is privately owned. In subsequent years, the depreciation tax deduction that would have been available for the existing equipment is lost. $\mathrm{C}_{\mathrm{tax}, 0}$ is equal to the NPV of these competing tax implications. It is uncommon for a K-12 school to be owned by a for-profit corporation, so this cash flow is nearly always zero.

\section{A.2.5 Financial Incentives ( $C_{\text {incent }}$ )}

Financial incentives from utilities or government entities can take many forms, including rebates, subsidies, tax credits, accelerated depreciation, low-interest loans, guaranteed loans, and free energy audits. As discussed in Section 2.2.3, DSIRE provides detailed information about nature and size of the incentives available in each state. These incentives can be quite significant, causing marginally cost-effective EEMs to produce large returns on investment. 
Financial incentives should not be ignored when evaluating EEMs for actual retrofit projects. For the example analysis, however, we do not include these incentives because they come and go over time, and our intention is to identify EEM packages that pay for themselves strictly through energy cost savings.

\section{A.2.6 Disposal Cost of Existing Equipment $\left(\mathrm{C}_{\text {disp }}\right)$}

Certain materials associated with the existing equipment may require special handling, recycling, or disposal procedures that can increase the overall cost of an EEM. Examples include fluorescent lamps, computers, refrigerators, and construction materials containing asbestos. These costs can be very different from one site to another, but generally are not very large compared to other costs associated with a project. For the example analysis, we used professional cost estimating methods to estimate disposal costs.

\section{A.2.7 Project Planning $\left(\mathrm{C}_{\text {plan }}\right)$}

Overall project planning includes all preparatory work conducted by school district staff before the EEMs that will be implemented are selected. After that point, management and coordination activities are most easily treated as overhead costs for individual EEMs. The following costs are examples of those included in project planning category:

- Form the internal project team.

- Perform energy benchmarking activities.

- Conduct a site energy audit.

- Write statements of work for subcontracted activities.

- Review bids and select contractors.

A study by Oak Ridge National Laboratory (Hughes et al. 2003) indicated that these planning costs are approximately $\$ 128,000$ for a fairly large appropriations-funded retrofit project in a federal government facility. This is probably a reasonable estimate for most large high school projects, and is the value we used for the example building analysis. Depending on the magnitude of the retrofit project and the nature of the processes and procedures that must be followed, a larger or smaller cost estimate for project planning may be appropriate.

\section{A.2.8 Electricity Cost Savings $\left(C_{\text {energy,elec,t }}\right)$ and Natural Gas Cost Savings $\left(C_{\text {energy,elec,t }}\right)$}

Energy savings can be very difficult to calculate without using a sophisticated modeling tool. Even straightforward EEMs such as lighting improvements have large interactions with space conditioning energy. As a result, we do not recommend using oversimplified techniques to quantify energy savings for complex projects that require large financial commitments and involve significant risk. DOE has assembled summaries of more than 300 building energy simulation tools (http://apps1.eere.energy.gov/buildings/tools_directory/), which can be quite helpful for organizations that do not have an established approach for energy analysis and may be seeking expert guidance for selecting the right tool.

Annual electricity cost savings include reductions in energy use (kilowatt-hours) and peak demand (kilowatts), but may also include changes to base utility charges if the school becomes eligible for a different rate schedule. Natural gas cost savings are most often based simply on the volume of gas used (1000 ft3). Utility rate structures are highly variable depending on geographic location, time of year, and facility size. Therefore, the actual utility rate schedule should be identified and used to calculate electricity cost savings. If actual utility rates cannot be found, estimated energy prices for each state are published by the EIA (www.eia.gov/). 
Energy savings can sometimes change over the life of a project. For example, if new equipment is not well maintained, its efficiency may degrade significantly or it may fail prematurely. Our assumption for the example analysis is that comprehensive $O \& M$ and $M \& V$ protocols are implemented by the school district to ensure the performance of new equipment is sustained. The cash flows associated with $O \& M$ and $M \& V$ are consistent with this assumption. The energy savings for a retrofit project can also diminish over time because the reference building must comply with local energy codes when equipment is replaced. If the reference building has a very old boiler with $70 \%$ combustion efficiency and 5 years of useful life remaining, we can expect that boiler to be replaced in 5 years by a new boiler with combustion efficiency greater than $80 \%$, as required by the federal equipment standards. As a result, the energy savings for a boiler retrofit EEM would diminish in 5 years because the energy use for the reference building would have decreased anyway.

Fuel price escalation rates may be applied to future energy savings cash flows. Fuel prices are very volatile, however, and are thus difficult to predict with any degree of accuracy. The most authoritative reference for fuel price projections is the EIA, which publishes the Annual Energy Outlook (www.eia.gov/forecasts/aeo/). Fuel price escalation rates should not include the effect of inflation. All values in the cash flow analysis should be in base year dollars.

In our example high school analysis, we used the EnergyPlus software to calculate energy savings for each relevant EEM and for each package of EEMs presented in this guide. The actual 2011 electricity price schedules were used for each of the five cities, including appropriate time-of-day and seasonal adjustments, and rate changes associated with peak demand reductions. Natural gas prices were based on either current utility schedules or state average gas prices published by DOE (www.eia.gov/dnav/ng/hg_pri_sum_dcu_nus_m.htm). Fuel price escalation rates were taken from the EIA Annual Energy Outlook 2011 (www.eia.gov/forecasts/aeo/pdf/0383(2011).pdf) (DOE 2011a).

\section{A.2.9 Additional O\&M Cost $\left(\mathrm{C}_{\mathrm{om}}\right)$}

The effect of retrofit EEMs on O\&M costs can be either positive or negative. Older equipment often breaks down or performs poorly, forcing maintenance personnel to invest substantial time into keeping it performing at an adequate level. In most cases, new energy-efficient equipment is more reliable, reducing the associated O\&M costs. But some newer equipment may be more complex and require additional interaction from O\&M personnel to keep it running properly.

Many of the RCx measures discussed in this guide include heightened attention to O\&M, such as regularly cleaning coils, replacing filters, calibrating sensors, and adjusting control settings. Ongoing costs associated with commissioning are almost always worthwhile from an energy savings and equipment lifetime perspective, but these costs should be quantified and included in the cash flow analysis to create a clear picture of the overall cost effectiveness of a building improvement project.

A maintenance escalation rate may be applied to O\&M costs in future years. In general, this rate is not much higher than the inflation rate, and the effect is small compared to the uncertainty in projecting future O\&M costs. We do not recommend using a maintenance escalation rate unless O\&M costs are very well defined.

For simplicity, we include what is sometimes referred to as repair and replacement costs in the O\&M category. Replacements in this category should be limited to components or elements of each EEM (such as lamp or filter replacements), not replacement of the entire EEM.

For the example building analysis, professional cost estimators provided the relative O\&M costs for each EEM. In some cases, there was insufficient basis for assuming any change to O\&M costs, and a value of zero was used. 


\section{A.2.10 Additional Measurement and Verification Costs $\left(C_{m v}\right)$}

$\mathrm{M} \& \mathrm{~V}$ costs are usually attributed to the project as a whole, but the performance of a particular piece of equipment may be tested or tracked very closely. In such cases it may be appropriate to attribute certain M\&V costs to the EEM, to provide a more complete accounting of costs and benefits for that EEM.

For the example analysis, we assigned $M \& V$ costs to packages of EEMs as a whole. Consequently, we used a value of zero for $\mathrm{C}_{\mathrm{mv}}$ when evaluating the NPV of individual EEMs. For packages of EEMs, we assumed that annual M\&V costs are equal to $5 \%$ of the estimated energy cost savings, as discussed in Section 6.

\section{A.2.11 Replacement Cost for Energy Efficiency Measures $\left(C_{\text {repl,eem }}\right)$}

You should assume that each EEM is replaced at the end of its useful life with a system of the same type and efficiency. In some cases, the replacement cost may be much lower than the original installation cost because the infrastructure is already in place and there are records of specific components, vendors, and procedures that were used the first time. In other cases there may be very little difference in cost.

The useful life can be estimated for most common EEMs using the table of service life estimates in Chapter 37 of ASHRAE (2011a). The list is primarily limited to HVAC EEMs. Estimated useful life estimates for many other EEMs, including envelope, domestic hot water, lighting, and refrigeration, can be found in life cycle cost analysis guidance published by the State of Washington General Administration (www.ga.wa.gov/eas/elcca/simulation.htm/). Recommended replacement schedules for most building components assemblies can also be found in the RSMeans Facilities Maintenance \& Repair Cost Data handbook (RSMeans 2009). Professional cost estimators provided the values of $\mathrm{C}_{\text {repl,eem }}$ used in our example analysis, which assumes a 20-year analysis period. Most EEMs that involve mechanical or electrical equipment are replaced at least once during that time period. Envelope EEMs usually last longer.

\section{A.2.12 Replacement Cost for Reference Case $\left(C_{\text {repl,ref }}\right)$}

To correctly evaluate net cash flows associated with an EEM, a realistic reference case must be developed for comparison. This reference case must include the equipment replacements and upgrades that would have occurred if the EEM was never implemented. In some cases, equipment would be replaced with similar equipment that has the same efficiency. In other cases, the worst-performing new equipment available on the market may be a significant upgrade over the existing equipment. This gradual improvement of the reference case over time also impacts energy savings.

Typically, equipment is replaced at the end of its useful life. In most scenarios, remaining useful life can be calculated by subtracting equipment age from the useful life estimated using the references discussed in the previous section.

In some cases, equipment may be considered at the end of its useful life because it is broken beyond repair, or building modifications are underway for nonenergy reasons that necessitate equipment replacement. In such cases, the remaining useful life is zero, and equipment replacement for the reference case happens during the first year of the project analysis period. This allows the consolidation of $\mathrm{C}_{\text {repl,ref }}, \mathrm{C}_{\text {pur }}$, and $\mathrm{C}_{\text {inst }}$ into a single incremental cost for improved equipment over a newer version of the current equipment (or the worst equipment allowed by code). If the replacement equipment lifetimes are the same for both the EEM and the reference case, $\mathrm{C}_{\text {repl,ref }}$ and $\mathrm{C}_{\text {repl,eem }}$ can also be combined into a single incremental cost for the improved equipment. Otherwise, cash flows for equipment replacement must be tracked separately for the two scenarios and assigned to the appropriate year.

For our analysis of standard retrofit EEMs in the example building, we assumed that all equipment is $50 \%$ through its useful life. We used the State of Washington (2010) service life estimates to determine the original useful life for existing equipment. 


\section{A.2.13 Tax Deductions for Depreciation $\left(C_{\text {depr,eem,t }}\right.$ and $C_{\text {depr,ref,t }}$ )}

Most EEMs discussed in this guide are capital expenditures that must be depreciated over a number of years for tax purposes if the building owner is a for-profit entity. The depreciable basis for such EEMs includes the purchase and installation costs of the equipment. The Modified Accelerated Cost Recovery System (MACRS) is required by the Internal Revenue Service for most equipment categories. Certain EEMs, including RCx measures and equipment with a useful life shorter than one year, may be treated as operating expenses and deducted immediately.

Most K-12 schools are owned by public or nonprofit organizations, and the depreciation cash flows can be ignored. If the building owner is a for-profit entity but the project does not include special tax incentives, such as the 179D Federal Energy Tax Deduction, these cash flows largely cancel out and are usually not worth the effort to analyze in detail. In such cases, the NPV can be reduced by the corporate tax rate (usually $35 \%$ ) to approximate the overall effect of taxes on the investment.

\section{A.2.14 Remaining Value of Energy Efficiency Measure and Reference Equipment at the End of the Analysis Period $\left(\mathrm{C}_{\text {rem,eem,20 }}\right.$ and $\left.\mathrm{C}_{\text {rem,ref,20 }}\right)$}

At the end of the 20-year analysis period, both the EEM and the equipment in the reference building are likely to have some remaining value. To produce a fair estimate of NPV, you should assume the equipment is sold at a price equal to the remaining value at Year 20. Unless better information is available for estimating the future value of installed equipment, we recommend that the adjusted basis for depreciation be used as a surrogate. Because the sale price is assumed to equal the "book value" of the equipment, there is no capital loss or gain at the end of the analysis period, and any tax implications can be neglected. The adjusted basis for depreciation is the original purchase and installation costs adjusted according to the MACRS schedule for the corresponding class of equipment (see Table A-1 and Table A-2).

For the example analysis in this guide, we simplified this approach, and assumed a straight line decrease in value over time for both the EEM and the reference cases. In the context of a K-12 school, the effect of the simplification was negligible. 
Table A-1 MACRS Depreciation Schedule

\begin{tabular}{|c|c|c|c|c|c|c|}
\hline $\begin{array}{c}\text { Recovery } \\
\text { Year }\end{array}$ & $\begin{array}{l}\text { 3-Year } \\
\text { Property }\end{array}$ & $\begin{array}{l}\text { 5-Year } \\
\text { Property }\end{array}$ & $\begin{array}{l}\text { 7-Year } \\
\text { Property }\end{array}$ & $\begin{array}{l}\text { 10-Year } \\
\text { Property }\end{array}$ & $\begin{array}{l}\text { 15-Year } \\
\text { Property }\end{array}$ & $\begin{array}{l}\text { 20-Year } \\
\text { Property }\end{array}$ \\
\hline 1 & 33.33 & 20.00 & 14.29 & 10.00 & 5.00 & 3.750 \\
\hline 2 & 44.45 & 32.00 & 24.49 & 18.00 & 9.50 & 7.219 \\
\hline 3 & 14.81 & 19.20 & 17.49 & 14.40 & 8.55 & 6.677 \\
\hline 4 & 7.41 & 11.52 & 12.49 & 11.52 & 7.70 & 6.177 \\
\hline 5 & & 11.52 & 8.93 & 9.22 & 6.93 & 5.713 \\
\hline 6 & & 5.76 & 8.92 & 7.37 & 6.23 & 5.285 \\
\hline 7 & & & 8.93 & 6.55 & 5.90 & 4.888 \\
\hline 8 & & & 4.46 & 6.55 & 5.90 & 4.522 \\
\hline 9 & & & & 6.56 & 5.91 & 4.462 \\
\hline 10 & & & & 6.55 & 5.90 & 4.461 \\
\hline 11 & & & & 3.28 & 5.91 & 4.462 \\
\hline 12 & & & & & 5.90 & 4.461 \\
\hline 13 & & & & & 5.91 & 4.462 \\
\hline 14 & & & & & 5.90 & 4.461 \\
\hline 15 & & & & & 5.91 & 4.462 \\
\hline 16 & & & & & 2.95 & 4.461 \\
\hline 17 & & & & & & 4.462 \\
\hline 18 & & & & & & 4.461 \\
\hline 19 & & & & & & 4.462 \\
\hline 20 & & & & & & 4.461 \\
\hline 21 & & & & & & 2.231 \\
\hline
\end{tabular}

Table A-2 MACRS Property Class Table

\begin{tabular}{|l|l|c|}
\hline \multicolumn{1}{|c|}{ Property Class } & \multicolumn{1}{c}{ Personal Property (All Property Except Real Estate) } \\
\hline 3-year property & - Property with asset depreciation range (ADR) class life of 4 years or less \\
\hline 5-year property & $\begin{array}{l}\text { - Information systems; computers/peripherals } \\
\text { - Property with ADR class life of more than } 4 \text { years and less than } 10 \text { years } \\
\text { - Certain geothermal, solar, and wind energy properties }\end{array}$ \\
\hline 7-year property & $\begin{array}{l}\text { - All other property not assigned to another class } \\
\text { - Office furniture, fixtures, and equipment (includes light fixtures) }\end{array}$ \\
\hline $\begin{array}{l}\text { - Property with ADR class life of more than } 10 \text { years and less than } 16 \text { years } \\
\text { 10-year property }\end{array}$ & $\begin{array}{l}\text { - Property with ADR class life of } 16-20 \text { years } \\
\text { 15-year property }\end{array}$ & - Property with ADR class life of 20 years or more and less than 25 years \\
\hline 20-year property & - Property with ADR class life of at least 25 years
\end{tabular}




\section{Appendix B}

\section{Detailed Approach for Selecting Recommended Packages}

\section{B.1 Overall Approach}

Building energy simulation was intensively used to support the development of this guide. Because of its strong capability to model different HVAC systems and equipment, EnergyPlus version 6.0 was selected as the simulation program to assess and quantify the energy and cost saving potential for individual EEMs. The quantified savings were then used together with the EEM implementation cost for the cost-effectiveness analysis (See Appendix A), which formed the basis to determine the retrofit packages. Each tiered package was then further evaluated to determine its total energy saving and cost effectiveness. Further details about the selection of EEMs for EBCx and whole-building retrofits are provided in Sections B.4 and B.5.

The following steps were followed to conduct the energy simulations in support of this guide:

- Baseline building model development and evaluation. A baseline building model was developed as a first step. This model was based on the DOE's Reference model for high schools (Deru et al. 2011). The model was adjusted to reflect the most common building design and operation practice for pre-1980 vintage buildings in each climate location. These modifications are listed in Section B.3.

- Individual retrofit EEM energy savings and cost-effectiveness analysis. Each retrofit EEM was individually evaluated in terms of its energy savings and cost effectiveness. The new model and the reference model used the same hardcoded equipment size and settings such as RTU cooling capacities. Site energy consumption was obtained by running EnergyPlus for the new model. In addition, based on the predefined utility rates, EnergyPlus also calculated the energy cost, including both energy consumption cost and electricity demand cost. The difference in site energy use between the reference and the new model was regarded as the energy savings for that EEM; the energy cost difference was the annual energy cost savings. This energy cost savings was then used together with the estimated EEM implementation cost to calculate cost-effectiveness metrics such as simple payback and NPV. Appendix C provides the detailed results of each individual retrofit EEM.

- Retrofit EEM categorization. Based on the energy savings and the cost effectiveness metrics for the retrofit EEMs from the previous step, retrofit EEMs were selected for development of the recommended retrofit packages.

- Retrofit package energy savings and cost-effectiveness analysis. After the retrofit package was determined, its overall energy savings and cost effectiveness was estimated as a whole in comparison with the original baseline. The package analysis took into account the interactions between different EEMs. Hence, the packaged energy saving is not simply the sum of total individual EEMs. The capacity of equipment that was not directly affected by the EEMs included in the package stayed the same between the new model and the reference model. 


\section{B.2 Commercial Reference Building Characteristics}

The reference building for our example analysis is the Pre-1980s Secondary School CRB (Deru et al. 2011), which is one of a series of reference buildings developed by DOE to help standardize the analysis of EEMs when applied to specific building sectors. It does not necessarily represent an average or typical high school in the United States. Consequently, energy and cost savings calculations in the context of the example building should not be extrapolated to other individual schools or the stock of K-12 schools as a whole. The Pre-1980s CRBs represent fairly old buildings, with one or more equipment replacements over 30+ years depending on the typical useful life of each piece of equipment. We did not assume the original equipment is still present in the building.

These CRBs take the form of EnergyPlus models. EnergyPlus is an accurate and flexible modeling program developed by DOE in partnership with modeling experts across the country. The CRB models have been thoroughly vetted by three national laboratories (NREL, PNNL, and LBNL), instilling a high degree of confidence that they are realistic and free of significant errors.

The CRB and recommended packages are tailored to each of five important U.S. climate regions. Simulations performed in support of the AEDGs indicated that there were limited differences in the optimal packages for new commercial buildings in cities within the same climate region. Climate dependence within the same region is expected to be even weaker for retrofit packages, and five locations should be able to provide sufficient diversity of results for this guide. The following climate regions were selected, represented by the city in parenthesis:

- Hot-humid (Miami, Florida)

- Hot-dry (Las Vegas, Nevada)

- Marine (Seattle, Washington)

- Cold (Chicago, Illinois)

- Very Cold (Duluth, Minnesota)

Energy managers can use the values in Table B-1 to compare the characteristics of their climate zone with those of the five represented climate zones in this guide. Approximate energy prices for the five cities are presented in Table B-2. Actual 2011 utility rate tariffs, which are considerably more complex, were used to analyze the example building.

\section{Table B-1 Key Climatic Characteristics of the Five Cities Used in the Development of Recommended EEM Packages (ASHRAE 2011a)}

\begin{tabular}{|c|c|c|c|c|c|}
\hline Location & $\begin{array}{l}\text { Winter Design } \\
\text { Temperature }\left({ }^{\circ} \mathrm{F}\right)\end{array}$ & $\begin{array}{l}\text { Summer Design } \\
\text { Temperature }\left({ }^{\circ} \mathrm{F}\right)\end{array}$ & $\begin{array}{l}\text { Summer Design } \\
\text { Humidity* (\% RH) }\end{array}$ & $\begin{array}{c}\text { Annual Heating } \\
\text { Degree Days } \\
\left.\text { ( }{ }^{\circ} \mathrm{F} \cdot \text { day }\right)\end{array}$ & $\begin{array}{c}\text { Annual Cooling } \\
\text { Degree Days } \\
\left.\text { ( }{ }^{\circ} \mathrm{F} \cdot \text { day }\right)\end{array}$ \\
\hline Miami & 47.7 & 91.8 & $53 \%$ & 130 & 4,458 \\
\hline Las Vegas & 30.5 & 108.3 & $11 \%$ & 2,105 & 3,348 \\
\hline Seattle & 24.5 & 84.9 & $34 \%$ & 4,729 & 177 \\
\hline Chicago & -4 & 91.9 & $45 \%$ & 6,311 & 842 \\
\hline Duluth & -19.5 & 84.5 & $49 \%$ & 9,425 & 209 \\
\hline
\end{tabular}

*Not coincident with summer design temperature 
Table B-2 Approximate Energy Prices for the Five Cities Used in the Analysis of Recommended EEM Packages

\begin{tabular}{|c|c|c|c|c|c|c|}
\hline Location & $\begin{array}{l}\text { Marginal } \\
\text { Electricity Rate } \\
(\$ / \mathrm{kWh})\end{array}$ & $\begin{array}{l}\text { Demand } \\
\text { Charge, } \\
\text { Summer } \\
(\$ / \mathrm{kW})\end{array}$ & $\begin{array}{c}\text { Demand } \\
\text { Charge, Winter } \\
(\$ / \mathrm{kW})\end{array}$ & $\begin{array}{l}\text { Duration } \\
\text { of Summer } \\
\text { Demand Rate } \\
\text { (months) }\end{array}$ & $\begin{array}{l}\text { Gas Rate } \\
(\$ / \text { therm })\end{array}$ & $\begin{array}{c}\text { Energy Tax } \\
\text { Rate }\end{array}$ \\
\hline Miami & 0.054 & 11.05 & 11.05 & 6 & 1.024 & $8.0 \%$ \\
\hline Las Vegas & 0.067 & 19.23 & 0.5 & 4 & 0.951 & $8.0 \%$ \\
\hline Seattle & 0.065 & 5.76 & 8.65 & 6 & 0.984 & $8.5 \%$ \\
\hline Chicago & 0.084 & 5.75 & 5.75 & 4 & 0.865 & $8.0 \%$ \\
\hline Duluth & 0.083 & 4.87 & 4.87 & 6 & 0.777 & $6.0 \%$ \\
\hline
\end{tabular}

A rendering of the CRB model is shown in Figure B-1. Summary information about the building is provided in Table B-3, and the distribution of space types in the building is presented in Table B-4.

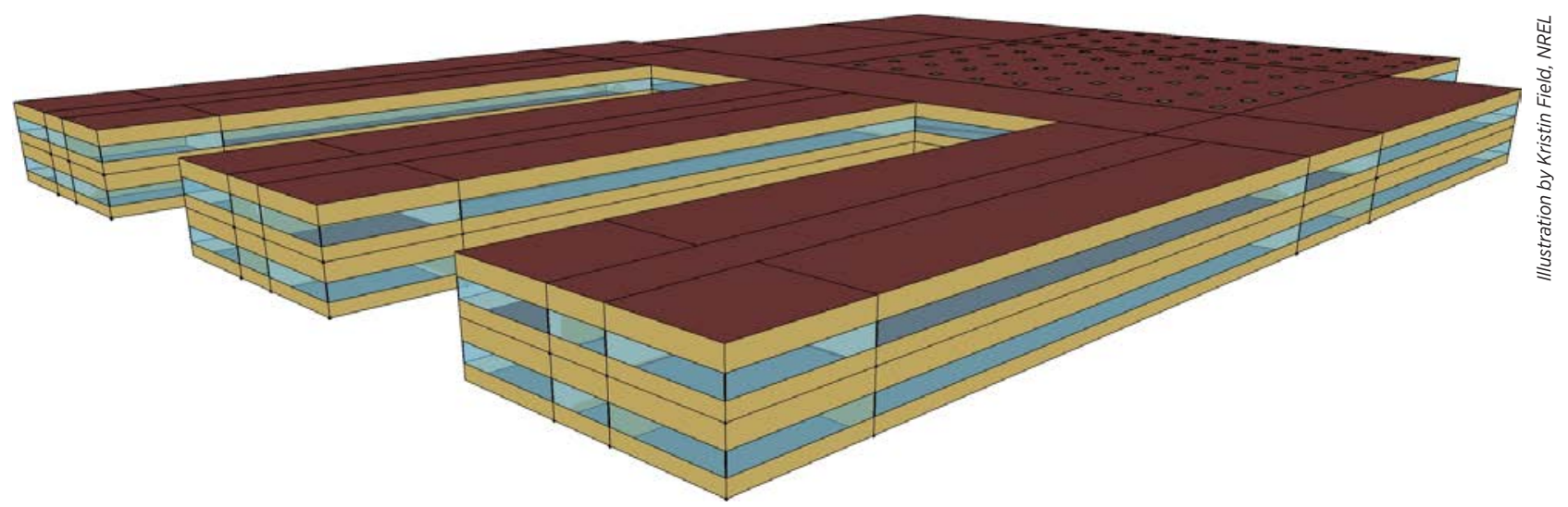

Figure B-1 Rendering of CRB (view from the southwest) 


\section{Table B-3 CRB Overview}

\begin{tabular}{|l|c|}
\hline Square footage & $210,810 \mathrm{ft}^{2}$ \\
\hline Number of floors & 2 \\
\hline Number of students & 1,200 \\
\hline Window-to-wall ratio & $35 \%$ \\
\hline Wall construction & Steel frame \\
\hline Roof construction & Insulation entirely above deck \\
\hline
\end{tabular}

\section{Table B-4 CRB Space Types and Floor Area Distribution}

\begin{tabular}{|l|c|c|}
\hline \multicolumn{1}{|c|}{ Space Type } & Area (ft $\left.{ }^{2}\right)$ & $\%$ of Total \\
\hline Auditorium & 10,635 & $5.0 \%$ \\
\hline Cafeteria & 6,717 & $3.2 \%$ \\
\hline Classroom & 74,400 & $35.3 \%$ \\
\hline Corridor & 45,208 & $21.4 \%$ \\
\hline Gym/multipurpose & 34,703 & $16.5 \%$ \\
\hline room & 2,325 & $1.1 \%$ \\
\hline Kitchen & 9,042 & $4.3 \%$ \\
\hline Library/media center & 4,521 & $2.4 \%$ \\
\hline Lobby & 7,363 & $3.5 \%$ \\
\hline Mechanical room & 11,453 & $5.4 \%$ \\
\hline Office & 4,521 & $2.1 \%$ \\
\hline Restroom & 210,887 & $100 \%$ \\
\hline Total & & \\
\hline
\end{tabular}

The CRB is served by nine separate HVAC systems. Four of these are constant air volume (CAV), multizone systems serving each of the three classroom wings and several of the smaller spaces (corridors, restrooms, offices). The CAV systems include terminal units that use reheat coils to provide independent temperature control of each room. The other five systems are packaged single-zone RTUs, serving the larger space types (gyms, cafeteria, and auditorium). The areas served by each of the nine systems are shown in Figure B-2 and Figure B-3. Schematic diagrams of the two system types are shown in Figure B-4 and Figure B-5, and performance characteristics are defined in Table B-5 and Table B-6. 


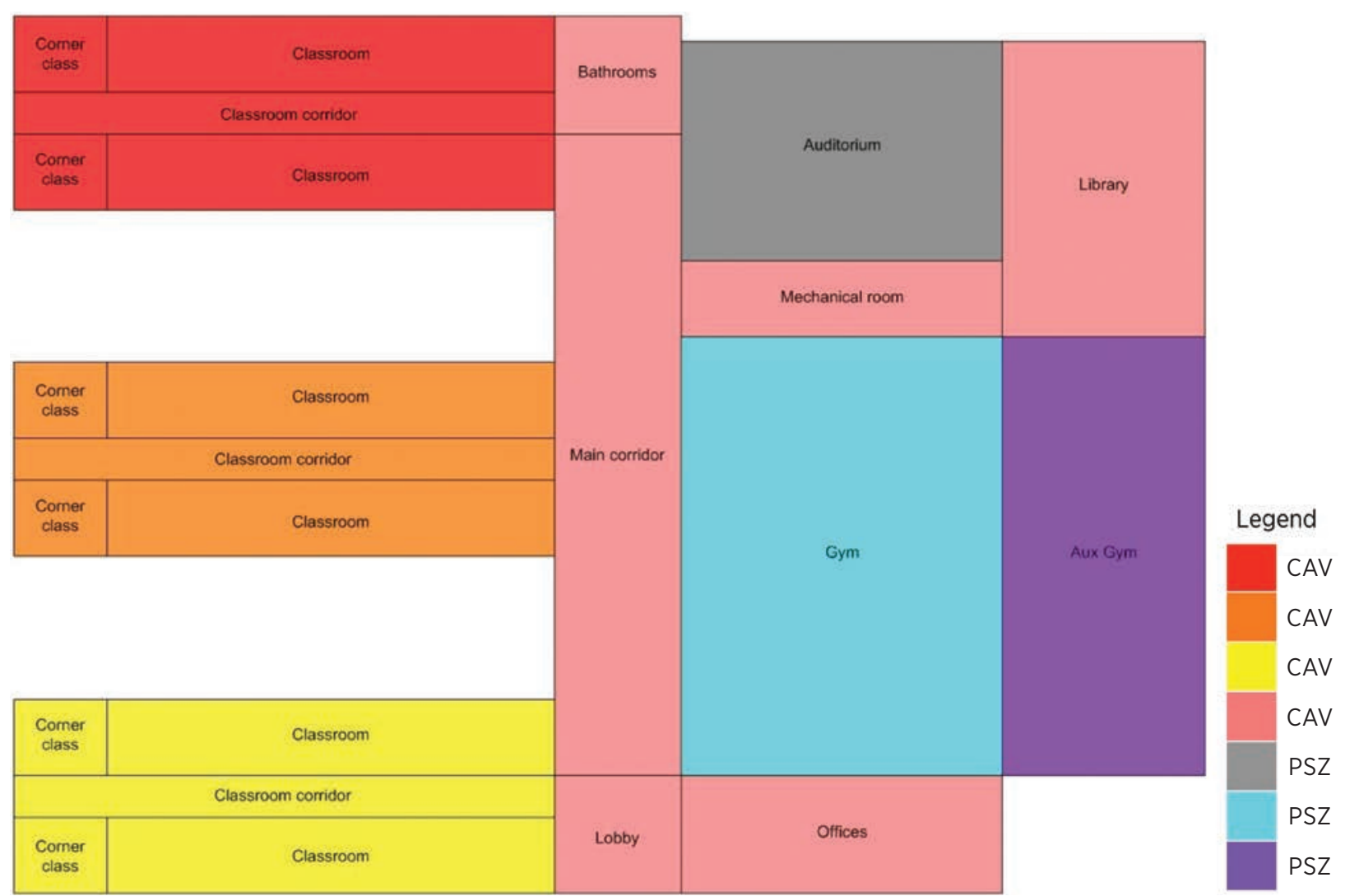

Figure B-2 First floor HVAC control zones

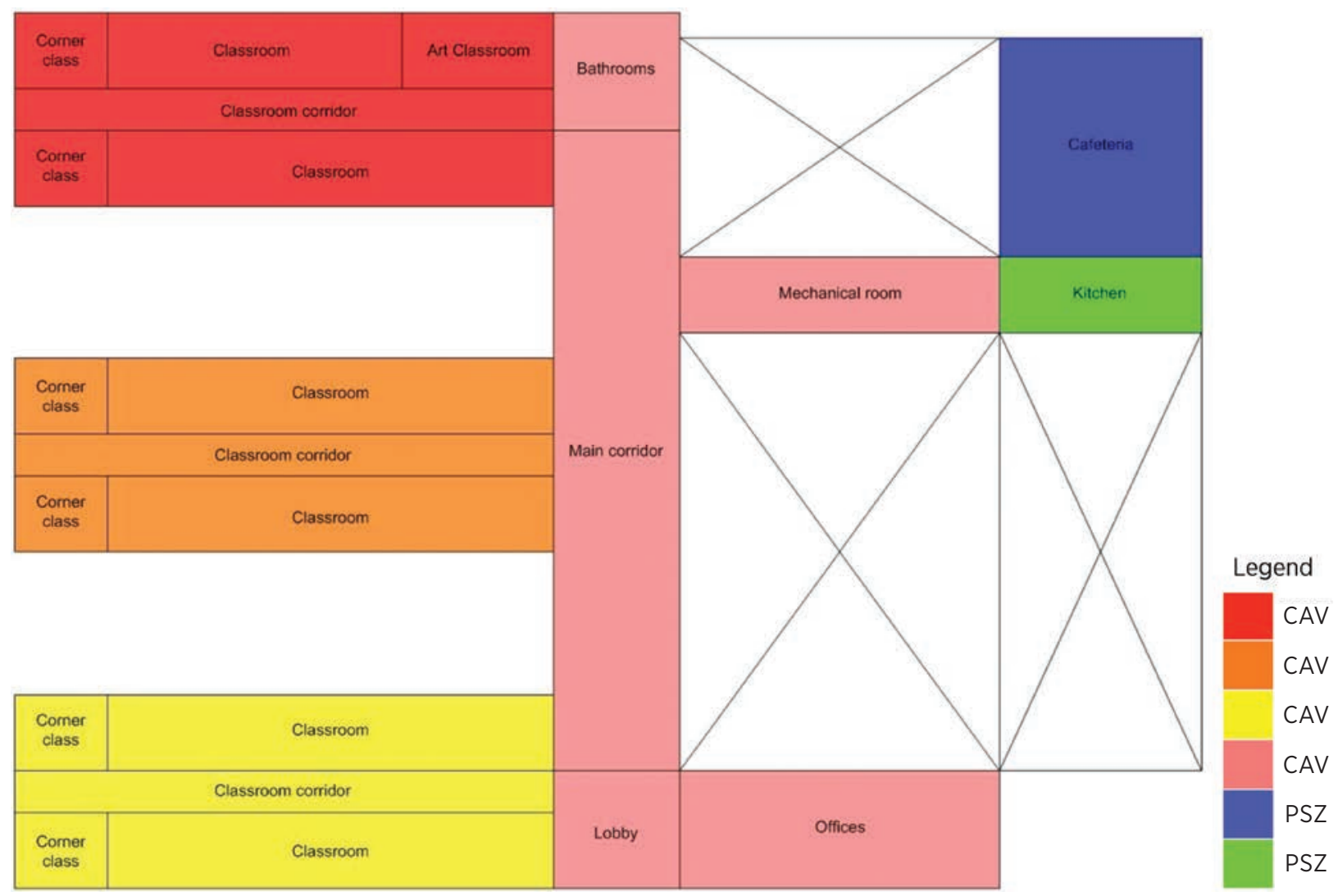

Figure B-3 Second floor HVAC control zones 

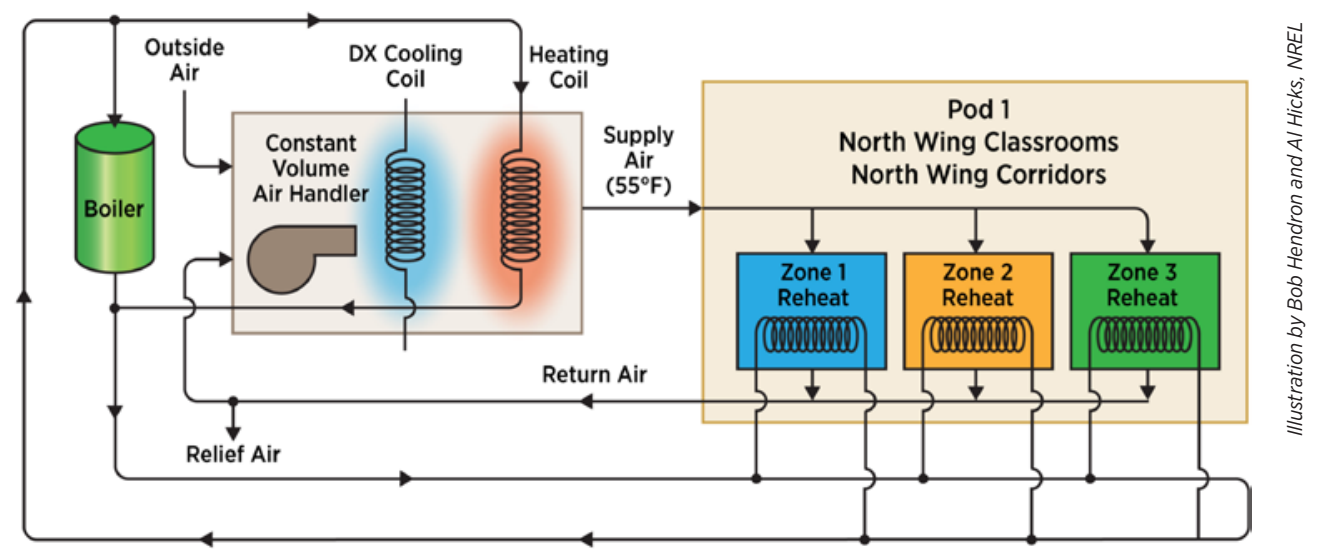

Figure B-4 CRB CAV system serving a series of classrooms

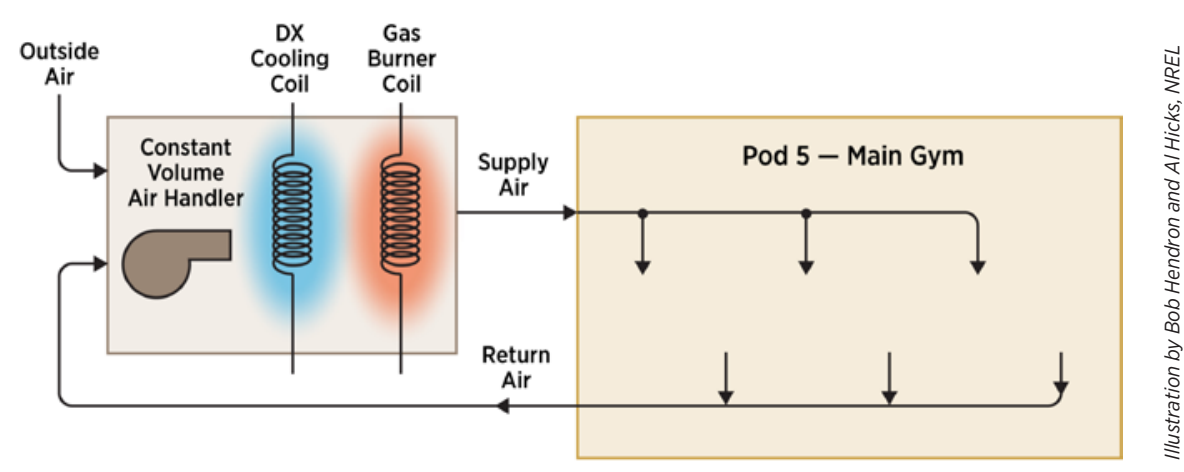

Figure B-5 CRB packaged single-zone system

Table B-5 Performance Specifications for Multizone Systems

\begin{tabular}{|l|l|}
\hline \multicolumn{1}{|c|}{ Characteristic } & \multicolumn{1}{c}{ Value } \\
\hline Heating plant & $78 \%$ efficient natural gas heating \\
\hline Cooling plant & 3.2 coefficient of performance (COP) DX cooling coil \\
\hline Pumps & Constant speed pumps, 90\% motor efficiency \\
\hline AHU & $\begin{array}{l}\text { Constant speed fan, } 60 \% \text { total fan efficiency; } 55^{\circ} \mathrm{F} \text { deck } \\
\text { temperature with reset based on worst case zone temperature }\end{array}$ \\
\hline Economizer & Dry-bulb economizer \\
\hline Terminal units & Hot water reheat coils \\
\hline
\end{tabular}

Table B-6 Performance Specifications for Packaged Single-Zone Systems

\begin{tabular}{|l|l|}
\multicolumn{1}{|c|}{ Characteristic } & \multicolumn{1}{c}{ Value } \\
\hline Heating system & $78 \%$ efficient natural gas fired heating \\
\hline Cooling system & 3.2 COP DX cooling coil \\
\hline Fan type & Constant speed fan, 60\% total fan efficiency \\
\hline Economizer & Dry-bulb airside economizer \\
\hline
\end{tabular}

Other details of the CRB can be found in the documentation of the CRBs (Deru et al. 2011b), in the spreadsheet summary posted online, or in the EnergyPlus input file. 


\section{B.3 Adjustments to the K-12 School Commercial Reference Building To Create the Example Building}

The following changes were made to the model of the Pre-1980s Secondary School CRB to create an appropriate example building for our purposes.

\section{B.3.1 Infiltration}

- The infiltration rate was reduced from $50 \%$ of the nominal value to $25 \%$ during periods when the HVAC system is operating (in accordance with the CRB documentation).

- Infiltration was increased in the entrance zone during peak hours of door operation to allow the analysis of vestibules.

- The infiltration schedule was modified to match HVAC operation schedule and heating/cooling set points.

\section{B.3.2 Daylighting}

- Ceiling reflectances were changed to 0.7 for daylighting.

- Visible transmittance was added to window inputs.

\section{B.3.3 Equipment/Loads}

- The internal load schedules, which had inappropriate values for SummerDesignDay that resulted in undersizing of the cooling system, were changed.

\section{B.3.4 Heating, Ventilation, and Air-Conditioning}

- A workaround was applied to the DX cooling coil object to address undersizing of the coil (possibly an EnergyPlus issue).

- The pump operation schedule was changed to match HVAC operation schedule (otherwise the pumps were operating 24/7).

- The four CAV multizone HVAC systems were changed to VAV.

- The boiler and service hot water pumps were changed from variable speed to constant speed.

- Automatic equipment sizing was disabled, except when an EEM included equipment replacement.

- Return fans were added to all the HVAC systems except the small RTU serving the kitchen.

\section{B.3.5 Other}

- The utility tariffs were updated to 2011 values. 


\section{B.4 Selection of Existing Building Commissioning Packages}

The DOE CRBs are assumed to be well commissioned. The modeling inputs are not consistent with suboptimal operating schedules, building controls that are no longer active, or degraded equipment performance caused by wear and tear. To model the energy savings for EBCx measures, we would have to artificially degrade the performance of the $\mathrm{CRB}$ and create a new reference building. Unfortunately, no authoritative studies of typical degradation patterns in existing buildings have been conducted that would allow us to confidently construct uncommissioned versions of the CRBs with a high degree of confidence. As a result, we did not try to model $\mathrm{EBCx}$ measures.

Instead, the recommended EBCx packages were developed based on subjective estimates of the likely energy savings of each EEM considered. We estimated energy savings for the EBCx package based on data from actual projects, combined with the CRB physical characteristics and energy use. Mills (2009) conducted a seminal study of commissioning projects across the country. This study provides useful cost and energy savings data as a function of building size for several categories of buildings. Unfortunately, the sample size for K-12 schools was not sufficiently large, so we used higher education buildings as proxies. Because the energy savings for higher education projects was a combination of new and existing buildings, we averaged the higher education savings (11\%) and the mean energy savings for all existing buildings (16\%) to estimate the expected national average energy savings for existing K-12 schools (13\%). Adjustments were made for each of the five cities based on modeling of retrofit EEMs performed by PNNL in support of the Office Building AERG (PNNL 2011). Initial cost ( $\left.\$ 0.31 / \mathrm{ft}^{2}\right)$, useful life (5 years), and the number of commissioning measures in a typical project (7.3) were estimated based on the Mills study.

\section{B.5 Selection of Retrofit Packages}

The EEMs included in the recommended retrofit packages were chosen based on the cost effectiveness of each EEM when applied to the example building model, using typical equipment costs and actual utility rates. A subset of the retrofit EEMs discussed in Appendix F were selected for inclusion in the detailed analysis, based on relevance to the example building, likelihood of producing significant energy savings, and complexity of implementation.

Each EEM was analyzed individually, and in combination with other EEMs when system interactions were large. This sequencing allowed for the possibility of downsizing HVAC equipment because of reduced heating and cooling loads. EEMs were selected for the recommended packages if their individual NPVs were greater than zero. A more sophisticated analysis might examine EEMs in various combinations to produce a more optimized package. A final analysis of each recommended package was performed to capture all remaining system interactions and verify that the combined package met the positive NPV requirement. The energy savings for the final recommended retrofit packages do not include the effects of EBCx. If a project includes both $\mathrm{EBCx}$ and retrofit EEMs, there will likely be significant interactions. Therefore, the combined energy savings for the two packages are not strictly additive. 


\section{Appendix C}

\section{Detailed Analysis of Individual Retrofit Energy Efficiency Measures in the Example Building}

This appendix documents the detailed simulation and cost analysis results that were used as the basis for the recommended standard retrofit packages for the example building. Table $\mathrm{C}-1$ provides a summary of key results for the 22 individual EEMs that were analyzed. Most of these EEMs are discussed in detail in Appendix F, and the others are listed at the end of that appendix under "Additional Measures for Consideration." The process for selecting EEMs was described in Appendix B. All reference case equipment and envelope components were assumed to be halfway through their useful lives. 


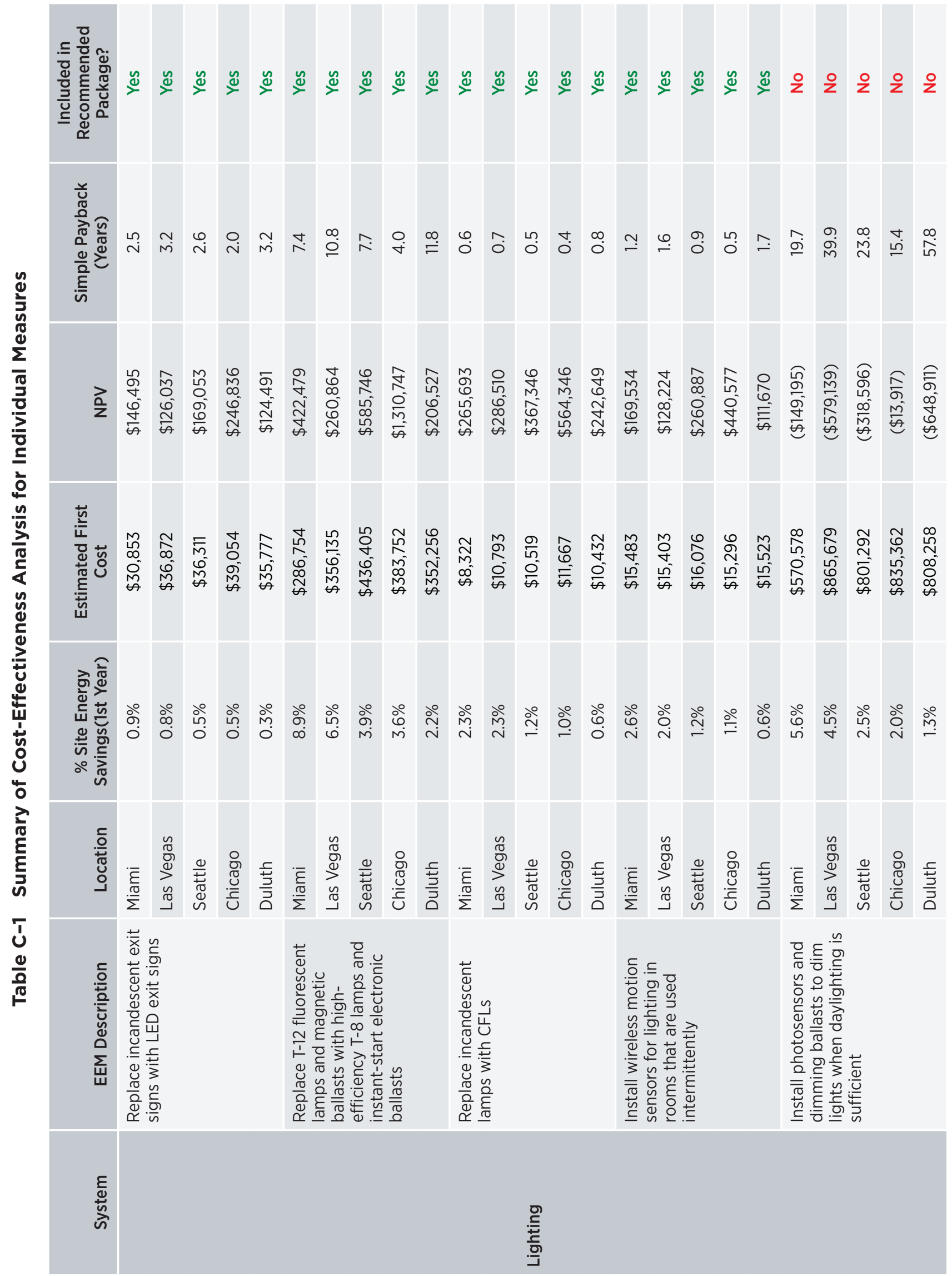




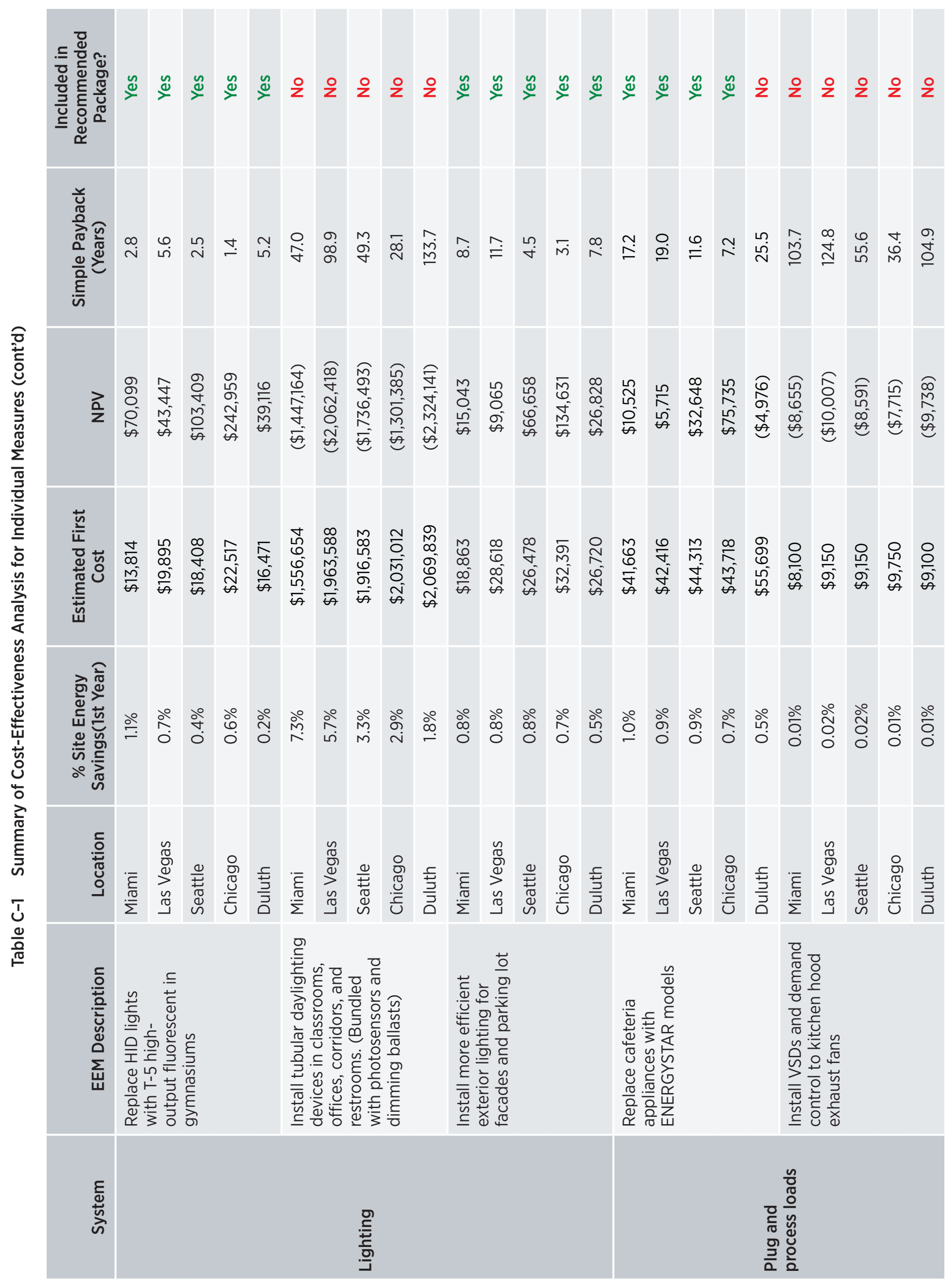




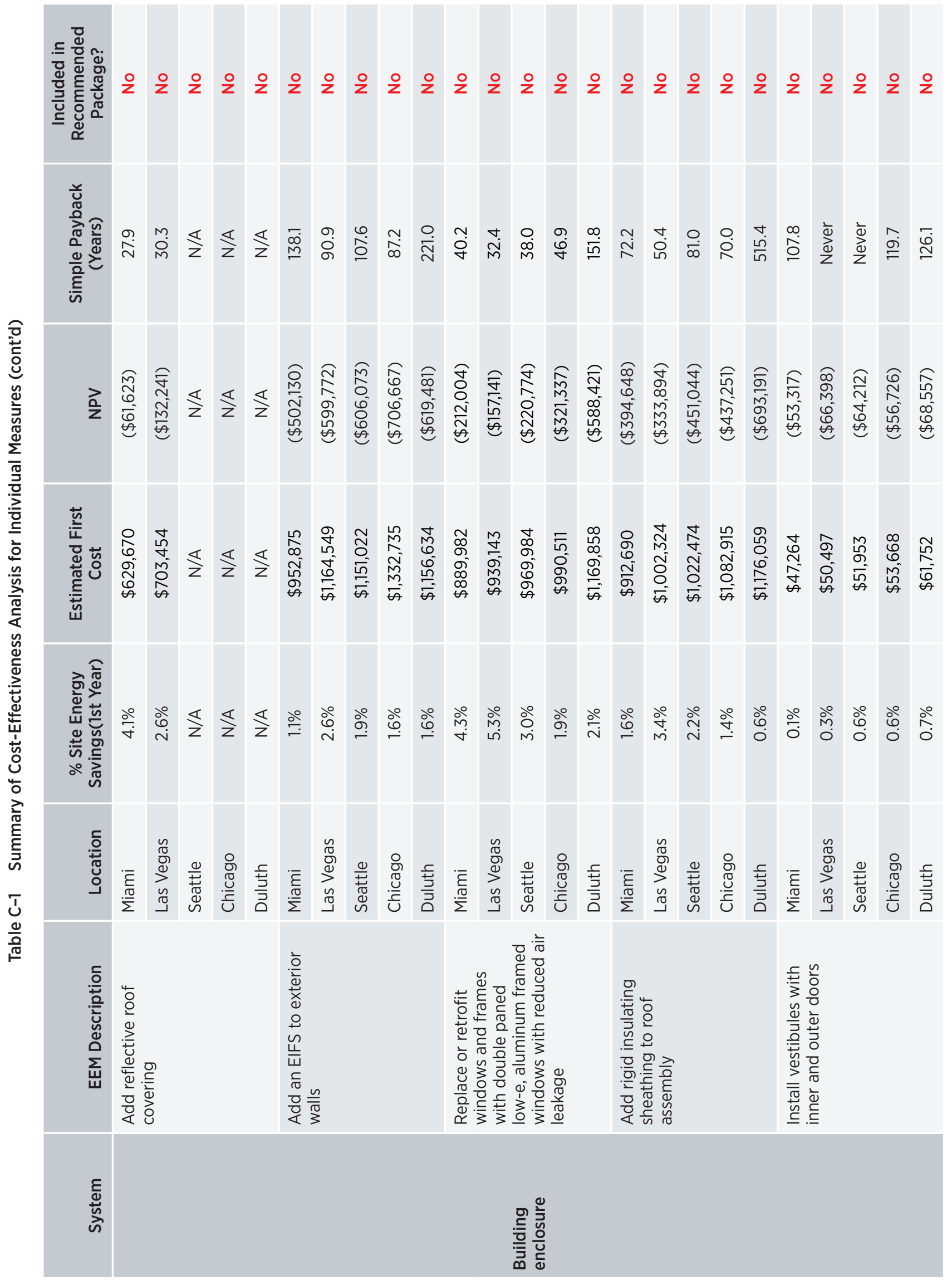




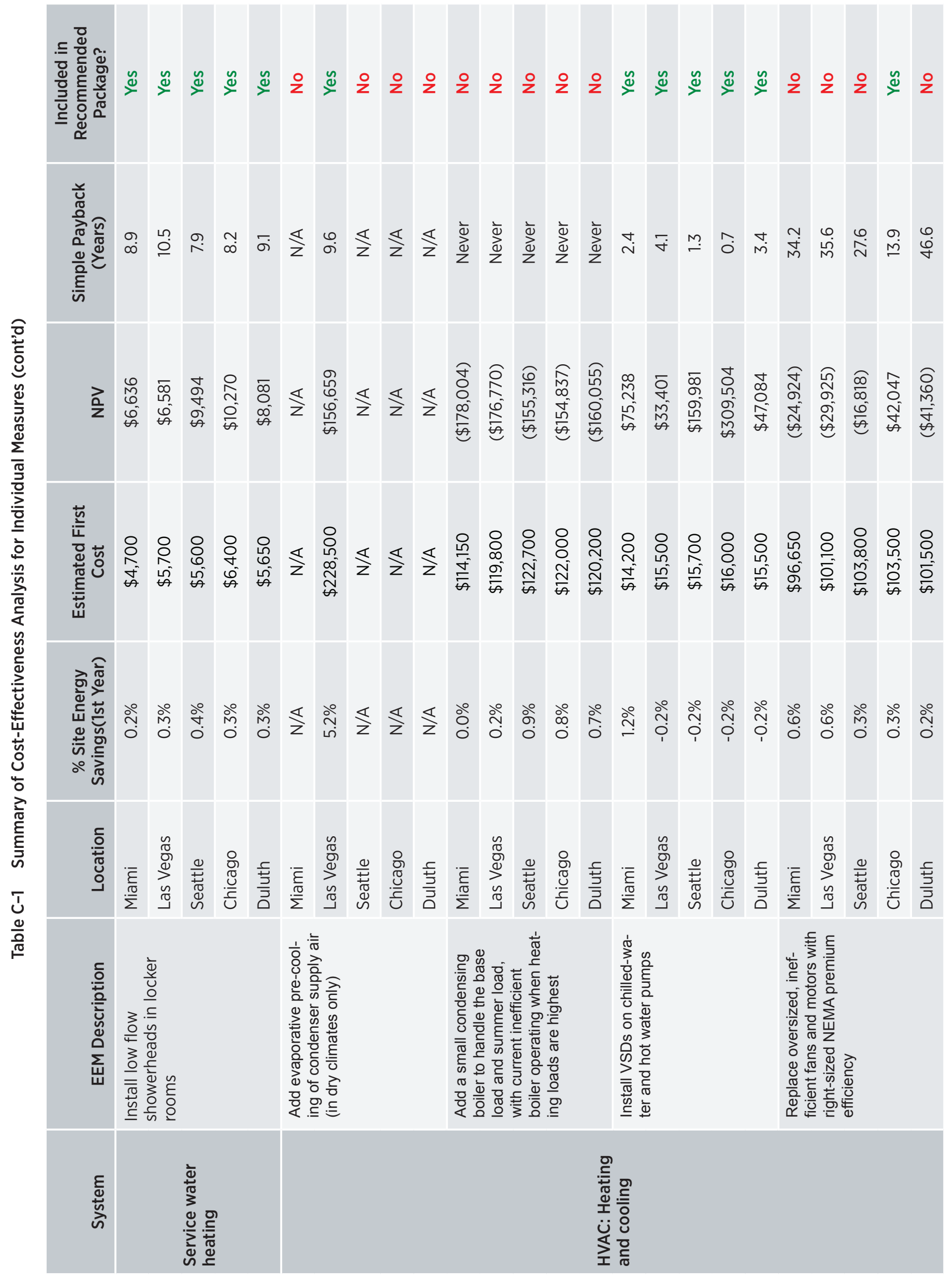




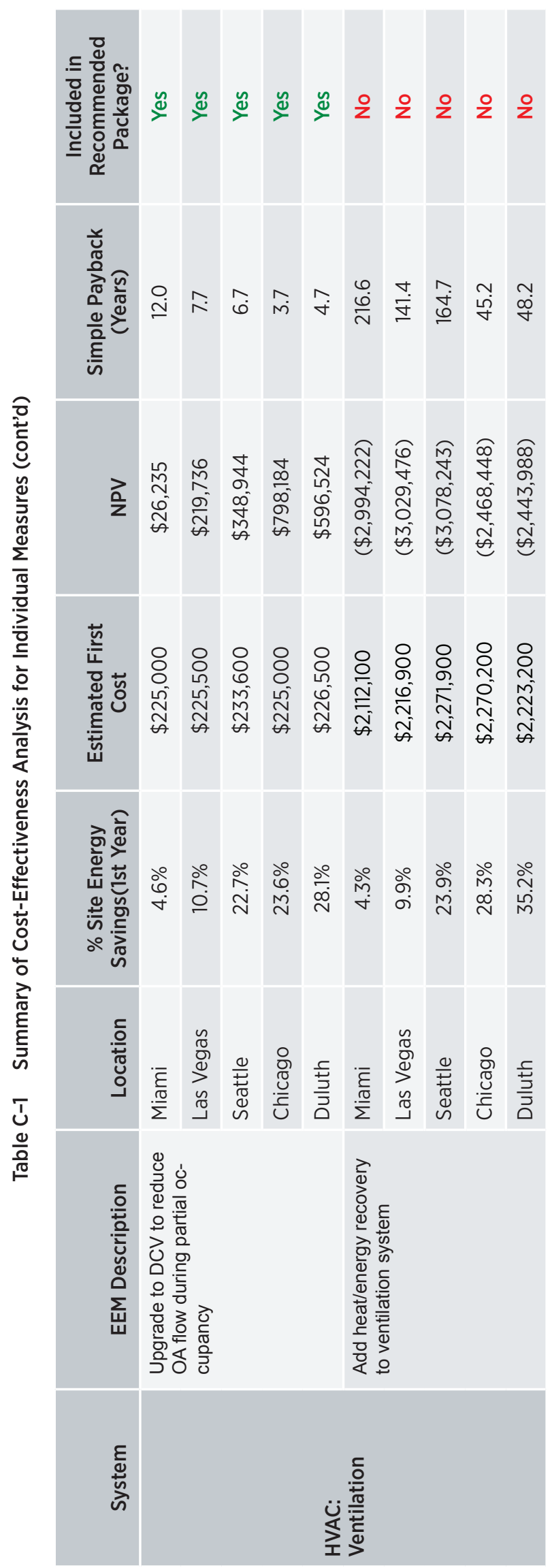




\section{C.1 Replace incandescent exit signs with LEDs}

\section{C.1.1 Implementation in Example Building}

The example building was assumed to have 120 exit signs, which we assumed (for modeling purposes) were in the corridors and lobby. The exit signs were replaced in their entirety (not just the lamps) with LED models. The energy reduction was modeled by reducing the duty cycle in the affected zones, which had the same effect as reducing peak power in those zones, but was much more straightforward to implement.

\section{C.1.2 Energy Savings Analysis}

The results of the energy simulations are summarized in Table $\mathrm{C}-2$.

Table C-2 Key Results of Energy Savings Analysis for LED Exit Signs

\begin{tabular}{|c|c|c|c|c|c|}
\hline Location & $\begin{array}{c}\text { \% Site Energy } \\
\text { Savings } \\
\text { (1st Year) }\end{array}$ & $\begin{array}{c}\text { Electricity } \\
\text { Savings (kWh) } \\
\text { (1st Year) }\end{array}$ & $\begin{array}{c}\text { Natural Gas } \\
\text { Savings (therms) } \\
\text { (1st Year) }\end{array}$ & $\begin{array}{c}\text { Energy Cost } \\
\text { Savings } \\
\text { (1st Year) }\end{array}$ & $\begin{array}{l}\text { O\&M Cost } \\
\text { Savings* } \\
\text { (1st Year) }\end{array}$ \\
\hline Miami & $0.9 \%$ & 49,183 & -3 & $\$ 3,608$ & $\$ 8,841$ \\
\hline Las Vegas & $0.8 \%$ & 42,831 & -76 & $\$ 3,274$ & $\$ 8,378$ \\
\hline Seattle & $0.5 \%$ & 33,848 & -253 & $\$ 5,520$ & $\$ 8,888$ \\
\hline Chicago & $0.5 \%$ & 37,437 & -263 & $\$ 11,451$ & $\$ 8,150$ \\
\hline Duluth & $0.3 \%$ & 34,533 & -315 & $\$ 2,957$ & $\$ 8,532$ \\
\hline
\end{tabular}

* O\&M includes relamping for lighting EEMs.

\section{C.1.3 Cash Flow Analysis}

The results of the cost-effectiveness analysis are summarized in Table $\mathrm{C}-3$.

Table C-3 Key Results of Cost-Effectiveness Analysis for LED Exit Signs

\begin{tabular}{|l|c|c|c|c|c|}
\hline & Installation & & $\begin{array}{c}\text { Include in } \\
\text { Recommended } \\
\text { Package? }\end{array}$ \\
\hline Miami & $\$ 17,580$ & First Cost & NPV & $\begin{array}{c}\text { Simple Payback } \\
\text { (Years) }\end{array}$ \\
\hline Las Vegas & $\$ 16,684$ & $\$ 20,188$ & $\$ 12,273$ & 2.5 & Yes \\
\hline Seattle & $\$ 17,678$ & $\$ 18,633$ & $\$ 169,053$ & 3.2 & Yes \\
\hline Chicago & $\$ 16,262$ & $\$ 22,792$ & $\$ 246,836$ & 2.6 & Yes \\
\hline Duluth & $\$ 16,975$ & $\$ 18,802$ & $\$ 124,491$ & 2.0 & Yes \\
\hline
\end{tabular}




\section{C.2 Replace T12 fluorescent lamps and magnetic ballasts with high-efficiency T8 lamps and instant-start electronic ballasts}

\section{C.2.1 Implementation in Example Building}

We assumed that most of the ambient lighting in the example building was provided by T12 fluorescent lamps, mounted in two-lamp fixtures with magnetic ballasts. For this EEM, 5,002 T8 lamps were installed, mostly in classrooms, along with 2,501 electronic ballasts. (In many situations, two fixtures - four lamps — can be tandem-wired to one ballast, reducing installation costs. To be conservative, we assumed this option was not available.) The EEM was modeled by reducing the lighting power density in each affected zone. There is a net reduction in relamping costs because T8 lamps tend to operate at a lower temperature and have a longer average life, and most high-performance T8 lamps come with a maintenance warranty.

\section{C.2.2 Energy Savings Analysis}

The results of the energy simulations are summarized in Table $\mathrm{C}-4$.

Table C-4 Key Results of Energy Savings Analysis for T8 Lamps and Ballasts

\begin{tabular}{|l|c|c|c|c|c|}
\hline & $\begin{array}{c}\text { \% Site Energy } \\
\text { Savings } \\
\text { (1st Year) }\end{array}$ & $\begin{array}{c}\text { Electricity } \\
\text { Savings (kWh) } \\
\text { (1st Year) }\end{array}$ & $\begin{array}{c}\text { Natural Gas } \\
\text { Savings (therms) } \\
\text { (1st Year) }\end{array}$ & $\begin{array}{c}\text { Energy Cost } \\
\text { Savings } \\
\text { (1st Year) }\end{array}$ & $\begin{array}{c}\text { O\&M Cost } \\
\text { Savings* } \\
\text { (1st Year) }\end{array}$ \\
\hline Miami & $8.9 \%$ & 460,352 & -43 & $\$ 38,401$ & $\$ 4,299$ \\
\hline Las Vegas & $6.5 \%$ & 389,219 & -1448 & $\$ 30,701$ & $\$ 5,649$ \\
\hline Seattle & $3.9 \%$ & 310,199 & -3862 & $\$ 56,418$ & $\$ 5,415$ \\
\hline Chicago & $3.6 \%$ & 335,052 & -3695 & $\$ 99,355$ & $\$ 6,126$ \\
\hline Duluth & $2.2 \%$ & 315,877 & -5059 & $\$ 27,850$ & $\$ 5,159$ \\
\hline
\end{tabular}

* O\&M includes relamping for lighting EEMs.

\section{C.2.3 Cash Flow Analysis}

The results of the cost-effectiveness analysis are summarized in Table $\mathrm{C}-5$.

Table C-5 Key Results of Cost-Effectiveness Analysis for T8 Lamps and Ballasts

\begin{tabular}{|c|c|c|c|c|c|}
\hline Location & Purchase Cost & $\begin{array}{l}\text { Installation } \\
\text { First Cost }\end{array}$ & NPV & $\begin{array}{c}\text { Simple Payback } \\
\text { (Years) }\end{array}$ & $\begin{array}{l}\text { Include in } \\
\text { Recommended } \\
\text { Package? }\end{array}$ \\
\hline Miami & $\$ 149,148$ & $\$ 137,606$ & $\$ 422,479$ & 7.4 & Yes \\
\hline Las Vegas & $\$ 147,360$ & $\$ 208,775$ & $\$ 260,864$ & 10.8 & Yes \\
\hline Seattle & $\$ 154,681$ & $\$ 281,724$ & $\$ 585,746$ & 7.7 & Yes \\
\hline Chicago & $\$ 147,456$ & $\$ 236,296$ & $\$ 1,310,747$ & 4.0 & Yes \\
\hline Duluth & $\$ 157,329$ & $\$ 194,927$ & $\$ 206,527$ & 11.8 & Yes \\
\hline
\end{tabular}




\section{C.3 Replace incandescent lamps with CFLs}

\section{C.3.1 Implementation in Example Building}

We assumed that the example building had a significant amount of incandescent lighting of the screw-in variety, especially in offices, lobbies, mechanical rooms, and the kitchen. A total of 492 incandescent lamps were replaced with CFLs producing equivalent light output. O\&M costs were reduced on the basis of a sevenfold increase in lamp life for the CFLs.

\section{C.3.2 Energy Savings Analysis}

The results of the energy simulations are summarized in Table C-6.

Table C-6 Key Results of Energy Savings Analysis for the CFL Retrofit

\begin{tabular}{|l|c|c|c|c|c|}
\hline & $\begin{array}{c}\text { Electricity } \\
\text { \% Site Energy } \\
\text { Savings(kWh) }\end{array}$ & $\begin{array}{c}\text { Natural Gas } \\
\text { Savings (therms) } \\
\text { (1st Year) }\end{array}$ & $\begin{array}{c}\text { Energy Cost } \\
\text { Savings } \\
(1 s t \text { Year) }\end{array}$ & $\begin{array}{c}\text { O\&M } \\
\text { Cost Savings* } \\
(1 s t \text { Year) }\end{array}$ \\
\hline Miami & $2.3 \%$ & 121,979 & -14 & $\$ 10,030$ & $\$ 7,800$ \\
\hline Las Vegas & $2.3 \%$ & 130,019 & -320 & $\$ 9,724$ & $\$ 9,717$ \\
\hline Seattle & $1.2 \%$ & 83,283 & -785 & $\$ 15,197$ & $\$ 9,464$ \\
\hline Chicago & $1.0 \%$ & 91,411 & -873 & $\$ 26,956$ & $\$ 10,460$ \\
\hline Duluth & $0.6 \%$ & 82,839 & -1193 & $\$ 7,383$ & $\$ 9,295$ \\
\hline
\end{tabular}

* O\&M includes relamping for lighting EEMs.

\section{C.3.3 Cash Flow Analysis}

The results of the cost-effectiveness analysis are summarized in Table $\mathrm{C}-7$.

Table C-7 Key Results of Cost-Effectiveness Analysis for the CFL Retrofit

\begin{tabular}{|c|c|c|c|c|c|}
\hline Location & Purchase Cost & $\begin{array}{l}\text { Installation } \\
\text { First Cost }\end{array}$ & NPV & $\begin{array}{c}\text { Simple Payback } \\
\text { (Years) }\end{array}$ & $\begin{array}{l}\text { Include in } \\
\text { Recommended } \\
\text { Package? }\end{array}$ \\
\hline Miami & $\$ 3,462$ & $\$ 4,860$ & $\$ 265,693$ & 0.6 & Yes \\
\hline Las Vegas & $\$ 3,420$ & $\$ 7,373$ & $\$ 286,510$ & 0.7 & Yes \\
\hline Seattle & $\$ 3,697$ & $\$ 6,822$ & $\$ 367,346$ & 0.5 & Yes \\
\hline Chicago & $\$ 3,322$ & $\$ 8,345$ & $\$ 564,346$ & 0.4 & Yes \\
\hline Duluth & $\$ 3,584$ & $\$ 6,848$ & $\$ 242,649$ & 0.8 & Yes \\
\hline
\end{tabular}

*Includes both purchase and installation. 


\section{C.4 Install wireless motion sensors for lighting in rooms that are used intermittently}

\section{C.4.1 Implementation in Example Building}

We assumed that lighting levels in the example building were controlled manually by school maintenance staff. Overnight lighting levels were already consistent with the minimum lighting necessary for security and safety purposes, and for janitorial services. Motion sensors would likely have the greatest benefit during periods when many zones are partially occupied, between 7:00 a.m. and 9:00 p.m. A total of 126 motion sensors and lighting controls were installed for this EEM, primarily in classrooms and office areas. O\&M savings accrue because lamps are on fewer hours each day, and require less frequent replacement.

\section{C.4.2 Energy Savings Analysis}

The results of the energy simulations are summarized in Table C-8.

Table C-8 Key Results of Energy Savings Analysis for Motion Sensors

\begin{tabular}{|c|c|c|c|c|c|}
\hline Location & $\begin{array}{c}\text { \% Site Energy } \\
\text { Savings } \\
\text { (1st Year) }\end{array}$ & $\begin{array}{c}\text { Electricity Savings } \\
\text { (kWh) } \\
\text { (1st Year) }\end{array}$ & $\begin{array}{c}\text { Natural Gas } \\
\text { Savings (therms) } \\
\text { (1st Year) }\end{array}$ & $\begin{array}{c}\text { Energy Cost } \\
\text { Savings } \\
\text { (1st Year) }\end{array}$ & $\begin{array}{l}\text { O\&M Cost } \\
\text { Savings* } \\
\text { (1st Year) }\end{array}$ \\
\hline Miami & $2.6 \%$ & 135,250 & -5 & $\$ 12,315$ & $\$ 137$ \\
\hline Las Vegas & $2.0 \%$ & 115,696 & -383 & $\$ 9,650$ & $\$ 208$ \\
\hline Seattle & $1.2 \%$ & 93,981 & -1157 & $\$ 18,356$ & $\$ 192$ \\
\hline Chicago & $1.1 \%$ & 102,341 & -1128 & $\$ 29,744$ & $\$ 235$ \\
\hline Duluth & $0.6 \%$ & 94,134 & -1550 & $\$ 8,737$ & $\$ 194$ \\
\hline
\end{tabular}

* O\&M includes relamping for lighting EEMs.

\section{C.4.3 Cash Flow Analysis}

The results of the cost-effectiveness analysis are summarized in Table C-9.

Table C-9 Key Results of Cost-Effectiveness Analysis for Motion Sensors

\begin{tabular}{|l|c|c|c|c|c|}
\hline Location & Purchase Cost & $\begin{array}{c}\text { Installation } \\
\text { First Cost }\end{array}$ & NPV & $\begin{array}{c}\text { Include in } \\
\text { Simple Payback } \\
\text { (Years) }\end{array}$ \\
\hline Miami & $\$ 14,113$ & $\$ 1,370$ & $\$ 169,534$ & 1.2 & Yesommended \\
Package?
\end{tabular}




\section{C.5 Install photosensors and dimming ballasts to dim lights when daylighting is sufficient}

\section{C.5.1 Implementation in Example Building}

This EEM was applied only to classrooms in the example building. The daylighting algorithm in EnergyPlus was used to calculate the necessary electric lighting to achieve 40 footcandles of illumination at a point $20 \mathrm{ft}$ from the windows and $3 \mathrm{ft}$ from the floor. A total of 76 photosensors and 1,540 dimmable ballasts were installed in 76 classrooms for this EEM.

\section{C.5.2 Energy Savings Analysis}

The results of the energy simulations are summarized in Table $\mathrm{C}-10$.

Table C-10 Key Results of Energy Savings Analysis for Photosensors

\begin{tabular}{|l|c|c|c|c|c|}
\hline & $\begin{array}{c}\text { \% Site Energy } \\
\text { Savings } \\
\text { (1st Year) }\end{array}$ & $\begin{array}{c}\text { Electricity } \\
\text { Savings (kWh) } \\
\text { (1st Year) }\end{array}$ & $\begin{array}{c}\text { Natural Gas } \\
\text { Savings (therms) } \\
\text { (1st Year) }\end{array}$ & $\begin{array}{c}\text { Energy Cost } \\
\text { Savings } \\
\text { (1st Year) }\end{array}$ & $\begin{array}{c}\text { O\&M } \\
\text { Cost Savings* } \\
\text { (1st Year) }\end{array}$ \\
\hline Miami & $5.6 \%$ & 293,123 & -1 & $\$ 31,104$ & $\$ 0$ \\
\hline Las Vegas & $4.5 \%$ & 256,517 & -540 & $\$ 22,841$ & $\$ 0$ \\
\hline Seattle & $2.5 \%$ & 165,063 & -1313 & $\$ 35,600$ & $\$ 0$ \\
\hline Chicago & $2.0 \%$ & 163,859 & -1238 & $\$ 57,613$ & $\$ 0$ \\
\hline Duluth & $1.3 \%$ & 147,447 & -1656 & $\$ 14,775$ & $\$ 0$ \\
\hline
\end{tabular}

* O\&M includes relamping for lighting EEMs.

\section{C.5.3 Cash Flow Analysis}

The results of the cost-effectiveness analysis are summarized in Table $\mathrm{C}-11$.

Table C-11 Key Results of Cost-Effectiveness Analysis for Photosensors

\begin{tabular}{|c|c|c|c|c|c|}
\hline Location & Purchase Cost & $\begin{array}{l}\text { Installation } \\
\text { First Cost }\end{array}$ & NPV & $\begin{array}{c}\text { Simple Payback } \\
\text { (Years) }\end{array}$ & $\begin{array}{c}\text { Include in } \\
\text { Recommended } \\
\text { Package? }\end{array}$ \\
\hline Miami & $\$ 442,666$ & $\$ 127,912$ & $(\$ 149,195)$ & 19.7 & No \\
\hline Las Vegas & $\$ 671,612$ & $\$ 194,067$ & $(\$ 579,139)$ & 39.9 & No \\
\hline Seattle & $\$ 621,424$ & $\$ 179,868$ & $(\$ 318,596)$ & 23.8 & No \\
\hline Chicago & $\$ 615,712$ & $\$ 219,650$ & $(\$ 13,917)$ & 15.4 & No \\
\hline Duluth & $\$ 627,063$ & $\$ 181,195$ & $(\$ 648,911)$ & 57.8 & No \\
\hline
\end{tabular}




\section{C.6 Replace high-intensity discharge lights with T5 high-output fluorescents in gymnasiums}

\section{C.6.1 Implementation in Example Building}

For this EEM, we assumed that nondimmable metal halide (MH) lighting in the large gym was replaced with dimmable T5 fluorescent lighting. Although the lighting efficacy was approximately the same, we estimated that the average power for lighting the gym could be reduced by $50 \%$ because of the dimming capability of the T5 fixtures. The average life of the T5 lamps was assumed to be longer than for MHs, but the relamping cost was assumed to be higher, resulting in about the same O\&M costs for either scenario. Additional O\&M savings may be associated with multilamp T5 fixtures because burned-out lamps do not require immediate replacement, and replacements are easier than for MH, but we neglected these effects for this analysis.

\section{C.6.2 Energy Savings Analysis}

The results of the energy simulations are summarized in Table $\mathrm{C}-12$.

Table C-12 Key Results of Energy Savings Analysis for T5 Gym Lighting

\begin{tabular}{|c|c|c|c|c|c|}
\hline Location & $\begin{array}{c}\text { \% Site Energy } \\
\text { Savings } \\
\text { (1st Year) }\end{array}$ & $\begin{array}{c}\text { Electricity } \\
\text { Savings (kWh) } \\
\text { (1st Year) }\end{array}$ & $\begin{array}{c}\text { Natural Gas } \\
\text { Savings (therms) } \\
\text { (1st Year) }\end{array}$ & $\begin{array}{l}\text { Energy } \\
\text { Cost Savings } \\
\text { (1st Year) }\end{array}$ & $\begin{array}{c}\text { O\&M } \\
\text { Cost Savings* } \\
\text { (1st Year) }\end{array}$ \\
\hline Miami & $1.1 \%$ & 60,387 & -50 & $\$ 5,017$ & $\$ 108$ \\
\hline Las Vegas & $0.7 \%$ & 50,763 & -392 & $\$ 3,742$ & $(\$ 28)$ \\
\hline Seattle & $0.4 \%$ & 42,895 & -836 & $\$ 7,102$ & $\$ 488$ \\
\hline Chicago & $0.6 \%$ & 56,419 & -703 & $\$ 16,337$ & $\$ 340$ \\
\hline Duluth & $0.2 \%$ & 40,827 & -904 & $\$ 3,357$ & $(\$ 17)$ \\
\hline
\end{tabular}

* O\&M includes relamping for lighting EEMs.

\section{C.6.3 Cash Flow Analysis}

The results of the cost-effectiveness analysis are summarized in Table $\mathrm{C}-13$.

\section{Table C-13 Key Results of Cost-Effectiveness Analysis for T5 Gym Lighting}

\begin{tabular}{|l|c|c|c|c|c|}
\hline & Installation & & $\begin{array}{c}\text { Include in } \\
\text { Recommended } \\
\text { Package? }\end{array}$ \\
\hline Location & Purchase Cost & Nirst Cost & $\begin{array}{c}\text { Simple Payback } \\
\text { (Years) }\end{array}$ & Yes \\
\hline Las Vegas & $\$ 14,362$ & $\$ 3,647$ & $\$ 70,099$ & 2.8 & Yes \\
\hline Seattle & $\$ 13,288$ & $\$ 5,533$ & $\$ 43,447$ & 5.6 & Yes \\
\hline Chicago & $\$ 16,255$ & $\$ 5,119$ & $\$ 103,409$ & 2.5 & Yes \\
\hline Duluth & $\$ 11,305$ & $\$ 6,263$ & $\$ 242,959$ & 1.4 & Yes \\
\hline
\end{tabular}




\section{C.7 Install tubular daylighting devices in classrooms, offices, corridors, and restrooms (bundled with photosensors and dimming ballasts)}

\section{C.7.1 Implementation in Example Building}

Enhanced daylighting from tubular skylights is unlikely to save much energy unless it is combined with daylighting controls. Because the example building does not have such controls, this EEM must be combined with the photosensor/dimming ballast EEM discussed in Section D.5. We assumed that tubular skylights were appropriate for second floor classrooms, offices, restrooms, and corridors only. A total of 500 tubular skylights, each with a diameter of 22 in., were assumed for this EEM.

\section{C.7.2 Energy Savings Analysis}

The results of the energy simulations are summarized in Table C-14.

Table C-14 Key Results of Energy Savings Analysis for Tubular Skylights

\begin{tabular}{|l|c|c|c|c|c|}
\hline & $\begin{array}{c}\text { \% Site Energy } \\
\text { Savings } \\
\text { (1st Year) }\end{array}$ & $\begin{array}{c}\text { Electricity } \\
\text { Savings (kWh) } \\
(1 \text { st Year) }\end{array}$ & $\begin{array}{c}\text { Natural Gas } \\
\text { Savings (therms) } \\
(1 s t \text { Year) }\end{array}$ & $\begin{array}{c}\text { Energy Cost } \\
\text { Savings } \\
\text { (1st Year) }\end{array}$ & $\begin{array}{c}\text { O\&M } \\
\text { Cost Savings } \\
(1 s t \text { Year) }\end{array}$ \\
\hline Miami & $7.3 \%$ & 377,353 & -2 & $\$ 39,246$ & $(\$ 5,381)$ \\
\hline Las Vegas & $5.7 \%$ & 325,874 & -826 & $\$ 28,037$ & $(\$ 7,775)$ \\
\hline Seattle & $3.3 \%$ & 229,990 & -2060 & $\$ 47,046$ & $(\$ 7,348)$ \\
\hline Chicago & $2.9 \%$ & 247,870 & -2254 & $\$ 83,477$ & $(\$ 9,579)$ \\
\hline Duluth & $1.8 \%$ & 232,992 & -3216 & $\$ 21,601$ & $(\$ 5,808)$ \\
\hline
\end{tabular}

\section{C.7.3 Cash Flow Analysis}

The results of the cost-effectiveness analysis are summarized in Table $\mathrm{C}-15$.

Table C-15 Key Results of Cost-Effectiveness Analysis for Tubular Skylights

\begin{tabular}{|c|c|c|c|c|c|}
\hline Location & Purchase Cost & $\begin{array}{l}\text { Installation } \\
\text { First Cost }\end{array}$ & NPV & $\begin{array}{c}\text { Simple Payback } \\
\text { (Years) }\end{array}$ & $\begin{array}{c}\text { Include in } \\
\text { Recommended } \\
\text { Package? }\end{array}$ \\
\hline Miami & $\$ 1,165,817$ & $\$ 390,837$ & $(\$ 1,447,164)$ & 47.0 & No \\
\hline Las Vegas & $\$ 1,389,582$ & $\$ 574,006$ & $(\$ 2,062,418)$ & 98.9 & No \\
\hline Seattle & $\$ 1,377,661$ & $\$ 538,922$ & $(\$ 1,736,493)$ & 49.3 & No \\
\hline Chicago & $\$ 1,343,304$ & $\$ 687,708$ & $(\$ 1,301,385)$ & 28.1 & No \\
\hline Duluth & $\$ 1,604,834$ & $\$ 465,005$ & $(\$ 2,324,141)$ & 133.7 & No \\
\hline
\end{tabular}




\section{C.8 Install more efficient exterior lighting for façades and parking lot}

\section{C.8.1 Implementation in Example Building}

MH lamps were assumed for all façade and parking lot lighting in the example building. When implementing this EEM, we replaced all MH lighting on the façade and in the parking lot with LEDs. We also assumed motion sensors could be used to control the level of lighting in the parking lot based on whether anyone was present. O\&M costs were reduced slightly from the combination of longer LED life with higher relamping costs.

\section{C.8.2 Energy Savings Analysis}

The results of the energy simulations are summarized in Table $\mathrm{C}-16$.

Table C-16 Key Results of Energy Savings Analysis for Exterior Lighting Retrofit

\begin{tabular}{|l|c|c|c|c|c|}
\hline & $\begin{array}{c}\text { \% Site Energy } \\
\text { Savings } \\
\text { (1st Year) }\end{array}$ & $\begin{array}{c}\text { Electricity } \\
\text { Savings (kWh) } \\
\text { (1st Year) }\end{array}$ & $\begin{array}{c}\text { Natural Gas } \\
\text { Savings (therms) } \\
\text { (1st Year) }\end{array}$ & $\begin{array}{c}\text { Energy Cost } \\
\text { Savings } \\
\text { (1st Year) }\end{array}$ & $\begin{array}{c}\text { O\&M } \\
\text { Cost Savings* } \\
\text { (1st Year) }\end{array}$ \\
\hline Miami & $0.8 \%$ & 42,217 & 0 & $\$ 2,275$ & $\$ 13$ \\
\hline Las Vegas & $0.8 \%$ & 42,144 & 0 & $\$ 2,537$ & $\$ 17$ \\
\hline Seattle & $0.8 \%$ & 42,077 & 0 & $\$ 6,084$ & $\$ 16$ \\
\hline Chicago & $0.7 \%$ & 42,149 & 0 & $\$ 10,835$ & $\$ 19$ \\
\hline Duluth & $0.5 \%$ & 42,096 & 0 & $\$ 3,547$ & $\$ 16$ \\
\hline
\end{tabular}

* O\&M includes relamping for lighting EEMs.

\section{C.8.3 Cash Flow Analysis}

The results of the cost-effectiveness analysis are summarized in Table $\mathrm{C}-17$.

Table C-17 Key Results of Cost-Effectiveness Analysis for Exterior Lighting Retrofit

\begin{tabular}{|l|c|c|c|c|c|}
\hline Location & Purchase Cost & $\begin{array}{c}\text { Installation } \\
\text { First Cost }\end{array}$ & NPV & $\begin{array}{c}\text { Include in } \\
\text { Recommended } \\
\text { Package? }\end{array}$ \\
\hline Miami & $\$ 16,450$ & $\$ 2,413$ & $\$ 15,043$ & Yimple Payback \\
(Years)
\end{tabular}




\section{C.9 Replace cafeteria appliances with ENERGY STAR models}

\section{C.9.1 Implementation in Example Building}

A typical collection of kitchen and cafeteria appliances were assumed for the example building, based on a survey of schools conducted by the University of Mississippi (Meyer 1997). Appliance efficiencies, hours of operation, peak power, and other equipment parameters for the example building were estimated based on the EPA Commercial Kitchen Equipment Savings Calculator (EPA 2011f). Kitchen appliances, not including refrigeration, meeting the minimum requirements for ENERGY STAR appliances were selected from the Qualified Products List (EPA 2011g) for pricing and modeling this EEM. Energy cost savings resulting from electricity use, electricity demand, natural gas use, and hot water use were all considered. O\&M savings were neglected, although advanced controls could decrease operating time and consequent wear and tear.

\section{C.9.2 Energy Savings Analysis}

The results of the energy simulations are summarized in Table $\mathrm{C}-18$.

Table C-18 Key Results of Energy Savings Analysis for Cafeteria Appliance Replacement

\begin{tabular}{|l|c|c|c|c|c|}
\hline $\begin{array}{c}\text { \% Site Energy } \\
\text { Savings } \\
\text { (1st Year) }\end{array}$ & $\begin{array}{c}\text { Electricity } \\
\text { Savings (kWh) } \\
\text { (1st Year) }\end{array}$ & $\begin{array}{c}\text { Natural Gas } \\
\text { Savings (therms) } \\
\text { (1st Year) }\end{array}$ & $\begin{array}{c}\text { Energy Cost } \\
\text { Savings } \\
\text { (1st Year) }\end{array}$ & $\begin{array}{c}\text { O\&M } \\
\text { Cost Savings } \\
\text { (1st Year) }\end{array}$ \\
\hline Miami & $1.0 \%$ & 26,203 & 824 & $\$ 2,676$ & $\$ 0$ \\
\hline Las Vegas & $0.9 \%$ & 24,160 & 810 & $\$ 2,572$ & $\$ 0$ \\
\hline Seattle & $0.9 \%$ & 21,108 & 774 & $\$ 4,355$ & $\$ 0$ \\
\hline Chicago & $0.7 \%$ & 21,583 & 731 & $\$ 7,246$ & $\$ 0$ \\
\hline Duluth & $0.5 \%$ & 20,778 & 654 & $\$ 2,372$ & $\$ 0$ \\
\hline
\end{tabular}

\section{C.9.3 Cash Flow Analysis}

The results of the cost-effectiveness analysis are summarized in Table $\mathrm{C}-19$.

Table C-19 Key Results of Cost-Effectiveness Analysis for Cafeteria Appliance Replacement

\begin{tabular}{|l|c|c|c|c|c|}
\hline Location & Purchase Cost & $\begin{array}{c}\text { Installation } \\
\text { First Cost }\end{array}$ & NPV & $\begin{array}{c}\text { Include in } \\
\text { Simple Payback } \\
\text { (Years) }\end{array}$ & $\begin{array}{c}\text { Recommended } \\
\text { Package? }\end{array}$ \\
\hline Miami & $\$ 39,339$ & $\$ 2,324$ & $\$ 10,525$ & 17.2 & Yes \\
\hline Las Vegas & $\$ 39,057$ & $\$ 3,359$ & $\$ 5,715$ & 19.0 & Yes \\
\hline Seattle & $\$ 41,139$ & $\$ 3,174$ & $\$ 32,648$ & 11.6 & Yes \\
\hline Chicago & $\$ 39,580$ & $\$ 4,138$ & $\$ 75,735$ & 7.2 & Yes \\
\hline Duluth & $\$ 39,339$ & $\$ 2,324$ & $(\$ 4,976)$ & 25.5 & No \\
\hline
\end{tabular}




\section{C.10 Install variable-speed drives and demand control on kitchen exhaust hood fans}

\section{C.10.1 Implementation in Example Building}

We assumed that the example building has one Type 1 and one Type 2 kitchen exhaust hood, removing $2400 \mathrm{cfm}$ and $1600 \mathrm{cfm}$ of exhaust air, respectively. To represent the EEM, a 30\% reduction in average exhaust flow rate from demand control was applied based on a study of five projects conducted by Fisher (2008). An efficiency of 69\% was assumed for the VSD (DOE 2008c), resulting in a net reduction in average power of 50\%. Flow rate control based on both temperature and optical sensors was assumed. The effect of reduced exhaust flow on total infiltration was not modeled.

\section{C.10.2 Energy Savings Analysis}

The results of the energy simulations are summarized in Table C-20.

Table C-20 Key Results of Energy Savings Analysis for Kitchen Exhaust Hood Retrofit

\begin{tabular}{|l|c|c|c|c|c|}
\hline $\begin{array}{c}\text { \% Site Energy } \\
\text { Savings } \\
\text { (1st Year) }\end{array}$ & $\begin{array}{c}\text { Electricity } \\
\text { Savings (kWh) } \\
\text { (1st Year) }\end{array}$ & $\begin{array}{c}\text { Natural Gas } \\
\text { Savings (therms) } \\
\text { (1st Year) }\end{array}$ & $\begin{array}{c}\text { Energy Cost } \\
\text { Savings } \\
\text { (1st Year) }\end{array}$ & $\begin{array}{c}\text { O\&M } \\
\text { Cost Savings } \\
(1 s t \text { Year) }\end{array}$ \\
\hline Miami & $0.01 \%$ & 873 & 0 & $\$ 78$ & $\$ 0$ \\
\hline Las Vegas & $0.02 \%$ & 873 & 0 & $\$ 73$ & $\$ 0$ \\
\hline Seattle & $0.02 \%$ & 873 & 0 & $\$ 164$ & $\$ 0$ \\
\hline Chicago & $0.01 \%$ & 873 & 0 & $\$ 267$ & $\$ 0$ \\
\hline Duluth & $0.01 \%$ & 873 & 0 & $\$ 86$ & $\$ 0$ \\
\hline
\end{tabular}

\section{C.10.3 Cash Flow Analysis}

The results of the cost-effectiveness analysis are summarized in Table C-21.

Table C-21 Key Results of Cost-Effectiveness Analysis for Kitchen Exhaust Hood Retrofit

\begin{tabular}{|l|c|c|c|c|c|}
\hline Location & Purchase Cost & $\begin{array}{c}\text { Installation } \\
\text { First Cost }\end{array}$ & NPV & $\begin{array}{c}\text { Include in } \\
\text { Simple Payback } \\
\text { (Years) }\end{array}$ & $\begin{array}{c}\text { Recommended } \\
\text { Package? }\end{array}$ \\
\hline Miami & $\$ 6,050$ & $\$ 2,050$ & $(\$ 8,655)$ & 103.7 & No \\
\hline Las Vegas & $\$ 6,150$ & $\$ 3,000$ & $(\$ 10,007)$ & 124.8 & No \\
\hline Seattle & $\$ 6,350$ & $\$ 2,800$ & $(\$ 8,591)$ & 55.6 & No \\
\hline Chicago & $\$ 6,100$ & $\$ 3,650$ & $(\$ 7,715)$ & 36.4 & No \\
\hline Duluth & $\$ 6,150$ & $\$ 2,950$ & $(\$ 9,738)$ & 104.9 & No \\
\hline
\end{tabular}




\section{C.11 Add reflective roof covering}

\section{C.11.1 Implementation in Example Building}

The roof of the example building was assumed to have a gray rubber exterior finish that reflects $30 \%$ of incident sunlight. The EEM was assumed to be a high albedo white polyvinyl chloride material that reflects $86 \%$ of incident sunlight. No change to the thermal insulation levels was assumed. A small reduction in O\&M costs was assumed because of lower roof temperatures. This EEM was evaluated in hot climates only.

\section{C.11.2 Energy Savings Analysis}

The results of the energy simulations are summarized in Table $\mathrm{C}-22$.

Table C-22 Key Results of Energy Savings Analysis for Reflective Roof

\begin{tabular}{|l|c|c|c|c|c|}
\hline & $\begin{array}{c}\text { \% Site Energy } \\
\text { Savings } \\
\text { (1st Year) }\end{array}$ & $\begin{array}{c}\text { Electricity } \\
\text { Savings (kWh) } \\
\text { (1st Year) }\end{array}$ & $\begin{array}{c}\text { Natural Gas } \\
\text { Savings (therms) } \\
(1 \text { 1st Year) }\end{array}$ & $\begin{array}{c}\text { Energy Cost } \\
\text { Savings } \\
(1 s t \text { Year) }\end{array}$ & $\begin{array}{c}\text { O\&M } \\
\text { Cost Savings } \\
(1 s t \text { Year) }\end{array}$ \\
\hline Location & $4.1 \%$ & 214,170 & -53 & $\$ 21,006$ & $\$ 1,731$ \\
\hline Las Vegas & $2.6 \%$ & 171,002 & -1105 & $\$ 20,935$ & $\$ 2,502$ \\
\hline Seattle & N/A & N/A & N/A & N/A & N/A \\
\hline Chicago & N/A & N/A & N/A & N/A & N/A \\
\hline Duluth & N/A & N/A & N/A & N/A & N/A \\
\hline
\end{tabular}

\section{C.11.3 Cash Flow Analysis}

The results of the cost-effectiveness analysis are summarized in Table $\mathrm{C}-23$.

Table C-23 Key Results of Cost-Effectiveness Analysis for Reflective Roof

\begin{tabular}{|l|c|c|c|c|c|}
\hline Location & Purchase Cost & $\begin{array}{c}\text { Installation } \\
\text { First Cost }\end{array}$ & NPV & $\begin{array}{c}\text { Include in } \\
\text { Simple Payback } \\
\text { Recommended } \\
\text { Package? }\end{array}$ \\
\hline Miami & $\$ 456,534$ & $\$ 173,136$ & $(\$ 61,623)$ & 27.9 & No \\
\hline Las Vegas & $\$ 453,263$ & $\$ 250,190$ & $(\$ 132,241)$ & 30.3 & No \\
\hline Seattle & N/A & N/A & N/A & N/A & No \\
\hline Chicago & N/A & N/A & N/A & N/A & No \\
\hline Duluth & N/A & N/A & N/A & N/A & No \\
\hline
\end{tabular}




\section{C.12 Add an exterior insulating finish system to exterior walls}

\section{C.12.1 Implementation in Example Building}

The example building was assumed to have steel-framed walls, with a small amount of partially degraded expanded polystyrene (EPS) rigid insulation on the exterior (1-2 in. depending on geographic location). The exterior finish of the example building was stucco, and the interior finish was painted gypsum board. For the EEM, we assumed an EIFS assembly with 4-in. EPS on the exterior of the steel framing, a new stucco-type exterior finish, and the same painted gypsum interior finish.

\section{C.12.2 Energy Savings Analysis}

The results of the energy simulations are summarized in Table C-24.

Table C-24 Key Results of Energy Savings Analysis for Wall Insulation Retrofit

\begin{tabular}{|l|c|c|c|c|c|}
\hline $\begin{array}{c}\text { \% Site Energy } \\
\text { Savings } \\
\text { (1st Year) }\end{array}$ & $\begin{array}{c}\text { Electricity } \\
\text { Savings (kWh) } \\
\text { (1st Year) }\end{array}$ & $\begin{array}{c}\text { Natural Gas } \\
\text { Savings (therms) } \\
\text { (1st Year) }\end{array}$ & $\begin{array}{c}\text { Energy Cost } \\
\text { Savings } \\
\text { (1st Year) }\end{array}$ & $\begin{array}{c}\text { O\&M } \\
\text { Cost Savings } \\
\text { (1st Year) }\end{array}$ \\
\hline Miami & $1.1 \%$ & 58,350 & 42 & $\$ 6,902$ & $\$ 0$ \\
\hline Las Vegas & $2.6 \%$ & 108,970 & 1011 & $\$ 12,812$ & $\$ 0$ \\
\hline Seattle & $1.9 \%$ & 48,894 & 1693 & $\$ 10,679$ & $\$ 0$ \\
\hline Chicago & $1.6 \%$ & 41,587 & 2098 & $\$ 15,267$ & $\$ 0$ \\
\hline Duluth & $1.6 \%$ & 28,491 & 3118 & $\$ 5,196$ & $\$ 0$ \\
\hline
\end{tabular}

\section{C.12.3 Cash Flow Analysis}

The results of the cost-effectiveness analysis are summarized in Table $\mathrm{C}-25$.

Table C-25 Key Results of Cost-Effectiveness Analysis for Wall Insulation Retrofit

\begin{tabular}{|l|c|c|c|c|c|}
\hline \multicolumn{1}{|c|}{ Location } & Purchase Cost & $\begin{array}{c}\text { Installation } \\
\text { First Cost }\end{array}$ & NPV & $\begin{array}{c}\text { Include in } \\
\text { Simple Payback } \\
\text { (Years) }\end{array}$ & $\begin{array}{c}\text { Recommended } \\
\text { Package? }\end{array}$ \\
\hline Miami & $\$ 469,694$ & $\$ 483,180$ & $(\$ 502,130)$ & 138.1 & No \\
\hline Las Vegas & $\$ 466,329$ & $\$ 698,219$ & $(\$ 599,772)$ & 90.9 & No \\
\hline Seattle & $\$ 491,184$ & $\$ 659,838$ & $(\$ 606,073)$ & 107.6 & No \\
\hline Chicago & $\$ 472,579$ & $\$ 860,156$ & $(\$ 706,667)$ & 87.2 & No \\
\hline Duluth & $\$ 635,073$ & $\$ 521,561$ & $(\$ 619,481)$ & 221.0 & No \\
\hline
\end{tabular}




\section{C.13 Replace or retrofit windows and frames with double-paned low-e, aluminum-framed windows with reduced air leakage}

\section{C.13.1 Implementation in Example Building}

The example building was assumed to have single-pane tinted glass in the warmer climates, and double-pane tinted glass in colder climates. Aluminum frames with no thermal break were assumed in all climates. For the EEM, we replaced 833 tinted windows with double-glazed low-e windows, with reduced solar heat gain and aluminum frames with thermal breaks. A $50 \%$ reduction in air leakage through the windows (approximately $16 \%$ of total infiltration) was assumed for the replacement windows.

\section{C.13.2 Energy Savings Analysis}

The results of the energy simulations are summarized in Table C-26.

Table C-26 Key Results of Energy Savings Analysis for Window Replacement

\begin{tabular}{|l|c|c|c|c|c|}
\hline & $\begin{array}{c}\text { \% Site Energy } \\
\text { Savings } \\
(1 \text { st Year) }\end{array}$ & $\begin{array}{c}\text { Electricity } \\
\text { Savings (kWh) } \\
\text { (1st Year) }\end{array}$ & $\begin{array}{c}\text { Natural Gas } \\
\text { Savings (therms) } \\
\text { (1st Year) }\end{array}$ & $\begin{array}{c}\text { Energy Cost } \\
\text { Savings } \\
\text { (1st Year) }\end{array}$ & $\begin{array}{c}\text { O\&M } \\
\text { Cost Savings } \\
\text { (1st Year) }\end{array}$ \\
\hline Miami & $4.3 \%$ & 222,686 & 15 & $\$ 21,796$ & $\$ 0$ \\
\hline Las Vegas & $5.3 \%$ & 269,881 & 354 & $\$ 28,567$ & $\$ 0$ \\
\hline Seattle & $3.0 \%$ & 102,288 & 1770 & $\$ 25,097$ & $\$ 0$ \\
\hline Chicago & $1.9 \%$ & 57,571 & 2046 & $\$ 20,783$ & $\$ 0$ \\
\hline Duluth & $2.1 \%$ & 46,904 & 3859 & $\$ 7,544$ & $\$ 0$ \\
\hline
\end{tabular}

\section{C.13.3 Cash Flow Analysis}

The results of the cost-effectiveness analysis are summarized in Table C-27.

Table C-27 Key Results of Cost-Effectiveness Analysis for Window Replacement

\begin{tabular}{|c|c|c|c|c|c|}
\hline Location & Purchase Cost & $\begin{array}{l}\text { Installation } \\
\text { First Cost }\end{array}$ & NPV & $\begin{array}{c}\text { Simple Payback } \\
\text { (Years) }\end{array}$ & $\begin{array}{c}\text { Include in } \\
\text { Recommended } \\
\text { Package? }\end{array}$ \\
\hline Miami & $\$ 767,171$ & $\$ 122,811$ & $(\$ 212,004)$ & 40.2 & No \\
\hline Las Vegas & $\$ 761,675$ & $\$ 177,468$ & $(\$ 157,141)$ & 32.4 & No \\
\hline Seattle & $\$ 802,271$ & $\$ 167,713$ & $(\$ 220,774)$ & 38.0 & No \\
\hline Chicago & $\$ 771,883$ & $\$ 218,628$ & $(\$ 321,337)$ & 46.9 & No \\
\hline Duluth & $\$ 1,037,291$ & $\$ 132,567$ & $(\$ 588,421)$ & 151.8 & No \\
\hline
\end{tabular}




\section{C.14 Add rigid insulating sheathing to roof assembly}

\section{C.14.1 Implementation in Example Building}

The example building was assumed to include 3-6 in. (depending on climate) of partially degraded EPS rigid insulation entirely above the roof deck. This EEM replaces the existing degraded insulation with 6 in. of fresh EPS insulation, resulting in a total roof assembly R-value of $25 \mathrm{~h} \cdot \mathrm{ft}{ }^{2} \cdot{ }^{\circ} \mathrm{F} / \mathrm{Btu}$.

\section{C.14.2 Energy Savings Analysis}

The results of the energy simulations are summarized in Table C-28.

Table C-28 Key Results of Energy Savings Analysis for Roof Insulation Retrofit

\begin{tabular}{|l|c|c|c|c|c|}
\hline Location & $\begin{array}{c}\text { \% Site Energy } \\
\text { Savings } \\
\text { (1st Year) }\end{array}$ & $\begin{array}{c}\text { Electricity } \\
\text { Savings (kWh) } \\
\text { (1st Year) }\end{array}$ & $\begin{array}{c}\text { Natural Gas } \\
\text { Savings (therms) } \\
\text { (1st Year) }\end{array}$ & $\begin{array}{c}\text { Energy Cost } \\
\text { Savings } \\
\text { (1st Year) }\end{array}$ & $\begin{array}{c}\text { O\&M } \\
\text { Cost Savings } \\
\text { (1st Year) }\end{array}$ \\
\hline Miami & $1.6 \%$ & 78,810 & 123 & $\$ 12,646$ & $\$ 0$ \\
\hline Las Vegas & $3.4 \%$ & 137,009 & 1431 & $\$ 19,891$ & $\$ 0$ \\
\hline Seattle & $2.2 \%$ & 53,536 & 1926 & $\$ 12,607$ & $\$ 0$ \\
\hline Chicago & $1.4 \%$ & 42,555 & 1612 & $\$ 15,482$ & $\$ 0$ \\
\hline Duluth & $0.6 \%$ & 13,918 & 1107 & $\$ 2,268$ & $\$ 0$ \\
\hline
\end{tabular}

\section{C.14.3 Cash Flow Analysis}

The results of the cost-effectiveness analysis are summarized in Table C-29.

\section{Table C-29 Key Results of Cost-Effectiveness Analysis for Roof Insulation Retrofit}

\begin{tabular}{|c|c|c|c|c|c|}
\hline Location & Purchase Cost & $\begin{array}{l}\text { Installation } \\
\text { First Cost }\end{array}$ & NPV & $\begin{array}{c}\text { Simple Payback } \\
\text { (Years) }\end{array}$ & $\begin{array}{c}\text { Include in } \\
\text { Recommended } \\
\text { Package? }\end{array}$ \\
\hline Miami & $\$ 700,019$ & $\$ 212,671$ & $(\$ 394,648)$ & 72.2 & No \\
\hline Las Vegas & $\$ 695,004$ & $\$ 307,320$ & $(\$ 333,894)$ & 50.4 & No \\
\hline Seattle & $\$ 732,047$ & $\$ 290,427$ & $(\$ 451,044)$ & 81.0 & No \\
\hline Chicago & $\$ 704,318$ & $\$ 378,596$ & $(\$ 437,251)$ & 70.0 & No \\
\hline Duluth & $\$ 946,495$ & $\$ 229,564$ & $(\$ 693,191)$ & 515.4 & No \\
\hline
\end{tabular}




\section{C.15 Install vestibules with inner and outer doors}

\section{C.15.1 Implementation in Example Building}

For the example building, we assumed that the main entrance is connected to the first floor lobby. We assumed eight swinging glass doors, with no vestibule. For this EEM, an unconditioned vestibule was added to the outside of the building, and the original doors remain. We assumed an average infiltration reduction of $800 \mathrm{cfm}$, which was about $3 \%$ of total infiltration. The infiltration effects were estimated based on a study by Cho et al. (2010).

\section{C.15.2 Energy Savings Analysis}

The results of the energy simulations are summarized in Table $\mathrm{C}-30$.

Table C-30 Key Results of Energy Savings Analysis for Vestibule

\begin{tabular}{|c|c|c|c|c|c|}
\hline Location & $\begin{array}{c}\text { \% Site Energy } \\
\text { Savings } \\
\text { (1st Year) }\end{array}$ & $\begin{array}{l}\text { Electricity Savings } \\
\text { (kWh) (1st Year) }\end{array}$ & $\begin{array}{c}\text { Natural Gas } \\
\text { Savings (therms) } \\
\text { (1st Year) }\end{array}$ & $\begin{array}{c}\text { Energy Cost } \\
\text { Savings } \\
\text { (1st Year) }\end{array}$ & $\begin{array}{l}\text { O\&M Cost Savings } \\
\text { (1st Year) }\end{array}$ \\
\hline Miami & $0.1 \%$ & 5,080 & 0 & $\$ 1,619$ & $(\$ 1,184)$ \\
\hline Las Vegas & $0.3 \%$ & 4,330 & 431 & $\$ 1,435$ & $(\$ 1,711)$ \\
\hline Seattle & $0.6 \%$ & 1,220 & 1074 & $\$ 1,518$ & $(\$ 1,617)$ \\
\hline Chicago & $0.6 \%$ & 2,083 & 1223 & $\$ 2,533$ & $(\$ 2,107)$ \\
\hline Duluth & $0.7 \%$ & 1,861 & 1865 & $\$ 1,743$ & $(\$ 1,278)$ \\
\hline
\end{tabular}

\section{C.15.3 Cash Flow Analysis}

The results of the cost-effectiveness analysis are summarized in Table C-31.

Table C-31 Key Results of Cost-Effectiveness Analysis for Vestibule

\begin{tabular}{|l|c|c|c|c|c|}
\hline & Luchation & Purche Cost & $\begin{array}{c}\text { Installation } \\
\text { First Cost }\end{array}$ & NPV & $\begin{array}{c}\text { Include in } \\
\text { Recommended } \\
\text { Package? }\end{array}$ \\
\hline Miami & $\$ 39,365$ & $\$ 7,899$ & $(\$ 53,317)$ & No \\
\hline Las Vegas & $\$ 39,083$ & $\$ 11,414$ & $(\$ 66,398)$ & Never & No \\
\hline Seattle & $\$ 41,166$ & $\$ 10,787$ & $(\$ 64,212)$ & Never & No \\
\hline Chicago & $\$ 39,607$ & $\$ 14,062$ & $(\$ 56,726)$ & 119.7 & No \\
\hline Duluth & $\$ 53,225$ & $\$ 8,526$ & $(\$ 68,557)$ & 126.1 & No \\
\hline
\end{tabular}




\section{C.16 Install low-flow showerheads in locker rooms}

\section{C.16.1 Implementation in Example Building}

We assumed 20 standard flow showerheads in each of the two locker rooms. This EEM reduced the shower hot water flow rate by $37 \%$. Assuming a negligible effect on shower duration because of school schedule constraints, the total hot water use was also reduced by $37 \%$.

\section{C.16.2 Energy Savings Analysis}

The results of the energy simulations are summarized in Table $\mathrm{C}-32$.

Table C-32 Key Results of Energy Savings Analysis for Low-Flow Showerheads

\begin{tabular}{|l|c|c|c|c|c|}
\hline & $\begin{array}{c}\text { \% Site Energy } \\
\text { Savings } \\
\text { Location }\end{array}$ & $\begin{array}{c}\text { Electricity Savings } \\
(\mathbf{k W h}) \text { (1st Year) }\end{array}$ & $\begin{array}{c}\text { Natural Gas } \\
\text { Savings (therms) } \\
\text { (1st Year) }\end{array}$ & $\begin{array}{c}\text { Energy Cost } \\
\text { Savings } \\
\text { (1st Year) }\end{array}$ & $\begin{array}{c}\text { O\&M Cost Savings } \\
\text { (1st Year) }\end{array}$ \\
\hline Miami & $0.2 \%$ & 1,274 & 385 & $\$ 517$ & $\$ 0$ \\
\hline Las Vegas & $0.3 \%$ & 488 & 493 & $\$ 534$ & $\$ 0$ \\
\hline Seattle & $0.4 \%$ & -9 & 638 & $\$ 694$ & $\$ 0$ \\
\hline Chicago & $0.3 \%$ & 190 & 690 & $\$ 762$ & $\$ 0$ \\
\hline Duluth & $0.3 \%$ & -46 & 824 & $\$ 609$ & $\$ 0$ \\
\hline
\end{tabular}

\section{C.16.3 Cash Flow Analysis}

The results of the cost-effectiveness analysis are summarized in Table $\mathrm{C}-33$.

Table C-33 Key Results of Cost-Effectiveness Analysis for Low-Flow Showerheads

\begin{tabular}{|c|c|c|c|c|c|}
\hline Location & Purchase Cost & $\begin{array}{l}\text { Installation } \\
\text { First Cost }\end{array}$ & NPV & $\begin{array}{c}\text { Simple Payback } \\
\text { (Years) }\end{array}$ & $\begin{array}{c}\text { Include in } \\
\text { Recommended } \\
\text { Package? }\end{array}$ \\
\hline Miami & $\$ 2,500$ & $\$ 2,200$ & $\$ 6,636$ & 8.9 & Yes \\
\hline Las Vegas & $\$ 2,500$ & $\$ 3,200$ & $\$ 6,581$ & 10.5 & Yes \\
\hline Seattle & $\$ 2,600$ & $\$ 3,000$ & $\$ 9,494$ & 7.9 & Yes \\
\hline Chicago & $\$ 2,500$ & $\$ 3,900$ & $\$ 10,270$ & 8.2 & Yes \\
\hline Duluth & $\$ 2,500$ & $\$ 3,150$ & $\$ 8,081$ & 9.1 & Yes \\
\hline
\end{tabular}




\section{C.17 Add evaporative precooling of condenser supply air (in dry climates only)}

\section{C.17.1 Implementation in Example Building}

The example building's roof had 11 large condensers. For this EEM, we added an evaporative coil to the supply airflow upstream of the condenser coil, reducing the temperature of the cooling air and providing more effective heat transfer from the cooling coil. Each evaporative precooling system included a small pump to provide mains water to the coil. Some additional O\&M costs were assumed because the system includes filters that must be cleaned or replaced on occasion.

\section{C.17.2 Energy Savings Analysis}

The results of the energy simulations are summarized in Table C-34.

Table C-34 Key Results of Energy Savings Analysis for Condenser Precooling

\begin{tabular}{|l|c|c|c|c|c|}
\hline $\begin{array}{c}\text { \% Site Energy } \\
\text { Savings } \\
\text { (1st Year) }\end{array}$ & $\begin{array}{c}\text { Electricity } \\
\text { Savings (kWh) } \\
\text { (1st Year) }\end{array}$ & $\begin{array}{c}\text { Natural Gas } \\
\text { Savings (therms) } \\
\text { (1st Year) }\end{array}$ & $\begin{array}{c}\text { Energy } \\
\text { Cost Savings } \\
\text { (1st Year) }\end{array}$ & $\begin{array}{c}\text { O\&M } \\
\text { Cost Savings } \\
\text { (1st Year) }\end{array}$ \\
\hline Miami & N/A & N/A & N/A & N/A & N/A \\
\hline Las Vegas & $5.2 \%$ & 277,420 & -78 & $\$ 45,566$ & $(\$ 21,900)$ \\
\hline Seattle & N/A & N/A & N/A & N/A & N/A \\
\hline Chicago & N/A & N/A & N/A & N/A & N/A \\
\hline Duluth & N/A & N/A & N/A & N/A & N/A \\
\hline
\end{tabular}

\section{C.17.3 Cash Flow Analysis}

The results of the cost-effectiveness analysis are summarized in Table $\mathrm{C}-35$.

Table C-35 Key Results of Cost-Effectiveness Analysis for Condenser Precooling

\begin{tabular}{|l|c|c|c|c|c|}
\hline Location & Purchase Cost & $\begin{array}{c}\text { Installation } \\
\text { First Cost }\end{array}$ & NPV & $\begin{array}{c}\text { Include in } \\
\text { Simple Payback } \\
\text { (Years) }\end{array}$ & $\begin{array}{c}\text { Recommended } \\
\text { Package? }\end{array}$ \\
\hline Miami & N/A & N/A & N/A & N/A & No \\
\hline Las Vegas & $\$ 189,000$ & $\$ 39,500$ & $\$ 156,659$ & 9.6 & Yes \\
\hline Seattle & N/A & N/A & N/A & N/A & No \\
\hline Chicago & N/A & N/A & N/A & N/A & No \\
\hline Duluth & N/A & N/A & N/A & N/A & No \\
\hline
\end{tabular}




\section{C.18 Add a small condensing boiler to handle the base load and summer load, with current inefficient boiler operating when heating loads are highest}

\section{C.18.1 Implementation in Example Building}

One standard-efficiency boiler was used in the example building, serving the three wings of classrooms and the main corridor and lobby areas. For this EEM, we assumed a relatively small high-efficiency condensing boiler was installed to serve the base heating needs of the four zones combined. This EEM also required the installation of DDCs to implement the boiler staging logic. Because the original boiler was reused for this EEM and replacement costs would have been incurred at the same time in both the reference and EEM cases, the remaining useful life of the existing equipment was not relevant to the analysis.

\section{C.18.2 Energy Savings Analysis}

The results of the energy simulations are summarized in Table C-36.

Table C-36 Key Results of Energy Savings Analysis for Small Staged Condensing Boiler

\begin{tabular}{|c|c|c|c|c|c|}
\hline Location & $\begin{array}{c}\% \text { Site } \\
\text { Energy Savings } \\
\text { (1st Year) }\end{array}$ & $\begin{array}{c}\text { Electricity } \\
\text { Savings (kWh) } \\
\text { (1st Year) }\end{array}$ & $\begin{array}{c}\text { Natural Gas } \\
\text { Savings (therms) } \\
\text { (1st Year) }\end{array}$ & $\begin{array}{l}\text { Energy } \\
\text { Cost Savings } \\
\text { (1st Year) }\end{array}$ & $\begin{array}{c}\text { O\&M } \\
\text { Cost Savings } \\
\text { (1st Year) }\end{array}$ \\
\hline Miami & $0.0 \%$ & 0 & 0 & $\$ 0$ & $(\$ 5,000)$ \\
\hline Las Vegas & $0.2 \%$ & 0 & 359 & $\$ 352$ & $(\$ 5,000)$ \\
\hline Seattle & $0.9 \%$ & 0 & 1595 & $\$ 1,702$ & $(\$ 5,000)$ \\
\hline Chicago & $0.8 \%$ & 0 & 1704 & $\$ 1,675$ & $(\$ 5,000)$ \\
\hline Duluth & $0.7 \%$ & 0 & 1761 & $\$ 1,296$ & $(\$ 5,000)$ \\
\hline
\end{tabular}

\section{C.18.3 Cash Flow Analysis}

The results of the cost-effectiveness analysis are summarized in Table C-37.

Table C-37 Key Results of Cost-Effectiveness Analysis for Small Staged Condensing Boiler

\begin{tabular}{|c|c|c|c|c|c|}
\hline Location & Purchase Cost & $\begin{array}{l}\text { Installation } \\
\text { First Cost }\end{array}$ & NPV & $\begin{array}{c}\text { Simple Payback } \\
\text { (Years) }\end{array}$ & $\begin{array}{c}\text { Include in } \\
\text { Recommended } \\
\text { Package? }\end{array}$ \\
\hline Miami & $\$ 106,000$ & $\$ 8,150$ & $(\$ 178,004)$ & Never & No \\
\hline Las Vegas & $\$ 107,800$ & $\$ 12,000$ & $(\$ 176,770)$ & Never & No \\
\hline Seattle & $\$ 111,600$ & $\$ 11,100$ & $(\$ 155,316)$ & Never & No \\
\hline Chicago & $\$ 107,500$ & $\$ 14,500$ & $(\$ 154,837)$ & Never & No \\
\hline Duluth & $\$ 108,500$ & $\$ 11,700$ & $(\$ 160,055)$ & Never & No \\
\hline
\end{tabular}




\section{C.19 Install variable-speed drives on chilled-water and hot water pumps}

\section{C.19.1 Implementation in Example Building}

The example building had one large boiler with two constant speed pumps (one primary and one backup). No chilled water loops were present in the example building. For this EEM, VSDs were installed on each pump, and the flow rate was reduced when heating loads were small.

\section{C.19.2 Energy Savings Analysis}

The results of the energy simulations are summarized in Table C-38.

Table C-38 Key Results of Energy Savings Analysis for Variable-Speed Pumps

\begin{tabular}{|c|c|c|c|c|c|}
\hline Location & $\begin{array}{c}\text { \% Site Energy } \\
\text { Savings } \\
\text { (1st Year) }\end{array}$ & $\begin{array}{c}\text { Electricity } \\
\text { Savings (kWh) } \\
\text { (1st Year) }\end{array}$ & $\begin{array}{c}\text { Natural Gas } \\
\text { Savings (therms) } \\
\text { (1st Year) }\end{array}$ & $\begin{array}{c}\text { Energy } \\
\text { Cost Savings } \\
\text { (1st Year) }\end{array}$ & $\begin{array}{c}\text { O\&M } \\
\text { Cost Savings (1st } \\
\text { Year) }\end{array}$ \\
\hline Miami & $1.2 \%$ & 80,423 & -610 & $\$ 6,509$ & $(\$ 500)$ \\
\hline Las Vegas & $-0.2 \%$ & 88,700 & -3342 & $\$ 4,322$ & $(\$ 500$ \\
\hline Seattle & $-0.2 \%$ & 84,549 & -3301 & $\$ 12,467$ & $(\$ 500)$ \\
\hline Chicago & $-0.2 \%$ & 82,024 & -3219 & $\$ 22,057$ & $(\$ 500)$ \\
\hline Duluth & $-0.2 \%$ & 74,719 & -2949 & $\$ 5,047$ & $(\$ 500)$ \\
\hline
\end{tabular}

\section{C.19.3 Cash Flow Analysis}

The results of the cost-effectiveness analysis are summarized in Table C-39.

Table C-39 Key Results of Cost-Effectiveness Analysis for Variable-Speed Pumps

\begin{tabular}{|l|c|c|c|c|c|}
\hline \multicolumn{1}{|c|}{ Location } & Purchase Cost & $\begin{array}{c}\text { Installation } \\
\text { First Cost }\end{array}$ & NPV & $\begin{array}{c}\text { Include in } \\
\text { Simple Payback } \\
\text { Recommended } \\
\text { Package?* }\end{array}$ \\
\hline Miami & $\$ 11,700$ & $\$ 2,500$ & $\$ 75,238$ & Yes \\
\hline Las Vegas & $\$ 11,850$ & $\$ 3,650$ & $\$ 33,401$ & 2.4 & Yes \\
\hline Seattle & $\$ 12,250$ & $\$ 3,450$ & $\$ 159,981$ & 4.1 & Yes \\
\hline Chicago & $\$ 11,500$ & $\$ 4,500$ & $\$ 309,504$ & 0.7 & Yes \\
\hline Duluth & $\$ 11,900$ & $\$ 3,600$ & $\$ 47,084$ & 3.4 & Yes \\
\hline
\end{tabular}

* This EEM is recommended because of reduced energy costs, even though total site energy increases slightly. 


\section{C.20 Replace oversized, inefficient fans and motors with rightsized NEMA premium efficiency}

\section{C.20.1 Implementation in Example Building}

For this EEM, we assumed replacement of the motors for all supply and return fans (17 motors in total). Motor efficiencies for the example building were equal to the minimum efficiency requirements of ASHRAE 90.1-2004 (ASHRAE 2004c). Similarly, the motor efficiencies for the EEM were equal to the minimum NEMA premium efficiency requirements. A small increase in motor useful life was assumed for this EEM.

\section{C.20.2 Energy Savings Analysis}

The results of the energy simulations are summarized in Table C-40.

\section{Table C-40 Key Results of Energy Savings Analysis for Premium Efficiency Motors}

\begin{tabular}{|l|c|c|c|c|c|}
\hline $\begin{array}{c}\text { \% Site Energy } \\
\text { Savings } \\
\text { (1st Year) }\end{array}$ & $\begin{array}{c}\text { Electricity } \\
\text { Savings (kWh) } \\
\text { (1st Year) }\end{array}$ & $\begin{array}{c}\text { Natural Gas } \\
\text { Savings (therms) } \\
\text { (1st Year) }\end{array}$ & $\begin{array}{c}\text { Energy } \\
\text { Cost Savings } \\
\text { (1st Year) }\end{array}$ & $\begin{array}{c}\text { O\&M } \\
\text { Cost Savings } \\
\text { (1st Year) }\end{array}$ \\
\hline Miami & $0.6 \%$ & 32,272 & -13 & $\$ 2,961$ & $\$ 0$ \\
\hline Las Vegas & $0.6 \%$ & 34,193 & -111 & $\$ 2,965$ & $\$ 0$ \\
\hline Seattle & $0.3 \%$ & 22,854 & -293 & $\$ 3,927$ & $\$ 0$ \\
\hline Chicago & $0.3 \%$ & 26,329 & -297 & $\$ 7,787$ & $\$ 0$ \\
\hline Duluth & $0.2 \%$ & 26,287 & -354 & $\$ 2,277$ & $\$ 0$ \\
\hline
\end{tabular}

\section{C.20.3 Cash Flow Analysis}

The results of the cost-effectiveness analysis are summarized in Table C- 41 .

Table C-41 Key Results of Cost-Effectiveness Analysis for Premium Efficiency Motors

\begin{tabular}{|l|c|c|c|c|c|}
\hline Location & Purchase Cost & $\begin{array}{c}\text { Installation } \\
\text { First Cost }\end{array}$ & NPV & $\begin{array}{c}\text { Include in } \\
\text { Simple Payback } \\
\text { (Years) }\end{array}$ & $\begin{array}{c}\text { Recommended } \\
\text { Package? }\end{array}$ \\
\hline Miami & $\$ 88,900$ & $\$ 7,750$ & $(\$ 24,924)$ & 34.2 & No \\
\hline Las Vegas & $\$ 89,900$ & $\$ 11,200$ & $(\$ 29,925)$ & 35.6 & No \\
\hline Seattle & $\$ 93,200$ & $\$ 10,600$ & $(\$ 16,818)$ & 27.6 & No \\
\hline Chicago & $\$ 89,700$ & $\$ 13,800$ & $\$ 42,047$ & 13.9 & Yes \\
\hline Duluth & $\$ 90,300$ & $\$ 11,200$ & $(\$ 41,360)$ & 46.6 & No \\
\hline
\end{tabular}




\section{C.21 Upgrade to demand control ventilation to reduce outdoor airflow during partial occupancy}

\section{C.21.1 Implementation in Example Building}

The example building provided full ventilation whenever the HVAC system was operating (generally 6:00 a.m. to 9:00 p.m. weekdays and as needed to meet the setback temperature), and no ventilation at all other times. This EEM used five $\mathrm{CO}_{2}$ sensors, each collecting from 27 sampling points, to reduce the ventilation rates for each HVAC control zone during times when the zone was partially occupied (between 6:00 a.m. and 9:00 p.m.). Only the peroccupant components of the ASHRAE 62-1999 ventilation rates were reduced during partial occupancy. The floor area component was maintained. The addition of a DDC system was necessary as part of this EEM.

\section{C.21.2 Energy Savings Analysis}

The results of the energy simulations are summarized in Table C-42.

Table C-42 Key Results of Energy Savings Analysis for DCV

\begin{tabular}{|c|c|c|c|c|c|}
\hline Location & $\begin{array}{c}\text { \% Site Energy } \\
\text { Savings } \\
\text { (1st Year) }\end{array}$ & $\begin{array}{c}\text { Electricity } \\
\text { Savings (kWh) } \\
\text { (1st Year) }\end{array}$ & $\begin{array}{c}\text { Natural Gas } \\
\text { Savings (therms) } \\
\text { (1st Year) }\end{array}$ & $\begin{array}{c}\text { Energy } \\
\text { Cost Savings } \\
\text { (1st Year) }\end{array}$ & $\begin{array}{c}\text { O\&M } \\
\text { Cost Savings } \\
\text { (1st Year) }\end{array}$ \\
\hline Miami & $4.6 \%$ & 207,203 & 1053 & $\$ 27,704$ & $(\$ 9,065)$ \\
\hline Las Vegas & $10.7 \%$ & 135,813 & 14,676 & $\$ 38,089$ & $(\$ 9,065)$ \\
\hline Seattle & $22.7 \%$ & 2,626 & 39,187 & $\$ 43,123$ & $(\$ 9,065)$ \\
\hline Chicago & $23.6 \%$ & 26,068 & 50,112 & $\$ 69,536$ & $(\$ 9,065)$ \\
\hline Duluth & $28.1 \%$ & 3,137 & 73,457 & $\$ 55,971$ & $(\$ 9,065)$ \\
\hline
\end{tabular}

\section{C.21.3 Cash Flow Analysis}

The results of the cost-effectiveness analysis are summarized in Table C-43.

Table C-43 Key Results of Cost-Effectiveness Analysis for DCV

\begin{tabular}{|l|c|c|c|c|c|}
\hline & & & & \multicolumn{2}{|c|}{$\begin{array}{c}\text { Include in } \\
\text { Recommended } \\
\text { Lackage? }\end{array}$} \\
\hline Miami & Purchase Cost & First Cost & NPV & $\begin{array}{c}\text { Simple Payback } \\
\text { (Years) }\end{array}$ & Yes \\
\hline Las Vegas & $\$ 225,000$ & $*$ & $\$ 26,235$ & 12.0 & Yes \\
\hline Seattle & $\$ 23,5,600$ & $*$ & $\$ 219,736$ & 7.7 & Yes \\
\hline Chicago & $\$ 225,000$ & $*$ & $\$ 348,944$ & 6.7 & Yes \\
\hline Duluth & $\$ 226,500$ & $*$ & $\$ 798,184$ & 3.7 & Yes \\
\hline
\end{tabular}

* Installation cost is included in the purchase cost for this EEM. 


\section{C.22 Add heat/energy recovery to ventilation system}

\section{C.22.1 Implementation in Example Building}

For this EEM we assumed desiccant wheel ERVs are added to each HVAC system except the kitchen. The ventilation rate for the kitchen HVAC was deemed too small to make energy recovery worthwhile. In drier locations, less expensive heat recovery ventilators would be more cost effective, but we decided to keep the EEM consistent across all climates for our example analysis.

\section{C.22.2 Energy Savings Analysis}

The results of the energy simulations are summarized in Table $\mathrm{C}-44$.

Table C-44 Key Results of Energy Savings Analysis for ERV

\begin{tabular}{|c|c|c|c|c|c|}
\hline Location & $\begin{array}{c}\text { \% Site Energy } \\
\text { Savings } \\
\text { (1st Year) }\end{array}$ & $\begin{array}{c}\text { Electricity } \\
\text { Savings (kWh) } \\
\text { (1st Year) }\end{array}$ & $\begin{array}{c}\text { Natural Gas } \\
\text { Savings (therms) } \\
\text { (1st Year) }\end{array}$ & $\begin{array}{c}\text { Energy } \\
\text { Cost Savings } \\
\text { (1st Year) }\end{array}$ & $\begin{array}{c}\text { O\&M } \\
\text { Cost Savings } \\
\text { (1st Year) }\end{array}$ \\
\hline Miami & $4.3 \%$ & 192,941 & 1,124 & $\$ 31,476$ & $(\$ 21,900)$ \\
\hline Las Vegas & $9.9 \%$ & 87,097 & 15,002 & $\$ 37,279$ & $(\$ 22,000)$ \\
\hline Seattle & $23.9 \%$ & $-53,151$ & 43,167 & $\$ 34,887$ & $(\$ 21,900)$ \\
\hline Chicago & $28.3 \%$ & $-7,652$ & 61,483 & $\$ 71,802$ & $(\$ 22,800)$ \\
\hline Duluth & $35.2 \%$ & $-34,667$ & 93,346 & $\$ 66,883$ & $(\$ 22,100)$ \\
\hline
\end{tabular}

\section{C.22.3 Cash Flow Analysis}

The results of the cost-effectiveness analysis are summarized in Table $\mathrm{C}-45$.

Table C-45 Key Results of Cost-Effectiveness Analysis for ERV

\begin{tabular}{|l|l|l|l|l|l|}
\hline & Purchase Cost & $\begin{array}{c}\text { Installation } \\
\text { First Cost }\end{array}$ & NPV & $\begin{array}{c}\text { Include in } \\
\text { Simple Payback } \\
\text { Recommended } \\
\text { Package? }\end{array}$ \\
\hline Miami & $\$ 1,923,900$ & $\$ 188,200$ & $(\$ 2,994,222)$ & 216.6 & No \\
\hline Las Vegas & $\$ 1,945,100$ & $\$ 271,800$ & $(\$ 3,029,476)$ & 141.4 & No \\
\hline Seattle & $\$ 2,015,000$ & $\$ 256,900$ & $(\$ 3,078,243)$ & 164.7 & No \\
\hline Chicago & $\$ 1,935,500$ & $\$ 334,700$ & $(\$ 2,468,448)$ & 45.2 & No \\
\hline Duluth & $\$ 1,952,900$ & $\$ 270,300$ & $(\$ 2,443,988)$ & 48.2 & No \\
\hline
\end{tabular}




\section{Appendix D}

\section{Prioritization of All Energy Efficiency Measures Considered}

A total of 183 EEMs were originally considered for this guide, based on the literature and several K-12 schools case studies. As discussed in Section 1.4, this list was narrowed down in several stages to determine the most important EEMs to describe in the guide, and the EEMs that were most appropriate to evaluate in the example building analysis. Table D-1 and Table D-2 provide the full list of EBCx and retrofit EEMs that were considered, along with the recommended prioritization when considering a retrofit project.

\section{Table D-1 Prioritization of EBCx Measures}

\begin{tabular}{|c|c|}
\hline Priority & Measure Description \\
\hline \multirow{8}{*}{$\begin{array}{l}\text { 1. Recommended in all } \\
\text { example packages }\end{array}$} & Provide power strips in easy-to-access locations to facilitate equipment shutdown \\
\hline & $\begin{array}{l}\text { Repair broken windows and weather-strip/caulk windows and doors where drafts can } \\
\text { be felt }\end{array}$ \\
\hline & Repair damaged or missing pipe and tank insulation \\
\hline & $\begin{array}{l}\text { TAB chilled water pumps and valves, refrigerant lines, AHUs, and flow modulation } \\
\text { devices }\end{array}$ \\
\hline & Verify or establish a comprehensive maintenance protocol for HVAC equipment \\
\hline & Verify correct operation of OA economizer \\
\hline & Apply thermostat setback/setup when building is unoccupied \\
\hline & Test and adjust ventilation flow rates as needed to meet ASHRAE 62.1 requirements \\
\hline \multirow{14}{*}{$\begin{array}{l}\text { 2. Important EEMs that } \\
\text { should be considered for } \\
\text { all projects (discussed in } \\
\text { this guide) }\end{array}$} & $\begin{array}{l}\text { Calibrate lighting controls and optimize settings based on building use patterns } \\
\text { anddaylight availability }\end{array}$ \\
\hline & $\begin{array}{l}\text { Improve janitorial workflow to consolidate activities in each area, allowing a reduction in } \\
\text { operating hours for lighting }\end{array}$ \\
\hline & $\begin{array}{l}\text { Control computer power management settings facility-wide through software or logon } \\
\text { scripts }\end{array}$ \\
\hline & Use timers or occupancy sensors for compressors and lights on vending machines \\
\hline & $\begin{array}{l}\text { Verify or establish an effective maintenance protocol for cooking equipment in kitchen } \\
\text { areas and break rooms, including cleaning exhaust vents, heating coils, and burners }\end{array}$ \\
\hline & Use pool cover when pool is not in use for an extended period \\
\hline & Precool spaces to reduce peak demand charges \\
\hline & Reset SAT based on building loads or OAT \\
\hline & Reset boiler temperature based on building loads or OAT \\
\hline & Verify adequate deadband between heating and cooling \\
\hline & Optimize equipment staging/sequence of operation \\
\hline & Optimize equipment start/stop procedures \\
\hline & Suspend ventilation during unoccupied periods \\
\hline & Replace or repair leaky and broken dampers \\
\hline
\end{tabular}


Table D-1 Prioritization of EBCx Measures (cont'd)

\begin{tabular}{|c|c|}
\hline Priority & Measure Description \\
\hline \multirow{17}{*}{$\begin{array}{l}\text { 3. Additional EEMs that } \\
\text { should be considered } \\
\text { in certain situations } \\
\text { (mentioned in this } \\
\text { guide) }\end{array}$} & Repair or replace interior shading devices \\
\hline & $\begin{array}{l}\text { Repaint interior wall and ceiling surfaces to increase average reflectance, reducing the } \\
\text { need for electric lighting }\end{array}$ \\
\hline & Improve motion sensor locations/move line-of-sight obstacles \\
\hline & $\begin{array}{l}\text { Adjust light levels to within } 10 \% \text { of the IES recommendations for the tasks conducted in } \\
\text { each area by delamping and/or relamping }\end{array}$ \\
\hline & Schedule cooking activities to use equipment at full capacity \\
\hline & Turn off refrigerator door heaters \\
\hline & Verify balanced 3-phase power and proper voltage levels \\
\hline & Verify that airflow paths around transformers are not blocked \\
\hline & Repair broken exterior doors \\
\hline & Cap unused air chases \\
\hline & Repair any leaky pipes and fixtures \\
\hline & Install low-flow aerators on faucets \\
\hline & Reduce set point for domestic hot water to $120^{\circ} \mathrm{F}$, with boost heating for dishwashers \\
\hline & Verify steam traps are operating and free of leaks \\
\hline & Turn off unneeded heating/cooling equipment during off-seasons \\
\hline & Seal leaky ducts and add duct insulation \\
\hline & Reset condenser temperature reset based on current building loads and usage patterns \\
\hline \multirow{13}{*}{$\begin{array}{l}\text { 4. Lower priority EEMs } \\
\text { considered unlikely to } \\
\text { save a large amount of } \\
\text { energy individually, but } \\
\text { when combined may } \\
\text { produce significant } \\
\text { savings (not addressed } \\
\text { in this guide) }\end{array}$} & Clean lamps, fixtures, and diffusers \\
\hline & $\begin{array}{l}\text { Activate disabled controls if the reason for disabling can be addressed or if no reason for } \\
\text { disabling is evident }\end{array}$ \\
\hline & $\begin{array}{l}\text { For fixtures with one or more burned-out lamps, replace all lamps with lower wattage } \\
\text { versions that produce equivalent or superior light output and quality }\end{array}$ \\
\hline & Flush system to remove sediment \\
\hline & Disable circulation pumps when building is unoccupied \\
\hline & Shut down water heater during summer months (primary schools only) \\
\hline & Clean coils and vents for major appliances \\
\hline & Inspect oven door seals and hinges and repair if necessary (secondary schools only) \\
\hline & $\begin{array}{l}\text { Calibrate cooking equipment temperature settings, repair broken knobs, ensure pilot } \\
\text { light is not overlit (secondary schools only) }\end{array}$ \\
\hline & $\begin{array}{l}\text { Group cooking equipment with similar ventilation requirements (Type } 1 \text { or } 2 \text {, light or } \\
\text { heavy duty, condensing or heat/fume hood), provide only the ventilation rate needed, } \\
\text { and align equipment with hood exhausts }\end{array}$ \\
\hline & Boil water at minimum setting possible \\
\hline & Install wash curtains and operate conveyer dishwashers in auto mode \\
\hline & Check electrical connections and clean terminals \\
\hline
\end{tabular}


Table D-1 Prioritization of EBCx Measures (cont'd)

\begin{tabular}{|c|c|}
\hline Priority & Measure Description \\
\hline \multirow{19}{*}{$\begin{array}{l}\text { 4. Lower priority EEMs } \\
\text { considered unlikely to } \\
\text { save a large amount of } \\
\text { energy individually, but } \\
\text { when combined may } \\
\text { produce significant } \\
\text { savings (not addressed } \\
\text { in this guide) }\end{array}$} & $\begin{array}{l}\text { Obtain lower electricity rates by allowing the utility to disable nonessential equipment } \\
\text { during peak load periods }\end{array}$ \\
\hline & If the school has an attic, make sure the vents are open and clear of debris \\
\hline & Clean heating coils, burners, radiators, and other heating system components \\
\hline & Clean or replace air, water, and lubricant filters \\
\hline & $\begin{array}{l}\text { Check flue gas temperature and concentrations for boilers and furnaces, and adjust } \\
\text { combustion airflow if necessary }\end{array}$ \\
\hline & $\begin{array}{l}\text { Ensure correct refrigerant charge in cooling systems and heat pumps, and repair any } \\
\text { refrigerant leaks }\end{array}$ \\
\hline & Check lubricant levels, pressures, and colors, refilling or replacing as needed \\
\hline & Align and tighten belts and pulleys \\
\hline & Post the correct operating parameters near each piece of equipment \\
\hline & Update and maintain a systems manual with O\&M requirements \\
\hline & Improve boiler blowdown and chemical treatment procedures \\
\hline & Correct motor shaft misalignments \\
\hline & Secure motor, compressor, and fan mountings to prevent vibration \\
\hline & $\begin{array}{l}\text { Reoptimize chilled water temperature reset based on current building loads and use } \\
\text { patterns }\end{array}$ \\
\hline & Calibrate time clocks \\
\hline & Implement optimized control of VAV supply fan, based on furthest open VAV damper \\
\hline & Verify that exhaust air is released outside the building, not the attic \\
\hline & Disable any humidifiers that are not needed to maintain comfort \\
\hline & Move improperly located thermostats to prevent over- or undercooling \\
\hline
\end{tabular}




\section{Table D-2 Prioritization of Retrofit EEMs}

\begin{tabular}{|c|c|}
\hline Priority & EEM Description \\
\hline \multirow{9}{*}{$\begin{array}{l}\text { 1. Recommended in all } \\
\text { example packages }\end{array}$} & Replace incandescent lamps in exit signs with LEDs \\
\hline & $\begin{array}{l}\text { Replace T12 fluorescent lamps and magnetic ballasts with T8 lamps and electronic } \\
\text { ballasts }\end{array}$ \\
\hline & Replace incandescent lamps with CFLs \\
\hline & Install wireless motion sensors for lighting in rooms that are used intermittently \\
\hline & Replace HID lights with T5 high-output fluorescents in gymnasiums \\
\hline & Install more efficient exterior lighting for façades and parking lot \\
\hline & Install low-flow showerheads in locker rooms \\
\hline & Install VSDs on chilled-water and hot water pumps \\
\hline & Upgrade to DCV to reduce OA flow during partial occupancy \\
\hline \multirow{8}{*}{$\begin{array}{l}\text { 2. Recommended in some } \\
\text { example packages }\end{array}$} & Install photosensors and dimming ballasts to dim lights when daylighting is sufficient \\
\hline & Replace cafeteria appliances with ENERGY STAR models \\
\hline & Add reflective roof covering \\
\hline & Add an EIFS to exterior walls \\
\hline & $\begin{array}{l}\text { Replace windows with double paned low-e, aluminum framed windows with reduced air } \\
\text { leakage }\end{array}$ \\
\hline & Add rigid insulating sheathing to roof assembly \\
\hline & Add evaporative precooling of condenser supply air (in dry climates only) \\
\hline & Replace oversized, inefficient fan motors with rightsized NEMA premium efficiency \\
\hline \multirow{10}{*}{$\begin{array}{l}\text { 3. Important EEMs that } \\
\text { should be considered for } \\
\text { all projects (discussed in } \\
\text { this guide) }\end{array}$} & Install tubular daylighting devices (bundled with photosensors and dimming ballasts) \\
\hline & Install vestibules with inner and outer doors \\
\hline & Install VSDs for demand control of kitchen hood exhaust fans \\
\hline & $\begin{array}{l}\text { Add a small condensing boiler to handle the base load boiler operating when heating } \\
\text { loads are highest }\end{array}$ \\
\hline & Add heat/energy recovery to ventilation system \\
\hline & Replace standard furnace with a high efficiency condensing furnace \\
\hline & Install an EMS and replace pneumatic controls with DDC \\
\hline & $\begin{array}{l}\text { Convert constant volume or dual duct air handling system to VAV (add dampers, } \\
\text { VSD fan motors) }\end{array}$ \\
\hline & Install VSDs on cooling tower fans \\
\hline & Install a differential dry-bulb controled airside economizer \\
\hline
\end{tabular}


Table D-2 Prioritization of Retrofit EEMs (cont'd)

\begin{tabular}{|c|c|}
\hline Priority & EEM Description \\
\hline \multirow{25}{*}{$\begin{array}{l}\text { 4. Additional EEMs that } \\
\text { should be considered in } \\
\text { certain situations (men- } \\
\text { tioned in this guide) }\end{array}$} & $\begin{array}{l}\text { Replace lighting system with a more efficient approach (reduced ambient light, greater } \\
\text { use of task lighting, indirect T5 fixtures in place of direct T12 fixtures) }\end{array}$ \\
\hline & Add skylights to increase daylighting \\
\hline & Install exterior automated louver shading systems on all sun-exposed windows \\
\hline & Install more efficient auditorium lighting \\
\hline & Add windows to increase daylighting \\
\hline & Replace electric exit signs with photoluminescents \\
\hline & $\begin{array}{l}\text { Lighten parking surface color to increase surface reflectance, reducing lumen } \\
\text { requirements from electric lighting. }\end{array}$ \\
\hline & $\begin{array}{l}\text { Install interior light shelves in classrooms to increase daylighting and reduce glare (must } \\
\text { be bundled with photosensor controls for electric lighting) }\end{array}$ \\
\hline & Add "smart switches" to classrooms to minimize vampire loads \\
\hline & Add clear high performance low-e film to existing windows \\
\hline & Make windows operable to allow free ventilation and cooling \\
\hline & Add slab insulation \\
\hline & Replace storage water heaters with high-efficiency condensing tankless water heaters \\
\hline & Install solar preheating for domestic hot water \\
\hline & Replace air or water-cooled heat pump with a rightsized ground source heat pump \\
\hline & $\begin{array}{l}\text { Supplement DX cooling system with an indirect evaporative cooler sized to meet small } \\
\text { and medium cooling loads (in dry climates only) }\end{array}$ \\
\hline & Replace standard boilers with rightsized high-efficiency condensing boilers \\
\hline & Replace single large boiler with several smaller, staged standard efficiency boilers \\
\hline & $\begin{array}{l}\text { Replace DX cooling system with more efficient rightsized model with evaporative } \\
\text { condenser }\end{array}$ \\
\hline & Install chilled beam cooling system \\
\hline & Install radiant rigid insulation board behind radiators \\
\hline & Install individual room temperature controls \\
\hline & $\begin{array}{l}\text { Install DOAS with high-efficiency heat recovery, reducing the heating, cooling, and } \\
\text { dehumidification loads }\end{array}$ \\
\hline & Convert to displacement ventilation system (where ceilings are higher than 9 feet) \\
\hline & Install or restore interior transoms for cross ventilation \\
\hline
\end{tabular}


Table D-2 Prioritization of Retrofit EEMs (cont'd)

\begin{tabular}{|c|c|}
\hline Priority & EEM Description \\
\hline \multirow{13}{*}{$\begin{array}{l}\text { 5. Lower priority EEMs } \\
\text { considered unlikely } \\
\text { to be cost effective or } \\
\text { to save a significant } \\
\text { amount of energy in } \\
\text { most K-12 schools (not } \\
\text { addressed in this guide) }\end{array}$} & Replace mercury vapor with $\mathrm{MH}$ \\
\hline & Install LEDs in all downlights \\
\hline & Install specular reflectors and delamp \\
\hline & Institute a "green purchasing" policy (replace with ENERGY STAR at end of useful life) \\
\hline & Add insulation to water heaters and pipes \\
\hline & Install low-flow prerinse spray valves in kitchen \\
\hline & Install automatic shutoff controls for sinks \\
\hline & Install water heater temperature setback controls \\
\hline & Drill and fill insulation in exterior wood-framed walls \\
\hline & $\begin{array}{l}\text { Install separate shades for upper and lower sections of taller classroom windows to } \\
\text { allow control of daylighting and glare }\end{array}$ \\
\hline & Install interior sash storm windows at existing insulated glass windows \\
\hline & If the building has a crawlspace, apply spray foam insulation above it \\
\hline & Add rigid insulation to basement walls \\
\hline
\end{tabular}


Table D-2 Prioritization of Retrofit EEMs (cont'd)

\begin{tabular}{|c|c|}
\hline Priority & EEM Description \\
\hline \multirow{29}{*}{$\begin{array}{l}\text { 5. Lower priority EEMs } \\
\text { considered unlikely } \\
\text { to be cost effective or } \\
\text { to save a significant } \\
\text { amount of energy in } \\
\text { most K-12 schools (not } \\
\text { addressed in this guide) }\end{array}$} & Add a VSD on the chiller compressors if applicable \\
\hline & Add insulation to steam/hot water pipes \\
\hline & Install a stack economizer to recover waste heat from boiler combustion process \\
\hline & Replace electric resistance furnaces with water source heat pumps \\
\hline & Improve condensing boiler efficiency by reducing return water temperature \\
\hline & $\begin{array}{l}\text { Use excess cooling tower capacity by plumbing them in parallel and installing VSDs for } \\
\text { cooling tower fans }\end{array}$ \\
\hline & Install controls to allow hot water temperature or steam pressure reset for boilers \\
\hline & $\begin{array}{l}\text { Reduce excess combustion air by installing a combustion monitoring and trim control } \\
\text { system }\end{array}$ \\
\hline & Add controls to stage chillers to operate closer to full capacity \\
\hline & $\begin{array}{l}\text { Install a water-side economizer to bypass chiller when conditions permit } \\
\text { (dry climates only) }\end{array}$ \\
\hline & Implement "dual maximums" control strategies for VAV terminals \\
\hline & Install a coil bypass to reduce pressure drop when there is no call for heating or cooling \\
\hline & Install pleated or angled filters to reduce pressure drop \\
\hline & Add duct insulation \\
\hline & Upgrade to cogged or synchronous belts \\
\hline & Replace OA swimming pool dehumidification system with desiccant or DX \\
\hline & Install direct drive motors on roof exhaust fans, eliminating fan belts \\
\hline & Install direct drive motors in walk in freezers \\
\hline & $\begin{array}{l}\text { Install point-of-use water heating for bathrooms, with a dedicated tankless water heater } \\
\text { for kitchen use }\end{array}$ \\
\hline & Replace electrical transformers with rightsized, higher efficiency models \\
\hline & Install triple-pane glazing in place of single-pane sash windows \\
\hline & Install overhangs above south-facing windows \\
\hline & Replace uninsulated exterior doors with insulated doors \\
\hline & Replace air-cooled chiller with high-efficiency, rightsized water-cooled chiller \\
\hline & Replace the HVAC system with variable refrigerant flow system \\
\hline & Install radiant cooling system. \\
\hline & Replace air-cooled chiller with high-efficiency, rightsized air-cooled chiller \\
\hline & Install a ground-coupled central chilled-water plant (central geothermal system) \\
\hline & $\begin{array}{l}\text { Install transpired solar collector panels on exterior east and south walls to preheat HVAC } \\
\text { intake air }\end{array}$ \\
\hline
\end{tabular}




\section{Appendix E}

\section{Detailed Existing Building Commissioning Energy Efficiency Measure Descriptions}

The following sections provide general overviews of the EBCx measures that are most likely to be effective in typical K-12 schools. Each section includes a technical overview, strengths and weaknesses, and special considerations to help energy managers select the measures that best meet their needs.

\section{E.1 Lighting}

\section{E.1.1 Calibrate any existing lighting controls and optimize settings based on building use patterns and daylight availability}

Schools may use a variety of strategies and technologies to provide automatic control of light levels. Control may be based on time-of-day, occupancy, and daylight levels. Even if these controls were properly installed and commissioned, they may have drifted from their optimum settings; students, teachers, or maintenance personnel may have tampered with them; or school operating patterns may have changed. For example, if lighting is automatically turned on or off based on school hours and maintenance schedules, and those schedules changed or the settings were altered, the set points should be changed or reset.

Problems with lighting controls are fairly common. For example, one study of daylight harvesting systems in more than 100 buildings of various types found that the systems often do not provide the expected energy savings (Vaidya et al. 2004). Another study found a high failure rate among the connectors in lighting control wiring (DOE 2002).

If the school uses daylight harvesting, in which electric lighting levels are adjusted up or down based on the amount of daylight present, the photosensors may need to recalibrated. This is especially true if the school layout has changed, leading to different light distribution patterns near the sensors.

The effectiveness of lights controlled by occupancy or motion sensors depends on setting the right sensitivity and time delay for particular spaces. In addition, correct positioning of the sensor will help to optimize coverage of the occupied area. If the school has been remodeled or furnishings moved so that the sensors are obstructed, the sensors should be moved. A typical recommendation for occupancy sensors for school rooms is to turn off lights if no activity is detected for 15 minutes (DOE 2009). For details on settings and positioning of occupancy sensors, see the EPA's Building Upgrade Manual, Chapter 6 (EPA 2008).

Checking these controls and their associated sensors will ensure students and teachers have the best educational experience and the school achieves maximum energy savings. The savings that can be achieved by tuning lighting controls will depend on how extensively controls are used and how well they have been maintained. Savings of more than $40 \%$ of lighting energy use have been found for occupancy sensors used in classrooms; in restrooms and corridors they can cut lighting energy use by 30\%-90\% (Maniccia et al. 2000).

\section{E.1.2 Improve janitorial workflow to consolidate activities in each area, allowing a reduction in operating hours for lighting}

Revised janitorial practices such as implementing team cleaning, revising hours, and coordinating with security help to reduce the operating time of lighting systems and cut electricity use in schools. Team cleaning confines janitors to a specific area, focusing on their respective tasks. When they complete their jobs in that area, they can shut off lights and move on to the next. Scheduling janitorial tasks for daylight hours, where possible, means those tasks can 
be performed without keeping lights on longer than necessary. Janitors can coordinate with the security crew to walk through the building and turn off unneeded equipment. Although no data are available on possible savings specifically in schools, the BOMA Building Energy Efficiency Program reports that implementing these strategies can produce $0.6 \%-8 \%$ savings per year in commercial buildings (Lord 2008).

There may be difficulties in transitioning to team cleaning. Many long-time traditional zone cleaning janitorial employees are unwilling to change their ways, and some labor unions see any attempts to institute team cleaning as a potential reduction in work hours. In addition, the transition to team cleaning requires a training and implementation plan to ensure quality and avoid confusion and communication problems between janitorial staff (Meyers 2003).

\section{E.2 Plug and Process Loads}

\section{E.2.1 Provide power strips in easy-to-access locations to facilitate equipment shutdown}

Schools use a variety of plug-in devices such as printers, fax machines, computers, and copiers. These should be turned off when they are not in use, during the school day as well as over weekends and holiday breaks. Even when turned off, this equipment draws a small amount of "phantom" power. Using power strips for school computers and all peripheral equipment allows the equipment to be completely disconnected from power, eliminating the phantom energy consumption. Easily accessible power strips allow quick shutdown of multiple pieces of equipment at once. "Smart" power strips with built-in occupancy sensors, timers, or logic that senses when attached devices are idle, can shut off printers and copiers when nobody is present.

Some power strips feature two outlet types, one with automatic shutoff functions and another that continuously supplies electricity. This enables equipment such as fax machines, which need to remain on when idle, to be plugged into the same power strip as other equipment, such as copy machines, which can be shut off when idle. The level of savings achieved depends on the control strategy employed, the type and number of appliances connected to the strip, and the use patterns. In the right applications, smart power strips can be very cost effective —often with simple payback periods shorter than two years.

To estimate the level of energy savings, multiply the difference in power draw between the fully off and idle modes (for all attached equipment) by the amount of time that the attached equipment is likely to be turned off. McKenney et al. (2010) provide estimates of standby power draw for a wide range of devices. Because the amount of time any equipment will be turned off by the strip depends on the specific control technology used and the school's use patterns, it generally needs to be estimated on a case-by-case basis (E Source 2011).

\section{E.2.2 Control computer power management settings facility wide through software or logon scripts}

Schools increasingly use computers as part of the learning curriculum and for administrative tasks. The average school computer is used for only a few hours per day, but is usually left on much longer - all day and sometimes all night. The EPA provides a Computer Power Management Savings Calculator (EPA 2009), which estimates potential energy savings from computer power management settings.

If your school uses a network, the administrator may be able to develop and deploy group policy objects or log-on scripts that control power management settings from the server level. This approach prevents users from changing settings and provides the flexibility to create groups of users with similar computing habits. When implemented properly, this approach can be cost effective because it ensures power management settings will be enabled and maintained at the appropriate level for each user without the need to purchase additional software. Some exceptions may be necessary for computers that are connected to certain equipment (e.g., weather stations), and for some users who may need remote access to their computers. 
If your school has multiple types of hardware and operating systems on the same network, power management software is a good solution. Software is installed on each computer and centrally controlled through the Internet or the school network. Depending on the program used, information technology staff can manually wake up computers for maintenance, monitor energy consumption and savings, and apply different settings to different groups of computers. These programs generally cost $\$ 10-\$ 20$ per computer and are often available at discounted rates for bulk purchases. For desktop computers, annual savings range from $\$ 25-\$ 75$ per machine.

The EPA offers EZ GPO, a free tool that provides centralized control of power management settings through a local area network. It is available for networked Windows 2000 and XP PC computers only. North Thurston Public Schools in Lacey, Washington, used EZ GPO to activate power management features on 4,000 computers during regular software upgrades. As a result, the district saves $\$ 45,000$ annually in electricity costs (EPA 2006).

A few technical challenges can dissuade implementation of facility-wide power management settings. Some schools may not have the information technology staff capability to install third-party power management software. Depending on the software, there can be issues with how to ensure that sleeping computers will receive critical administrative software updates, such as security patches and antivirus updates. The EPA provides technical consultations to answer questions about the various options for updating sleeping computers with security and other software patches while running EZ GPO.

\section{E.2.3 Use timers or occupancy sensors for compressors and lights on vending machines}

Refrigerated vending machines often operate 24 hours per day, seven days per week. They consume more than 3000 $\mathrm{kWh} / \mathrm{yr}$ of electricity and add to cooling loads in the spaces they occupy. At $\$ 0.10 / \mathrm{kWh}$, annual operating costs typically exceed $\$ 300$ (Sanchez et al. 2007). Timers or occupancy sensors can yield significant savings because they allow the machines to turn on only when a customer is present or when the compressor must run to maintain the product at the desired temperature. Some vending machine suppliers will install a timer for free, if asked. At least one device now on the market uses a passive infrared occupancy sensor to turn off the compressor and fluorescent lights in a vending machine when no one is around; a temperature sensor will power up the machine only as needed to keep products cool. Typical energy savings from occupancy-sensor based systems run about $20 \%-40 \%$ at a cost of about $\$ 90$ per machine. An independent study also found that the system could reduce maintenance costs by reducing compressor cycling (Foster-Miller 2002).

Deactivating the fluorescent lamps that typically illuminate a vending machine can also save energy— $990 \mathrm{kWh} / \mathrm{yr}$ according to Quantec (2007). The same study concludes that vending machines built before 2002 typically use T12 fluorescent lighting and could save $385 \mathrm{kWh} / \mathrm{yr}$ with an upgrade to T8 lighting. However, in most cases that kind of retrofit cannot be done in the field.

\section{E.2.4 Verify or establish an effective maintenance protocol for cooking equipment in kitchen areas and break rooms, including cleaning exhaust vents, heating coils, and burners}

Keeping kitchen surfaces and appliances clean is important for sanitary purposes; maintaining clean vents, coils, and burners helps to ensure they run efficiently. According to Pacific Gas \& Electric's (PG\&E) Food Service Technology Center, the commercial food sector wastes up to $80 \%$ of purchased energy (EPA 2009). Simply reducing the operating time of cooking equipment in a school kitchen can reduce energy use by up to $60 \%$ (PERI 2004). For example, ovens do not need to be preheated longer than 15 minutes, and oven fans and vent hoods should be used only when necessary to maintain comfort and air quality. Keep refrigerator coils clean and free of obstructions, and delay turning on appliances such as warmers and mixers. Staff training will help to encourage efficient practices. Training should cover equipment maintenance, operational schedules and set points, startup and shutdown procedures, and emergency procedures. 


\section{E.2.5 Use a pool cover when the pool is not in use for an extended period}

Evaporation accounts for approximately $70 \%$ of the heat lost from indoor and outdoor pools (DOE 2011b). The remaining heat losses are primarily radiant for outdoor pools, and through ventilation for indoor pools. Simply covering the pool reduces the evaporation rate, which in turn reduces the need to heat makeup water. For indoor pools, this reduction means that less energy is required to ventilate and condition the intake air. Energy savings of $50 \%-70 \%$ are possible, along with a $30 \%-50 \%$ reduction in makeup water, and a $35 \%-60 \%$ savings in chemicals (DOE 2009). For indoor pools, the actual savings achieved will depend predominantly on how long the pool is covered. For outdoor pools, the evaporation losses are driven by the ambient temperature, humidity, and average wind speed-windy, drier environments cause faster evaporation and higher energy losses. Estimating the energy savings of an outdoor pool cover in a specific application requires complex modeling to account for the pool characteristics, its use patterns, and the local climate. Table E-1 shows the heating costs that might be expected for outdoor pools in different locations, with and without pool covers.

\section{Table E-1 Covering Your Losses: Estimated Costs for Heating Outdoor Pools}

\begin{tabular}{|c|c|c|c|}
\hline \multirow[b]{2}{*}{ City } & \multirow[b]{2}{*}{ Pool Season } & \multicolumn{2}{|c|}{ Pool Heating Cost } \\
\hline & & With Cover (\$) & Without Cover (\$) \\
\hline Atlanta & April 1 to October 31 & 424 & 2,248 \\
\hline Boston & May 1 to August 31 & 328 & 2,096 \\
\hline Chicago & May 1 to September 30 & 296 & 2,072 \\
\hline Dallas & April 1 to October 31 & 280 & 1,920 \\
\hline Denver & May 1 to August 31 & 168 & 2,120 \\
\hline Kansas City & May 1 to October 31 & 416 & 1,872 \\
\hline Los Angeles & May 1 to October 31 & 304 & 2,376 \\
\hline Miami & January 1 to December 31 & 584 & 2,848 \\
\hline Minneapolis & June 1 to September 30 & 248 & 1,776 \\
\hline Phoenix & March 1 to October 31 & 168 & 1,776 \\
\hline Seattle & June 1 to August 31 & 424 & 1,784 \\
\hline
\end{tabular}

Pool covers vary in materials and deployment methods. Covers are typically made of vinyl or some form of ultraviolet-stabilized plastic. They may be transparent or opaque. In outdoor applications, opaque covers keep out more of the sun's energy if the pool is covered during daylight hours, which could impact pool heating loads.

Deployment choices range from manual to fully automatic. The most expensive covers are incorporated into the pool structure and include automated retraction and stowage capabilities. Less expensive covers can be manually removed and stowed or rolled onto a large trolley-mounted spool.

An alternative to the conventional pool cover is a chemical cover, which provides some evaporation protection and does not need to be moved on and off the pool. A utility-funded study found a $13 \%$ reduction in gas consumption over a 10-month period, saving 0.57 therms $/ \mathrm{ft}^{2}$ of pool surface at a large outdoor swimming pool in Oceanside, California (IES 2010). These products may be alcohol or silicon based, and typically require daily replenishment in small amounts. They are designed for use while the pool is in use, but their effectiveness diminishes when the pool surface is disturbed by swimmers or wind. As the wind and swimmer activity subside, the alcohol molecules float to the surface and reorganize into a single-molecule protective layer within 5-10 minutes, depending on the size of the pool (Flexible Solutions 2011). Under the best placid water conditions, savings from chemical pool covers will be less than what a physical cover would provide, but the low cost (on the order of $\$ 0.12 /$ day $/ 100 \mathrm{ft}^{2}$ of pool surface) and demonstrated effectiveness make this type of product worthy of consideration, alone or in conjunction with a physical cover. 


\section{E.3 Building Enclosure}

\section{E.3.1 Repair broken windows and weather-strip/caulk windows and doors where drafts can be felt}

Windows and doors are important components of the building envelope, and are critical for controlling infiltration, convection, radiation, and conduction (see Figure E-1). All doors and windows should be inspected periodically for air leaks and tight closure when the HVAC system is operating. Units that do not close tightly, have cracks, or are not weatherized allow conditioned air to escape and unconditioned air to infiltrate, thus increasing the heating and cooling system loads. Water leaks through windows are also a concern in schools because of the potential for mold growth and IAQ problems, which can lead to health problems. Leaky windows and doors should be repaired with caulking and weather-stripping, and cracked glass should be replaced. Caulking and weather-stripping are low-cost EEMs that can have a one-year payback from savings associated with the decreased demand on the HVAC system (EWC 2011).

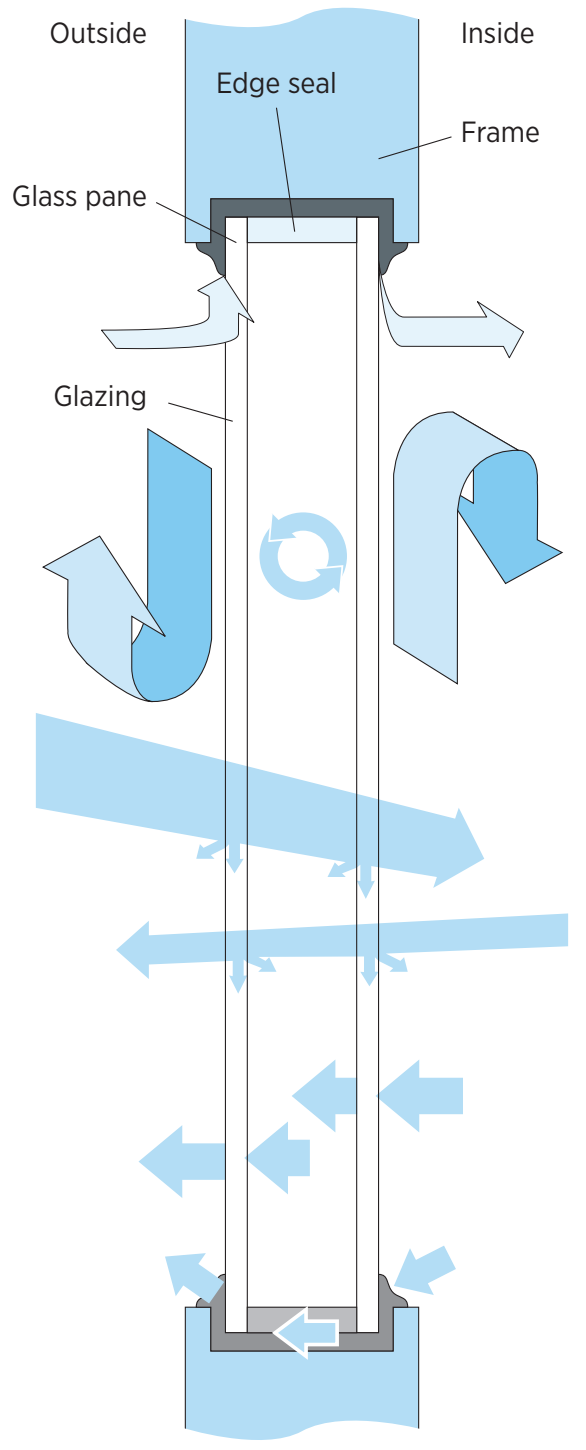

\section{Infiltration}

Air leaks around the frame, around the sash, and through gaps in movable window parts. Infiltration is foiled by careful design and installation (especially for operable windows), weather stripping, and caulking.

\section{Convection}

Convection takes place in gas. Pockets of high-temperature, low-density gas rise, setting up a circular movement pattern. Convection occurs within multiple-layer windows and on either side of the window. Optimally spacing gas-filled gaps minimizes combined conduction and convection

\section{Radiation}

Radiation is energy that passes directly through air from a warmer surface to a cooler one. Radiation is controlled with low-emissivity films or coatings.

\section{Conduction}

Conduction occurs as adjacent molecules of gases or solids pass thermal energy between them. Conduction is minimized by adding layers to trap air spaces, and putting low-conductivity gases in those spaces. Frame conduction is reduced by using low-conductivity materials such as vinyl and fiberglass.

Figure E-1 Windows exchange energy with the environment through a combination of convection, conduction, radiation, and air infiltration 


\section{E.4 Service Water Heating}

\section{E.4.1 Repair damaged or missing pipe and tank insulation}

A routine inspection of water heater tanks and pipes can identify sources of inefficiencies from standby loss (heat loss from water stored in tank), cycling loss (heat loss as water cycles through pipes), and water leaks. Corrosion on pipes and fixtures often indicates leakage. Insulation should be inspected for signs of degradation, such as discoloration and cracking, which tends to happen over time, especially if insulation is exposed to sunlight.

Insulation for pipes and storage tanks is recommended in all climate zones, especially in cold climates, where there is greater heat loss potential. The costs associated with maintaining insulation are low, and the payback is quick. Pipe insulation repairs typically have a payback of one to two years, and increased insulation levels can pay for themselves in less than six months (DOE 2009).

To specify pipe insulation, consider the minimum and maximum temperatures it will be exposed to. For example, if the piping will transport hot and cold streams depending on the season, it will need a vapor barrier to prevent condensation from ruining the insulation during the air-conditioning season.

\section{E.5 HVAC: Heating and Cooling}

\section{E.5.1 Test, adjust, and balance chilled water pumps and valves, refrigerant lines, air handling units, and flow modulation devices to ensure heating and cooling loads are met}

As schools age, so do their internal systems. Equipment slowly degrades, occupants alter system set points away from ideal settings, and cooling loads fluctuate as occupancy levels and spaces uses change. This can lead to inadequate cooling in occupied spaces, hot and cold spots, and equipment overloading. TAB brings the cooling system back into balance, increases equipment life and occupant comfort, and decreases energy waste.

The TAB process involves testing equipment functionality and making improvements and repairs as needed, adjusting system parameters, and balancing them to efficiently meet building loads and satisfy local ordinances. Typical heating and cooling system parameters, such as water flow rates, fan speeds and pump pressures, temperature set points, and airflow rates (supply, return, exhaust, and OA) are investigated during a TAB analysis. TAB also reveals leaks in the air distribution system, chipped fan blades, improper refrigerant charge, and overheated water pumps.

TAB may be needed if building staff are constantly adjusting HVAC components to maintain comfort, occupants are frequently submitting complaints about comfort issues, or spaces have been repurposed. TAB analysis should also be conducted occasionally as part of any major renovation or recommissioning efforts. A balanced system can fall out of "tune" in a year or two with constant use, so rebalancing every few years keeps HVAC systems operating efficiently. Savings through TAB are hard to generalize because they depend heavily on building conditions, but improper operations from the heating and cooling systems will eventually lead to occupant discomfort and wasted energy. 


\section{E.5.2 Verify or establish a comprehensive maintenance protocol for HVAC equipment, including cleaning cooling and heating coils, cooling towers, burners, radiators, and filters}

EBCx identifies all major HVAC equipment problems and necessary repairs. Establishing maintenance schedules and procedures ensures that efficient operation of the HVAC system will continue, and will lengthen the useful life of the system and its components.

An important step is to acquire or create reference maintenance materials for all HVAC equipment and systemsincluding product literature and service manuals - from the manufacturer and maintenance logs to record all maintenance activities. With these documents in place, you should establish preventative maintenance schedules and actions for each HVAC system component.

Scheduling preventative maintenance EEMs helps you avoid major system failures. The preventative method gives building staff an opportunity to evaluate HVAC systems regularly and identify potential problems before they become major operational problems. These schedules will also drive procurement schedules and ensure replacement parts are available when they are needed. Important components to consider include condenser and evaporator coils, cooling towers, burners, radiators, and filters.

Coils. To maintain efficiency in a vapor compression cooling system, it is important to keep condenser and evaporator coils clean. Dirt on the evaporator coil reduces system airflow and degrades the coil's heat-transfer efficiency, which in turn reduces cooling capacity. Inspect the evaporator coil at least annually to ensure the filters are doing their job. Shining a light through the coil is one way to inspect it, although enhanced fin designs, with their wavy patterns, can make this difficult. An alternative is to measure supply-fan current and filter or coil pressure drop with clean filters in place. If the amps are lower and the pressure drop is higher than last year's measurement, the coil needs to be cleaned.

Unlike the evaporator coil, the condenser coil sees unfiltered OA, and therefore degrades more rapidly. A dirty coil reduces the cooling capacity of the air blowing across the condenser coils. For example, if the dirty coil causes the condensing temperature to increase from $95^{\circ} \mathrm{F}$ to $105^{\circ} \mathrm{F}$, cooling capacity will decrease by about $7 \%$ and power draw will increase by about $10 \%$.

The best tool for cleaning the coils is a power washer that feeds cleaning solution into a high-pressure water flow. Some companies specialize in performing this type of cleaning at a competitive price. They typically use tank trucks and custom self-contained equipment. Spray-on cleaning solutions that are intended to be used with a brush and a hose will not adequately clean the coils, even though they may brighten the outer surface.

Before and after measurements of the temperature difference across the coil will verify the effectiveness of the cleaning. These measurements should be included in a maintenance report. Improper power washing-for example, using the wrong spray angle or excessive pressure — can bend or break the fins.

Cooling towers. In schools cooled with chillers, cooling tower maintenance is critical. Scaling, corrosion, and biological growth reduce efficiency and raise maintenance costs because of the resultant condenser fouling and loss of heat transfer capability. Water with high concentrations of dissolved mineral salts, which become increasingly concentrated during the evaporation process, accelerates the problem. Legionella pneumophila and other pathogens that can cause health problems can grow in cooling tower water. Placing cooling towers away from air intake vents can cut the risk of transmitting pathogens into the building. The typical solution to this and the other cooling tower water problems is to treat the water. Biocides can inhibit biological growth, corrosion inhibitors can maintain equipment surfaces, and other chemicals can maintain proper pH. Finally, a significant amount of "blowdown" (deliberate water overflow) is typically used so fresh makeup water reduces the buildup of salts and pollutants. 
Although treatment chemicals are necessary for maintaining cooling towers, they can be hazardous to handle and dispose. Chemicals also increase operating costs. To reduce these problems, one company offers a system that uses electrolysis to automatically add the biocide bromine to the tower water as needed. This approach eliminates the need for maintenance staff to manually perform the task — reducing the risk of exposure — and could reduce the amount of chemicals used that must later be disposed.

Some companies have attempted to develop nonchemical treatments, with mixed results. Magnetic field treatments, in particular, have yet to conclusively demonstrate their value. There is no scientific explanation for how magnetic fields could influence particles and microorganisms in water to prevent fouling, so their success cannot be predicted for any given condensing water system.

Another nonchemical treatment is ozone. It is an effective biocide, but it is unclear under what circumstances it works well for cooling towers. It is still debated as to how—or even if - it can prevent scale buildup or corrosion. Some ozone system manufacturers recommend using chemicals in addition to the ozone.

Burners. Over time, burners can become fouled because of buildup from minerals, corrosion, or soot, reducing the efficiency of the combustion process. Burners should be checked regularly for cleanliness and proper flame control. There are several indicators that a burner needs cleaning. Burners may be overfiring, indicated by a large flame blowing past the thermocouple that measures the temperature of the flames. An underfired burner will have a small flame that does not engulf the thermocouple. A flame with a yellow tip suggests a lack of primary air. Yellow or orange streaks indicate the presence of dust or other particles that will lead to soot buildup. Perform regular maintenance to keep burners clean by removing burners and brushing and vacuuming thoroughly. Check to ensure all ports are free of debris before placing them back in their original positions. This will help the heating system achieve peak combustion efficiencies.

Radiators. Radiators transfer heat to conditioned spaces. They are quite popular, partly because they are reliable and low maintenance, but they still require regular checking for leaks and loose fittings, and require annual air bleeding. Radiator pipes will expand and contract many times during their lives, so connections will eventually loosen. Valves can loosen as well, or deteriorate over time, causing leaks. Air will likely infiltrate the system during the cooling season. This air takes away from system efficiency by preventing the water from circulating as designed. To bleed out the air, turn all the water supply valves on, then turn the heating system on and wait for it to warm up. Then starting with the radiator at the highest point or furthest from the boiler, open the bleed valve on each radiator. Any trapped air will exhaust through the valve. Once hot water starts coming out, the bleeding is complete. Close the bleed valve and move to the next radiator in the system, repeating the actions, and continuing with each radiator until you reach the boiler.

Filters. Filters help maintain IAQ and protect the downstream components of an air handling system (the evaporator coil and fan) from accumulating dirt. Filter changing intervals are typically determined by calendar scheduling or visual inspection, but can also be based on the measured pressure drop across the filter. Scheduled intervals are usually between one and six months, depending on the local air quality, both indoors and out. More frequent changes may be needed during the economizer season, because OA is usually dirtier than indoor air.

Measuring pressure drop is the most reliable way to determine whether filters need cleaning, but requires some effort because most RTUs do not have built-in pressure taps. Taps can be made by drilling into the cabinet wall and installing $1 / 4$-in. tubing with removable caps. A technician can then use a handheld pressure meter or manometer to check filter status. For accurate readings, cabinet access panels must be shut tightly, with all screws replaced. In facilities with predictable and regular filter loading, pressure measurements can be used to establish the proper filter change interval; thereafter, filter changes can simply be scheduled. 


\section{E.5.3 Verify correct operation of outside air economizer}

Economizers provide "free" cooling by drawing in cool OA to offset mechanical cooling when outside temperatures are sufficiently low (see Figure E-2). When economizers operate as designed, they can save considerable energy. Simulations for eight U.S. cities show that standard economizers can cut HVAC energy use by $1 \%-5 \%$; highperformance units can save $8 \%-20 \%$. (See Section 4 for retrofit EEMs that can improve economizer performance.) Savings are greatest in milder climates (PECI 2011).

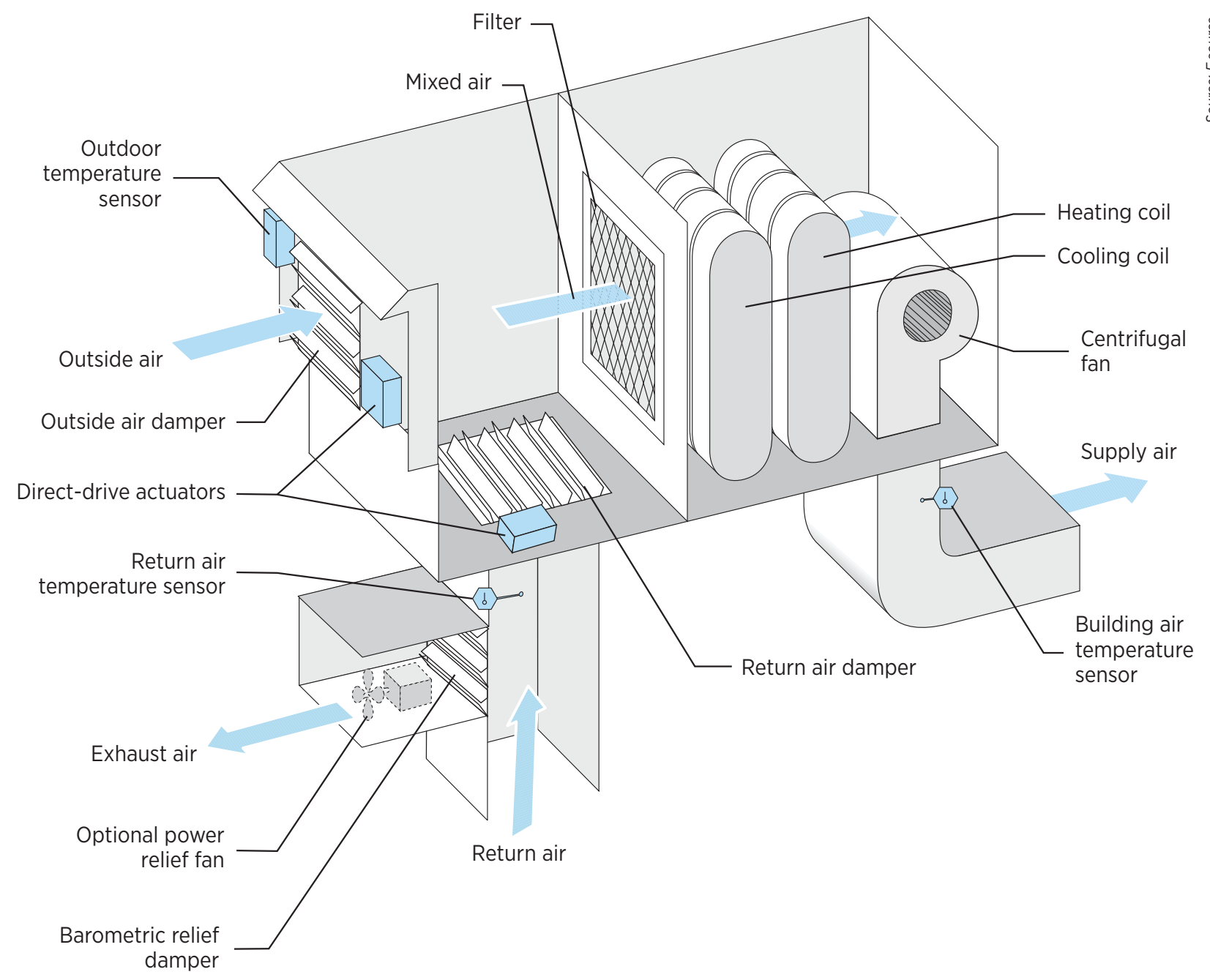

Figure E-2 Economizers include a number of components that must be properly maintained

Economizers often do not operate as designed. Between 2001 and 2004, the New Buildings Institute compiled the results of several field studies conducted in the western United States. Of 503 economizers on rooftop HVAC units, $64 \%$ had failed or required adjustment (Cowan 2004). Common problems included corrosion-frozen dampers, broken linkages between the actuator and damper, malfunctioning OAT sensors, and improperly set controls.

Economizers stuck in the open position risk overloading the cooling coil with warm OA; economizers stuck in the closed position eliminate the free cooling potential. Roth et al. (2002) estimated that economizer malfunctions waste $20 \%-30 \%$ of all HVAC energy consumed. In another study, simulations indicated that in hot-humid locations, if an economizer damper is stuck in the open position, it can increase cooling energy use by as much as $50 \%$ (E Source 2009). 
To ensure economizers provide their expected energy savings, conduct an annual maintenance program that includes functional testing, which can identify failed actuators, linkages, and stuck dampers. Portland Energy Conservation, Inc. provides a free checklist for economizers: Functional Performance Test, Air-Side Economizer. PG\&E offers a General Commissioning Procedure for Economizers. Portable data loggers can also help identify problem areas (PG\&E 2002). BASs can also be used to monitor economizer performance if they are equipped with the right sensors and diagnostic software.

Regular maintenance should include cleaning, lubricating, and inspecting dampers up to three or four times per year. Economizers can be cleaned with a power washer or with soapy water and a brush. Once the dampers are cleaned, they should be run through their full range of motion. The economizer set point should also be checked and damper response confirmed.

Finally, flawed equipment can cause economizers to perform poorly. A simple fix is now available for an inaccurate dry bulb sensor widely used in economizers. Correcting the flaw can reduce building energy use by $8 \%$ (E Source 2009).

Economizer maintenance costs are hard to pin down because service contracts usually cover the air-conditioning system rather than specific components. A survey of HVAC contractors across the United States found that the cost of a service contract for a 10 -ton unit is $\$ 1,000-\$ 1,200$, but coverage varies: some may provide only visual inspections of economizers; others perform functional testing (E Source 2009).

\section{E.5.4 Increase thermostat setback/setup when building is unoccupied}

Heating and cooling account for more than $50 \%$ of a typical school's energy consumption, so setting thermostat setback and setup procedures for unoccupied hours can save significant energy. During occupied hours, the Alliance to Save Energy recommends lowering the thermostat setting to $68^{\circ}-70^{\circ} \mathrm{F}$ during the heating season, and raising it to $78^{\circ} \mathrm{F}$ in the warmer months if the building uses air-conditioning (ASE 2011). Some functional spaces (such as gymnasiums and cafeterias) can often have different set points than classrooms and offices.

During unoccupied periods such as nights, weekends, and holidays, set temperatures according to climate, season, and length of time the space is unoccupied. For example, during the heating season, for long breaks over the weekend or a holiday, the temperature can be set back to $55^{\circ} \mathrm{F} ; 60^{\circ}-63^{\circ} \mathrm{F}$ may be more appropriate for a shorter break (ASE 2009). For every degree of change in temperature, energy costs change about $2 \%-3 \%$. For instance, if a school can keep the temperature at $68^{\circ} \mathrm{F}$ rather than $72^{\circ} \mathrm{F}$, that $4^{\circ} \mathrm{F}$ difference means about a $12 \%$ energy savings (State of Connecticut 2009).

Changing temperature settings for different times or situations is easiest to accomplish with an EMS or BAS. If those systems are not in use, programmable thermostats should be installed. Teachers and staff should be trained to ensure proper programming and maintenance.

The optimal temperature changes vary depending on the specific systems and features of the building and climate. A recent study used the building energy simulation program, EnergyPlus, to investigate the effect of heating setback and cooling setup on the energy consumption of a classic double corridor classroom building in 15 U.S. climate zones (Guo and Nutter 2010). The study found that optimal setbacks and setups vary day to day based on OAT and the type of building construction. The author provides temperature set points for a classic double corridor school in each climate zone, which can be used as a general guideline for establishing set points (Table E-2). These numbers are based on energy modeling data and should be used as guidelines only. For a warm-humid climate zone such as Miami, the optimal night setback for heating is about $5^{\circ} \mathrm{F}$, and the optimal night setup during cooling season is approximately $10^{\circ} \mathrm{F}$. In a cold-dry climate such as Montana, the optimal night setback temperature is around $20^{\circ} \mathrm{F}$, and the optimal night setup is approximately $9^{\circ} \mathrm{F}$. 
Table E-2 Recommended Temperature Setbacks and Setups for U.S. Climate Zones

\begin{tabular}{|c|c|c|c|c|}
\hline \multirow{2}{*}{ Climate Zone } & \multicolumn{2}{|c|}{ Massive Building } & \multicolumn{2}{|c|}{ Metal Building } \\
\hline 1A & $\begin{array}{c}\text { Heating } \\
\text { Setback }\left({ }^{\circ} \mathrm{F}\right)\end{array}$ & $\begin{array}{c}\text { Cooling } \\
\text { Setup }\left({ }^{\circ} \mathrm{F}\right)\end{array}$ & $\begin{array}{c}\text { Heating } \\
\text { Setback }\left({ }^{\circ} \mathrm{F}\right)\end{array}$ & $\begin{array}{c}\text { Cooling } \\
\text { Setup }\left({ }^{\circ} \mathrm{F}\right)\end{array}$ \\
\hline 2A & 4.3 & 10.4 & 4.1 & 7.7 \\
\hline 3A & 9.4 & 13.9 & 10.1 & 11.2 \\
\hline 4A & 9.4 & 13.1 & 13.3 & 12.9 \\
\hline 5A & 19.4 & 16.4 & 20.7 & 15.3 \\
\hline 6A & 18 & 10.8 & 22.1 & 13.5 \\
\hline 2B & 20.5 & 10.4 & 23.9 & 12.7 \\
\hline 3B & 9.7 & 20.5 & 8.6 & 15.5 \\
\hline 4B & 7.9 & 14.2 & 12.1 & 13.5 \\
\hline 5B & 20.7 & 16.5 & 21.9 & 15.8 \\
\hline 6B & 19.4 & 10.6 & 22.1 & 12.1 \\
\hline 7 & 19.4 & 10.3 & 22.3 & 12.1 \\
\hline 8 & 20.7 & 8.8 & 6.3 & 11.5 \\
\hline
\end{tabular}

\section{E.5.5 Precool spaces to reduce peak demand charges}

Precooling involves using either the cooling system or the economizer to flush the building with cool air overnight. The building mass then acts as a heat sink the following day, absorbing heat from internal gains and reducing the amount of energy needed for cooling during periods of lower electricity charges, and reducing the peak demand charge (Figure E-3).

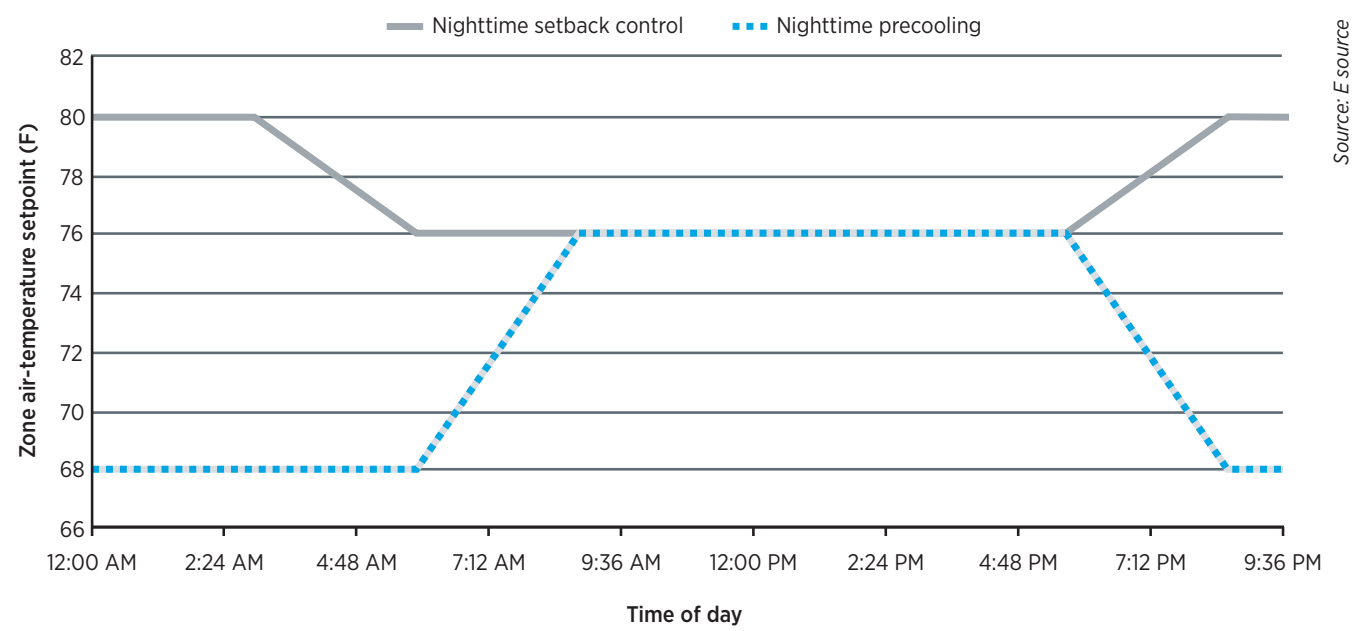

\section{Figure E-3 Comparing nighttime precooling and nighttime setback}

Most buildings use nighttime setbacks and allow inside air temperatures to rise at night, then cool things down in the morning before occupants arrive. Nighttime precooling is nearly the opposite-the nighttime temperature set point is about $68^{\circ} \mathrm{F}$, but the building air temperature is warmed up in time for the occupants' morning arrival. In the example shown here, the desired occupied temperature is $76^{\circ} \mathrm{F}$ for both strategies. 
Recent modeling suggests that precooling can reduce peak demand by up to $30 \%$ in commercial buildings (Lee and Braun 2008). In another study, tests comparing a conventional night setup and a simple precooling control strategy found that the precooling strategy reduced peak demand loads from $9 \%$ to $31 \%$, depending on the location of the specific zone in a building (Braun and Lawrence 2002).

Night precooling has the potential to be more cost effective than mechanical thermal storage, because it eliminates the need to install pumps and tanks. It does, however, require special control hardware and software. When performed with an economizer, this technique also introduces extra fresh air to a building, which can improve IAQ.

Building simulations and field studies have demonstrated that precooling can be effective in cool and moderately warm climates and that peak demand savings rise with increased building thermal mass. Xu et al. (2009) also suggest that precooling in hotter climates may be as effective as it is in cool and moderate ones. Yin et al. (2010) also found that for a concrete building with medium thermal mass, the whole-building electrical peak demand can be reduced by up to $15 \%$ and $21 \%$ during peak hours in warm and hot climate zones, respectively. In the same study, a control strategy that combines precooling with exponential temperature setup achieved the greatest peak demand savings and the flattest afternoon electric load shape. In this approach, the building is precooled during the early morning hours, then the zone temperature reset set points are allowed to exponentially increase during the afternoon when peak use typically occurs, until after hours when the temperature is allowed to float.

\section{E.5.6 Reset supply air temperature based on building loads or outside air temperature}

If the right controls are in place, the SAT can be reset to reduce energy use. In typical CV HVAC systems, the SAT for the building is set at a constant set point, usually $53^{\circ}-55^{\circ} \mathrm{F}$, to satisfy cooling demands on the hottest days of the year, and is designed to provide cooling to the zone with the peak demand. In zones with lower cooling loads, the air will be reheated as it enters. The SAT can be reset to minimize this simultaneous cooling and heating. In this approach, cooled water or refrigerant flow is reduced to create warmer supply air (reset) in response to a decrease in cooling demand. This reset is controlled by measuring OATs (OA reset) or by measuring the warmest area (warmest zone reset). Warmest zone reset directly measures the indoor air temperature and is more accurate. However, OA reset uses much simpler controls. Resetting the SAT reduces the load on the cooling system and results in less need for energy to reheat the supply air.

If your school already has a VAV system, the optimal SAT minimizes the combined energy for fan, cooling, and heating energy and depends on the specific conditions and climate. For example, low SAT can be a better choice in warm and humid climates where there are fewer potential economizer hours and dehumidification is important. Based on simulations of VAVs in various climates, CEC (2005a) provides general guidelines for optimizing systems.

\section{E.5.7 Reset boiler temperature based on building loads or outdoor air temperature}

OA reset controls monitor OATs and use that information, plus a building-specific heat loss coefficient, to match boiler output to heating demands. This approach leads to savings that result from fewer on/off cycles, increased burner efficiency, and lower average water temperatures.

These control systems have been implemented for many years, with studies as far back as the 1980s claiming savings from OA reset controls. In fact, most new boilers sold today have an OA reset strategy built into their onboard electronic control system. Modern electronic controllers can be retrofitted on boilers without these controls and perform OA reset functions along with other options such as advanced control interfaces that can communicate with BAS controls, sequencing coordination, and warm weather shutdown. Savings estimates are quoted at $10 \%-15 \%$ (Siegenthaler 2001), but the rule of thumb is an older and less efficient boiler stands to gain more efficiency points through EEMs than a newer, more efficient boiler. 
There are other benefits to OA reset controls. Reducing the number of on/off heating cycles improves temperature stability, which improves occupant comfort. Fewer on/off cycles also increase boiler life.

\section{E.5.8 Verify adequate deadband between heating and cooling}

HVAC systems switch between heating and cooling modes depending on the temperature; typically, with a deadband, or temperature range in which no heating or cooling is provided. The narrower the deadband, the more time and energy the HVAC system has to spend meeting those conditions. If the deadband is too narrow, simultaneous heating and cooling can occur as the HVAC system bounces between heating and cooling set points. When these systems compete against each other, they waste considerable energy and unnecessarily cycle systems on and off. Widening the deadband by increasing cooling set points and lowering heating set points will save energy and reduce runtime and maintenance costs on fans, pumps, chillers, cooling towers and boilers. Itron (2007) found that increasing the deadband from $\pm 0^{\circ} \mathrm{F}$ to $\pm 2.5^{\circ} \mathrm{F}$ saved more than $400,000 \mathrm{kWh}$ and 500 therms annually.

There is a limit to how wide a deadband can be, because the wider the deadband, the more likely occupant comfort is to deteriorate. In particular, buildings with wide deadbands in humid climates can experience large variations in relative humidity. Deadbands should generally be $5^{\circ}-15^{\circ} \mathrm{F}$ during occupied periods (Price and Rosenow 2009), but to determine the optimum setting, you should widen the deadband gradually and determine whether students and teachers are still comfortable. ASHRAE Standard 55-2004, "Thermal Environmental Conditions for Human Occupancy," states that temperature set points can be adjusted according to the way occupants dress (ASHRAE 2004a). This allows cooling set points to be raised during the cooling season because occupants dress lighter, and similarly, heating set points can be lowered during the heating season as occupants dress more warmly. These set points should be adjusted over several weeks so occupants will not perceive significant changes. Weekends and extended holidays are also good opportunities to make these changes.

\section{E.5.9 Optimize equipment staging and sequence of operation}

Schools that operate multiple chillers or boilers have an opportunity to save energy by optimizing the way they work together. Every chiller has a range of loading conditions where it operates most efficiently. For most chillers, efficiency drops dramatically at loads below $30 \%$, although for some that cutoff can be as high as $50 \%$. Each chiller's operating efficiency must be evaluated separately.

In standard sequencing practice, the first chiller is almost fully loaded before a second is started. When multiple chillers of different sizes are in place, the smallest should be started first. When the second chiller kicks in, both run at equal percentages until they are almost fully loaded. Then a third chiller can be started, and so on. When the load decreases, the chillers cycle off in reverse order.

An alternative sequencing method uses one small chiller — called the swing chiller-with one or more large chillers. The swing chiller is started and runs close to its maximum. At that point it is shut down and one of the larger systems is started. The larger system is not started until it can operate in its maximum efficiency range. When the load exceeds the maximum efficiency range of the larger chiller, the swing chiller is restarted and the two chillers carry the load until it exceeds their combined capacity. At that point, the swing chiller is stopped again and the second large chiller is started. As the load decreases, the chiller unloading follows the same logic. Energy consumption is reduced using the swing method by properly loading each chiller and switching off pumps and fans with their associated chillers.

For either strategy, the potential savings vary widely with chiller characteristics and the range of cooling loads experienced by the school. The manufacturer can provide chiller characteristics, but few plant operators are certain about their building's cooling load profiles. Fortunately, it costs little to experiment manually with sequencing strategies and to estimate savings through observation (E Source 1997). 
DOE (2008a) provides an example of savings from optimized staging at a Goodyear tire plant in Union, Tennessee. An assessment of the plant's steam process revealed that four boilers were operating at part load to meet steam needs. Analysis of the steam system and plant requirements showed that steam demands could be met by operating just two boilers, a large and small boiler at higher part loads. This saved the plant 70,000 MBtu and nearly $\$ 500,000$ annually.

In a separate example, a manufacturing plant with two 200-ton centrifugal chillers ran both chillers simultaneously at less than $45 \%$ capacity for extended periods. Calculations showed that savings of about $5 \%$ could be achieved by operating a single chiller at $90 \%$ load. Shutting down one chiller allowed the auxiliary chilled water and condenser water pumps that serve it to be shut down (E Source 1997).

\section{E.5.10 Optimize equipment start and stop procedures}

Similar to setbacks based on the time-of-day, start/stop optimization considers OA and indoor air conditions to determine when to operate the HVAC system. When the start/stop procedures of an HVAC system are optimized, parts of it, such as boilers and chillers, will start up "just in time" for the indoor space to reach comfort set points before the students arrive. For example, during the winter, AHUs are started right before students arrive in the morning while the heating system warms the school from its night setback. Building staff should also ensure each heating and cooling system has its own startup schedule to ensure the cooling system does not add to the load of the heating system.

An optimized procedure will shut down certain systems some time before an unoccupied period begins. The building's thermal mass allows indoor conditions to remain acceptable for occupants for some time after these systems have been shut off, depending on the OA and the rate of heat loss. For example, if indoor temperatures are at the desired level, and the $\mathrm{OAT}$ is $45^{\circ} \mathrm{F}$, the heating system could probably be turned off for at least an hour. In contrast, if the $\mathrm{OAT}$ is $10^{\circ} \mathrm{F}$, turning the heating system off early probably is not an option.

It will take school facilities staff some time to find the right balance of OATs and the ideal shutoff time. Consider tracking temperature set points and shutoff times to develop a simple algorithm based on indoor and outdoor temperatures to determine the ideal shutoff time based on present conditions. Another approach is to gradually lower the heating set point toward the end of the day. Arends and Sandusky $(2010)$ found that optimized start/stop procedures in a five-story office building produced annual savings of almost $\$ 2,000$. 


\section{E.6 HVAC: Ventilation}

\section{E.6.1 Suspend ventilation during unoccupied periods}

Most schools base their ventilation rates on ASHRAE Standard 62.1, which specifies the minimum amount of OA that must be brought into the building, depending on its type and use. This usually leads to a fixed ventilation rate based on assumed occupancy. School building occupancy varies during the day, however, and schools can be virtually unoccupied during evening and weekend hours. If ventilation systems are still operating at full capacity during these unoccupied periods, a lot of energy is being wasted. Suspending ventilation during unoccupied periods also reduces wear and tear on ventilation equipment, extending system life and lowering maintenance costs. In humid climates, unnecessary ventilation during unoccupied periods can also lead to elevated relative humidity levels. This results in occupant discomfort and increased demand on the HVAC system to lower humidity to acceptable levels. CEC (2005b) found that 30\% of observed systems were operating ventilation fans during unoccupied periods, and Callahan et al. (1999) observed that $56 \%$ of investigated systems lacked control over ventilation air during unoccupied periods.

\section{E.6.2 Test and adjust ventilation flow rates as needed to meet ASHRAE 62.1 requirements}

In general, school ventilation rates should meet the requirements of ASHRAE Standard 62.1. These rates are set to maintain healthy IAQ - particularly important for schools, as poor school building IAQ can decrease student performance (Schneider 2002). Furthermore, poor IAQ tends to affect younger children more than adults (Apter et al. 1994). Energy can be saved by testing and adjusting ventilation rates so they do not exceed the ASHRAE requirements. Because occupancy rates change frequently during the school day, a DCV system (see Section 4) can lead to significant savings.

\section{E.6.3 Replace or repair leaky and broken dampers}

OA dampers endure a continual flow of dirty air that fouls the pivot points and actuator mechanism. Properly operating dampers ensure the minimum ventilation rate is satisfied. When dampers are serviced, all movable surfaces should be cleaned and lubricated. The cleaning can be done with a power washer or a bucket of soapy water and a brush. As long as a service technician is already on the roof, this should take about 15 minutes. The damper should then be tested and run through its full range of motion. 


\section{E.7 Additional Energy Efficiency Measures for Consideration}

Several of the most important and frequently occurring EBCx measures were discussed in the preceding sections. Many additional low-cost EEMs may be worth exploring, depending on the school's condition. A number of these EEMs are listed in Table E-3, and further possibilities can be found in the reference documents listed in Section 3.4.

Table E-3 Additional EBCx Measures That Should Be Considered

\begin{tabular}{|c|c|}
\hline System & EEM Description \\
\hline \multirow{4}{*}{ Lighting } & Repair or replace interior shading devices \\
\hline & Repaint interior wall and ceiling surfaces to increase average reflectance \\
\hline & Improve motion sensor locations and move line-of-sight obstacles \\
\hline & $\begin{array}{l}\text { Adjust light levels to within } 10 \% \text { of the IES recommendations for the tasks conducted in each } \\
\text { area by delamping or relamping }\end{array}$ \\
\hline \multirow{4}{*}{$\begin{array}{l}\text { Plug and } \\
\text { process loads }\end{array}$} & Schedule cooking activities to use equipment at full capacity \\
\hline & Turn off refrigerator door heaters \\
\hline & Verify balanced 3-phase power and proper voltage levels \\
\hline & Verify airflow paths around transformers are not blocked \\
\hline \multirow{2}{*}{$\begin{array}{l}\text { Building } \\
\text { enclosure }\end{array}$} & Repair broken doors \\
\hline & Cap unused air chases \\
\hline \multirow{3}{*}{$\begin{array}{l}\text { Service water } \\
\text { heating }\end{array}$} & Repair leaky pipes and fixtures \\
\hline & Install low-flow aerators on faucets \\
\hline & Reduce set point for service hot water to $120^{\circ} \mathrm{F}$, with boost heating for dishwashers \\
\hline \multirow{4}{*}{ HVAC } & Verify steam traps are operating and free of leaks \\
\hline & Turn off unneeded heating and cooling equipment during off seasons \\
\hline & Seal leaky ducts and add duct insulation \\
\hline & Reset condenser temperature reset based on current building loads and use patterns \\
\hline
\end{tabular}




\section{Appendix F \\ Detailed Retrofit Energy Efficiency Measure Descriptions}

The following sections provide general overviews of the retrofit measures that are most likely to be effective in typical K-12 schools. Each section includes a technical overview, strengths and weaknesses, and special considerations to help energy managers select the measures that best meet their needs.

\section{F.1 Lighting}

Lighting represents about $14 \%$ of electricity consumption in a typical school, not including its impact on cooling loads. Lighting retrofits tend to be one of the most important cost-saving EEMs, saving as much as $30 \%-50 \%$ of lighting energy, plus $10 \%-20 \%$ of cooling energy (EPA 2008), and generally have shorter payback times than other building system retrofits.

\section{F.1.1 Replace exit signs that use incandescent lamps with LEDs}

Inefficient exit signs can consume considerable energy in a school building because they remain lit 24 hours per day, 7 days per week. Most have been converted to efficient fixtures with LED technology. If you think some or all of the exit signs in your schools have not been converted, this should be your first priority. LEDs can be produced in various colors, and have been used for many years in the consumer electronics industry. They are now making headway in many commercial lighting systems, and exit signs are the most common application (see Figure F-1).

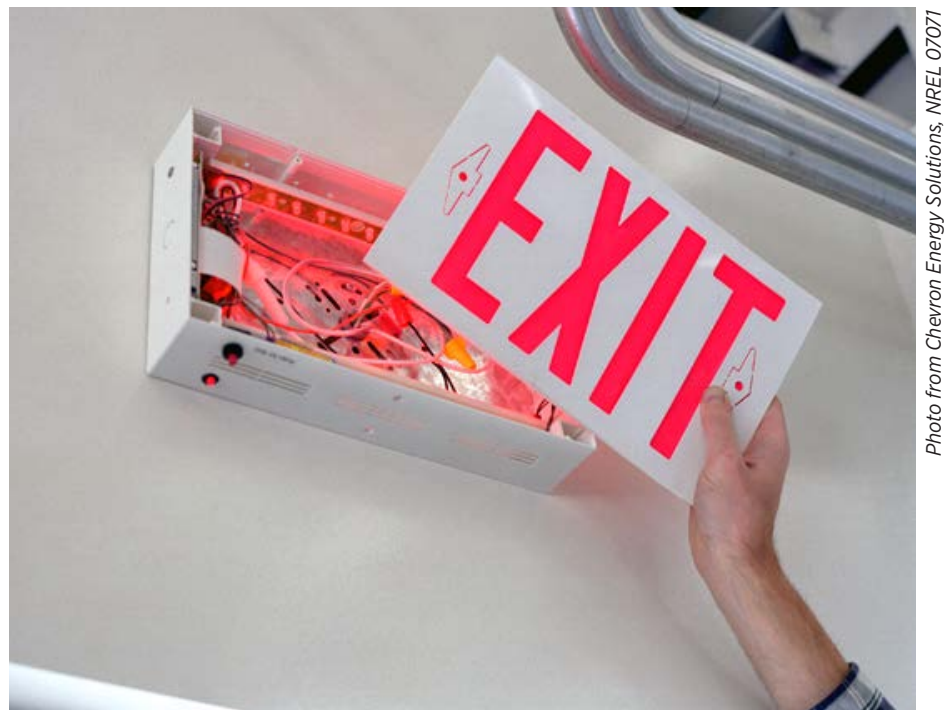

Figure F-1 Exit sign illuminated with LED lamp

LED exit signs offer several advantages when installed in school buildings (EPA 2003c):

- Lower energy costs. An LED exit sign typically uses less than $44 \mathrm{kWh} / \mathrm{yr}$, and costs about $\$ 4 / \mathrm{yr}$ to operate. This represents about $5 \%$ of the annual energy cost for an exit sign using incandescent lamps (95\% savings).

- Reduced maintenance costs. LEDs in exit signs typically maintain their rated illumination levels for 10-25 years. Incandescent lamps must be replaced several times each year. This greatly reduces the relamping costs associated with exit signs. 
- Improved safety. LEDs typically provide better visibility than incandescent exit signs because LEDs are brighter and result in greater color contrast. In an emergency, this can help the students exit the building quickly and safely.

The major disadvantage of LED exit signs is their initial cost. In most applications, however, the higher first cost is repaid within the first year or two. ENERGY STAR (2011) developed a free analysis tool to help building owners evaluate the economics of LED exit signs.

\section{F.1.2 Replace T12 fluorescent lamps and magnetic ballasts with high- efficiency T8 lamps and instant-start electronic ballasts}

Fluorescent lighting is used in many K-12 school applications (see Figure F-2). Many school buildings still have fluorescent lighting systems that use very old, inefficient technology. These old systems typically contain:

- T12 fluorescent lamps. T12 systems are characterized by "fat" bulbs that are 1.5 in. diameter. T12 systems are common, but can use twice as much energy as modern T8 systems.

- Magnetic ballasts. Magnetic ballasts were usually paired with T12 bulbs because their initial cost was low. They flicker and hum, which many people find objectionable. They may also contain potentially hazardous polychlorinated biphenyls.

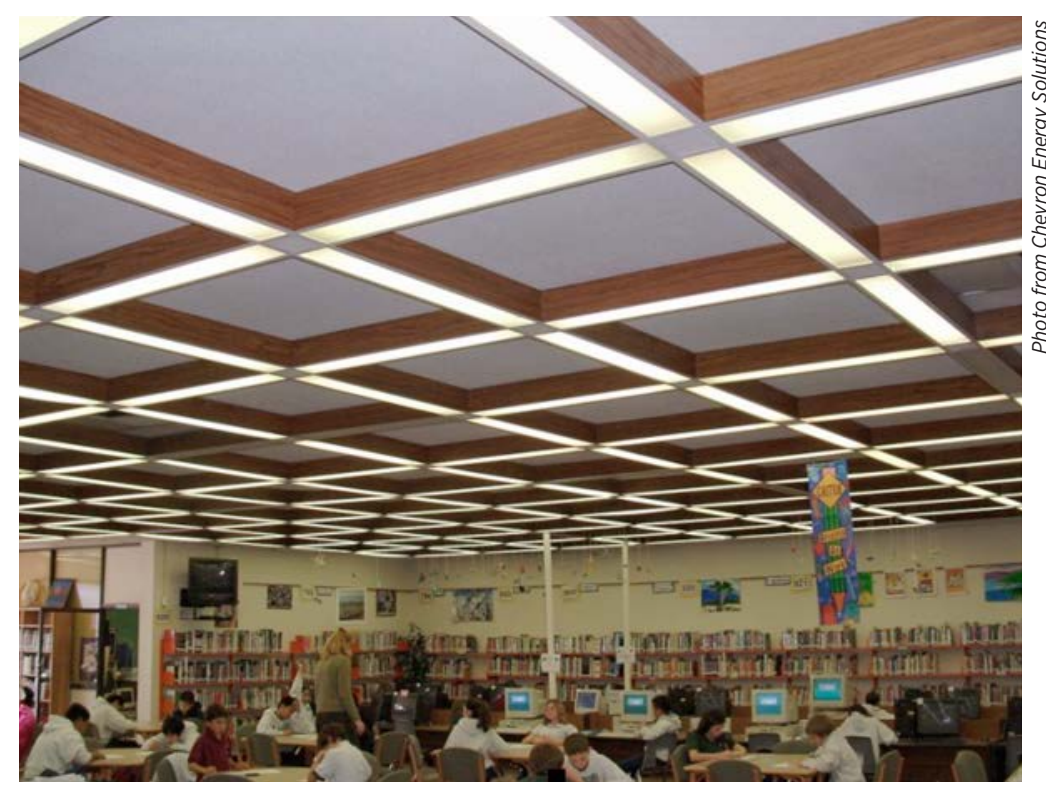

Figure F-2 Fluorescent lighting in a high school library

Energy-efficient fluorescent lighting systems using T8 (1-in. diameter) lamps offer improved efficiency, better light quality, and potentially longer life because their light output degrades less over time. T8 lighting systems have been in widespread use since the mid-1990s, are commonly available, and can be installed by any electrician or lighting company. Their capabilities are constantly evolving to meet market needs, and many now offer dimming capabilities (see Section F.1.5).

A fluorescent lighting fixture requires a ballast, which is a special kind of transformer. For T8 systems, the two main types are instant-start and rapid-start electronic ballasts. Instant-start ballasts generally provide more energy savings than rapid-start systems, but specifying the optimal system in situations where building owners are trying to maximize either energy savings or light output usually requires consultation with a lighting design professional. 
If you have not already upgraded to T8 lamps with electronic ballasts, or if you upgraded to T8s, but not the most efficient models, you can achieve significant savings from a lighting retrofit. The newest high-performance T8 lamps and NEMA Premium ballasts boost efficiency and offer improved color quality and longer lamp life. All upgrades to more efficient lighting also reduce the cooling loads on air-conditioning equipment. A new T8 system should also effectively eliminate lighting maintenance costs for a number of years. T8 system lamps and ballasts are manufactured by major companies and typically carry warranties of three to five years.

The principal disadvantages of retrofitting a T12 system to T8 are the first cost of the retrofit and a modest heating cost increase; however, because this lighting retrofit saves so much energy it often provides a very quick payback.

\section{F.1.3 Replace incandescent lamps with compact fluorescent lamps}

Use CFLs to replace incandescent lamps in downlights, sconces, table lamps, task lights, and wall washers. They cost more initially than incandescent lamps, but quickly pay for themselves through energy and maintenance savings. The longer the annual operating hours, the more attractive the economics of CFLs become, because more incandescent relamping costs are being avoided per year. ENERGY STAR offers a free calculator to help building owners estimate the economics of CFL bulb replacement programs (EPA 2011h).

CFLs come in two general forms - self-ballasted or pin-base. Selfballasted CFLs - also known as screw-base, screw-in, or integrally ballasted CFLs - can replace incandescent lamps without modifying the fixtures. They combine a lamp, ballast, and base in a single sealed assembly that is discarded when the lamp or ballast burns out.

Pin-base CFLs, the type most commonly employed in commercial buildings, are used with separate ballasts. They are available in lower

Top O\&M Cost-Saving EEMs in the Example Building

1. Replace incandescent lamps with CFLs.

2. Replace exit signs that use incandescent lamps with LED exit signs.

3. Replace $T 12$ fluorescent lamps and magnetic ballasts with high-efficiency T8 lamps and instant-start electronic ballasts. power versions, which can replace incandescent lamps, and in higher power versions, which can replace linear fluorescent lamps or HID lamps. Pin-base systems feature a ballast and pin-base fluorescent lamp socket that the manufacturer wires into a fixture or that is part of a retrofit kit. Because they are hardwired, dedicated systems, they eliminate the possibility that a user will return to using an inefficient incandescent bulb.

One of the most common uses of CFLs in school buildings is in recessed downlight cans. A wide range of fixtures are now available for this fixture class, some with very good reflector designs, good optical control, and dimming capabilities. Care must be taken in this application to ensure excess heat buildup does not shorten the lamp life.

When using CFLs, remember these key points:

- Go for a 3:1 ratio. Lamp manufacturers often publish a 4:1 ratio for replacing incandescent bulbs with CFLs (that is, a 25-W CFL can replace a 100-W incandescent lamp). A 3:1 ratio is more appropriate (a 25-W CFL can replace a $75-\mathrm{W}$ incandescent lamp) - in practice, CFL output is lower than the nominal rating because of lumen degradation and the effects of temperature and position on lamp output.

- Limit the number of CFL types. CFLs are available in a wide variety of sizes and shapes - it is useful to standardize on just a few types to reduce stocking requirements and confusion at relamping time.

- Use dedicated fixtures. To prevent users from replacing CFLs with incandescent bulbs, use dedicated fixtures that will accept pin-base CFLs only.

- Choose CFLs that have the ENERGY STAR rating. This ensures reliability and efficiency in self-ballasted CFLs. 


\section{F.1.4 Install wireless motion sensors for lighting in rooms that are used intermittently}

The easiest and cheapest way to save energy on lighting is to turn lights off in unoccupied rooms. Unfortunately, teachers, administrators, and custodial personnel often forget this. Many school districts employ occupancy sensors (infrared or acoustic or both) to control electric lighting. If the sensors detect that a room is unoccupied, they signal a lighting control system to turn off the lighting. This can produce significant energy savings in rooms that are frequently empty.

To avoid problematic lighting shutoff, (e.g., when a class is nearly motionless while taking a math test), occupancy sensor systems

\section{Quickest Payback EEMs in Example} Building

1. Replace incandescent lamps with CFLs.

2. Install wireless motion sensors for lighting in rooms that are used intermittently.

3. Install VSDs on chilled-water and hot water pumps..

typically do not shut off lights for several minutes. This "delay time" is user set, and is usually 5-15 minutes, depending on the use of the room. Most systems shut the power off completely at the end of the delay time. More sophisticated control systems on lights with dimmable ballasts can be set to gradually turn down the light level, in case there is actually someone in the room.

Vacancy sensor systems may also require that the lights be manually switched on when the room is reoccupied, rather than turned on automatically when the sensors recognize occupancy. This allows a teacher, for example, to decide that the classroom is bright enough from daylight alone and does not require artificial light.

The principal advantages of using motion sensors in schools are reduced energy costs for lighting and less lighting systems maintenance due to decreased run hours. The savings available from motion sensors can be substantial (see Table F-1).

Table F-1 Potential Energy Savings for Controlling Lighting Using Motion Sensors

\begin{tabular}{|c|c|}
\hline Space Type & Energy Savings \\
\hline Private office & $13 \%-50 \%$ \\
\hline Open-plan office & $20 \%-28 \%$ \\
\hline Classroom & $40 \%-46 \%$ \\
\hline Conference room & $22 \%-65 \%$ \\
\hline Restroom & $30 \%-90 \%$ \\
\hline Corridors & $30 \%-80 \%$ \\
\hline Storage/closet & $45 \%-80 \%$ \\
\hline
\end{tabular}

The disadvantages of motion sensors are their installation costs, a modest increase in heating costs, and their need for proper installation, calibration, and maintenance. If first cost is a major issue, you might want to consider the new wireless sensor systems, which are easier to install. The sensor's field of view must be carefully selected and adjusted so it responds only to motion in the space served by the controlled lighting. For example, an occupancy sensor controlling lights in an office should not detect motion in the corridor outside the office. 


\section{F.1.5 Install photosensors and dimming ballasts to dim lights when daylighting is sufficient}

On bright, sunny days, the natural light available in classrooms, offices, gymnasiums, and other school facilities can make the use of electric lighting systems superfluous. A system that senses the light in a room (photosensor), and signals dimmable ballasts to lower lighting levels, or signals nondimming ballasts to shut off, can provide significant energy cost savings with no degradation of light levels. Using daylight saves energy and enhances learning. Controls can be expensive and disruptive to retrofit, but wireless control systems, which are easier to install and adjust, are becoming available. Daylighting systems need to be designed and commissioned carefully to avoid glare, overheating, and distracting changes in light levels (E Source 2005).

A photosensor/daylighting system provides several types of energy savings (U.S. Army Corps of Engineers 2010):

- Lighting energy. Dimmable lighting systems can save $25 \%-50 \%$ of the energy used by systems with nondimming electronic ballasts. Schools in areas that have frequent overcast days will experience lower savings.

- Cooling energy. Dimmable lighting systems reduce the energy required to air condition school facilities by reducing the run time of fixtures. Even efficient lighting systems produce heat when they are operating, so lower run time reduces the heat that must be removed by the air-conditioning.

- Demand charges. Dimmable lighting systems reduce kilowatt-hour use and can reduce peak demand charges. This may be especially significant in schools that are subject to demand-ratchet billing, in which the highest demand for a single hour sets the demand charge for a season or even a full year.

As with motion sensors, the disadvantages of photosensors are their installation costs, a small increase in heating costs, and the need for proper installation, calibration, and maintenance. When the sun is low on the horizon, some rooms may experience excessive glare from direct sunlight, which can be mitigated with retrofitted light shelves and/or window films.

\section{F.1.6 Replace metal halide high-intensity discharge lights with T5 or T8 high-output fluorescents in gymnasiums}

MH HID high-bay fixtures have been the preferred technology for school gym lighting for about 20 years, and many gyms have been retrofitted from incandescent or T12 fluorescent to MH systems. However, high-bay fixtures that use T5 or T8 HO lamps are supplanting MH (see Figure F-3), because they offer several advantages:

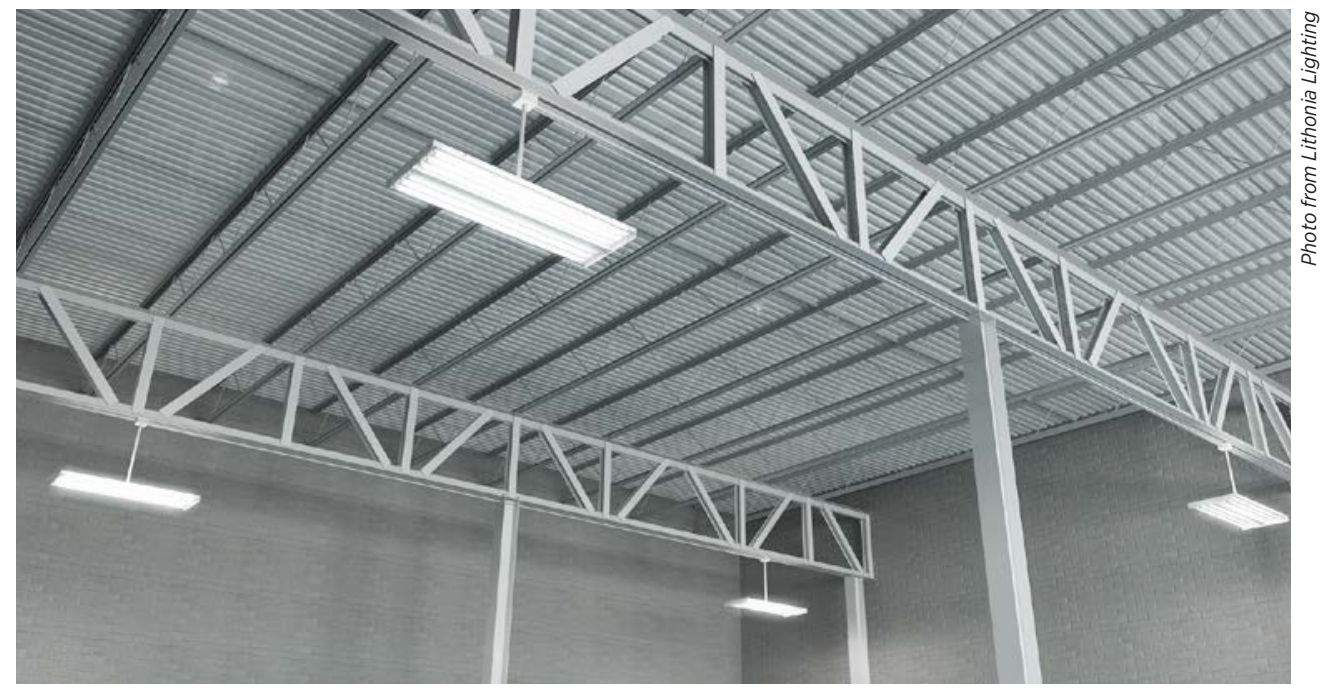

Figure F-3 T5 HO high-bay fixtures 
- Efficiency. T5 and T8 HO lighting systems produce more light per kilowatt-hour than most MH lighting systems. When the entire system (lamp and ballast) is taken into account, MH systems with electronic ballasts and HO pulse start lamps can be almost as efficient as T5 HO systems; however, MH fixtures with magnetic ballasts still lag far behind those with T5 HO lamps. Neither the T5 nor the MH system is as efficient as a high-performance T8 system.

- Stocking and maintenance. Retrofitting from MH to T5 or T8 can simplify lighting maintenance by reducing the number of lamp and ballast types that must be stocked (no $\mathrm{MH}$ ) and by allowing maintenance personnel to concentrate on fewer lamp types.

- Warmup versus instant-on. Fluorescent lamps provide virtually instant illumination and can be switched on and off as needed. MH lamps require 5-15 minutes to reach full output. This results in MH systems being left on, rather than being switched off, when the gym is empty during unused class periods, nights, and weekends.

- Controls. T5 and T8 systems offer more control options that can save energy: turning off some bulbs in a fixture rather than a whole fixture, dimming to take advantage of available daylight, and using motion or occupancy sensors to turn off fixtures. New technologies make it possible to dim MH fixtures, but their long restrike and warmup times limit the ability to shut them off when the gym is unoccupied.

- Light characteristics. T5 and T8 systems generally provide better color rendering than MH and less degradation of light output over time: about 5\% for T5 and T8 and 20\%-40\% for MH. Also, the color of an MH system output changes over time, which can be a problem if a single bulb must be replaced, and the new bulb casts a different color of light in an essential part of a gym that is used for interscholastic athletic events (e.g., over a basketball backboard).

\section{F.1.7 Install more efficient exterior lighting for façades and parking lot}

Careful attention to parking lot and exterior lighting systems can save significant energy, make the school grounds safer and more attractive, and, because schools are often located in residential neighborhoods, minimize the annoyance that exterior lighting often causes neighbors. Designing and implementing an optimal exterior lighting system, however, requires the expertise of a lighting design professional.

Several types of lighting systems - HID, T5 and T8 fluorescent, and LED - are suitable for outdoor lighting systems. Mercury vapor lights, which once were commonplace, are quickly becoming obsolete.

Many school facilities were either built before the modern set of lighting technologies were available, or did not use optimal lighting design. Parking lots and exterior façades were flooded with light on the theory that more light makes the school grounds safer. Modern design standards take into account a range of factors, including:

- Nighttime visibility. Parking lot lighting design should minimize glare for drivers and pedestrians, focusing more light on the driving lanes and less on the parking areas. The color of the light can also be a safety factor, as evidence shows that the whiter light from LEDs, T5s, and T8s provides more visibility than the yellowish light from high-pressure sodium lights.

- Safety. Illumination should be sufficient for visitors to have the impression of safety and to make the exterior façade of the facility welcoming rather than forbidding.

- Aesthetics. Façade lighting should accentuate the attractive architectural aspects of the facility.

- Light trespass and pollution. Using fixtures with appropriate hooding can minimize the trespass of light onto neighboring properties. Lowering the overall wattage of exterior systems and focusing the light where it is needed on the ground can limit the dome of light pollution that characterizes many public facilities. For more detailed information about this subject, consult the IESNA (2011) and DOE (2011c). 
- Controls. Computerized control systems and motion sensors can limit the run hours of exterior lighting systems and enhance security.

The major disadvantage is the capital cost of a new lighting system, and exterior lighting redesign is often postponed and made a component of a major school renovation. However, a standalone exterior lighting retrofit project may have a surprisingly short payback, depending on the amount of overlighting and lack of control in a current system, as well as local utility prices.

\section{F.2 Plug and Process Loads}

Plug and process loads are important contributors to energy consumption in schools - they include electric and gas loads such as computers, printers, laboratory equipment, machine shop equipment, refrigerators, and cooking appliances. Measures can be taken to reduce supplemental loads, which in turn can reduce the operating time and energy consumption of HVAC systems.

\section{F.2.1 Replace cafeteria appliances with ENERGY STAR models}

Replacing old appliances with new, ENERGY STAR models can save significant energy in K-12 school cafeterias. A wide range of appliances are used in a typical cafeteria, including ovens, fryers, griddles, steamers, dishwashers, refrigerators, freezers, and hot/cold holding cabinets (see Figure F-4).

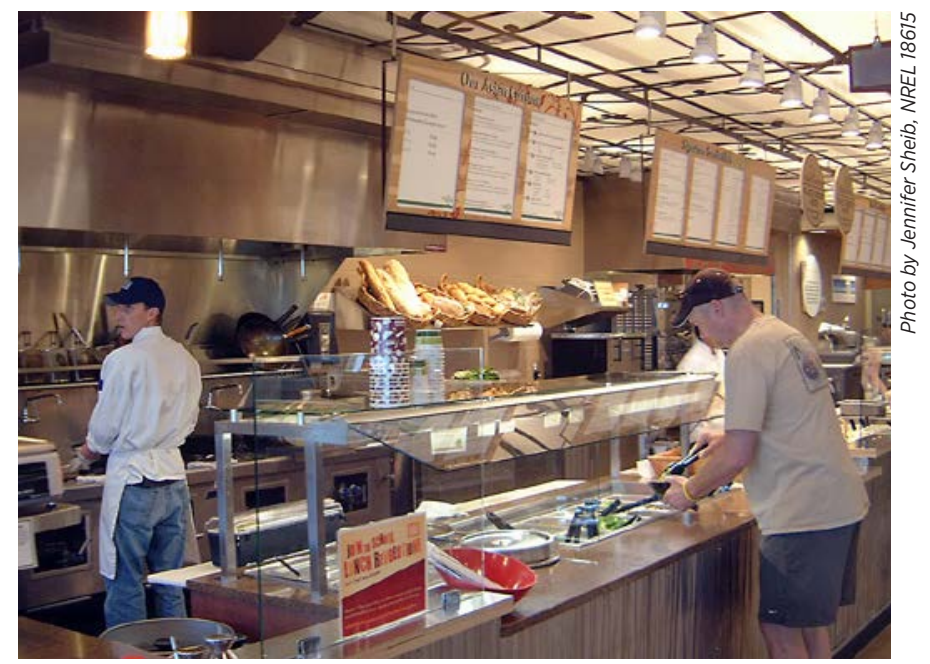

\section{Figure F-4 Cooking equipment and holding cabinets can offer excellent energy savings opportunities}

Outdated refrigerators and freezers (walk-in or freestanding) may be inefficient because they have old compressors, primitive controls, or failed door gaskets. They may also be poorly maintained or improperly located. Consider these factors when buying new refrigerators and freezers:

- It is important to purchase the right size for the school's needs and compare models on the basis of energy efficiency. Installing a larger unit than needed will waste energy.

- The units should be located so the ventilation system can remove the rejected heat.

- The units should be located away from stoves and other equipment that may leak heat. 
Inefficient cooking equipment wastes energy dollars directly and generates excess heat that adds to the load on the school's ventilating, air-conditioning, and refrigeration equipment. It can also increase worker fatigue. The cost effectiveness of replacing cooking equipment depends on the age and condition of existing equipment, the price of the replacement equipment, and the energy savings and utility rates. ENERGY STAR-rated cooking equipment comes with a wide variety of energy-efficient features, including computerized controls to automatically control the time to cook certain foods.

Convection and microwave ovens have become very energy efficient and do not require outside ventilation. The more efficiently these ovens cook the food, the greater the reduction in waste heat, smoke, odors, and grease vapors. Reducing these cooking by-products reduces ventilation requirements, consequently saving energy. Excessive ventilation wastes energy from running the ventilation equipment and conditioning the air that must replace the exhaust air.

ENERGY STAR-rated cooking equipment is more energy efficient and typically requires less O\&M than older cooking systems.

Antiquated dishwashing systems use large volumes of heated water and air. ENERGY STAR dishwashing systems reduce temperatures and pressures to the minimum required by health codes for cleaning and drying dishes. This equipment typically requires very little maintenance. Even with efficient equipment, it is important to run full rather than partial loads to avoid wasting energy and water. Depending on the size of the system, a wastewater heat recovery system may be a cost-effective addition to the dishwashing equipment.

\section{F.2.2 Install variable-speed drives for demand control of kitchen hood exhaust fans}

One of the most energy-efficient kitchen upgrades is improving the ventilation system. Installing a VSD on kitchen exhaust fans allows the ventilation system to respond to the actual load on the system, in contrast to the CV exhaust fans typically found in school kitchens. VSDs on exhaust fans are probably the most common energy improvements installed in school kitchens because they save a great deal of energy. These systems are often sold with a controls package and tend to require only moderate cleaning and maintenance, similar to other fan control systems. Sensors can also be installed that measure the amount of smoke and particulates from cooking and modulate the speed of the exhaust fan to match the emissions. The ideal control system monitors the exhaust and makeup air fans associated with the kitchen hoods to maintain proper air balance. In most cases, kitchen exhaust hood systems are equipped with a local override button. If the override button is used to return fans to full speed, a trouble alarm should be activated and sent to the appropriate school staff so the problem can be addressed. In most cases VSDs can improve the control of kitchen temperature conditions and can be integrated into the school's EMS, which constantly monitors the VSD and increases energy savings. 


\section{F.3 Building Enclosure}

The building envelope includes windows, doors, walls, the roof, and the foundation, and is important for controlling the movement of heat and airflow in and out of a building. OA can infiltrate a building through a variety of placesmost commonly the windows, doors, walls, and roof - but can be controlled through proper insulation and weatherization. Problems with the building envelope, such as insufficient insulation and air sealing, result in uncontrolled air and heat movement into and out of a building.

\section{F.3.1 Add a reflective roof covering}

Adding a reflective roof coating or installing a reflective roof membrane to a school building can minimize its heat gain and reduce its cooling loads (see Figure F-5). Reducing the temperature on the roof reduces the building's interior temperature, which saves cooling energy. Larger single-story school buildings in warmer climates, with high ratios of roof area to total facility square footage, will achieve the most energy savings if they operate during the summer. Cool roofs are not cost effective in all situations, but are most likely to pay off under one or more of the following conditions:

- The school has high air-conditioning use.

- The cooling season dominates energy consumption.

- There is little or no insulation.

- The climate is hot and sunny.

- The building is scheduled for reroofing.

Use the ENERGY STAR Roofing Comparison Calculator (ORNL and LBNL 2011) to help evaluate cool roofs for your school.

Solar reflectance is the most important characteristic of a roof coating product for saving energy. Another significant factor in the performance of "cool roofs" is the amount of energy that is released based on the heat that has been absorbed from the sun. In warmer climates where the cooling load is dominant, high emissivity helps reduce cooling loads; however, lower emissivity is preferable for buildings in colder climates as it reduces the heating loads.

An additional benefit of reflective roofing treatments is that the life of the roof may be prolonged by reducing the temperature of its components. To maintain reflectivity over time, the roof may need occasional cleaning. Otherwise, the roof maintenance should be similar to the maintenance of other roofs.

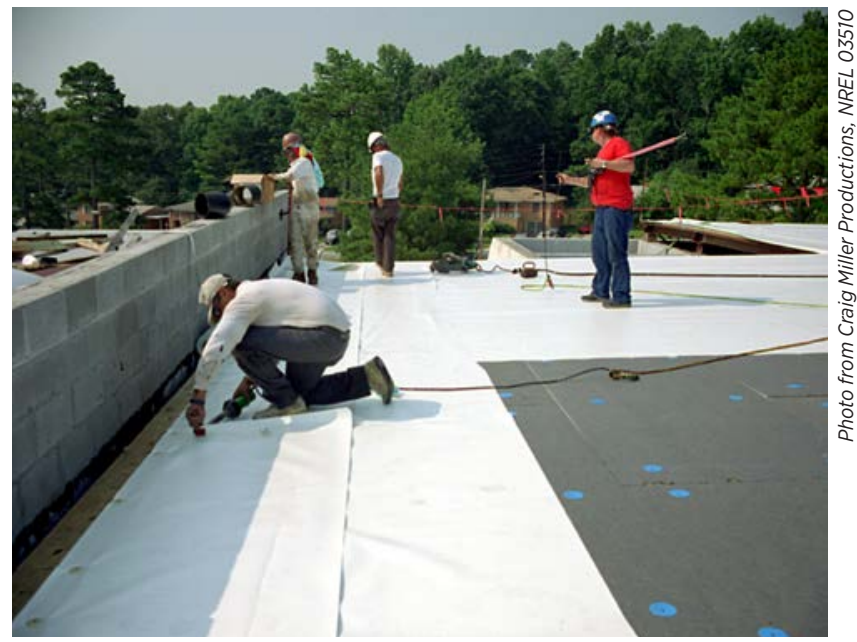

Figure F-5 Installation of a reflective roof membrane on a building in Atlanta 


\section{F.4 Service Water Heating}

Water heating accounts for approximately $10 \%$ of the energy use in K-12 schools (see Table 2-1), and is used primarily for cooking, hand washing, showering, and cleaning.

\section{F.4.1 Install low-flow showerheads in locker rooms}

An attractive opportunity to reduce the amount of hot water used in high schools is to install water-conserving, lowflow showerheads. User acceptance of high-quality replacement showerheads is very high and is a common EEM used in high schools.

Many older showerheads may use as much as $5 \mathrm{gal} / \mathrm{min}$ of hot water. Current federal standards require that showerheads use no more than $2.5 \mathrm{gal} / \mathrm{min}$ and some low-flow showerheads work effectively at a $1.75 \mathrm{gal} / \mathrm{min}$ flow rate. The following considerations are important in selecting a low-flow showerhead:

- The showerhead should deliver sufficient pressure with a nonaerating spray to properly rinse long hair. Nonaerating spray reduces heat loss and increases shower comfort. If the flow rate is too low, the length of a shower might be extended, which defeats the purpose.

- The showerhead should compensate for fluctuations in water pressure so it conveys a consistent spray velocity over a wide range of water pressures for effective performance.

- The showerhead should have a sediment filter that prevents line debris from clogging the showerhead. Ideally, the showerhead should have a self-cleaning spray adjustment that helps maintain performance over time.

The cost effectiveness of showerhead replacement depends on the cost of the showerheads and the amount of water and energy savings resulting from the installation. For schools that have hard water, a water softening system should be installed to reduce mineral buildup in the plumbing that could decrease the performance of the showerheads and to reduce the run time of showers (hard water requires a longer rinse time). Properly installed showerheads with a well-maintained plumbing system should require very little maintenance.

\section{F.5 HVAC: Heating and Cooling}

Heating and cooling systems combined account for more than 50\% of a typical school's energy consumption (see Table 2-1), making them a major target for substantial energy savings. When systems are approaching the end of their useful lives, consider replacing them with high-efficiency systems. For example, replace a standard furnace with a high- efficiency condensing furnace. Upgrades to heating and cooling systems are best implemented after other steps have been taken to reduce loads. New equipment sized to meet the new loads can be smaller and less costly, and will operate more efficiently. Numerous other EEMs can be cost effective even before the existing heating and cooling equipment reaches the end of its useful life. Some of these EEMs are discussed in the following sections.

\section{F.5.1 Add evaporative cooling of condenser supply air}

Most cooling systems for schools include a rooftop condenser unit (see Figure F-6). In hot and dry climates, condenser coils can be evaporatively cooled. The water evaporation lowers the temperature of the condensing coil, which increases the efficiency of the cooling system. Evaporative cooling works best during hot days with low humidity. It is typically used in very dry climates, because the higher the humidity level the less evaporation takes place and the less cooling can be provided to the condenser coil. 
An alternative approach is to install an evaporative coil in the condenser supply airflow upstream of the condenser coil. This lowers the air temperature and increases the heat transfer from the condenser coil.

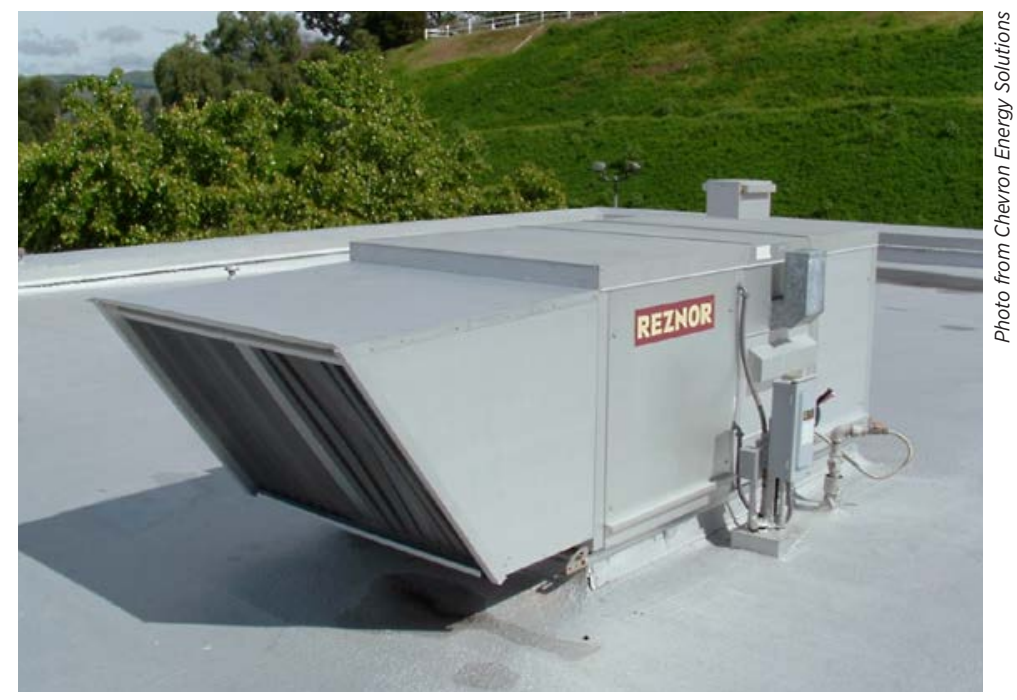

Figure F-6 Typical rooftop condenser

Evaporative cooling systems can also save considerable energy compared to a cooling system that is completely refrigerant based. Water costs and mineral buildup on condenser coils cause maintenance concerns. The LCC of evaporative cooling equipment must be carefully evaluated relative to the predicted energy savings.

\section{F.5.2 Add a small condensing boiler to handle the base load and summer load, with current inefficient boiler operating when heating loads are highest}

Operating old oversized boilers, which usually run at $60 \%$ of design capacity, is an inefficient method for schools to produce heat. Adding a small condensing boiler for base heating loads (hot water and reheat), or replacing these boilers with multiple, cascading, high-efficiency near-condensing or condensing boilers can be very cost effective. A typical boiler system is shown in Figure F-7.

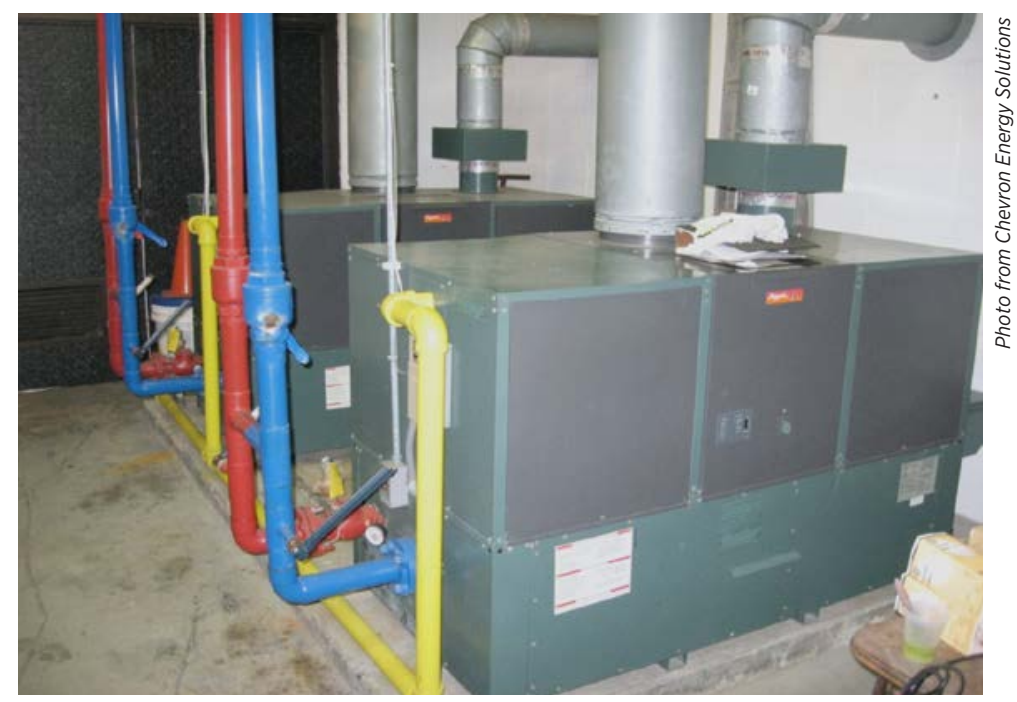

Figure F-7 Boiler used for space heating in a school 
Staged, energy-efficient boilers offer several advantages:

- The combustion efficiency of a modular boiler is $88 \%-94 \%$, compared to the $70 \%-80 \%$ for a typical large boiler.

- A modular boiler system allows for staging the system to fire only the number of boilers required to meet the heat load at a particular time, eliminating the inefficiency of firing an large oversized boiler for small or medium heating loads.

- A modular boiler system has built-in redundancy with excess capacity in the event one of the small boilers fails.

- A modular boiler system increases the efficiency and flexibility of the heating system. If additions are built on to the school, boilers can be added with minimal changes to the heating plant.

- A modular boiler can also be used to make domestic hot water with the addition of a storage tank. There are more pieces of equipment to maintain with this strategy, but most of the small units will be identical.

The disadvantages of modular boiler systems include:

- The scheduling and sequencing should be rotated so the number of operating hours on each unit can be equalized to reduce maintenance costs. This requires detailed operating control of the system, which can be done by an automated boiler control system.

- High-efficiency condensing boilers require water treatment and maintenance to ensure long-term performance. They may require more frequent replacement because of breeching from condensation. Because they cannot operate in the condensing mode much of the time when return water temperatures are too high, near condensing small package boilers ( $88 \%$ efficiency) may provide most of the energy savings with lower maintenance costs. Sometimes a combination of condensing and near-condensing boilers may be the optimum combination.

- Small boilers cannot accept variable water flow. But a system with both primary and secondary pumping loops can be used to maximize energy savings. Installing a VSD on the secondary building loop pump (which is connected by a hydronic bridge to the primary boiler pumping system) allows the building loop pump to vary pumping speed according to heat load requirements. Energy savings result from lower pumping horsepower, lower water temperatures, and higher combustion efficiency.

- The condensate from condensing boilers is acidic and may require water treatment for proper maintenance to protect the plumbing drain that collects the condensate. It is a good strategy to obtain an outside contract for water treatment, unless your staff can be trained to provide the treatment protocol required by the manufacturer.

\section{F.5.3 Install variable-speed drives on chilled-water and hot water pumps}

CV pumping circulates the same amount of chilled or heated water through the system, even when the load does not require it. A VSD allows the building to vary the volume of circulating chilled water as the cooling load varies. Installing a VSD to modulate pump speed, combined with a NEMA premium efficiency motor and two-way valves at each coil, can dramatically reduce pumping costs and the energy costs to make chilled water. It can also improve temperature control in the conditioned space. Similar benefits accrue for hot water pumps used for space heating.

As with other HVAC modifications, an engineer should quantify the cooling load to correctly design and size these modifications to the cooling system. The level of maintenance on these VSDs is similar to that of a VAV air handling system (see Section F.5.7). The economics of this EEM will depend on the magnitude and variability of annual cooling and heating loads, and local electricity costs. 


\section{F.5.4 Replace standard furnace with a high-efficiency condensing furnace}

Fuel-burning furnaces are rated in terms of annual fuel utilization efficiency, a percentage rating of expected performance equal to the Btu of heating output divided by the Btu of fuel input during a representative heating season. The annual fuel utilization efficiency, takes into account heat losses up the chimney, the effects of cycling the unit on and off, and losses through the furnace housing. The annual fuel utilization efficiency, of a condensing furnace should be at least $90 \%$.

The unit must be sized correctly so it delivers the proper amount of heating and ventilation for the space. Too large a unit will waste energy and too small a unit will not be able to maintain comfortable temperatures. An engineer should calculate the heat load of the building to ensure that the furnace is properly sized. A high-efficiency condensing furnace may exhaust flue gas at a low enough temperature that allows it to be vented through a wall rather than a chimney.

As with a condensing boiler, the condensate generated by a condensing furnace is acidic and may require water treatment. Condensing furnaces may also be noisier than conventional furnaces, so it is important to consider the acoustics of their location.

\section{F.5.5 Install an energy management system and replace pneumatic controls with direct digital controls}

An EMS provides schools with automatic programmed controls that can manage temperature and equipment operating schedules. An EMS consists of a computer, software to monitor and manage equipment performance and equipment schedules, sensors and controls, and a communications network.

There are two general types of EMS: pneumatic and DDC. Pneumatic controls found in older systems do not supply the level of reliability and accuracy that DDC provides. Pneumatic controls depend on a properly functioning air compressor and clear air lines (rather than electronic signals), which require continuous maintenance. Using DDCs instead of pneumatics reduces long-term maintenance costs. There is a cost premium to replace all the pneumatic controls with DDCs, which should be compared to the expected energy and maintenance savings from a new DDC system. Sometimes a hybrid system may be the best economic choice.

Advances in EMS technology have reduced costs and increased system capabilities. A significant advantage for a school EMS is that the system can control equipment and scheduling more reliably and precisely than manual controls. An EMS can also provide equipment monitoring data and track indoor and outdoor temperatures, which allow the operating schedules of HVAC equipment to be optimized. These capabilities save energy, improve comfort conditions, and trigger automatic diagnostic alarms when equipment is operating outside its correct schedule or temperature set points. Proper EMS programming that is checked to verify functional control of the equipment and energy management strategies is a requirement for effective system performance.

An EMS is most effective when the school's operating staff is trained to use its capabilities. It must be monitored regularly to make sure the programmed schedules and settings are up to date and that the energy management strategies are working. Be sure to select a system that school staff can be effectively trained to operate or obtain a service contract to support system operation. One weakness of an EMS is that it requires appropriate operator action in response to some of the data on equipment performance. Operator indifference or lack of awareness and response to significant data provided by the EMS reduces its value as an energy savings strategy. Operator interference or error can compromise system schedules or set points. For example, if the EMS is temporarily changed to accommodate a schedule variation and is not reset to its proper settings, energy savings can be lost. 
The energy savings available from an EMS in K-12 school facilities are usually less than $10 \%$ of total building energy consumption. It depends on the operational status and manual control of the equipment before the EMS is installed. For example, a small school building with a rigorous manual control system may not realize significant savings from a new EMS. An EMS may, however, provide significant O\&M savings for school districts with many buildings that are spread over a large area. Multiple buildings can be operated by a single integrated EMS. This allows maintenance staff to remotely monitor the operation of equipment from a centralized location and to make adjustments to control settings without having to physically visit the buildings linked to the system.

\section{F.5.6 Replace oversized, inefficient fans and motors with rightsized NEMA premium efficiency models}

Motor efficiency is the ratio of mechanical power output to the electrical power input and is usually expressed as a percentage. Improvements in the design and the use of higher quality materials enable premium efficiency motors to accomplish more work per unit of electricity used. Additionally, premium efficiency motors have longer service lives, longer insulation and bearing lives, lower waste heat output, and less vibration, which increase the reliability of motor performance. Many motor manufacturers also offer longer warranties for energy-efficient models.

In most schools, new premium efficiency motors are selected to replace older motors of 5 horsepower and higher. It is usually a good idea to retain a professional engineer to assist in a motor replacement project, because projects usually involve more than just a one-for-one swap of old motors for efficient motors. For example, the most common reason for motor replacement is that the existing motor will not accept VSD control. Using a premium efficiency motor in a VSD system is important, but correctly sizing the motor to the load is even more critical. In many schools, old motors were originally oversized, so can be replaced by motors with lower horsepower ratings.

High-efficiency motors may also run somewhat faster than standard motors. When powering loads such as fan or pumps, the higher speed can increase energy use. To avoid this, when replacing a standard motor with a high- efficiency one, the engineer will match the motor speed in rotations per minute as closely as possible to the old motor, or compensate for the increased speed by adjusting fan sheaves or trimming pump impellers.

The economics of motor replacement depend on the age, condition, operating hours, and size of the existing motors and the electricity cost for motor operation. In general, the cost effectiveness is there only when an old motor fails. To be considered a premium efficiency motor, its performance must equal or exceed nominal full load efficiency values established by NEMA (2011).

\section{F.5.7 Convert a constant volume or dual-duct air handling system to variable air volume}

$\mathrm{CV}$ fan systems waste energy by moving excessive amounts of hot or cold air to maintain zone set point temperatures. By installing VSDs on fan motors, the speed of the motors can be controlled so that the system provides only the appropriate amount of air and heat to meet the space temperature and ventilation needs. As the amount of air volume moved by the fan system decreases, the amount of electrical energy required decreases dramatically. Not only is fan energy reduced, but the amount of energy needed to heat or cool the air is decreased.

Some advantages for schools to use the VAV approach are individual room temperature controls, proper OA ventilation, better temperature control, quiet operation, and energy efficiency. VAV systems are robust and flexible, and with appropriate dampers will adjust to the room conditions to provide the proper volume and temperature of air to satisfy the heating or cooling load in the space. As the temperature reaches room set point, the air volume adjusts to its preset minimum flow to provide the necessary ventilation. 
Some potential disadvantages of VAV systems include inadequate air circulation at low loads, and poor reliability caused by inadequate maintenance and increased complexity of controls. These systems are most economic when the system that was replaced was an oversized CV system with excessive run times.

\section{F.5.8 Install variable-speed drives on cooling tower fans}

VSDs can be applied to cooling tower fans and other cooling system components to better match the speed of equipment operation to the actual loads on the cooling system. Having a VSD on school cooling tower fans will allow for improved control, which will significantly increase energy efficiency. ASHRAE studies have shown that adding VSDs to cooling towers is frequently a cost-effective EEM. Taylor (2011) wrote an article examining the impact of cooling system controls.

\section{F.6 HVAC: Ventilation}

Ventilation accounts for about 9\% of an average school's energy consumption. It is critical for IAQ, and a specific amount is required to meet the ASHRAE 62.1 (ASHRAE 2010) ventilation standards for K-12 schools.

\section{F.6.1 Install a dry-bulb airside economizer}

Economizers are some of the simplest devices to install in school HVAC systems. When the OA is cool enough and there is a demand for cooling in the school, economizers can use the OA to cool the space by opening and closing dampers installed in the air handling equipment. One damper opens to the outside and the other reduces the return air to the unit, which makes the unit draw in more OA. Most of the savings from an economizer system occur during the shoulder months when there is a cooling load and outdoor temperatures and humidity levels are low enough to provide free cooling.

The most common way to determine whether the $\mathrm{OA}$ is cool enough for economizer operation is to install an outdoor dry-bulb temperature sensor to control the changeover to economizer operation. This approach works most effectively in areas that have low outdoor humidity. In more humid regions, the dry-bulb temperature setting must be adjusted to a lower level for effective economizer operation, because a wet-bulb system that senses both temperature and humidity is generally too expensive.

The OA sensor must be properly located for optimal economizer performance. When the system enters economizer mode, dampers adjust based on sensors mounted in the mixed air stream to modulate the return and OA dampers, mixing the two air streams to supply air at about $55^{\circ} \mathrm{F}$.

The more OA that can be used for cooling, the longer the cooling compressor can remain off, which saves energy. The economizer can actually extend the life of a well-maintained cooling system.

The primary limitation of using the economizer strategy is the humidity level of the OA. When relative humidity is too high, excess moisture can be brought into the building, resulting in uncomfortable conditions and increased load on the cooling system. Savings achieved vary by climate: moderate climates save more and hot or humid areas save considerably less. 


\section{F.6.2 Upgrade to demand control ventilation to reduce outdoor air flow during partial occupancy}

In large school spaces such as auditoriums, gymnasiums, and cafeterias, the occupancy is highly variable, which results in a very wide range in the required OA ventilation rate. Two or three people in a large space require much less fresh air than do 200-300 people. A system that varies the ventilation based on occupancy can be a substantial energy saver because the amount of OA that must be heated or cooled is reduced during hours of low occupancy. It also reduces the need to manage the humidity impacts of excessive OA ventilation. As the number of occupants in the space increases, the $\mathrm{OA}$ increases to provide the ventilation required by code.

Measured $\mathrm{CO}_{2}$ provides a reasonably good indicator of the number of people in a space. $\mathrm{CO}_{2}$ levels can be measured by sensors and used to regulate the amount of OA ventilation that is needed. One strategy is to locate $\mathrm{CO}_{2}$ sensors in the return duct for the air handlers that serve those spaces. More sophisticated systems can sample from several locations and calculate a weighted average of the $\mathrm{CO}_{2}$ concentration in each zone. The $\mathrm{CO}_{2}$ sensors should be self-calibrating so they maintain accuracy over time. The readings of $\mathrm{CO}_{2}$ levels can also be integrated into an EMS, which provides control signals to the ventilation equipment. Whenever the sensors indicate higher $\mathrm{CO}_{2}$ levels, ventilation with $\mathrm{OA}$ is increased to reduce the $\mathrm{CO}_{2}$ levels. This provides a very flexible control strategy that is based on occupant comfort and health. When replacing unit ventilators it may be worthwhile to include a $\mathrm{CO}_{2}$ sensor to control OA ventilation.

Today's high-quality $\mathrm{CO}_{2}$ sensors are very durable and require little maintenance; however, periodic testing to verify the calibration of $\mathrm{CO}_{2}$ sensors is advisable. The primary variables that determine cost effectiveness are the relative costs of heating and cooling and the amount by which OA ventilation can be reduced in the controlled zones.

\section{F.6.3 Add energy recovery to the ventilation system}

ERVs exchange heat and moisture between OA and exhaust air, which means less energy is required to heat or cool the building. Energy transfer is typically done with an energy recovery wheel that rotates between the exhaust air and supply air in an ERV cabinet. ERV equipment can reduce infiltration of air contaminants from the outdoors and significantly reduce HVAC loads (EPA 2003a).

In winter, as exhaust air passes through the ERV, its energy is captured and transferred into the incoming air stream to heat and humidify the incoming air closer to required indoor air conditions. This reduces the load on the heating system. When cooling is required, heat and humidity are captured from the OA and transferred to the cooler and drier exhaust air as it passes through the ERV. This reduces the energy consumed by the cooling system. An

EEMs With Largest Energy Savings in Example Building

1. Replace $\mathrm{T} 12$ fluorescent lamps and magnetic ballasts with high-efficiency T8 lamps and instant-start electronic ballasts.

2. Add energy recovery to the ventilation system.

3. Upgrade to DCV to reduce OA flow during partial occupancy.

ERV that reduces the HVAC system load also reduces the heating and cooling capacity needed, allowing the school to buy smaller units when it is time to replace the boiler, furnace, or chiller. An ERV can also improve IAQ, especially through humidity control.

The economics of an ERV depend on how much energy can be saved in the cooling and heating modes. Energy recovery wheels are designed to last for the life of an HVAC system with minimal maintenance. ERVs should not be installed close to rooftop sources of pollution (plumbing vents, exhaust fans, etc.). 


\section{F.7 Additional Energy Efficiency Measures for Consideration}

Industry experts identified the preceding EEMs as the most likely to be significant energy savers. These are cost effective in a variety of situations, but many other retrofit EEMs may provide strong financial returns under the right circumstances. Every school has unique opportunities, and it is important to keep an open mind about potential building improvements. Several additional ideas for retrofit projects are listed in Table F-2. Many other possibilities can be found in the various guides and handbooks listed in Section 4.7.

Table F-2 Additional EEMs That Should Be Considered

\begin{tabular}{|c|c|c|}
\hline System & EEM Description & $\begin{array}{l}\text { Analysis Performed in } \\
\text { Example Building? }\end{array}$ \\
\hline \multirow{9}{*}{ Lighting } & $\begin{array}{l}\text { Replace lighting system with a more efficient approach (reduced ambient } \\
\text { light, greater use of task lighting, indirect T-5 fixtures in place of direct T-12 } \\
\text { fixtures) }\end{array}$ & No \\
\hline & Add skylights to increase daylighting & No \\
\hline & $\begin{array}{l}\text { Install exterior automated louver shading systems on all sun-exposed } \\
\text { windows }\end{array}$ & No \\
\hline & Install more efficient auditorium lighting & No \\
\hline & $\begin{array}{l}\text { Install tubular daylighting devices in classrooms, offices, corridors, and } \\
\text { restrooms (must be bundled with photosensor controls for electric lighting) }\end{array}$ & No \\
\hline & Add windows to increase daylighting & No \\
\hline & Replace electric exit signs with photoluminescent & No \\
\hline & $\begin{array}{l}\text { Lighten parking surface color to increase surface reflectance, reducing } \\
\text { lumen requirements from electric lighting. }\end{array}$ & No \\
\hline & $\begin{array}{l}\text { Install interior light shelves in classrooms to increase daylighting and } \\
\text { reduce glare (must be bundled with photosensor controls for electric } \\
\text { lighting) }\end{array}$ & No \\
\hline $\begin{array}{l}\text { Plug and } \\
\text { process loads }\end{array}$ & Add "smart" switches to classrooms to minimize vampire loads & No \\
\hline \multirow{7}{*}{$\begin{array}{l}\text { Building } \\
\text { enclosure }\end{array}$} & Add an exterior insulating finish system (EIFS) to exterior walls & Yes \\
\hline & $\begin{array}{l}\text { Replace or retrofit windows and frames with double paned low-e, } \\
\text { aluminum framed windows with reduced air leakage }\end{array}$ & Yes \\
\hline & Install vestibules with inner and outer revolving doors & Yes \\
\hline & Add rigid insulating sheathing to roof assembly & Yes \\
\hline & Add clear high performance low-e film to existing windows & No \\
\hline & Make windows operable to allow for free ventilation and cooling & No \\
\hline & Add slab insulation & No \\
\hline \multirow{2}{*}{$\begin{array}{l}\text { Service water } \\
\text { heating }\end{array}$} & $\begin{array}{l}\text { Replace storage water heaters with high efficiency condensing tankless } \\
\text { water heaters }\end{array}$ & No \\
\hline & Install solar preheating for domestic hot water & No \\
\hline
\end{tabular}


Table F-2 Additional EEMs That Should Be Considered (cont'd)

\begin{tabular}{|c|c|c|}
\hline System & EEM Description & $\begin{array}{l}\text { Analysis Performed in } \\
\text { Example Building? }\end{array}$ \\
\hline \multirow{8}{*}{$\begin{array}{l}\text { HVAC: Heating } \\
\text { and cooling }\end{array}$} & $\begin{array}{l}\text { Replace air or water-cooled heat pump with a right-sized ground source } \\
\text { heat pump }\end{array}$ & No \\
\hline & $\begin{array}{l}\text { Supplement DX cooling system with an indirect evaporative cooler sized to } \\
\text { meet small and medium cooling loads (in dry climates only) }\end{array}$ & No \\
\hline & $\begin{array}{l}\text { Replace standard boilers with right-sized high efficiency condensing } \\
\text { boilers }\end{array}$ & No \\
\hline & $\begin{array}{l}\text { Replace single large boiler with several smaller, staged standard efficiency } \\
\text { boilers }\end{array}$ & No \\
\hline & $\begin{array}{l}\text { Replace DX cooling system with more efficient right-sized model with } \\
\text { evaporative condenser }\end{array}$ & No \\
\hline & Install chilled beam cooling system & No \\
\hline & Install radiant rigid insulation board behind radiators & No \\
\hline & Install individual room temperature controls & No \\
\hline \multirow{3}{*}{$\begin{array}{l}\text { HVAC: } \\
\text { Ventilation }\end{array}$} & $\begin{array}{l}\text { Install dedicated outside air systems (DOAS) with high-efficiency heat } \\
\text { recovery, reducing the heating, cooling, and dehumidification loads }\end{array}$ & No \\
\hline & Convert to displacement ventilation system (where ceilings are over 9 feet) & No \\
\hline & Install or restore interior transoms for cross ventilation & No \\
\hline
\end{tabular}




\section{Appendix $\mathbf{G}$ \\ Integrated Design Principles for Retrofit Projects}

This appendix provides principles of integrated design for more aggressive school retrofits in combination with a comprehensive renovation, allowing a much wider range of opportunities and higher potential energy savings than a typical retrofit project. Recommendations are presented for both the entire school and for individual building subsystems. Integrated design is essential when pursuing an aggressive energy savings target. Much of the material in the following sections was developed for this AERG by Rocky Mountain Institute as part of its RetroFit Depot initiative. A comprehensive discussion of this process can be found at www.retrofitdepot.org/.

\section{G.1 Overview: The Right Steps in the Right Order}

Investing in greater efficiency and load reduction can actually eliminate significant costs by downsizing, or even eliminating, mechanical systems - an occurrence known as "tunneling through the cost barrier" (Lovins et al. 1999). Take these general steps to reap the greatest energy savings and to realize multiple benefits from single expenditures:

1. Define the specific end user needs. What do the building occupants need and what services do they require? Start from the desired outcomes: think of purpose and application before equipment. Think of cooling, not chillers; a hole, not a drill; then ask why you want the cooling or the hole. How much energy (or other resource), of what quality, at what scale, from what source, can do the task in the safest and most cost-effective way?

2. Understand the existing building structure and systems. Understand and assess the current state of the school building. What needs are not being met? Why not?

3. Understand the scope and costs of planned or needed renovations. What systems or components require replacement or renovation for nonenergy reasons? What are the costs of interruptions to service or occupancy?

4. Reduce loads. Select EEMs to reduce loads:

a. First, through passive means (such as increased insulation)

b. Then, by specifying the most efficient non-HVAC equipment and fixtures.

5. Select appropriate and efficient HVAC systems. After reducing loads as much as possible, consider what HVAC system types and sizes are most appropriate to handle these drastically reduced loads.

6. Find synergies between systems and EEMs. Seek synergies across disciplines and find opportunities to recover and reuse waste streams. Through this exercise, you can often realize multiple benefits from a single expenditure.

7. Optimize controls. After selecting the most appropriate and efficient technologies, focus on optimizing the control strategies.

8. Realize the intended design. Tune the OPRs and implement $M \& V$ and continuous commissioning to ensure the intended design is realized. $M \& V$ will also help staff prevent problems, ensure correct diagnosis, and permit monitoring to improve operation and future retrofit work, and to educate students and teachers. 


\section{G.2 Lighting (Daylighting and Electric)}

In a whole-building retrofit, opportunities to reduce lighting energy use and improve student and staff visual comfort extend well beyond lamp switch-outs, delamping, or installing occupancy sensors. Take advantage of efforts already being invested into the envelope, fenestration, and interior programming to also dramatically improve daylight performance, electric lighting performance, and complementary interior design. A comprehensive lighting retrofit can result in a dramatically more appealing space, an improved visual environment that meets the needs of students and staff, significant energy savings, along with multiple benefits of controlling solar heat gain and reducing cooling loads.

\section{G.2.1 Define Needs-Identify Visual Task Requirements}

More light does not necessarily equate to better vision. Providing a comfortable visual environment is about tuning that environment to specific tasks at hand. You may be surprised that, for the most part, light level requirements in a school are actually quite low. The following criteria are as critical as providing adequate light levels:

- Light distribution. Are light levels pleasantly and evenly distributed throughout spaces, or are there uncomfortable dark corners and high contrast areas?

- Glare. Is it easy for students to focus on the blackboard, computer monitors, desktops, and other tasks at hand, or do specific lighting fixtures or direct sunlight cause distracting brightness or reflections?

DiLaura et al. (2011) provide detailed lighting guidelines to address different visual tasks in typical school space types. Take a light meter into different spaces to understand current light levels and distribution. As a starting point, consider the important qualitative visual needs listed in Table G-1. Talk to school staff to find out how well these visual needs are being met and identify major deficiencies that should be addressed along with energy efficiency.

\section{Table G-1 Visual Needs for Space Types in K-12 Schools}

\begin{tabular}{|l|l|l}
\hline \multicolumn{1}{|c|}{ Space Type } & \multicolumn{1}{c}{ Visual Programming Need } \\
\hline $\begin{array}{ll}\text { - Adequate and evenly distributed ambient light levels for simple visual tasks, typically } \\
\text { reading and writing, which tend to be concentrated on horizontal (desktop) and } \\
\text { vertical (blackboard) surfaces. } \\
\text { - Could require different light level control depending on activity being performed } \\
\text { (audiovisual presentation, exam-taking, etc.). } \\
\text { - Could require different light level control depending on occupant age. This is } \\
\text { especially relevant for classrooms that double as education spaces for adult } \\
\text { continuing education, etc. }\end{array}$ \\
\begin{tabular}{|l} 
- Ability to minimize glare, especially for viewing blackboards and monitors. \\
Specialized classrooms \\
(e.g., labs, woodshops)
\end{tabular} & $\begin{array}{l}\text { Could require task lighting in strategic locations to provide adequate visual clarity for } \\
\text { the use of specialized or dangerous equipment. }\end{array}$ \\
\hline $\begin{array}{l}\text { Interior and exterior } \\
\text { circulation spaces }\end{array}$ & $\begin{array}{l}\text { - Low-contrast visual environment to promote safety. } \\
\text { - Adequate visual cues for wayfinding. }\end{array}$ \\
\hline $\begin{array}{l}\text { Large mixed-use spaces } \\
\text { (e.g., auditoriums, theaters, } \\
\text { gymnasiums, cafeterias) }\end{array}$ & $\begin{array}{l}\text { - Could require the option to choose between different light settings, depending on } \\
\text { the activity (e.g., school dance or performance versus general public assembly). }\end{array}$ \\
\hline
\end{tabular}




\section{G.2.2 Design Strategies and Energy Efficiency Measures To Reduce Loads}

\section{Optimize Passive Daylighting}

Effective daylighting can meet most visual needs in typical schools, and can add delight and variation to aesthetically challenged spaces, transforming how students perceive their environment, and impacting how well they learn. A growing body of case studies and literature supports the correlation between improved daylighting and improved student performance (Plympton et al. 2000).

Maximize daylight as the primary source of ambient light in regularly occupied spaces to minimize the use of electric lights. In many schools, perimeter classrooms are shallow (less than $30 \mathrm{ft}$ deep) and are therefore great candidates for having $100 \%$ of lighting needs met with daylight. That said, in most retrofits, we inherit the pros and cons of existing building orientation, massing, and window count and placement. The first step is to consider the geometric proportions of spaces in relation to existing windows and skylights. Then, search for opportunities to improve daylight penetration and distribution throughout regularly occupied areas despite those limitations.

DiLaura et al. (2011) and Egan and Olgyay (2002) provide detailed practical guidance on daylight design.

To use daylight, we must first let it into the building through openings in the envelope such as windows, skylights, and light tubes. If you are already considering a retrofit to sections of the envelope (for example, to add insulation on the exterior walls or roof, or to reconfigure RTUs and equipment), it could be a good opportunity to piggyback off required service interruptions or construction to add, resize, or reconfigure envelope apertures.

Strategic sizing and placement of windows are important for balancing visual with thermal performance. Remember, bigger and more are not always better. Toplighting can be a good solution in situations where immovable interior walls or deep floor plates prevent natural sidelight from reaching core spaces (see Figure G-1 for an example). Consider that, properly designed, only $3 \%-5 \%$ of roof area needs be dedicated to skylights to daylight $100 \%$ of the adjacent space below. For budgets or existing conditions that cannot incorporate skylights, consider light tubes to bring toplighting to multiple floors below. Minimize roof penetrations by bundling tubes with vertical shafts, columns, or other multifloor penetrations. For retrofits involving a major interior reconfiguration, consider light wells or atriums to bring light to core spaces and provide a connection to and welcome views of the outdoors.

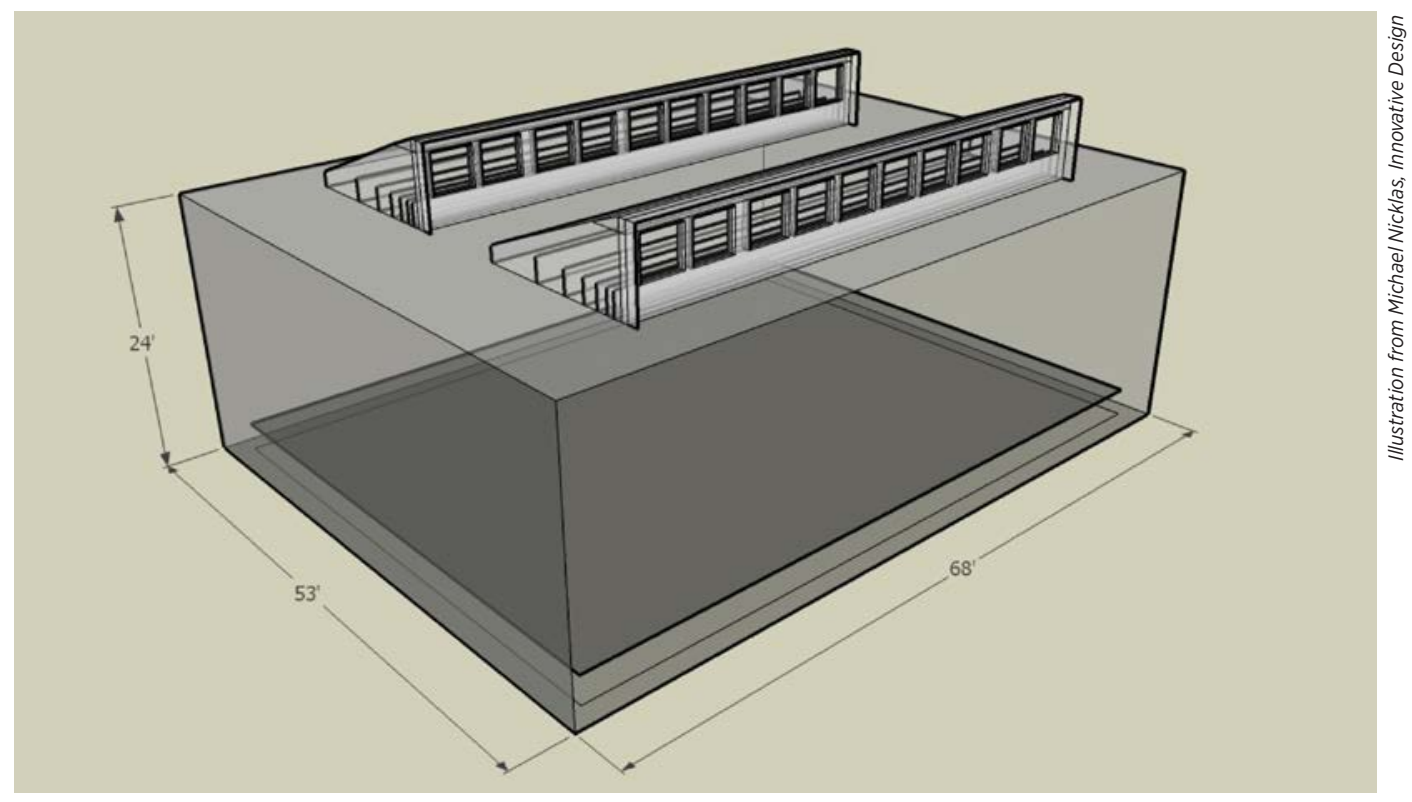

Figure G-1 Indirect toplighting using sawtooth design 
Adding or retrofitting exterior shading devices. Exterior shading devices can help control solar heat gain and glare, and intentionally redirect light to ceilings and other interior surfaces for improved distribution. Adding or retrofitting exterior shading devices can help "fix" existing windows that let in too much or too little solar heat, or compromise visual comfort with excessive glare. Consider structural requirements and limitations of the existing envelope when selecting and detailing exterior shading devices. One concept using an exterior overhang and louvers to distribute daylight deep into a classroom is shown in Figure G-2.

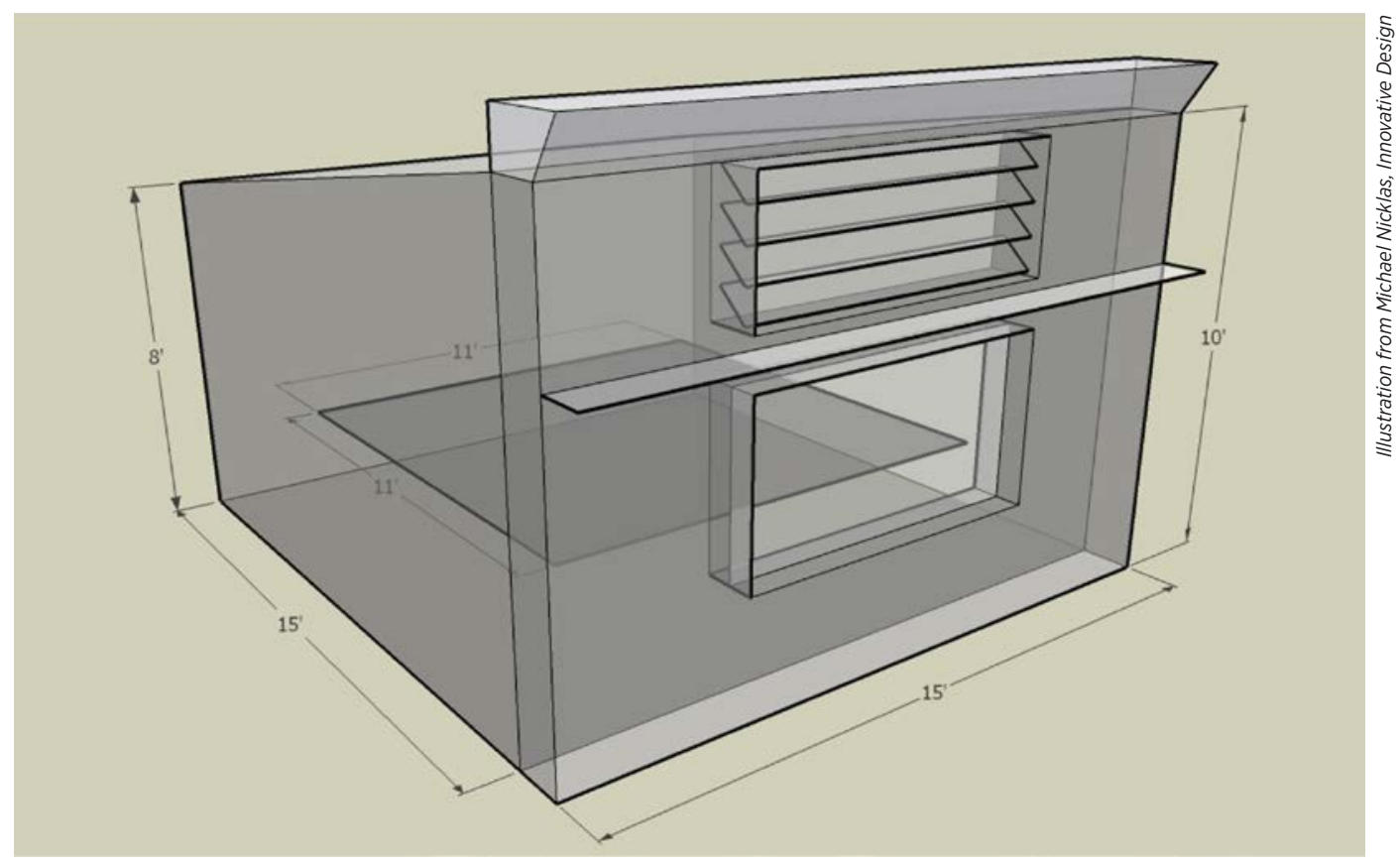

\section{Figure G-2 Daylighting enhancement using a light shelf with louvers for top section of the window}

Replacing or retrofitting glazing in existing windows. Careful glazing selection can also help balance the visual and thermal properties of sunlight entering the building. Glazing EEMs to consider include:

- Switch out existing glazing for glass with an improved solar heat gain coefficient (SHGC) and visible light transmittance.

- Improve glazing performance by adding a second or third pane or gas fill.

- Add a film to the window.

Because northern light is diffuse in the northern hemisphere, concentrate your retrofit efforts on south-, east-, and west-facing glazing where they will have the most advantageous impact on electric lighting and heating/cooling loads.

Interior spaces can be shaped and configured to help redirect light, optimize light distribution and illuminance levels, and reduce glare. When changes to windows and exterior shading are possible, relatively inexpensive interior improvements can help make the most of your envelope investments. Even exclusive of window improvements, changes to interior reconfiguration and design can make a big difference in perceived light quality. Depending on the scope of interior work being considered, your project could take advantage of the following opportunities: 
Relocating or reconfiguring program spaces. Are the right rooms getting access to daylight? As part of reprogramming, consider relocating spaces that could most benefit from daylight to the perimeter of the building. In office areas, consider open offices at the perimeter and private closed offices (if required) at the core. Shape new spaces with care so spatial proportions are most compatible with daylight design.

Raising ceiling heights. Higher ceilings can help redirect and distribute daylight deeper into interior spaces. Even a 12-in. raise can make a dramatic difference in perceived light levels. If you are already planning to reconfigure or downsize ceiling ducts and HVAC equipment, this could be a good opportunity to eliminate dropped ceilings. If only portions of the ceiling can be raised, you may want to:

- Reconfigure ducts and equipment to provide zones of raised ceiling relief, preferably perpendicular to sidelighting apertures so light can be distributed away from the window toward the opposite interior wall.

- Provide a sloped ceiling profile (down and away from windows and skylights) to reduce contrast and improve perceived daylight distribution from those apertures.

Adding or retrofitting interior light shelves and louvers. Interior light shelves and louvers can make the most of existing windows by controlling glare and redirecting daylight upward toward the ceiling and further into interior spaces. They can be part of the fix for windows in rooms where the blinds always seem to be drawn. Bottom-up shades can also help block glare while allowing light in at the clerestory level; careful attention should be paid to blind slat size and angle so you can reap the benefits of redirecting (as opposed to rejecting) light.

Adding glazing to interior partition walls. Do you remember—or still have —-transom windows above classroom doors? Openings in partition walls can help perimeter spaces share daylight with adjacent corridors and core spaces. Couple glazing components with doors if you are already considering replacing or reframing doors. Prefer clerestory glazing to light the ceiling surface of adjacent interior spaces and to preserve visual privacy. Where audio privacy is not an issue, leave cutouts unglazed.

Reconfiguring furniture. Reconfigure desks and computer monitors so they sit perpendicular to windows, minimizing glare and distracting contrast. Relocate blackboards, TV screens, or projector screens to locations that do not compete with glare.

Improving surface reflectances. Light-colored ceilings, walls, floors, and furniture can aid significantly in perceived light distribution.

These EEMs should not be considered in isolation. They work together to optimize lighting conditions; in some cases, it does not make sense to pursue only one EEM. For example, if you invest in skylights or light tubes, you should not diminish the daylighting design by using dark colors for most of your interior surfaces. Similarly, bundling light shelves together with raised ceilings can significantly improve resulting light penetration into interior spaces. 

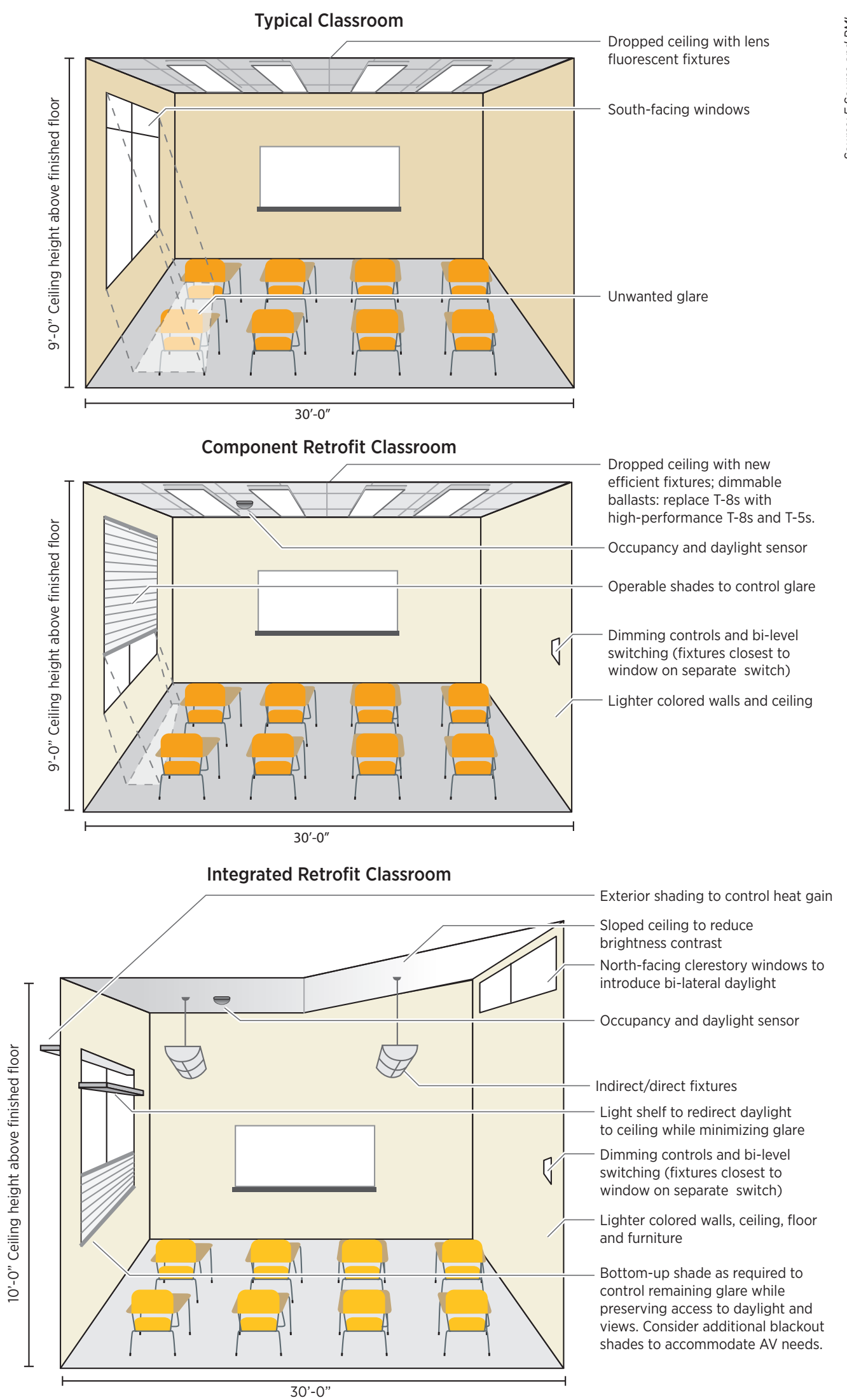

Figure G-3 Example packages of lighting EEMs for component-level and integrated retrofits 


\section{Efficient Electric Lighting}

Only when daylight conditions are inadequate should electric lights be used. An electric lighting system should be functionally capable of meeting all the school's required lighting needs; in practice, controls (discussed under Efficient Controls) should be deployed to dim or minimize electric lights as appropriate to take advantage of daylight.

An important metric to track when assessing electric lighting efficiency is your lighting power density. or W/ft². With today's technology and design capabilities, your target $\mathrm{W} / \mathrm{ft}^{2}$ should be $0.4-0.9$ for interior spaces. To quickly determine where you currently stand with respect to different space types, calculate:

[Watts per lamp $] \times[\#$ of lamps in room $] \div$ [total square feet area in room $]=\mathrm{W} / \mathrm{ft}^{2}$ in space type

Refer to DiLaura et al. (2011) to identify lighting needs for exterior spaces such as parking and sport fields and facilities. Some schools pay a significant surcharge to light their fields, and system efficiency represents one way to help reduce that cost.

Interior lamp efficiency. Three effective ways to quickly and cost-effectively increase electric lighting efficiency are to replace incandescent bulbs with higher efficiency CFLs (see Section F.1.3), replace linear fluorescent lamps with higher efficiency lamps (e.g., switch out 32-W T8s to 25-W T8s) with, and delamp fixtures (remove one or more lamps from a multilamp light fixture) in areas that are overlit.

Interior fixture efficiency. When rethinking fixture selection, consider ambient lighting needs separate from specialized accent and task lighting needs. For ambient lighting, you can upgrade typical fixtures to T8 or T5 fixtures to increase energy efficiency. This may be necessary to get closer to the target lighting power density, especially if your school still employs the older T12 lighting technology with magnetic ballasts. Be sure to replace all magnetic ballasts with high-efficiency electronic dimming ballasts where daylight is available (see Section F.1.5). Consider the use of indirect-direct fixtures in spaces with high ceilings (e.g., $10 \mathrm{ft}$ or higher) to redirect some of the light to the ceiling to improve brightness ratios and soften shadows.

Consider efficient upgrades for specialized fixtures. For example, remove inefficient exit signs and replace with LED signs that consume $5 \mathrm{~W}$ or less.

Interior reconfiguration and design. Interior design can go a long way to complement electric lighting design, just as it can with daylighting design. Consider room proportion and geometry, surface reflectances, location and height of interior partitions, and location of specialized tasks or displays to ensure they work well with the electric lighting design to optimize lighting conditions and minimize contrast.

Most of the EEMs discussed above are noninvasive, and therefore should be considered regardless of whether other ceiling upgrades are being considered. Refer to Table G-2 to determine how invasive these EEMs can be to your school's ceilings. 
Table G-2 Impacts of Recommended Lamp and Fixture Upgrades to Existing Ceilings

\begin{tabular}{|c|c|c|}
\hline EEM & $\begin{array}{l}\text { Dropped, Grid } \\
\text { Ceiling Types }\end{array}$ & Drywall, Plaster, and Other Ceiling Types \\
\hline $\begin{array}{l}\text { Replace lamps with higher } \\
\text { efficiency lamps }\end{array}$ & Noninvasive & Noninvasive \\
\hline $\begin{array}{l}\text { Delamp fixtures in areas that } \\
\text { are overlit }\end{array}$ & Noninvasive & Noninvasive \\
\hline $\begin{array}{l}\text { Replace fixture ballasts with } \\
\text { high efficiency electronic } \\
\text { dimming ballasts }\end{array}$ & Noninvasive & Noninvasive \\
\hline Reconfigure fixture layouts & $\begin{array}{l}\text { Minimally invasive: Rewiring } \\
\text { could be required to } \\
\text { support larger loads or new } \\
\text { zoning strategy, refer to } \\
\text { Controls section. }\end{array}$ & $\begin{array}{l}\text { Invasive: } \\
\text { Requires patching holes in old fixture locations and } \\
\text { making incisions at new locations. } \\
\text { When this requires significant ceiling demolition, } \\
\text { consider bundling with one-for-one fixture } \\
\text { replacements and other upgrades to HVAC equipment } \\
\text { configuration and ceiling height. }\end{array}$ \\
\hline $\begin{array}{l}\text { Replace fixtures (one-for-one) } \\
\text { with high- efficiency fixtures }\end{array}$ & Noninvasive & $\begin{array}{l}\text { Potentially invasive: } \\
\text { Level of patchwork required depends on how new } \\
\text { fixtures differ in size/shape from existing ones. }\end{array}$ \\
\hline
\end{tabular}

Exterior lighting. Install higher efficiency full cutoff exterior lighting at building façades, sports fields, and parking lots, with photocell controls. Full cutoff light fixtures mitigate light pollution onto surrounding areas and into the sky, and save energy by directing light down toward the ground where it is needed (allowing you to use lower wattage lamps). Benya et al. (2011) introduced a new rating system through the Model Lighting Ordinance that goes beyond addressing cutoff alone, and assesses luminaires based on the amount of light they emit in backlight, upward, and glare zones (coined the "BUG" rating system). Consider voluntary adoption of the rating system requirements as part of your retrofit, to limit expenses that may be required should your jurisdiction require compliance in the near future.

\section{Efficient controls}

Proper controls are essential for ensuring that electric lighting is minimized during unoccupied periods and integrated with daylighting to eliminate the unnecessary use of electric lights. Key control strategies were described in Section F.1. Consider bilevel switching in classrooms to improve the view of blackboards and other presentation screens by enabling control of back room lights separate from front room lights. Zoning can also be strategized to control perimeter lighting (for areas near windows) separate from inboard lighting fixtures. Rewiring or recircuiting for improved zoning could be required when the existing circuit structure is not accommodating. Most of these EEMs are noninvasive or minimally invasive, depending on your project's ceiling types and walls (see Table G-3). In situations where controls could mean significant wall and ceiling work, consider emergent wireless control technologies to minimize invasiveness and determine how invasive these EEMs can be to your project's existing ceiling types and walls. 


\section{Table G-3 Impacts of Recommended Controls Upgrades to Existing Ceilings and Walls}

\begin{tabular}{|c|c|c|c|}
\hline EEM & Dropped, Grid Ceiling Types & $\begin{array}{l}\text { Drywall, Plaster and Other } \\
\text { Ceiling Types }\end{array}$ & $\begin{array}{l}\text { Drywall, Plaster Wall Types } \\
\text { (for Wall-Mounted Controls) }\end{array}$ \\
\hline $\begin{array}{l}\text { Rezone fixtures } \\
\text { to enable bilevel } \\
\text { switching/ } \\
\text { dimming }\end{array}$ & $\begin{array}{l}\text { Noninvasive, whether or } \\
\text { not recircuiting is required. } \\
\text { Install a control device in the } \\
\text { ceiling and patch wall/ceiling } \\
\text { accordingly. }\end{array}$ & $\begin{array}{l}\text { Noninvasive, if no recircuiting } \\
\text { required: Install a control } \\
\text { device in the ceiling and patch } \\
\text { wall/ceiling accordingly. } \\
\text { Minimally invasive to invasive, } \\
\text { if recircuiting required: } \\
\text { Ceiling access is a must. In } \\
\text { many cases, most work can be } \\
\text { done via access panels or light } \\
\text { fixture holes. If not, invasive } \\
\text { ceiling work will be required. }\end{array}$ & $\begin{array}{l}\text { Noninvasive, if replacing wall- } \\
\text { mounted control device. Reuse } \\
\text { of existing conduit, wiring, and } \\
\text { electrical box. } \\
\text { Minimally invasive to invasive, } \\
\text { if relocating existing control } \\
\text { device or adding new control } \\
\text { device in new location: } \\
\text { Requires pulling new conduit } \\
\text { and wiring and installing new } \\
\text { electrical box/control device in } \\
\text { desired location. Cut/patch wall } \\
\text { accordingly. }\end{array}$ \\
\hline $\begin{array}{l}\text { Occupancy sensors } \\
\text { to enable shutoff } \\
\text { when lights are } \\
\text { unnecessary }\end{array}$ & $\begin{array}{l}\text { Minimally invasive: Minor } \\
\text { cutting/patching required } \\
\text { in ceiling panels where } \\
\text { occupancy sensors are } \\
\text { installed. }\end{array}$ & $\begin{array}{l}\text { Minimally invasive: Minor } \\
\text { cutting/patching required in } \\
\text { ceiling areas where occupancy } \\
\text { sensors are installed. }\end{array}$ & Same as above. \\
\hline $\begin{array}{l}\text { Photosensors to } \\
\text { determine daylight } \\
\text { levels }\end{array}$ & $\begin{array}{l}\text { Minimally invasive: Minor } \\
\text { cutting/patching required in } \\
\text { panels where ceiling-mounted } \\
\text { photosensors are installed. }\end{array}$ & $\begin{array}{l}\text { Minimally invasive: Minor } \\
\text { cutting/patching required in } \\
\text { areas where ceiling-mounted } \\
\text { photosensors are installed. }\end{array}$ & Same as above. \\
\hline
\end{tabular}

\section{G.2.3 Climate Considerations}

\section{Thermal risks and opportunities}

When making changes to apertures, glazing, and shading, you need to take into account solar heat gain and overall insulation performance of the envelope. Understand the needs in your climate and strategize size and location of glazing and shading devices accordingly. Can the building take advantage of solar heat gain? Retrofit shading to allow beneficial solar heat gain during winter months and to block solar heat in the summer. Minimize windows on west- and east-facing façades where solar heat and glare are hardest to control. Be strategic about glazing size to mitigate compromises to envelope performance.

\section{Façade-specific approach to window and daylight design}

Daylight color temperature, height of the sun, and controllability vary throughout the day and between seasons. Different spaces will have different lighting and thermal concerns, advantages and disadvantages, depending on their location in the school's massing and their relationship to the passing sun. Develop a tailored approach to window and daylight design that responds to distinct concerns at each façade.

\section{Overcast versus sunny skies}

Consider whether your climate is dominated by sunny or cloudy skies. Even cloudy sky climates can use daylight to meet most lighting needs, but glazing placement, orientation, selection, and shading design could differ to meet your goals.

\section{Exterior lighting functionality}

Select exterior lighting fixtures and lamps that can function well in your climate type. LEDs generally outperform fluorscents in most climates, and excel in colder climates. 


\section{G.3 Plug Miscellaneous Loads and Occupant Behavior}

Plug and miscellaneous loads represent a significant portion of total building energy use and are typically subject to occupant behavior. There are numerous low- and no-cost solutions, as well as solutions that require significant capital expenditures. A whole-building retrofit provides an opportunity to consider all EEMs and perhaps integrate them with other upgrades (for efficiency or otherwise) for greater cost effectiveness and convenience.

\section{G.3.1 Define Needs-What services do the loads provide?}

The end uses of plug and miscellaneous loads generally fall into three categories:

- All the electrical devices teachers and students need to create an effective education environment. These include overhead projectors, computers, telephones, printers, and copiers.

- All the appliances in the teachers' break room and the cafeteria, such as coffee makers, vending machines, and refrigerators.

- "Other," which includes electrical transformers (the devices that take high-voltage electricity from the grid and convert it to voltages appropriate for plug loads and some lighting systems) and any other device not captured in the first two categories.

\section{G.3.2 Design Strategy and Energy Efficiency Measures To Reduce Loads}

The approach to addressing plug and miscellaneous loads can be summarized by three steps:

1. Replace or decommission existing equipment.

2. Add plug load controls.

3. Educate teachers, students, and staff.

The cost effectiveness of these steps can vary greatly. For the more cost-effective EEMs, see the EBCx and standard retrofit discussions in Sections 3 and 4. This section will describe some strategies for selecting EEMs for wholebuilding retrofit projects that may not be so cut and dry.

\section{Replace or decommission existing equipment}

Many pieces of equipment in schools are unneeded, obsolete, or inefficient. If the equipment is unneeded or obsolete, the answer is simple: decommission it, dispose of it, or replace it with something more efficient, preferably something ENERGY STAR certified. If the equipment is inefficient, which is likely if it is more than a few years old, replace it.

Many school administrators wish to wait until equipment has neared the end of its useful life before replacing it with something more efficient. Understandably, they believe sending a good piece of equipment to the landfill is wasteful. This is certainly true, but waste is also associated with unnecessary energy use. Moreover, if a local recycling company is willing to pick up the equipment and salvage all the materials, these can become feedstock for new manufacturing without going to the landfill.

Administrators may not find that the energy cost savings justify replacing the equipment. They also need to consider the other benefits associated with the new equipment. For example, an energy-efficient combined copier/scanner/ printer may free up enough space in the office for some new greenery, which contributes to a friendlier and more pleasant environment. 


\section{Add plug load controls}

Plug load controls reduce or eliminate energy use when equipment is not being used. Most equipment (even small items such as cell phone chargers) still uses energy when it is plugged in but not serving a useful purpose - a phenomenon known as phantom energy use. These nonessential items can be wired into an EMS that turns them off (a more elegant and reliable solution than power strips with timers). Computer monitors can be tied to a network control.

Some plug load control strategies can be visible aspects of sustainability in schools. For example, vending machine lighting can be controlled to switch on only when someone approaches it, showing the person that the machine uses energy only when needed.

\section{Educate students, teachers, and staff}

Addressing plug and miscellaneous loads offers a great opportunity to engage students, teachers, and staff in reducing energy consumption both at school and at home - the concept of phantom energy (also known as vampire load) use may be good fodder for a Halloween party. An effective way to engage building occupants is through a short educational workshop on ways they can reduce energy use.

\section{G.3.3 Climate Considerations}

Strategies to reduce energy consumption from plug and miscellaneous loads do not vary by climate. However, the effects of reducing plug and miscellaneous energy consumption on other building systems may change by climate, ultimately leading to a different decision about whether to implement the load-reducing EEMs. Schools in temperate climates are dominated by internal gains, and heat gain from plug loads has a much larger impact on peak cooling loads. A reduction in plug load power (and therefore internal heat gains) could be significant in terms of downsizing the cooling system, especially if these load reductions can be achieved during peak cooling hours in the late afternoon.

\section{G.3.4 Leverage a Planned Facility Improvement}

It is clearly most advantageous to replace equipment when it is already due for replacement, but other instances may be less obvious. Do you plan to significantly reduce your electricity consumption? Consider decommissioning a transformer or two. Are you rewiring an older school? Consider creating "essential" and "nonessential" circuits that are separately controlled by an EMS and turned off at programmed times.

\section{G.4 Building Envelope}

The building envelope is the first line of defense against the elements and a blanket of comfort for those inside; windows and doors are essential links between environments. Common energy retrofits rarely touch the envelope, but an integrated comprehensive renovation should always address the envelope, and schools need not be stuck with a poorly performing or poorly constructed building. A whole-building retrofit is an ideal time to address many façade and roof issues and correct original construction defects, and may enable you to downsize mechanical equipment slated for replacement and save capital costs. The high-performance envelope improvements also increase enrollment, ignite school pride, and may even improve academic performance. Envelope technology and products have evolved significantly since the 1990s, so any school constructed before that time may be a prime candidate for major envelope retrofits. 


\section{G.4.1 Define End-Use Priorities}

For a building enclosure, address infiltration first and then thermal performance. Basic maintenance ensures a functionally sealed building against water infiltration, but too often air infiltration is allowed free rein after a building reaches a certain age, and sometimes construction defects were present from day one. During a whole-building retrofit, we recommend, at a minimum, targeting contemporary performance requirements for reducing air infiltration to comprehensively mitigate this common condition. For perspective on current targets, consider that ASHRAE Standard 189.1 (ASHRAE 2009b), intended for high-performance building design, currently recommends an air leakage limit that is at least double the allowed air leakage under the very high-performance Passive House guidelines.

Once infiltration is addressed, the next priority is to improve thermal performance by adding insulation to walls and roof. The roof is often the largest exposed surface at any time of day, so it can be the most valuable place for added insulation. For walls, additional insulation should not come at a cost of creating moisture problems, so approach thermal EEMs with care. Done correctly, improving thermal performance can be quite effective. Done wrong, it can cost a lot of money later (Rose 2005). Hygrothermal modeling tools such as THERM (LBNL 2011), HEAT2 (Blocon 2011), and WUFI (ORNL 2011) can inform your decision about when and where to add insulation.

\section{G.4.2 Design Strategy and Energy Efficiency Measures To Reduce Loads}

In comprehensive retrofits, the design strategy for building envelopes should be one of integrated design processes and solutions. Envelope retrofits can have a number of benefits from single expenditures; however, the first step in addressing envelope condition in a whole-building retrofit should always be investigation; initiate building enclosure commissioning.

- Where are the weak points in the system?

- Is there significant room for improvement?

- Are envelope conditions affecting more than just energy consumption?

- Is the condition of the envelope affecting student performance or behavior?

This most often includes occupant surveys, monitoring, infrared thermal imaging, and blower door testing, which can reveal all the ugliness in the system. The testing results also provide a great teaching tool for math and science.

Walls

The building walls serve as the face of the school and are vital to establishing a first impression for prospective students and ongoing pride in current students. If envelope failures require reconstruction or the school needs aesthetic work through a comprehensive retrofit, this is also a great time to address performance.

1. Seal the cracks. Addressing infiltration is the highest priority in the envelope system. Infrared thermal images will point to areas where air or water is clearly passing through the walls unintentionally. Most often, these are at joints between walls and roof/floor, where materials change, and at penetrations such as vents. If accessible, seal the joint areas from the interior of the building with an expandable sealant appropriate for the adhering material. Seal material transitions and penetrations from the exterior and interior. If the building is constructed of masonry, check mortar and expansion joints for infiltration issues. Extensive repointing, which can significantly extend the life of a building and reduce energy consumption, may be in order. 
2. Insulate. Thermal performance is most certainly affected by conduction - the movement of heat through material. Adding insulation adds resistance to heat movement. To create continuous insulation spanning the enclosure, installation on the outside of the wall assembly is the most effective. This can change the character of the building significantly, and interior options are entirely viable, although they provide slightly lower energy savings. For buildings that need a facelift, consider some of the new high-performance insulated façade systems as an alternative to the overused and occasionally problematic synthetic stucco EIFS products, although even they may be appropriate in some instances. Again, carefully assess the impacts of adding insulation.

3 Shade and reflect. Radiation is the most obvious source of heat gain. It is also one of the easiest to mitigate while adding value to the building. There are two approaches to mitigating radiative effects - shade the building or reflect the radiation into the atmosphere. In designing a whole-building retrofit, if you can shade any part of the wall during hot months, do it. If the school needs a facelift on all or a portion of the façade, consider adding a rain screen, vegetated green screen, or louvered wall assembly tuned to block the summer sun, and include a radiative barrier within the east and west façade assemblies. Pay attention to exterior finish colors and selective surfaces, as these can either create a radiative heat sink (good for cold climates) or reflect heat (good for hot climates), depending on the color and reflectivity. Plant deciduous trees on the school grounds on the east, south, and west sides to shade the façade and improve the landscape. If possible, calibrate, construct, or extend roof overhangs to perform a useful function and shade walls during the hotter months.

4 Reduce heat island. Heat convection can impact a building envelope in unforeseen ways and is a thread that ties it to radiation and infiltration. An adjacent asphalt parking lot may affect cooling loads more than you realize. By creating a pocket of warm air over hard surfaces likely to be close to building openings, it is also radiating heat onto walls and creating a source of warm air for infiltration penetrating a building you are trying to cool. Is it time to replace the parking surface? Consider concrete or other lighter surfaces - even permeable material. Can you shade the parking surface? Add photovoltaic shade structures or landscaped tree islands to reduce the microclimate temperature. Eliminate the hardscape immediately adjacent to the walls and replace it with high albedo landscaping. This will lower the temperature of the wall surfaces.

\section{Roof}

At any given time of day, the roof is generally the largest area of exposed envelope surface, and certainly experiences the most hours of direct exposure to the sun. This can have considerable impact on energy consumption if the roof is deficient. The roof may actually be the most valuable focus for envelope efficiency in a whole-building retrofit.

1. Seal the cracks. Roof EEMs to address infiltration are similar to wall EEMs, but there are usually more equipment penetrations on a roof than on the wall, so assess them thoroughly. Seal skylights and light tubes as well. If infiltration is indeed a problem at the roof-wall intersection, consider reroofing to completely eliminate the gap, especially if rooftop HVAC equipment is being replaced.

2. Insulate. Adding insulation to walls can be problematic, but roof insulation is often much easier to improve. Comprehensive renovations commonly coincide with roof replacement, so take the opportunity to install additional continuous rigid insulation to the exterior of the roof surface and meet roof insulation recommendations stated in ASHRAE Standard 189.1 (ASHRAE 2009a). 
3. Reduce radiative heat gains. Roofs take the brunt of the sun's radiation. Installing a reflective radiant barrier beneath roof decking can reduce heat gain by $40 \%$ in hot climates (Fairey 1984). Radiant barriers are generally recommended anywhere south of the Mason-Dixon Line. If roofing is being replaced, choose a reflective white or light-colored roof to further mitigate the effect of solar radiation on the building in hot, sunny climates. In colder climates, darker roof colors can help warm the building, so treat the roof as an asset. The roof is also a viable location for a vegetated surface. New green roof technology has migrated this design element to the forefront of green building features with limited risk for failure if designed by a professional. Vegetation lowers the roof's surface temperature by as much as $60^{\circ} \mathrm{F}$ on an average summer day, and reduce interior cooling load by as much as $20 \%$ (UT Austin 2008). Lighter colors and green roofs also create an ideal surface for photovoltaic electric systems, which operate more efficiently at cooler temperatures.

\section{Doors and windows}

Doors and windows are the most vulnerable parts of the envelope. They require tolerances for movement, feature continuous cracks that are ripe for infiltration, and must be lightweight enough for human control.

1. Seal the cracks. Windows and door openings should be weather-sealed during basic maintenance, but the window and door units often develop gaps where dissimilar materials join - such as at the connection of glass to frame. In a common example of construction defects, windows and doors are too often installed poorly with unsealed or uninsulated voids in the framing. It may be worthwhile to reinstall good windows and doors if the installation is poor. Deep energy retrofits are a good time to address all the windows and doors at once to save on costs. Wood units and component assemblies are especially reparable and can be resealed or completely retrofit. If the units are irreparable, replace with high-performance products that meet ASHRAE Standard 189.1, and avoid sliding sash units in favor of tilt or casement styles for an optimum seal. In moderate to cold climates, construct vestibules at primary entrances if possible to reduce air infiltration.

2. Reduce thermal bridging. In windows and doors especially, thermal bridging in the frame or glazing panel can be particularly detrimental to performance. As stated earlier, some units can be retrofitted, and some cannot. Insulated glazing panels can even be retrofitted to mitigate thermal bridging while also addressing radiation (Empire State Building 2011). Older steel windows are particularly challenging. If windows are neither replaceable nor candidates for retrofitting, consider installing either interior or exterior storm windows to achieve a thermal break and potentially meet the requirements of ASHRAE Standard 189.1. Be sure to allow for window operation if the unit is operable when adding storm windows.

3. Shade and filter. In the past, many schools addressed excessive window heat gain by applying dark films and installing full height blinds. This created cave-like classrooms, sleepy students, and dissatisfied staff. Today, spectrally selective window film technology allows us to reject a high percentage of heat (with a low SHGC) while admitting more visible light (high visible transmittance). It is available in a retrofit product with good warranties. Simple tinted or low-e films do not necessarily achieve the same results, so choose products wisely. Consider adding or restoring awnings and other shading devices. Exterior window louvers should be designed with the sun's path in mind for real utility - typically, but not always, horizontal slats should be used on the south façade and vertical on the east and west. Often enhancing architectural character while blocking up to $40 \%$ of direct sunlight, these simple devices can dramatically improve both the interior learning environment and energy use. Understand that the solution should differ from the south elevation to the east/west elevations for optimal efficacy. 


\section{G.4.3 Climate Considerations}

As with any architectural decision, each EEM should be assessed in its appropriate regional and climatic context. Across all climates, reducing infiltration is critical, and in hot and humid climates, moisture barriers become extremely important. Put your money and effort there when prioritizing. If your school is in a cold climate, a lightcolored roof may not save energy. In some climates, schools are dominated by internal loads, and the envelope becomes a relative nonissue. Also, the insulation of the envelope is much more important in heating-dominated climates - it may not be cost effective to add insulation to cooling-dominated buildings. In very hot climates, window shading devices and SHGC should be chosen to block even winter sun.

Changing climate should also be considered. Sometimes referred to as global weirding, shifting climate and weather patterns can wreak havoc on cities both in terms of temperature extremes and of high wind speeds. Designing resilient and efficient schools means we often meet the needs of a $100^{\circ} \mathrm{F}$ summer day and a $-7^{\circ} \mathrm{F}$ winter day in one building, which until recently may have experienced a much narrower range of temperatures. Add to that higher wind speeds from increasingly violent storms, and we are compelled to create tight, well-insulated, durable buildings in an effort to keep our students safe and comfortable.

\section{G.4.4 Leverage a Planned Facility Improvement}

Whole-building retrofits should be timed with major physical improvements to create an integrative opportunity to address whole systems sustainability. This means that aesthetic improvements should also take into account envelope performance improvements. Landscape projects should also reduce building energy if possible. Major retrofit projects for programming purposes should weave envelope EEMs into the programming. Improving daylighting for student performance goals? Retrofit the windows for energy efficiency. Got a grant for historic preservation work? Repoint brick to reduce infiltration.

\section{G.5 Service Water Heating}

Service water is often overlooked within the commercial building sector, as it is not typically a significant end use in terms of overall energy costs. However, service water heating retrofits can often be some of the most cost effective to pursue and should be considered in any whole-building retrofit project.

\section{G.5.1 Define Needs-Specify End Use Temperatures}

Service water heating is necessary in K-12 schools to provide warm or hot water for:

- Restroom hand washing at lavatory faucets

- Dishwashing and general cleaning (cafeteria/kitchens)

- Showers (locker rooms)

- A comfortable swimming pool environment for student exercise and team sports.

The incoming water from the utility is typically at about $50^{\circ}-60^{\circ} \mathrm{F}$ in most climates, so some heating is required to satisfy these needs. Consider the needs that must be met, and re-evaluate the water temperatures required. For instance, the energy consumption for each degree rise in outdoor swimming pool temperature will cost $10 \%-30 \%$ more in energy costs, depending on your location. Pool water temperatures are typically $78^{\circ}-82^{\circ} \mathrm{F}$. The American Red Cross recommends a temperature of $78^{\circ} \mathrm{F}$ for competitive swimming, but this may be too cool for young children. Evaluate the occupant and end use needs, and specify appropriate temperatures for lavatory faucets, showers, and swimming pools. Finally, do not heat the incoming stream of water for a pool to a temperature higher than it needs to be. 


\section{G.5.2 Design Strategies and Energy Efficiency Measures To Reduce Loads}

Retrofits to a service hot water system present a unique opportunity to conserve not only energy, but also water, which is a rapidly depleting natural resource. Some EEMs only reduce the energy required to heat the service water, but others save energy by simply reducing the amount of hot water that is being used. The cost effectiveness of these EEMs is heavily dependent on the water utility rates and their expected escalation in the coming years.

\section{Reduce hot water consumption}

In restrooms, install aerators to reduce flow in lavatory faucets to as low as $1 \mathrm{gpm}$. If you are able to replace the faucets, specify sensor or timed electronic faucets with automatic shutoffs. Replace older showerheads with low-flow (1.5-2 gpm) showerheads - use this opportunity to ensure that the water pressure is adequate.

\section{Reduce energy for water heating}

Once you have reduced the amount of water being used, you can tackle the energy required for heating. Make sure you are covering the basics by addressing heat loss and controls. Minimize the standby heat losses from distribution piping storage tanks by increasing insulation, and using anti-convection valves and heat traps. For swimming pools, use insulated pool covers whenever the pool is not in use. Use recirculation timers to control the circulation of hot water based on demand.

On the equipment side, consider heat pump water heaters, tankless (instantaneous) water heaters, or a solar thermal system. Solar thermal systems are especially appropriate for schools with high hot water use (often from cafeterias and swimming pools). If the distribution piping is already being overhauled, rezone your hot water systems according to temperature requirements and demand patterns. Finally, consider heat recovery options with other air or water streams, especially for indoor swimming pools with dehumidification needs.

\section{G.5.3 Climate Considerations}

In general, most service water heating retrofits will be more cost effective in colder climates, particularly those that minimize standby heat loss. The cost effectiveness of solar thermal systems is highly dependent on the amount and regularity of solar radiation on site. When considering solar thermal systems, carefully study the amount of available solar radiation and the freeze protection requirements.

\section{G.5.4 Leverage a Planned Facility Improvement}

Often planned facility improvements can make additional energy retrofits more cost effective. Is the roof being replaced? This is an excellent time to install roof-mounted solar thermal collectors. Is a ground excavation occurring? Consider underground solar thermal storage tanks. Finally, research current utility and government incentive programs for service water heating rebates that can improve the cost effectiveness of the project. 


\section{G.6 Heating, Ventilation, and Air-Conditioning}

HVAC systems have a significant effect on the health, comfort, productivity, and academic performance of students and teachers. Many U.S. schools are facing issues with poor IAQ and inadequate thermal comfort. A whole-building retrofit allows the selection of a new HVAC system that meets the current and future needs of the students and faculty. Although many types of HVAC systems could be used in K-12 schools, the systems listed in Table G-4 are the most common:

\section{Table G-4 Common K-12 School HVAC System Types}

\begin{tabular}{|l|l|}
\hline System configuration & $\begin{array}{l}\text { - Packaged (heating, cooling, and fan all in one unit) } \\
\text { - Central plant (chillers and boilers produced hot and chilled } \\
\text { water for distributed secondary systems) }\end{array}$ \\
\hline Zoning & $\begin{array}{l}\text { - Single zone } \\
\text { - Multiple zone units (central unit with zone-level VAV boxes) }\end{array}$ \\
\hline Heating type & $\begin{array}{l}\text { - Indirect gas-fired heaters } \\
\text { - Electric resistance heat } \\
\text { - Hot water boilers } \\
\text { - Heat pump }\end{array}$ \\
\hline Cooling type & $\begin{array}{l}\text { - DX (air cooled by refrigerant) } \\
\text { - Water chiller (air cooled by cold water) }\end{array}$ \\
\hline Condenser type & - Air/evaporatively cooled \\
- Water-cooled \\
- Ground-cooled \\
\hline Ventilation
\end{tabular}

\section{G.6.1 Define Needs-Specify Temperature, Humidity, and Outside Air}

HVAC systems affect the occupant's thermal comfort by controlling the temperature and humidity of the room air. The most cost-effective way to reduce energy for HVAC systems is to expand the allowable ranges for indoor temperature and humidity. Carefully study the thermal comfort needs of the occupants in each space type, and determine acceptable ranges for temperature and humidity in the space. These comfort ranges can be found in ASHRAE Standard 55 (ASHRAE 2004). Be sure to consider radiation effects when performing this exercise. For specialty spaces such as document storage and server rooms, ensure you comply with all applicable codes and standards.

Next, consider the amount of ventilation air required by the building occupants in each space type. Conditioning OA is one of the most energy-intensive jobs an HVAC system performs - the first step is minimizing the amount of $\mathrm{OA}$ that needs to be conditioned. Calculate the required exhaust and ventilation air according to local codes (most reference ASHRAE Standard 62.1 [ASHRAE 2010]), using the actual occupancy rates as opposed to the default occupancies provided in the standard. As the default values are very conservative, this simple step can sometimes reduce the OA by more than $30 \%$, saving energy and also reducing the size of the system required.

\section{G.6.2 Design Strategies and Energy Efficiency Measures To Reduce Loads}

\section{Size and Select a System}

Evaluate heating and cooling system options only after the loads have been drastically reduced from other retrofit EEMs. These reduced loads may change the appropriateness of various system options. For instance, passive chilled beams are only viable in spaces with very low cooling density requirements. When choosing a system type, consider 
the following:

- Extent of renovation. In a major renovation, there is often an opportunity to completely replace the HVAC system. If the renovation is less extensive, it may not be cost effective to completely change the air and water distribution systems.

- Climate. What system types can best capitalize on the climate characteristics of your site?

- OA. What is the best way to condition the OA? Is it more efficient to decouple the ventilation load from the cooling load? If so, specify a DOAS as part of the design.

- Zoning. What system types are appropriate for your school? Where individual room control is desired or there are diverse loads, choose zone level systems, such as chilled beams, fan coils units, or VAV systems.

- Finally, rightsize the chosen systems. Accurate sizing of equipment leads to lower equipment costs, lower utility costs, better dehumidification performance, and more comfortable conditions.

\section{Specify Efficient Equipment}

Once the systems have been chosen and sized, specify equipment with high peak and part load efficiencies. Consider condensing boilers, VSD compressors, and high-efficiency fans, motors, and pumps. Part load performance is just as important as the rated efficiency, so carefully consider performance curves when choosing equipment.

\section{Optimize Distribution Design}

In a major renovation, there is sometimes an opportunity to overhaul the air and water distribution systems. This often translates into significant fan and pump energy savings. Low pressure drop (and therefore low energy use) ductwork and piping design involves short, direct runs with minimal fittings and the least amount of turbulence possible. Finally, group exhaust air streams together to facilitate sensible heat or energy recovery with OA.

\section{Optimize Controls}

Optimizing HVAC controls is a cost-effective energy-saving strategy and is a key component to any whole-building retrofit project. Use DDC systems for greater accuracy, performance, and energy savings and incorporate these data into a BAS that the facility manager can use to operate the building. The most common and profitable control strategies to consider for schools include:

- Off hours controls. During unoccupied periods, employ temperature setbacks and do not bring in any OA.

- DCV. With DCV controls, you can control the amount of OA being provided to each zone based on the occupancy. $\mathrm{CO}_{2}$ sensors should be used in densely occupied zones with highly variable occupancy patterns, such as gymnasiums, auditoriums, multipurpose spaces, cafeterias, and some classrooms. For the other zones, occupancy sensors should be used to reduce ventilation when a zone is temporarily unoccupied.

- Economizers. Consider the use of either an airside or waterside economizer to capitalize on "free cooling." Consider expanding the economizer operating range beyond the ASHRAE recommendations, as they are often conservative.

- Static pressure reset. Many supply fans on VAV systems are controlled to maintain static pressure within ductwork at a single set point. A more efficient strategy, and one that is required by the ASHRAE 90.1 Standard (ASHRAE 2009a), is to use DDC to reset this set point at the zone level. With this dynamic control strategy, the fan only generates the pressure required to satisfy the zone requiring the most pressure, improving overall fan efficiency (Taylor 2007).

- Central plant controls. Develop an overall controls strategy for the entire central plant (if applicable) that includes variable speed motors, equipment sequencing, water temperature resets, soft-starting of motors, and demand control. 


\section{Recover and Reuse Waste Streams}

Because conditioning OA for ventilation is such a big contributor to energy use in a K-12 school, either heat or energy recovery from the exhaust air is recommended. Examine other opportunities to capture and reuse heat across zones or between the HVAC system and service water heating systems. Does your school have simultaneous heating and cooling loads? A water-source heat pump system is well suited to transfer heat from an interior zone, where cooling may be desired, to the perimeter, where heating may be needed. Finally, consider ways to recover and reuse condensate for onsite irrigation needs.

\section{Bundle Energy Efficiency Measures to Optimize Synergies}

Always consider interrelated EEMs that should be implemented together to maximize savings and return on investment. For example, a chilled beam system can be coupled with a DOAS and a separate means for heating (if required).

\section{G.6.3 Climate Considerations}

Climate characteristics should play a role in every decision and strategy within a comprehensive HVAC retrofit. For instance, humid climates would benefit from the use of a DOAS that decouples the dehumidification load from the sensible cooling load. In hot and dry climates, evaporative cooling should be considered, along with nighttime precooling (should be coupled with thermal mass). Generally speaking, it is valuable to:

- Address the thermal risks and opportunities in the climate. Is there an opportunity to eliminate a perimeter heating system with a super insulated envelope?

- Consider the solar gain characteristics of the climate to guide passive heating and shading strategies and to evaluate renewable alternatives.

- Evaluate contributions to peak heating and cooling loads. Is this building dominated by heating or cooling loads? Is the climate (envelope loads) a major factor or are the loads driven by internal gains?

\section{G.6.4 Leverage a Planned Facility Improvement}

Often planned facility improvements can make additional energy retrofits more cost effective. If major capital equipment, such as a boiler or a chiller, is nearing the end of its useful life, this is an ideal opportunity to redesign and resize your HVAC equipment. Are changes to the utility rates being considered? Evaluate the cost effectiveness of peak shifting thermal storage systems coupled with a time of use rate. Are the parking lots being repaved or are new sports fields being developed? This would be an ideal time to install a ground source heat pump. Finally, research current utility and government incentive programs for service water heating rebates that can improve the cost effectiveness of the project. 


\section{EMNERGY}

Energy Efficiency \&

Renewable Energy
Building Technologies Office

\section{buildings.energy.gov}

Cover photo from istock/16732254

Printed with a renewable-source ink on paper containing at least $50 \%$ wastepaper, including $10 \%$ post consumer waste.
Prepared by the National Renewable Energy Laboratory (NREL) NREL is a national laboratory of the U.S. Department of Energy Office of Energy Efficiency and Renewable Energy

Operated by the Alliance for Sustainable Energy, LLC

DOE/GO-102013-4333 • December 2013 